NATIONAL LABORATORY

MANAGED BY UT-BATTELLE

FOR THE DEPARTMENT OF ENERGY

\title{
Comparison of Different Internal Dosimetry Systems for Selected Radionuclides Important to Nuclear Power Production
}

June 2013

R. W. Leggett

K. F. Eckerman

R. P. Manger

Oak Ridge National Laboratory

Oak Ridge, Tennessee 37831

Prepared for the

U.S. Nuclear Regulatory Commission Office of Nuclear Regulatory Research

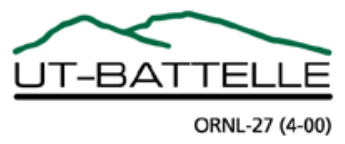




\section{CONTENTS}

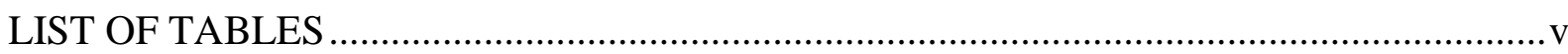

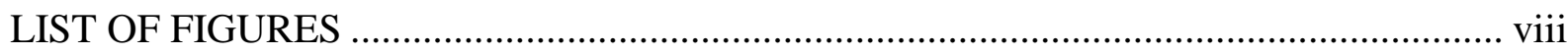

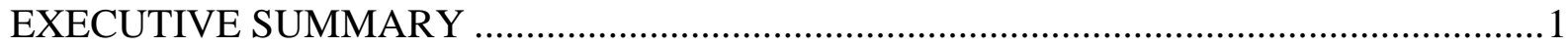

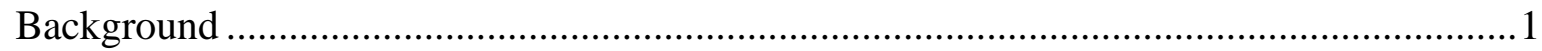

Objectives of this report ...................................................................................................

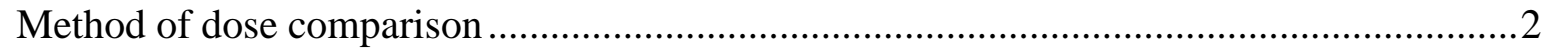

Main results..............................................................................................................

Differences in fundamental dosimetric concepts of NRC77 and later systems .................3

Comparison of dose estimates for individual radionuclides in drinking water..................4

Comparison of dose estimates for inhalation of individual radionuclides ........................5

Comparison of external dose coefficients in RG 1.109 and FGR-12...............................

Comparison of dose estimates for reference mixtures of radionuclides .............................9

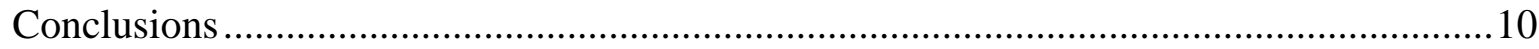

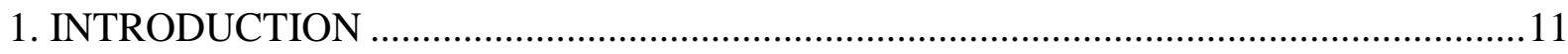

2. SUMMARY OF THE PUB2, NRC77, PUB30, AND PUB72 SYSTEMS ..........................13

2.1. Dosimetry system of Pub2 ....................................................................................13

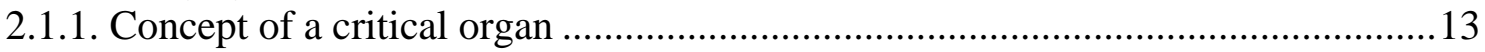

2.1.2. Respiratory tract model of Pub2.......................................................................13

2.1.3. Gastrointestinal model of Pub2 ……..............................................................15

2.1.4. Systemic biokinetic models of Pub2 …………...................................................15

2.1.5. Approach to internal dosimetry in Pub2 .......................................................16

2.2. Implementation of the Pub2 dosimetry system in NRC77............................................17

2.3. Dosimetry system of Pub30 ....................................................................................20

2.3.1. Concept of effective dose equivalent .............................................................20

2.3.2. Respiratory tract model of Pub30..................................................................21

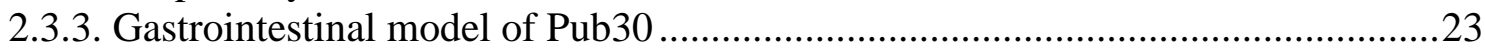

2.3.4. Systemic biokinetic models of Pub30 ..............................................................24

2.3.5. Approach to internal dosimetry in Pub30 ........................................................25

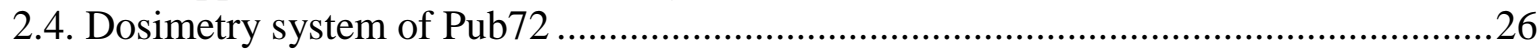

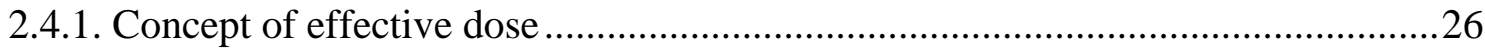

2.4.2. ICRP series on age-specific dose coefficients..................................................27

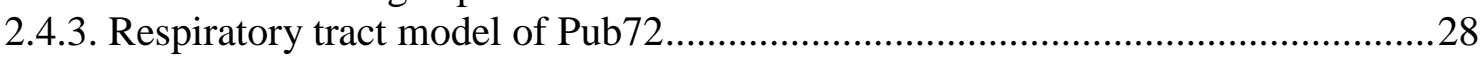

2.4.4. Gastrointestinal model of Pub72 ……................................................................30

2.4.5. Systemic biokinetic models of Pub72 …………................................................30

2.4.6. Approach to internal dosimetry in Pub72 ………..................................................32

3. COMPARISON OF IMPORTANT PARAMETERS IN DOSIMETRY MODELS ............33

3.1. Gastrointestinal absorption fractions …………………..............................................33

3.2. Respiratory models.....................................................................................................34

3.3. Systemic biokinetic models …………………………...............................................38 


\section{CONTENTS (cont'd)}

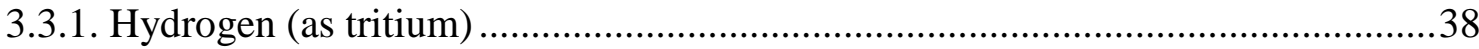

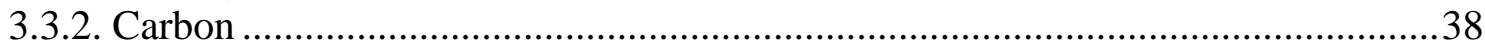

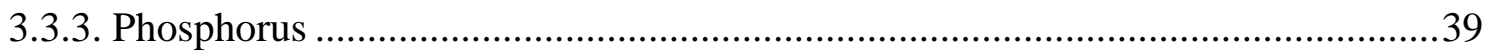

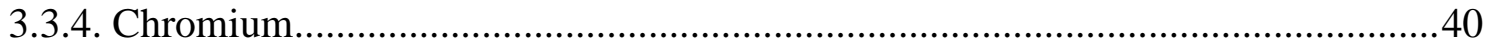

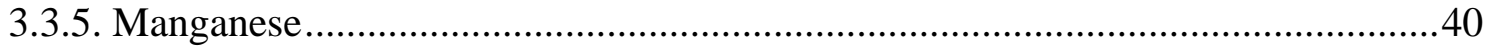

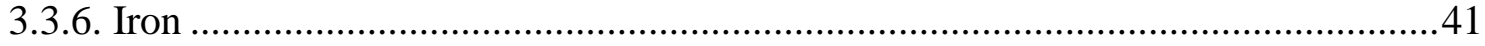

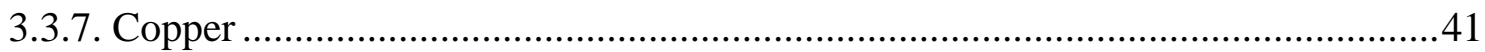

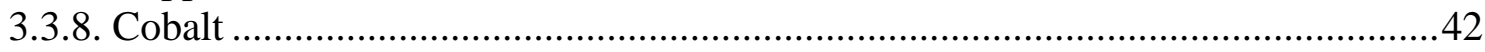

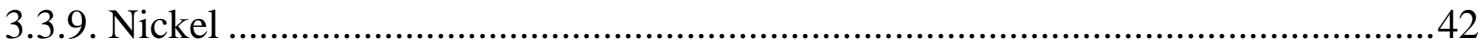

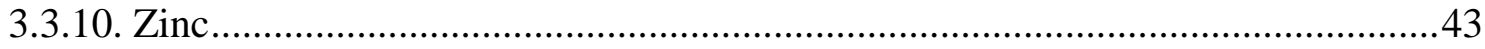

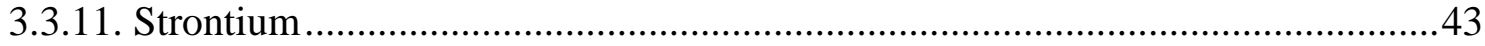

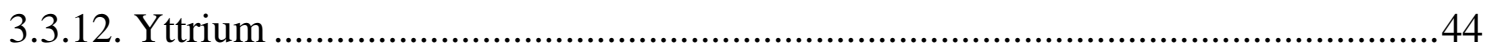

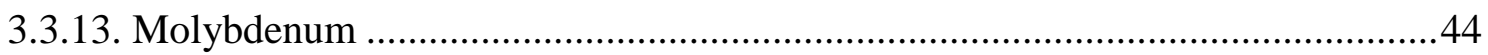

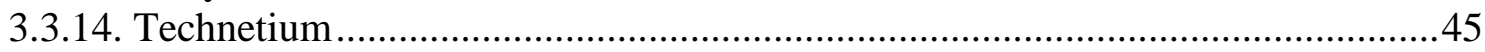

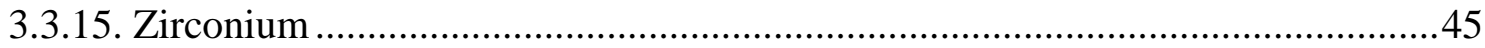

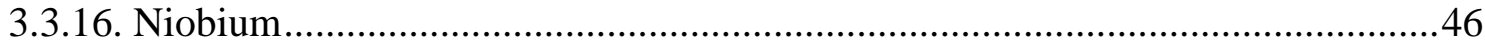

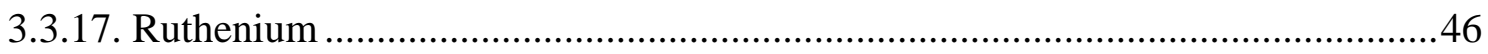

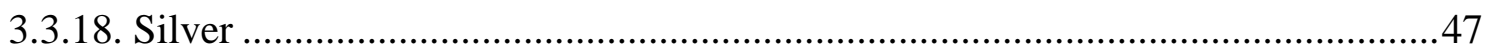

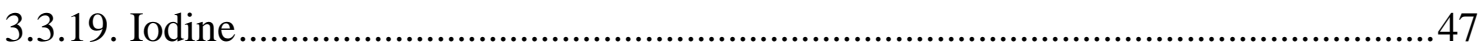

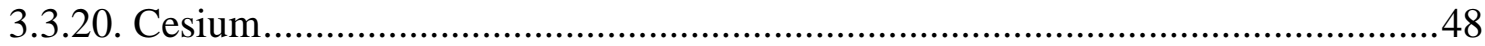

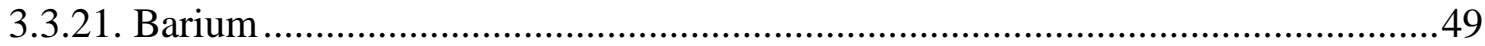

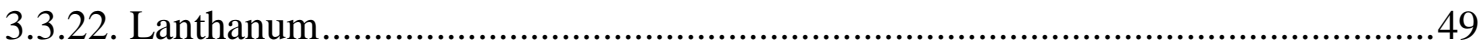

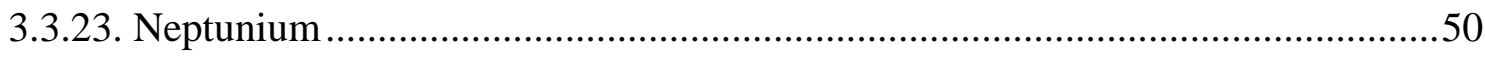

\section{COMPARISON OF INGESTION AND INHALATION DOSE COEFFICIENTS}

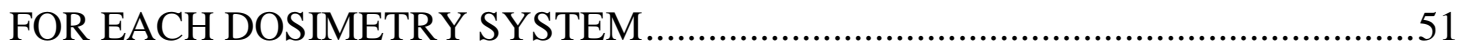

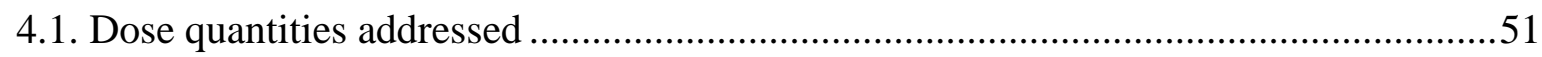

4.2. Comparisons of dose estimates for adults ............................................................52

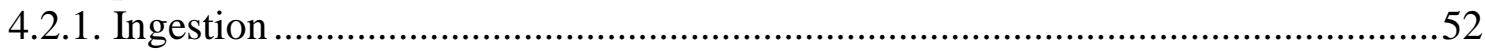

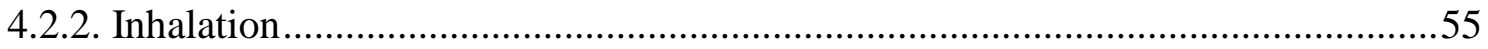

4.3. Comparison of age-specific dose estimates ………................................................57

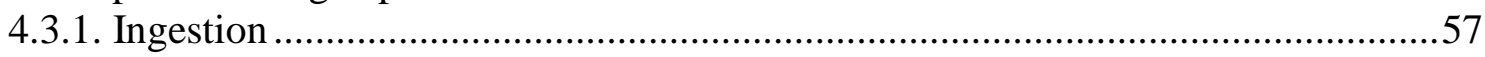

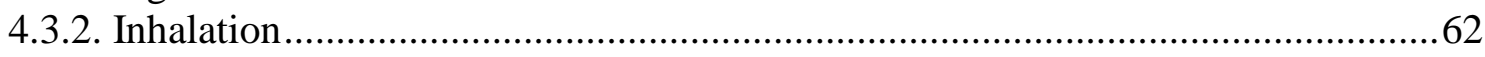

4.4. Comparison of key dose quantities .........................................................................67

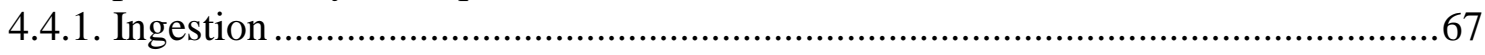

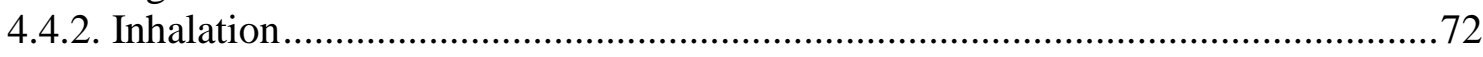

5. COMPARISON OF EXTERNAL DOSE COEFFICIENTS FROM NRC77 WITH UPDATED COEFFICIENTS ....................................................................................78

6. EVALUATION OF THE IMPACT OF USING ICRP 103 RECOMMENDATIONS.........83

7. COMPARATIVE DOSE ASSESSMENTS FOR NUCLEAR POWER PLANT LIQUID AND GASEOUS EFFLUENTS BASED ON DIFFERENT DOSE COEFFICIENTS 


\section{CONTENTS (cont'd)}

APPENDIX A: SUMMARY OF NUCLEAR DECAY DATA FOR RADIONUCLIDES ADDRESSED IN INTAKE SCENARIOS.............................................................90

APPENDIX B: DETAILED TABULATIONS OF COMPARATIVE DOSE ESTIMATES FOR RADIONUCLIDES IN DRINKING WATER ................................91

APPENDIX C: DETAILED TABULATIONS OF COMPARATIVE DOSE ESTIMATES FOR INHALED RADIONUCLIDES

APPENDIX D: COMPARISON OF DOSE ESTIMATES FOR MIXTURES OF RADIONUCLIDES BASED ON DIFFERENT DOSIMETRY SYSTEMS

REFERENCES 


\section{LIST OF TABLES}

Table 2.1. Age-specific biological half-times applied in NRC77. .19

Table 2.2. Mass and effective radius of body organs for the four age groups of NRC77

Table 2.3. Tissue weighting factors given in ICRP Publication 26 (1977) and ICRP

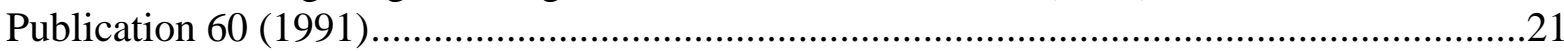

Table 2.4. Parameters of the TGLM for $1-\mu \mathrm{m}$ AMAD particles ...............................................22

Table 3.1. Summary of gastrointestinal uptake fractions ( $f_{1}$ values) applied in comparisons of doses from intake of radionuclides

Table 3.2. Fractional uptake of inhaled activity to blood .......................................................35

Table 3.3. Lung dose coefficients of NRC77, Pub30 and Pub72 …...........................................37

Table 4.1. For ingestion of individual radionuclides in drinking water, comparison of maximum organ doses based on NRC77 and Pub72

Table 4.2. For ingestion of individual radionuclides in drinking water, maximum total body doses based on NRC77 and maximum effective dose based on Pub72

Table 4.3. For inhalation of individual radionuclides, comparison of maximum organ doses based on NRC77 and Pub72

Table 4.4. For inhalation of individual radionuclides, maximum total body doses based on NRC77 and maximum effective doses based on Pub72 .75

Table 5.1. Decay data for noble gas radionuclides addressed in this report..... .78

Table 5.2. Comparison of air dose rate coefficients of Table B-1 of RG 1.109 with values based on the decay data of ICRP Publication 38

Table 5.3. Comparison of tissue dose rate coefficients of Table B-1 of RG 1.109 with values based on contemporary nuclear decay data

Table 5.4. Comparison of external dose coefficients of Table E-6 of RG 1.109 with those of Federal Guidance Report 12 for contaminated ground surface

Table 6.1. Tissue weighting factors given in Pub72 and Pub103 .83

Table 6.2. Recommended Transit Times through the Alimentary Tract in Pub72 and Pub103 


\section{LIST OF TABLES (cont’d)}

Table 7.1. Liquid exposure pathways assumed in design certifications ...................................85

Table 7.2. Gaseous exposure pathways assumed in design certifications .................................85

Table 7.3. Liquid effluent dose comparison ....................................................................86

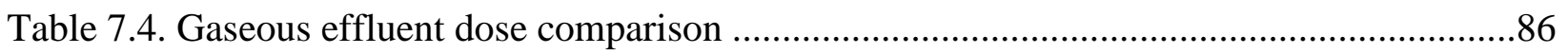

Table 7.5. Radionuclide contribution to total dose for liquid effluent releases ..........................87

Table 7.6. Radionuclide contribution to total dose for gaseous effluent releases........................88

Table 7.7. Change in overall dose using Pub72 versus Pub2 dosimetry methods.......................89

Table A.1. Summary of decay data for radionuclides addressed in the dose

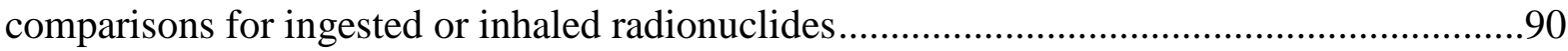

Table B.1. Base-case values for the adult: Estimated committed doses from one-year intake of drinking water with radionuclide concentration of $1 \mathrm{pCi} / \mathrm{L}$ based on NRC77

Table B.2. For adults, ratios of individual organ dose estimates D30 : D77 and D72 : D77 for annual intake of radionuclide in drinking water, where D30, D72, and D77 are based on Pub30, Pub72, and NRC77, respectively

Table B.3. Dose estimates for 1-y intake of radionuclide in drinking water based on NRC77, Pub30, and Pub72, normalized to the NRC77 critical organ dose for the adult

Table C.1. Base-case values for the adult: Estimated committed doses from one-year intake of air with radionuclide concentration of $1 \mathrm{pCi} / \mathrm{m}^{3}$, based on NRC77

Table C.2. For adults, ratios of organ dose estimates D30 : D77 and D72 : D77 for annual intake of radionuclides in air, where D30, D72, and D77 are the doses to a given organ based on Pub30, Pub72, and NRC77, respectively.....

Table C.3. Dose estimates for 1-y intake of radionuclide in air based on NRC77, Pub30, and Pub72, normalized to the NRC77 critical organ dose for the adult .104

Table D.1. Reference values for annual releases of radionuclides in liquids from nuclear power plants, used to compare doses from mixtures of radionuclides in drinking water 


\section{LIST OF TABLES (cont'd)}

Table D.2. Comparison of maximum doses in specific age groups and across age groups from drinking water based on NRC77, Pub30, and Pub72 for a reference mixture of radionuclides in BWR effluents

Table D.3. Comparison of maximum doses in specific age groups and across age groups from drinking water based on NRC77, Pub30, and Pub72 for a reference mixture of radionuclides in PWR effluents

Table D.4. Reference values for annual releases of radionuclides into air from nuclear power plants, used to compare doses from inhalation of mixtures of radionuclides

Table D.5. Comparison of maximum inhalation doses based NRC77, Pub30, and Pub72 for a reference mixture of radionuclides in BWR airborne emissions

Table D.6. Comparison of maximum inhalation doses based NRC77, Pub30, and Pub72 for a reference mixture of radionuclides in PWR airborne emissions.

Table D.7. Annual beta and gamma air doses for noble gas releases of a PWR .116

Table D.8. Annual beta and gamma air doses for noble gas releases of a BWR......................116

Table D.9. Annual dose to skin and total body from noble gas releases of a PWR

Table D.10. Annual dose to skin and total body from noble gas releases of a BWR

Table D.11. Annual skin and total body dose from radionuclides released to atmosphere by a PWR and deposited on the ground surface

Table D.12. Annual skin and total body dose from radionuclides released to atmosphere by a BWR and deposited on the ground surface 


\section{LIST OF FIGURES}

Figure ExecSum-1. For selected radionuclides, comparison of maximum organ doses based on Pub72 and NRC77 for annual intake in drinking water.............................................6

Figure ExecSum-2. For selected radionuclides, comparison of maximum effective dose E based on Pub72 and maximum total body dose based on NRC77 for annual intake in drinking water

Figure ExecSum-3. For selected radionuclides, comparison of the maximum effective dose E based on Pub72 with the critical organ dose based on NRC77 for annual intake in drinking water.

Figure ExecSum-4. For selected radionuclides, comparison of the maximum organ dose based on Pub72 with the maximum organ dose based on NRC77 for annual intake in inhaled air

Figure ExecSum-5. For selected radionuclides, comparison of the maximum effective dose E based on Pub72 to the maximum total body dose based on NRC77 for annual intake in inhaled air

Figure ExecSum-6. For selected radionuclides, comparison of the maximum effective dose E based on Pub72 with the critical organ dose based on NRC77 for annual intake in inhaled air

Figure 2.1. Respiratory model used in Pub2.......................................................................14

Figure 2.2. Gastrointestinal tract model used in Pub2 …….......................................................15

Figure 2.3. Systemic biokinetic model for cobalt used in Pub2 …............................................16

Figure 2.4. Modification of the Pub2 respiratory model used in NRC77 ...................................18

Figure 2.5. Structure of the Task Group Lung Model (TGLM) used in Pub30 (ICRP, 1979) ..22

Figure 2.6. The GI tract model used in Pub30 and Pub72 ..........................................................24

Figure 2.7. Systemic biokinetic model for cobalt used in Pub30 ................................................25

Figure 2.8. Structure of the respiratory model of Pub72 (ICRP, 1994b) ....................................28

Figure 2.9. Generic model structure for bone-volume-seeking radionuclides applied in Pub72 


\section{LIST OF FIGURES (cont'd)}

Figure 2.10. Generic model structure for bone-surface-seeking radionuclides applied in Pub72

Figure 2.11. Systemic biokinetic model for cobalt used in Pub72

Figure 3.1. Deposition in respiratory tract models used in NRC77, Pub30 and Pub68/72. ......34

Figure 3.2. Cumulative fractional absorption to blood of inhaled radionuclides. .36

Figure 4.1. For intake of ${ }^{55} \mathrm{Fe}$ in drinking water by an adult, organ dose estimates based on Pub30 and Pub72, as multiples of corresponding values based on NRC77 .....

Figure 4.2. For intake of ${ }^{95} \mathrm{Nb}$ in drinking water by an adult, organ dose estimates based on Pub30 and Pub72, as multiples of corresponding values based on NRC77

Figure 4.3. For intake of ${ }^{137} \mathrm{Cs}$ in drinking water by an adult, organ dose estimates based on Pub30 and Pub72, as multiples of corresponding values based on NRC77

Figure 4.4. For inhalation of ${ }^{60} \mathrm{Co}$ by an adult, organ dose estimates based on Pub30 and Pub72, as multiples of corresponding values based on NRC77

Figure 4.5. For inhalation of ${ }^{95} \mathrm{Zr}$ by an adult, organ dose estimates based on Pub30 and Pub72, as multiples of corresponding values based on NRC77

Figure 4.6. For inhalation of ${ }^{239} \mathrm{~Np}$ by an adult, organ dose estimates based on Pub30 and Pub72, as multiples of corresponding values based on NRC77

Figure 4.7. Comparison of annual dose estimates to any organ from ingestion of ${ }^{3} \mathrm{H}$ in drinking water based on NRC77, Pub30, and Pub72. Values are normalized to the uniform dose to the adult based on NRC77.....

Figure 4.8. Comparison of estimated annual dose to LLI from ingestion of ${ }^{60} \mathrm{Co}$ in drinking water based on NRC77, Pub30, and Pub72. Values are normalized to the dose to the critical organ in the adult based on NRC77 (LLI).

Figure 4.9. Comparison of estimated annual dose to liver from ingestion of ${ }^{60} \mathrm{Co}$ in drinking water based on NRC77, Pub30, and Pub72. Values are normalized to the dose to the critical organ in the adult (LLI) based on NRC77.

Figure 4.10. Comparison of annual dose estimates from ingestion of ${ }^{63} \mathrm{Ni}$ in drinking water based on NRC77 (bone), Pub30 (bone surface), and Pub72 (bone surface). Values are normalized to the dose to the critical organ in the adult (bone) based on NRC77 


\section{LIST OF FIGURES (cont'd)}

Figure 4.11. Comparison of estimates of dose to thyroid from ingestion of ${ }^{131} \mathrm{I}$ in drinking water based on NRC77, Pub30, and Pub72. Values are normalized to the dose to thyroid in the adult based on NRC77.

Figure 4.12. Comparison of annual dose estimates to any organ from inhalation of ${ }^{3} \mathrm{H}$ based on NRC77, Pub30, and Pub72. Values are normalized to the uniform dose to the adult based on NRC77

Figure 4.13. Comparison of estimated annual dose to lung from inhalation of ${ }^{60} \mathrm{Co}$ based on NRC77, Pub30 (Class W, $1 \mu \mathrm{m}$ AMAD), and Pub72 (Type M, $1 \mu \mathrm{m}$ AMAD). Values are normalized to the dose to the critical organ in the adult (lung) based on NRC77

Figure 4.14. Comparison of estimated annual dose to liver from inhalation of ${ }^{60} \mathrm{Co}$ based on NRC77, Pub30 (Class W, $1 \mu \mathrm{m}$ AMAD), and Pub72 (Type M, $1 \mu \mathrm{m}$ AMAD). Values are normalized to the dose to the critical organ in the adult (lung) based on NRC77

Figure 4.15. Comparison of estimated annual dose to lung from inhalation of ${ }^{239} \mathrm{~Np}$ based on NRC77, Pub30 (Class W, $1 \mu \mathrm{m}$ AMAD ), and Pub72 (Type M, $1 \mu \mathrm{m}$ AMAD). Values are normalized to the dose to the critical organ in the adult (LLI) based on NRC77

Figure 4.16. Comparison of estimated annual dose to liver from inhalation of ${ }^{239} \mathrm{~Np}$ based on NRC77, Pub30 (Class W, $1 \mu \mathrm{m}$ AMAD ), and Pub72 (Type M, $1 \mu \mathrm{m}$ AMAD). Values are normalized to the dose to the critical organ in the adult (LLI) based on NRC77

Figure 4.17. For ingestion of radionuclides in drinking water, comparison of maximum organ doses across all age groups based on NRC77 and Pub72.

Figure 4.18. For ingestion of radionuclides in drinking water, ratio of maximum effective dose E (Pub72) to maximum total body dose (NRC77)

Figure 4.19. For ingestion of radionuclides in drinking water, the ratio of the maximum effective dose $\mathrm{E}$ (Pub72) to the maximum critical organ dose (NRC77).

Figure 4.20. For inhalation of radionuclides, comparison of maximum organ doses across all age groups based on NRC77 and Pub72.

Figure 4.21. For inhalation of radionuclides, ratio of maximum effective dose E (Pub72) to maximum total body dose (NRC77) 


\section{LIST OF FIGURES (cont'd)}

Figure 4.22. For inhalation of radionuclides, the ratio of the maximum effective dose $\mathrm{E}$ (Pub72) to the maximum critical organ dose (NRC77) ...............................................77 


\section{EXECUTIVE SUMMARY}

\section{Background}

10 CFR Part 50, Appendix I, requires U.S. Nuclear Regulatory Commission (NRC) licensees to design their effluent control systems and procedures to meet specified dose criteria. NRC requires licensees to calculate doses to members of the public from actual effluents for comparison with these dose criteria. Guidance for the dose calculations is provided in Regulatory Guide 1.109 (RG 1.109) (NRC, 1977), which was based on the dosimetry system of Publication 2 of the International Commission on Radiological Protection (ICRP, 1959) as extended to pre-adult ages in NUREG-0172 (Hoenes and Soldat, 1977).

Reliance on dosimetry concepts and models of ICRP Publication 2 is inconsistent with the current version of 10 CFR Part 20, which is based on the later dosimetry system for occupational intake of radionuclides described in ICRP Publication 26 (1977) and Publication 30 (1979, 1980, 1981, 1988). More recently, the ICRP published agespecific biokinetic and dosimetric models and dose coefficients for members of the public (ICRP Publication 56, 1989; ICRP Publication 67, 1993; ICRP Publication 69, 1995a; ICRP Publication 71, 1995b; ICRP Publication 72, 1996) based on primary guidance given in ICRP Publication 60 (1991), which superseded ICRP Publication 26. An updated ICRP dosimetry system based on primary guidance given in ICRP Publication 103 (2008) is currently under development.

The following abbreviations are used for the dosimetry systems addressed in this report:

- Pub2 is the dosimetry system introduced in ICRP Publication 2.

- NRC77 is the age-specific version of Pub2 developed in NUREG-0172 and applied in RG 1.109.

- Pub30 is the dosimetry system for workers based on primary guidance in ICRP Publication 26 and biokinetic and dosimetric models for a reference worker in ICRP Publication 30.

- Pub72 is the dosimetry system for members of the public based on primary guidance in ICRP Publication 60 and age-specific biokinetic and dosimetric models and dose coefficients in ICRP Publications 56, 66, 67, 69, 71, and 72.

\section{Objectives of this report}

The main purpose of this report is to compare dosimetric concepts and models of NRC77, Pub30, and Pub72 and estimated annual doses based on these three dosimetry systems for intake of each of 28 radionuclides often identified in power reactor effluents. Two modes of intake of radionuclides are addressed: ingestion in drinking water and inhalation. Estimated doses to individual organs and to the whole body based on each dosimetry system are compared for each of four age groups defined in NRC77: infant, child, teenager, and adult. Maximum estimated doses among all four age groups are also compared. An appendix compares dose estimates for hypothetical mixtures of 
radionuclides in liquid or gaseous effluents from Boiling Water Reactors (BWRs) or Pressurized Water Reactors (PWRs).

For completeness this report also compares external dose coefficients given in RG 1.109 with updated values from Federal Guidance Report 12 (FGR-12) (EPA, 1993). Two modes of external exposure are addressed: submersion in contaminated air and standing on a contaminated ground surface. Comparisons for contaminated air are made for 14 noble gas radionuclides. Comparisons for a contaminated ground surface are made for 77 radionuclides often released in particulate form.

\section{Method of dose comparison}

For comparison of doses from ingestion or inhalation of radionuclides, a set of base case dose estimates is first established for each of 28 radionuclides often identified in power plant effluents. The base case for ingestion involves estimation of committed doses to organs from annual intake of drinking water based on age-specific water consumption rates and ingestion dose coefficients specified in RG 1.109. The base case for inhalation involves estimation of committed doses to organs from annual intake of air based on agespecific air intake rates and inhalation dose coefficients specified in RG 1.109. A unit activity concentration of a radionuclide in drinking water $(1 \mathrm{pCi} / \mathrm{L})$ or air $\left(1 \mathrm{pCi} / \mathrm{m}^{3}\right)$ is assumed.

For a given mode of intake the analysis is repeated, first substituting the age-independent dose coefficients from Pub30 and then substituting the age-dependent dose coefficients from Pub72. Age dependence in dose estimates is reflected in the calculations based on Pub30 only in that age-specific intake rates of drinking water and air are considered. Comparisons of doses based on the different dosimetry systems are then made, and reasons for differences and similarities in the dose estimates, including differences in the underlying fundamental dosimetry concepts, are discussed. The dose quantities indicated in items 1-2 below are compared for all three dosimetry systems, and those indicated in items 3-5 are compared only for NRC77 and Pub72:

1. The dose to each organ addressed in NRC77 (by age group). For a given radionuclide and intake mode, NRC77 provides age-specific dose coefficients for some or all of the following organs: lower large intestine (LLI), bone, liver, kidneys, thyroid, and lung. For example, dose coefficients for C-14 are provided for all six organs, but dose coefficients for Fe-55 are provided only for lung, LLI, bone, and liver because kidneys and thyroid are not considered as "organs of reference" (sites of accumulation) for iron isotopes in NRC77. For each organ and each age group (infant, child, teen, or adult), the organ dose based on NRC77 is compared with the corresponding dose based on Pub30 and Pub72. The dose to bone based on NRC77 is compared with the most closely related dose quantity in Pub30 or Pub72, namely, the dose to bone surface. 
2. Whole-body dose (by age group). For a given radionuclide, intake mode, and age group, the dose to total body based on NRC77 is compared with the effective dose equivalent $\mathrm{H}_{\mathrm{E}}$ based on Pub30 and the effective dose $\mathrm{E}$ based on Pub72.

3. Maximum organ dose (among all estimated organ doses for all four age groups). For a given radionuclide and intake mode, this refers to the maximum dose to any organ considered in a given dosimetry system. For example, for ingestion of Fe-55 in drinking water, the maximum organ dose based on NRC77 is the highest dose at any age to any of the four target organs addressed for Fe-55 in NRC77 (estimated to be the dose to bone in the child), while the maximum organ dose based on Pub72 is the highest dose at any age to any of the 24 target organs addressed in Pub72 for Fe-55 (estimated to be the dose to spleen in the infant).

4. Maximum whole body dose (among all four age groups). For a given radionuclide and intake mode, the maximum dose to total body based on NRC77 is compared with the maximum effective dose E based on Pub72.

5. The maximum value of the primary dose quantity (among all four age groups) in each system. The maximum organ dose (critical organ dose) based on NRC77 is compared with the maximum effective dose E based on Pub72.

For each of the two modes of external exposure addressed, dose rate coefficients for skin and total body taken from Table B-1 of RG 1.109 are compared directly with corresponding dose coefficients from FGR-12 (EPA, 1993).

\section{Main results}

\section{Differences in fundamental dosimetric concepts of NRC77 and later systems}

The design criteria in 10 CFR Part 50, Appendix I, specify maximum organ doses and total body doses from liquid and gaseous effluents to any individual in an unrestricted area. These dose criteria reflect dosimetric concepts introduced in Pub2 and carried over to NRC77. The fundamental dosimetric concepts of Pub2 are the dose to the critical organ, which is the primary limiting quantity in that system, and the total body dose, which provides a way of summing doses from mixtures of radionuclides or from external exposure and internally deposited radionuclides.

Information developed since the appearance of ICRP Publication 2 indicates that the critical organ concept does not provide a consistent measure of radiogenic risk because risk per unit absorbed dose varies greatly from one tissue to another. Also, it is evident that the total body dose as defined in ICRP Publication 2 is not a consistent measure of risk from internal emitters because it accounts only for activity that is absorbed to blood, which often represents a small fraction of the nuclear transformations in the body following intake of a radionuclide. 
ICRP Publication 26 (1977) introduced new primary guidance for controlling the risks from radiation based on improved organ-specific dose-response relations for radiogenic cancer. The goal of the new guidance was to provide a more consistent basis for controlling the exposure to radiation, particularly from internally deposited radionuclides, than could be achieved with the critical organ concept of ICRP Publication 2. Dosimetric guidance in ICRP Publication 26 was based on a new concept referred to as the effective dose equivalent, $\mathrm{H}_{\mathrm{E}}$, which is a weighted sum of tissue doses intended to represent the same cancer risk from a non-uniform irradiation of the body as that produced when the whole body is uniformly irradiated. The quantity $\mathrm{H}_{\mathrm{E}}$ replaced not only the concept of critical organ dose as a primary measure of radiation risk but also the concept of total body dose as a means of summing doses for mixtures of radionuclides or from different modes of exposure. The primary guidance in ICRP Publication 26 together with the biokinetic and dosimetric models of ICRP Publication 30 (1979, 1980, 1981, 1988) represent the Pub30 system applied in the present report. A limitation of Pub30 for purposes of dose assessment for members of the public is that the models and methods are intended for application to workers and do not account for differences with age in the biokinetics and dosimetry of radionuclides.

The dosimetry system referred to in this report as the Pub72 system is a modification and extension of the Pub30 system rather than a replacement of that system. The main changes from Pub30 are a modification of the effective dose quantity introduced in Publication 26, with the name changed to the effective dose, E (ICRP, 1991); and use of age-specific mathematical phantoms and age-specific biokinetic models for calculation of age-specific doses from inhaled or ingested radionuclides (ICRP, 1989, 1993, 1995a, 1995b, 1996). In contrast to Pub30, the Pub72 system is designed for application to members of the public.

Comparison of dose estimates for individual radionuclides in drinking water

The following differences in the three dosimetry systems were found to result in substantial differences in organ dose estimates for intake of some radionuclides in drinking water:

- gastrointestinal absorption fractions ( $f_{1}$ values);

- systemic biokinetic models, i.e., models describing the distribution, retention, and excretion of activity absorbed to blood;

- dosimetric models, particularly consideration of cross irradiation of organs in Pub30 and Pub72 but not in NRC77;

- consideration of changes with age in organ masses and, to some extent, biokinetics of radionuclides in NRC77 and Pub72 but not in Pub30;

- application of a relative damage factor for bone for certain radionuclides in NRC77 but not in Pub30 or Pub72;

- application of an RBE of 1.7 in NRC77 to low-energy beta radiation compared with an RBE of 1.0 applied in Pub30 and Pub72. 
The comparisons of dose estimates for ingestion of individual radionuclides in drinking water indicate that:

- With a few exceptions, Pub30 and Pub72 yield reasonably consistent dose estimates for ingestion of radionuclides by adults. Pub30 often yields substantially lower dose estimates than NRC77 or Pub72 for younger age groups due to the use of age-invariant dosimetry models in Pub30.

- For the 28 radionuclides addressed, the ratio of the maximum organ dose based on Pub72 to that based on NRC77 ranges from 0.04 to 10 (see illustrative cases in Figure ExecSum-1).

- Overall, the total body dose based on NRC77 is not closely related to the effective dose E based on Pub72. The main exceptions are for radionuclides that are assumed in both systems to be nearly completely absorbed to blood and fairly uniformly distributed in the body (e.g., H-3). For poorly absorbed or nonuniformly distributed radionuclides the maximum total body dose based on NRC77 may differ from the maximum effective dose E based on Pub72 by several orders of magnitude (see illustrative cases in Figure ExecSum-2).

- For 24 of the 28 radionuclides addressed, the maximum organ dose (critical organ dose) based on NRC77 is greater than the maximum effective dose E based on Pub72. For the other four radionuclides, the maximum effective dose E based on Pub72 is 1.5-2.5 times the critical organ dose based on NRC77 (see illustrative cases in Figure ExecSum-3).

\section{Comparison of dose estimates for inhalation of individual radionuclides}

Factors contributing to substantial differences in estimated organ doses for inhaled radionuclides include those listed above for ingestion of drinking water. An additional factor for inhaled radionuclides is that the three systems have three substantially different respiratory models. The respiratory model of NRC77 typically yields the highest cumulative activity of inhaled material in the lungs among the three models.

The comparisons of dose estimates for inhalation of individual radionuclides indicate that:

- As is the case for ingested radionuclides, Pub30 and Pub72 yield reasonably similar dose estimates for inhalation of most radionuclides by adults, but Pub30 often yields relatively low dose estimates for younger age groups compared either with Pub72 or NRC77 due to the use of age-invariant models in Pub30.

- For 27 of the 28 radionuclides addressed, the maximum organ dose based on Pub72 is lower than that based on NRC77. The ratio of maximum organ doses Pub72 : NRC77 ranges from 0.005 to 1.8 (see illustrative cases in Figure ExecSum-4).

- As is the case for ingested radionuclides, the total body dose based on NRC77 differs greatly from the effective dose E based on Pub72 for a number of radionuclides. The two quantities are reasonably similar for radionuclides that are assumed in both systems to be nearly completely absorbed to blood and fairly uniformly distributed in the body. In some cases the maximum total body dose 
based on NRC77 differs by several orders of magnitude from the maximum effective dose E based on Pub72 (see illustrative cases in Figure ExecSum-5).

- For all 28 radionuclides the maximum critical organ dose based on NRC77 was greater than the maximum effective dose E across all ages based on Pub72 (see illustrative cases in Figure ExecSum-6).

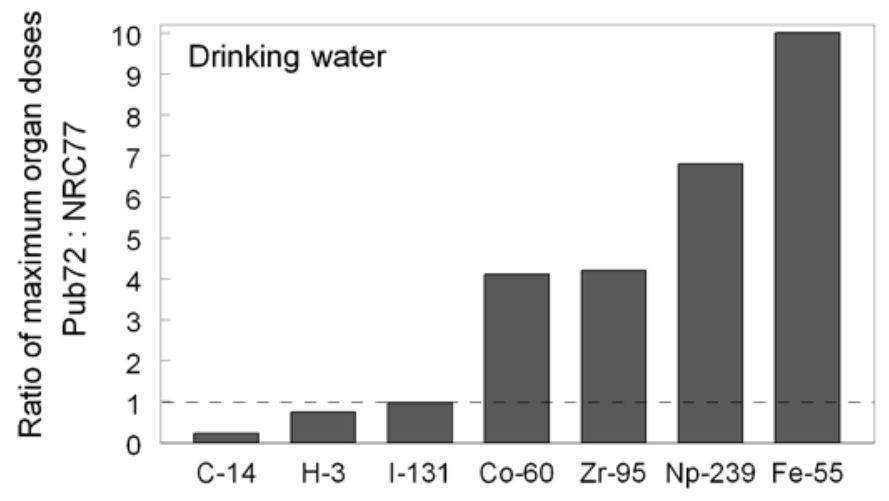

Figure ExecSum-1. For selected radionuclides, comparison of maximum organ doses based on Pub72 and NRC77 for annual intake in drinking water. For example, for a 1-y intake of Co-60, the maximum organ dose based on Pub72 (dose to liver in the infant) is 4.1 times the maximum organ dose based on NRC77 (dose to LLI in the adult).

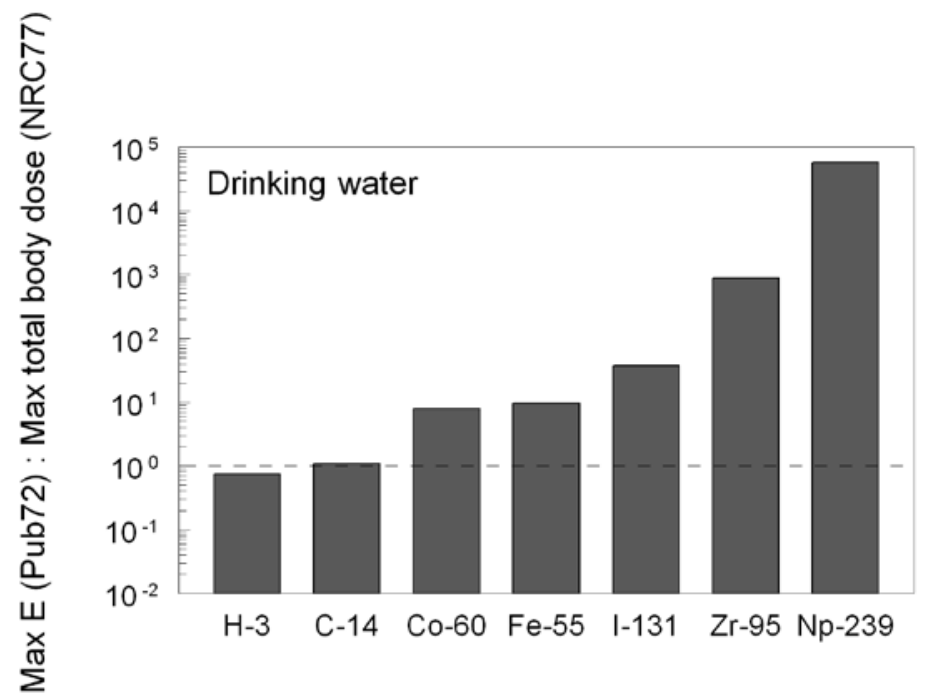

Figure ExecSum-2. For selected radionuclides, comparison of maximum effective dose $E$ based on Pub72 and maximum total body dose based on NRC77 for annual intake in drinking water. For example, for a 1-y intake of Co-60, the maximum of $E$ (the value for the infant) is 7.9 times the maximum total body dose based on NRC77 (also for the infant). 


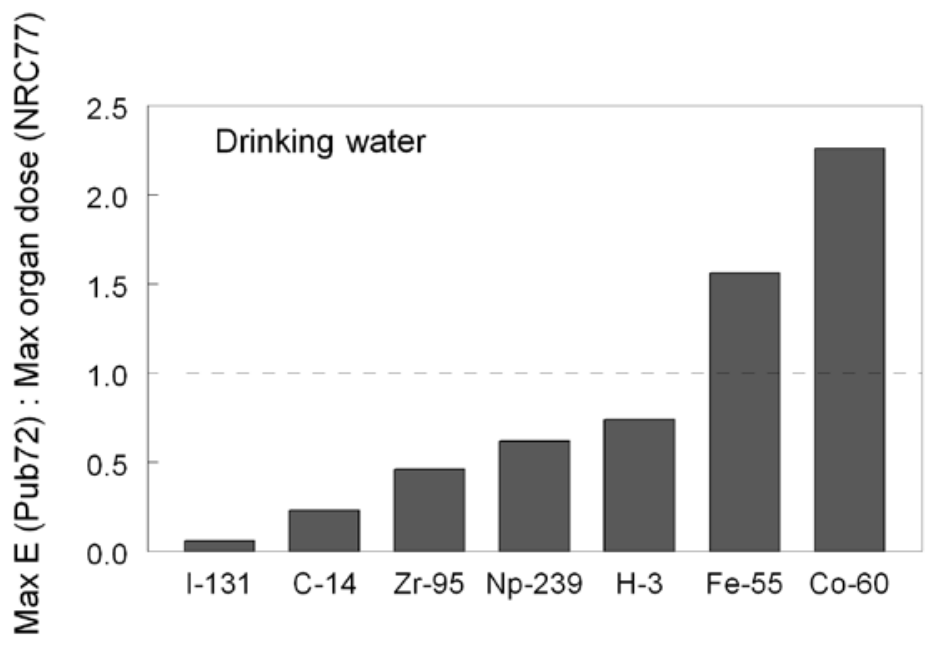

Figure ExecSum-3. For selected radionuclides, comparison of the maximum effective dose $E$ based on Pub72 with the critical organ dose based on NRC77 for annual intake in drinking water. For example, for a 1-y intake of $\mathrm{H}-3$, the maximum value of $E$ (the value for the infant) is 0.74 times the maximum organ dose based on NRC77 (the uniform dose calculated for the child).

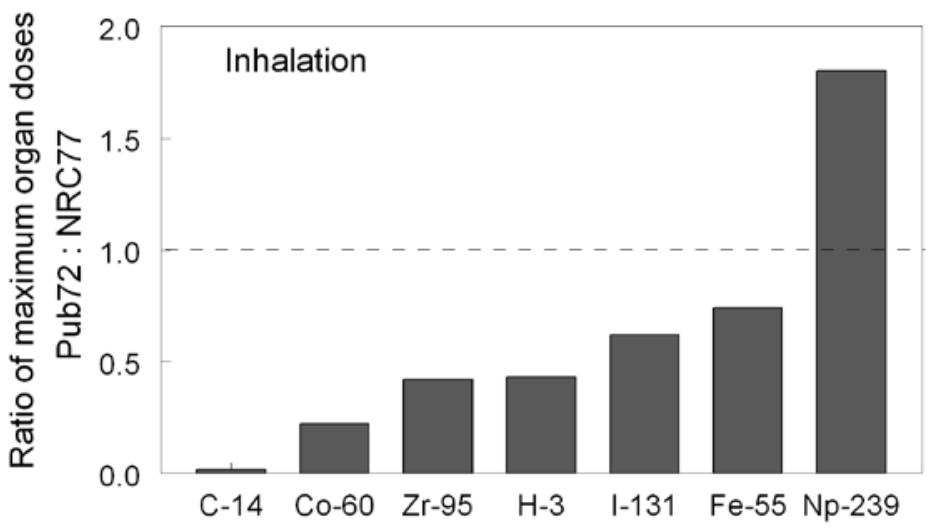

Figure ExecSum-4. For selected radionuclides, comparison of the maximum organ dose based on Pub72 with the maximum organ dose based on NRC77 for annual intake in inhaled air. For example, for a 1-y intake of Co-60, the maximum organ dose based on Pub72 (dose to lung in the teen) is 0.22 times the maximum organ dose based on NRC77 (also dose to lung in the teen). 


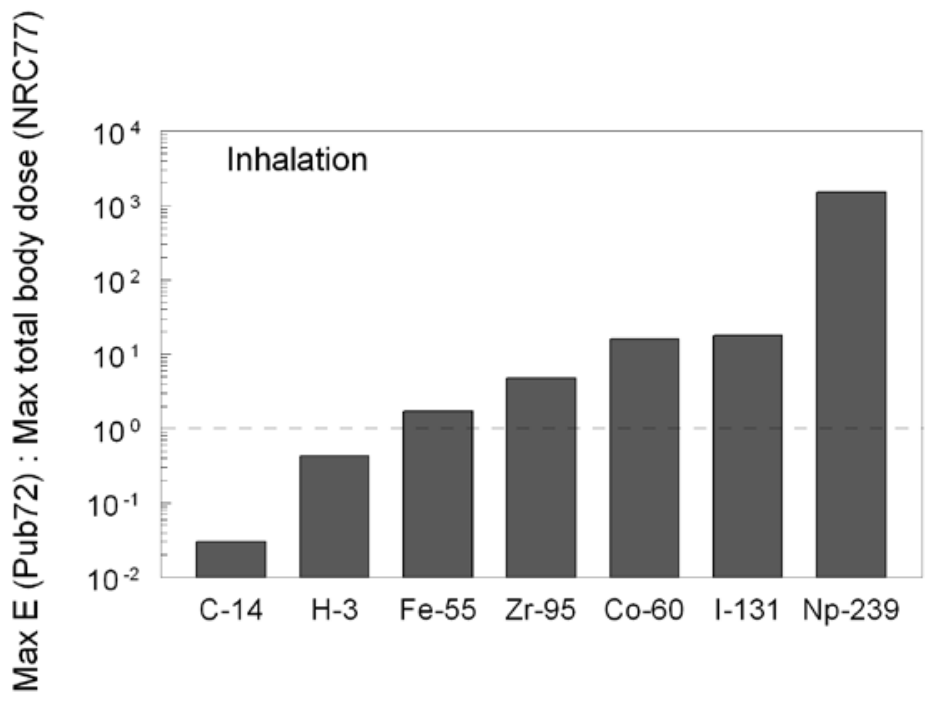

Figure ExecSum-5. For selected radionuclides, comparison of the maximum effective dose $E$ based on Pub72 to the maximum total body dose based on NRC77 for annual intake in inhaled air. For example, for a 1-y intake of Co-60, the maximum value of $E$ (value for the teen) is 16 times the maximum total body dose based on NRC77 (value for the child).

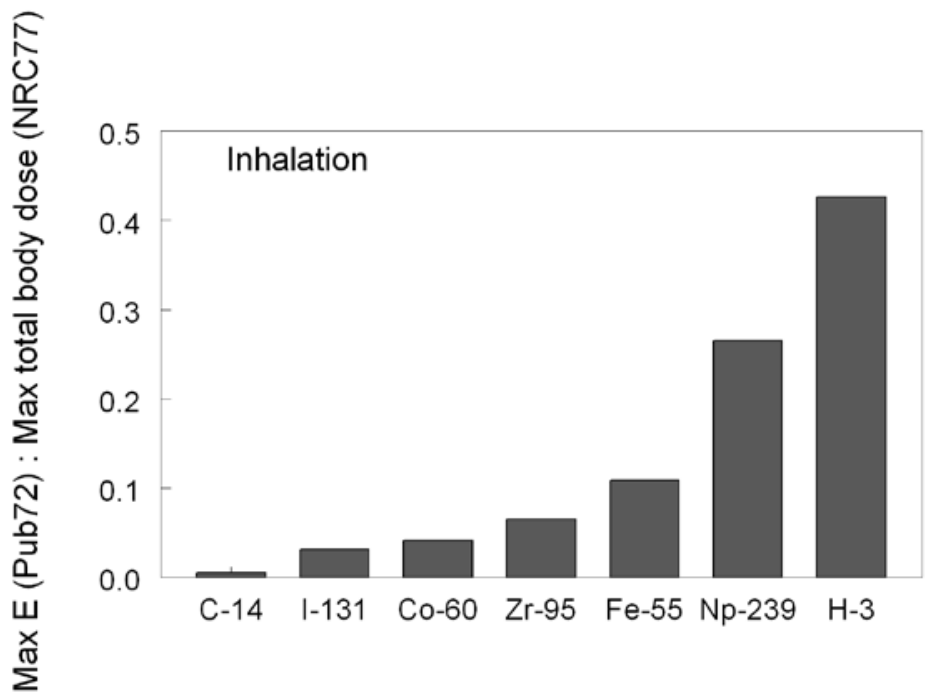

Figure ExecSum-6. For selected radionuclides, comparison of the maximum effective dose $E$ based on Pub72 with the critical organ dose based on NRC77 for annual intake in inhaled air. For example, for a 1-y intake of $\mathbf{N p}-239$, the maximum value of $E$ (the value for the teen) is 0.26 times the maximum organ dose based on NRC77 (the dose to LLI in the teen). 
For noble gas radionuclides in air, dose rate coefficients from RG 1.109 for skin range from 0.82 to 1.02 times corresponding values in FGR-12. Values for total body from RG 1.109 range from 0.54 to 2.24 times values in FGR-12.

For particulate radionuclides on the ground surface, large differences are seen for some radionuclides for both skin and total body. In most instances the values of RG 1.109 are lower than those of FGR-12. For skin, the values of RG 1.109 range from five orders of magnitude lower to a factor of 23 higher than the corresponding FGR-12 coefficients.

\section{Comparison of dose estimates for reference mixtures of radionuclides}

For a reference mixture of BWR effluents in drinking water, maximum organ and wholebody doses based on Pub72 are roughly five times corresponding values based on NRC77 and roughly 20 times higher than values based on Pub30. The comparatively high dose estimates based on Pub72 result mainly from a high content of Fe-55 in the reference mixture of radionuclides and presumably improved models of gastrointestinal absorption and systemic biokinetics of iron in Pub72.

For a reference mixture of PWR effluents in drinking water, maximum organ and wholebody doses based on NRC77 are roughly two times corresponding values based on Pub72 and four times corresponding values based on Pub30. The higher values for NRC77 result in part from a relatively high Sr-90 content in the reference mixture and a conservative ingestion dose coefficient for Sr-90 in NRC77.

For a reference mixture of BWR effluents in air, the maximum organ and whole body doses based on NRC77 are about a factor of 1.7 higher than corresponding values based on Pub72 and a factor of 2 greater than corresponding values based on Pub30. All three systems predict that the thyroid receives the highest tissue dose in all age groups, primarily from intake of I-131 and I-133.

For a reference mixture of PWR effluents in air, all three dosimetry systems predict that the lung receives the highest tissue dose in all age groups, primarily from inhalation of Co-60. The maximum lung dose based on NRC77 is about four times that based on Pub72 and eight times that based on Pub30. The maximum whole body dose predicted by any of the systems is the effective dose $\mathrm{E}$ to the teen based on Pub72, which is about two times the maximum total body dose based on NRC77 and 1.3 times the maximum effective dose equivalent $\mathrm{H}_{\mathrm{E}}$ based on Pub30.

For reference mixtures of noble gases released from either PWRs or BWRs, annual external (air) dose estimates based on RG 1.109 are in reasonable agreement with the values based on current nuclear decay data, despite significant differences in the contributions of the various radionuclides to the total doses. For reference mixtures of particulate radionuclides released from PWRs, annual external doses from activity on the ground surface based on FGR-12 are almost a factor of two greater than values based on 
RG 1.109 for both skin and total body. For releases from BWRs the skin dose and total body estimates based on FGR-12 are, respectively, almost three and two times those based on RG 1.109.

\section{Conclusions}

The design criteria in 10 CFR Part 50, Appendix I, specify maximum organ doses and whole body doses from liquid and gaseous effluents to any individual in an unrestricted area. These dose criteria reflect dosimetric concepts introduced in ICRP Publication 2 and carried over to NRC77, which provides guidance on calculation of doses from radionuclides in power plant effluents. The fundamental dosimetric concepts as well as the biokinetic and dosimetric models used to implement those concepts have been improved in later ICRP dosimetry systems referred to here as Pub30 and Pub72. Pub30 was designed for application to workers and is not well suited to dose assessment of releases of radionuclides into unrestricted areas. Pub72 was designed for application to members of the public and involves age-specific biokinetic and dosimetric models.

Comparison of dose estimates for ingestion or inhalation of individual radionuclides commonly released in power plant effluents reveals that Pub72 sometimes gives substantially higher or lower estimates of maximum organ dose and whole body dose than does NRC77. In most of the cases addressed, the maximum organ dose across age groups based on NRC77 is higher than the maximum effective dose E based on Pub72.

It should be noted that the dosimetric changes discussed in this report reflect the changes that were introduced in the internal dosimetry models recently introduced by the ICRP. They do not, however, indicate the corresponding changes in the effects of exposure to effluents, both air and liquid, from nuclear facilities. To determine the latter, it is necessary to consider the mix of radionuclides that are emitted from the facility and their activity concentrations, their transport through the various environmental pathways, and the usage of the environmental media by the exposed populations. The effect of these considerations may cause any marked changes in the dosimetry of specific radionuclides, when considered only from a dosimetry perspective, to have little or no impact when considering effluents from specific facilities. The results from this report should therefore be viewed as inputs to environmental transport calculations for the facilities under consideration. 


\section{INTRODUCTION}

10 CFR Part 50, Appendix I, requires U.S. Nuclear Regulatory Commission (NRC) licensees to design their effluent control systems and procedures to meet specified dose criteria. NRC requires licensees to calculate doses to members of the public from power plant effluents for comparison with these dose criteria. Guidance for the dose calculations is provided in Regulatory Guide 1.109 (RG 1.109) (NRC, 1977). This guidance is based on dosimetry concepts and models recommended in Publication 2 of the International Commission on Radiological Protection (ICRP, 1959) and extended to pre-adult ages in NUREG-0172 (Hoenes and Soldat, 1977).

The ICRP has issued two major updates of its dosimetric guidance since the publication of RG 1.109:

- ICRP Publication 26 (1977) updated primary guidance on occupational exposure to radionuclides. Updated biokinetic and dosimetric models, dose coefficients, derived air concentrations, and annual limits on intake for workers based on the guidance of Publication 26 were published in ICRP Publication 30(1979, 1980, 1981, 1988).

- ICRP Publication 60 (1991) superseded ICRP Publication 26. Biokinetic and dosimetric models and dose coefficients for members of the public based on ICRP Publication 60 were issued in a series of documents published between 1993 and 1996 (ICRP Publication 67, 1993; Publication 66, 1994a, Publication 69, 1995a; Publication 71, 1995b; Publication 72, 1996). Dose coefficients for infants, children, adolescents, and adults from this series are summarized in ICRP Publication 72 (1996).

An updated ICRP dosimetry system based on primary guidance recently published in ICRP Publication 103 (2008) is currently under development.

The main purpose of this report is to compare doses from radionuclides potentially released from nuclear power plants based on biokinetic and dosimetric models and dosimetry concepts of: (1) ICRP Publication 2, as extended in NUREG-0172 and applied in RG 1.109; (2) ICRP Publication 26, as applied in ICRP Publication 30; and (3) ICRP Publication 60 as applied in a series of ICRP documents on doses to the public, ending with the summary document ICRP Publication 72 (1996).

Section 2 summarizes the main features of these three dosimetry systems and examines fundamental differences in the dose concepts applied in the three systems. Dose comparisons are then made for ingestion of individual radionuclides in drinking water (Section 3), inhalation of individual radionuclides (Section 4), and external exposure to individual radionuclides (Section 5). An appendix compares dose estimates for hypothetical mixtures of radionuclides in liquid or gaseous effluents from Boiling Water Reactors (BWRs) or Pressurized Water Reactors (PWRs). 
As a starting point for comparing doses from ingestion or inhalation of radionuclides, doses are estimated for the case of a one-year intake of each of 28 selected radionuclides, based on reference age-specific values for intake of drinking water or air given in RG 1.109 and dose coefficients tabulated in that document. The analysis is repeated using dose coefficients based on ICRP Publications 26 and 30 and again using coefficients based on ICRP Publication 60 and subsequent reports on doses to members of the public. Comparisons of the three sets of doses are then made, and reasons for differences and similarities in the three sets of dose estimates are investigated. Throughout this report the term "dose" as applied to ingested or inhaled radionuclides refers to a committed dose, in units of rem or sievert, resulting from a chronic one-year intake.

The discussion addresses differences in dose estimates resulting from the following differences in the three systems: fundamental dosimetry concepts, biokinetic and dosimetric models, and dose conversion factors as applied to age groups, tissues, and organs and weighting factors for tissues and organs. Complications in comparing results based on the total body and critical organ concepts of ICRP Publication 2 with guidance of ICRP Publication 26 and ICRP Publication 60 are discussed. Total body dose, critical organ dose, effective dose equivalent $\left(\mathrm{H}_{\mathrm{E}}\right)$, and effective dose $(\mathrm{E})$ results are tabulated as ratios expressing the relative difference of each set of results to RG 1.109 as the base case.

The radionuclides considered in the comparisons of doses from ingestion or inhalation are ${ }^{3} \mathrm{H},{ }^{14} \mathrm{C},{ }^{32} \mathrm{P},{ }^{51} \mathrm{Cr},{ }^{54} \mathrm{Mn},{ }^{55} \mathrm{Fe},{ }^{59} \mathrm{Fe},{ }^{58} \mathrm{Co},{ }^{60} \mathrm{Co},{ }^{63} \mathrm{Ni},{ }^{64} \mathrm{Cu},{ }^{65} \mathrm{Zn},{ }^{89} \mathrm{Sr},{ }^{90} \mathrm{Sr},{ }^{90} \mathrm{Y},{ }^{95} \mathrm{Zr}$, ${ }^{95} \mathrm{Nb},{ }^{99} \mathrm{Mo},{ }^{99 \mathrm{~m}} \mathrm{Tc},{ }^{106} \mathrm{Ru},{ }^{110 \mathrm{~m}} \mathrm{Ag},{ }^{131} \mathrm{I},{ }^{133} \mathrm{I},{ }^{134} \mathrm{Cs},{ }^{137} \mathrm{Cs},{ }^{140} \mathrm{Ba},{ }^{140} \mathrm{La}$, and ${ }^{239} \mathrm{~Np}$. Halflives and other basic nuclear decay data for these radionuclides are summarized in Appendix A.

Comparisons of dose for individual radionuclides are based on a unit activity concentration of each of these radionuclides in drinking water $(1 \mathrm{pCi} / \mathrm{L})$ or air $\left(1 \mathrm{pCi} / \mathrm{m}^{3}\right)$.

External dose coefficients given in RG 1.109 for these and other radionuclides including noble gases are compared with external dose coefficients implied by the nuclear decay data used in current ICRP documents. The updated external dose coefficients used in the comparison are those listed in Federal Guidance Report 12 (FGR-12) (EPA, 1993) or implied by the methodology described in that document.

The following abbreviations of dosimetry systems are used throughout this report:

Pub2 refers to the dosimetry system for workers introduced in ICRP Publication 2 (1959).

NRC77 refers to the modified Pub 2 system described in NUREG-0172 (Hoenes and Soldat, 1977) and applied in NRC RG 1.109, Revision 1 (1977). NRC77 extends the Pub2 system to an age-specific dosimetry system. 
Pub30 refers to the dosimetry system for workers consisting of the primary guidance given in ICRP Publication 26 (1977) and biokinetic and dosimetric models described in ICRP Publication 30 (1979, 1980, 1981, 1988).

Pub72 refers to the ICRP's dosimetry system for members of the public. It consists of the primary guidance given in ICRP Publication 60 (1991) and the age-specific biokinetic and dosimetric models described in ICRP Publication 67 (1993), Publication 66 (1994a), Publication 69 (1995a), Publication 71 (1995b), and Publication 72 (1996). The system is referred to here as Pub72 because ICRP Publication 72 (1996) summarizes the age-specific effective dose coefficients provided in this series.

The discussion of the evolution of the ICRP's biokinetic and dosimetric models starts with models as originally formulated in Pub2, although comparisons of dose estimates in this report are restricted to NRC77, Pub30, and Pub72.

\section{SUMMARY OF THE PUB2, NRC77, PUB30, AND PUB72 SYSTEMS}

\subsection{Dosimetry system of Pub2}

\subsubsection{Concept of a critical organ}

Guidance in Pub2 is based on the concept of the critical organ. Factors considered in the determination of the critical organ include the organ that accumulates the greatest concentration of a radionuclide; the importance of the organ to the well being of the entire body; the organ damaged by route of entry of the radionuclide into the body; and the radiosensitivity of the organ, meaning the organ damaged by the lowest dose. In practice the organ identified as the critical organ by the methods of Pub2 is generally the organ estimated to receive the highest dose.

For a given radionuclide, dose estimates are made in Pub2 for a few selected organs with presumably elevated deposition of the radionuclide after absorption to blood and also are made for "total body". The selected organs are referred to as the "organs of reference" for the radionuclide or, more precisely, for the corresponding element since the organs of reference generally are element specific. The total body dose is calculated as an aid in computing maximal permissible concentrations in air and water for mixtures of radionuclides and as a check on the simplistic retention models and dosimetric methods applied to individual organs. Total body dose is based on the assumption of uniform distribution of the absorbed portion of the radionuclide in tissues and removal with a biological half-time intermediate to individual organs of reference.

\subsubsection{Respiratory tract model of Pub2}

The respiratory model of Pub2 consists of the following assumptions: 
(1) $25 \%$ of inhaled activity is exhaled immediately, $50 \%$ deposits in the upper respiratory tract, and $25 \%$ deposits in the lower respiratory tract.

(2) Activity deposited in the upper respiratory tract is swallowed immediately, i.e., transferred immediately to the stomach.

(3) Any soluble material deposited in the lower respiratory tract is transferred immediately to blood.

(4) Half of any insoluble material deposited in the lower respiratory tract is cleared from the tract and swallowed immediately. The other half clears from the lower respiratory tract to the environment (disappears from the body) with a biological halftime of $120 \mathrm{~d}$ except for plutonium and thorium, which are assigned longer halftimes. With the exception of plutonium and thorium compounds, the term "insoluble" as used in Pub2 does not appear to refer to highly insoluble material, judging from the assumptions concerning residence time in the lungs and the level of absorption to blood. Rather, the term seems to refer to moderately soluble material, which may reside in the lungs for a period of months.

(5) A fraction $\mathrm{f}_{1}$ of swallowed activity is absorbed from the gastrointestinal (GI) tract to blood and $1-f_{1}$ is excreted in feces. The value $f_{1}$ depends on the element but not on the solubility of the inhaled material.

Thus, if the inhaled material is soluble, the fraction of inhaled activity that reaches blood is $0.25+0.5 f_{1}$. If the inhaled material is insoluble, the fraction reaching blood is $0.625 f_{1}$, where 0.625 is the sum of the deposition in the upper respiratory (0.5) and half the deposition in the lower respiratory tract (i.e., half of 0.25).

A schematic of the respiratory tract model of Pub2 is shown in Figure 2.1.

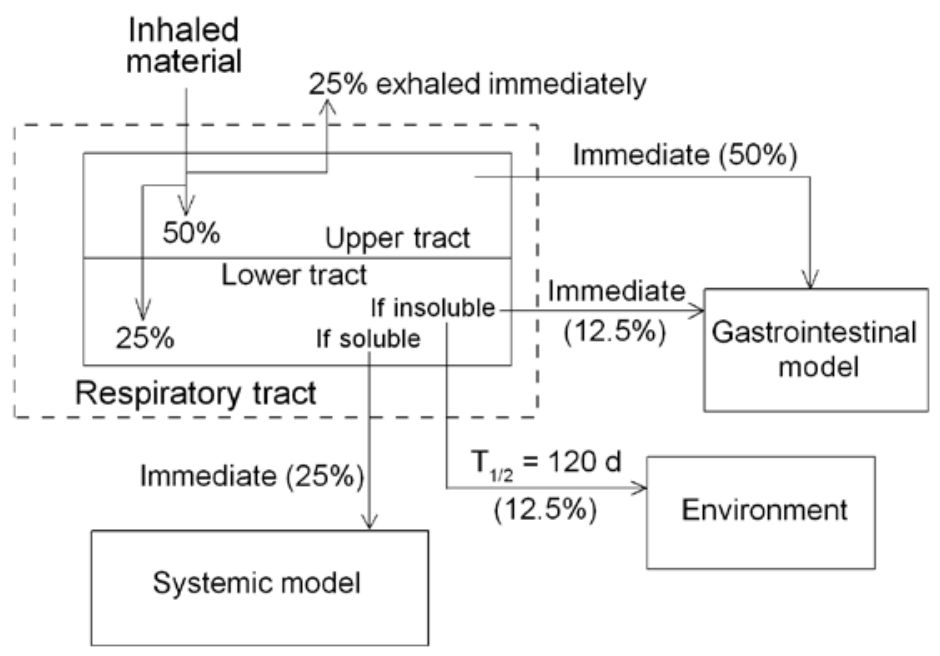

Figure 2.1. Respiratory model used in Pub2. All percentages refer to the inhaled amount. 


\subsubsection{Gastrointestinal tract model of Pub2}

The gastrointestinal (GI) tract model used in Pub2 is shown in Figure 2.2. The GI tract is represented as a series of four segments: stomach (St), small intestine (SI), upper large intestine (ULI), and lower large intestine (LLI). Assumed residence times of material in these segments are $1,4,8$, and $18 \mathrm{~h}$, respectively. Flow of material through a segment is treated as "slug flow" rather than as first-order removal. For example, material entering St contents is assumed to remain in the contents exactly one hour and then to be abruptly removed to SI contents. Absorption to the systemic circulation is assumed to occur in SI. Gastrointestinal absorption fractions applied in Pub2 and those applied in later dosimety systems are listed in Appendix B.

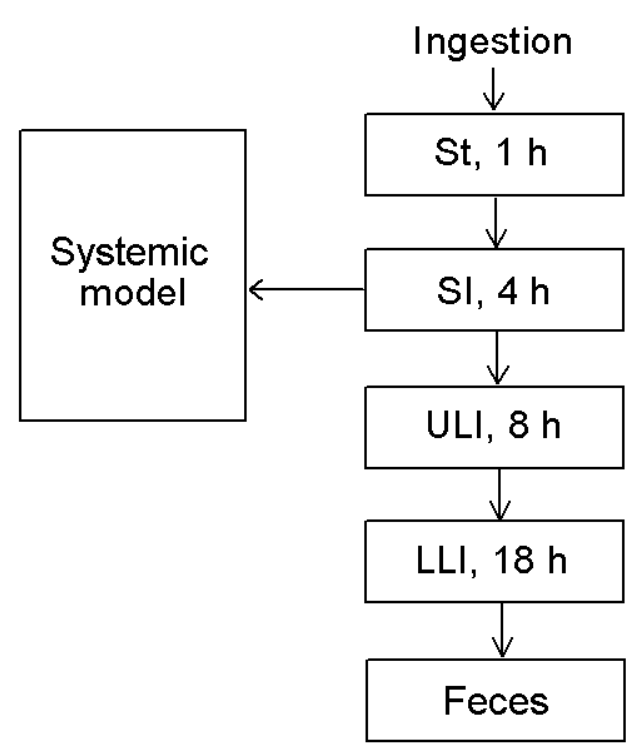

Figure 2.2. Gastrointestinal tract model used in Pub2. The time given for a segment of the tract is the residence time of material in the contents of that segment.

\subsubsection{Systemic biokinetic models of Pub2}

The systemic biokinetic models of Pub2 are described in Appendix B for all of the radionuclides addressed in this report. The systemic model for cobalt shown in Figure 2.3 illustrates the simplistic formulations of these models. 


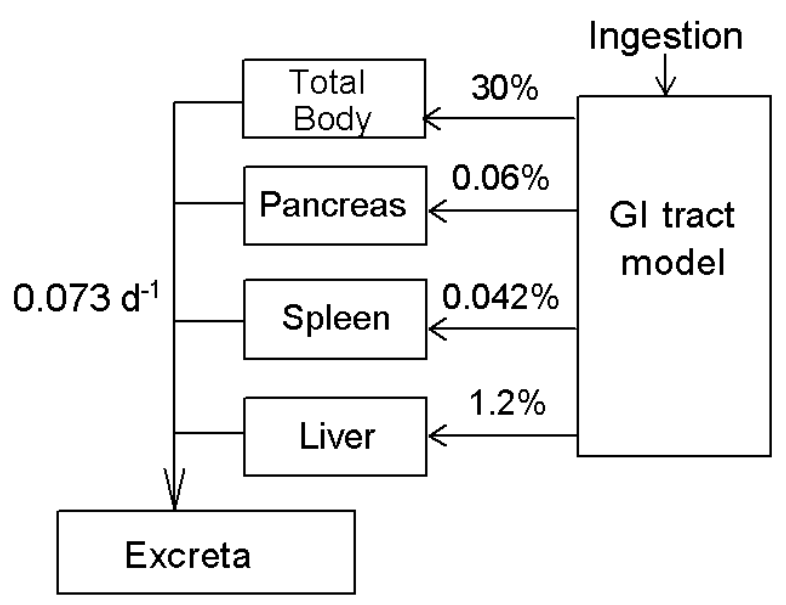

Figure 2.3. Systemic biokinetic model for cobalt used in Pub2. The portion of ingested cobalt assigned to total body includes the portions assigned to pancreas, spleen, and liver.

In general, a radionuclide entering blood is assumed to be delivered instantaneously to the organs of reference for that radionuclide (e.g., pancreas, spleen, liver, and total body in the model for cobalt). Each of the organs of reference is assigned a deposition fraction, called $\mathrm{f}_{2}$ '. The deposition fraction for the total body is 1.0. The deposition fractions $\mathrm{f}_{2}$ ' for individual organs of deposition (i.e., excluding total body) generally do not account for the total absorbed amount, i.e., the sum of the $\mathrm{f}_{2}$ ' values generally is less than 1.0. In effect, the rest of the activity (i.e., 1.0 minus the sum of the $f_{2}$ ' values) is immediately removed from the body.

The fraction $\mathrm{f}_{\mathrm{w}}$ of an ingested radionuclide assigned to a systemic organ with deposition fraction $f_{2}{ }^{\prime}$ is $f_{w}=f_{1} f_{2}$, where $f_{1}$ is the fraction of activity entering the gastrointestinal tract that is absorbed to blood. Since the deposition fraction $\mathrm{f}_{2}$ ' for total body is 1.0, the fraction of an ingested radionuclide assigned to total body is $\mathrm{f}_{1}$. For each of the radionuclides addressed in this report, the $f_{1}$ value used in Pub2 is compared in Appendix A with values applied in the other dosimetry systems discussed in this report.

Retention in an organ is characterized by a single biological half-life intended to provide a cautiously high estimate of dose to that organ. Activity removed from an organ by biological processes is assumed to exit the body instantaneously.

\subsubsection{Approach to internal dosimetry in Pub2}

In general, the dose to the wall of a segment of the GI tract is assumed to be due only to activity in the contents of that segment. Exceptions arise for radionuclides that are assumed to be completely absorbed and uniformly distributed. For example, for ingested ${ }^{3} \mathrm{H}$ or ${ }^{14} \mathrm{C}$ the GI tract walls are assigned the total-body dose. 
For computation of dose from activity in the contents of a segment of the GI tract, the dose is calculated to the contents of a segment of the GI tract, assumed to be spherical in shape with an assigned effective radius. The dose to the intestinal wall is assumed to be one-half the dose to the contents for beta and gamma radiation and $1 \%$ of the dose to the contents for alpha emitters, based on evidence that alpha particles do not penetrate the mucosal layer of the walls to an appreciable extent.

In calculations of dose from absorbed activity, only the source organs (organs of reference) are considered as target organs. Only the self-dose to an organ is considered, i.e., cross-irradiation is not addressed for penetrating radiation. Each organ is represented as a sphere with an effective radius. For example, the effective radius is $30 \mathrm{~cm}$ for the total body, $5 \mathrm{~cm}$ for bone, $10 \mathrm{~cm}$ for the stomach, $5 \mathrm{~cm}$ for the lower large intestine, and $10 \mathrm{~cm}$ for the liver. For alpha and beta emitters the dosimetry based on this simplistic geometry is consistent with later methods based on relatively sophisticated mathematical models of the body and its organs (phantoms), except for changes in organ masses. On the other hand, dose estimates can be relatively sensitive to the assigned geometries of the organs in the case of penetrating radiations.

Dose calculations include consideration of the relative biological effectiveness (RBE) of different radiation types. RBE is 1 for $\beta^{-}, \beta^{+}$, $\mathrm{e}^{-}$, and $\gamma$ radiation except that RBE is 1.7 for $\beta^{-}, \beta^{+}$, and $\mathrm{e}^{-}$with maximum energy $\leq 0.03 \mathrm{MeV}$. For example, the dose estimates for $^{3} \mathrm{H}$ based on Pub2 include an RBE of 1.7 for ${ }^{3} \mathrm{H}$ because it is a beta emitter with maximum energy $<0.03 \mathrm{MeV} .{ }^{1} \mathrm{RBE}$ is 10 for alpha radiation and 20 for recoil atoms.

The bone dosimetry model of Pub2 compares the effective energy absorbed in the skeleton with that for a body burden of $0.1 \mu \mathrm{Ci}$ of ${ }^{226} \mathrm{Ra}$, a bone-seeking radionuclide that resides mainly in bone volume. The dose is calculated for $7 \mathrm{~kg}$ of marrow-free skeleton. The absorbed dose to this tissue is modified by a "relative damage factor" equal to 1 for isotopes of radium or pure gamma emitters and 5 for other radionuclides that emit mainly alpha or beta radiation. The relative damage factor apparently accounts for additional damage caused by radionuclides that, unlike ${ }^{226} \mathrm{Ra}$, reside largely on bone surface.

\subsection{Implementation of the Pub2 dosimetry system in NRC77}

The dosimetry concepts and dose coefficients (dose conversion factors) in NRC77 are based on recommendations and models in Pub2, as updated in some cases in ICRP Publication 6 (1962) or ICRP Publication 10 (1968). For example, in the respiratory tract model of Pub2, half of the $25 \%$ of inhaled insoluble activity depositing in the lower respiratory tract is assumed to be removed from this region and to disappear from the body with a biological half-time of $120 \mathrm{~d}$. In ICRP Publication 10 it is assumed that this slowly cleared activity is "taken up into the body fluids" and distributed among systemic tissues (Figure 2.4). This modified version of the Pub2 respiratory model was applied by Hoenes and Soldat (1977) to derive the dose coefficients used in NRC77.

\footnotetext{
${ }^{1}$ The dose coefficients for ${ }^{3} \mathrm{H}$ currently used in the 10 CFR 50, Appendix I, compliance calculations are based on an RBE of 1, rather than the value 1.7 from the Pub2 dosimetry system. Other departures from Regulatory Guide 1.109 are noted in reports by Strenge et al. $(1986,1987)$.
} 


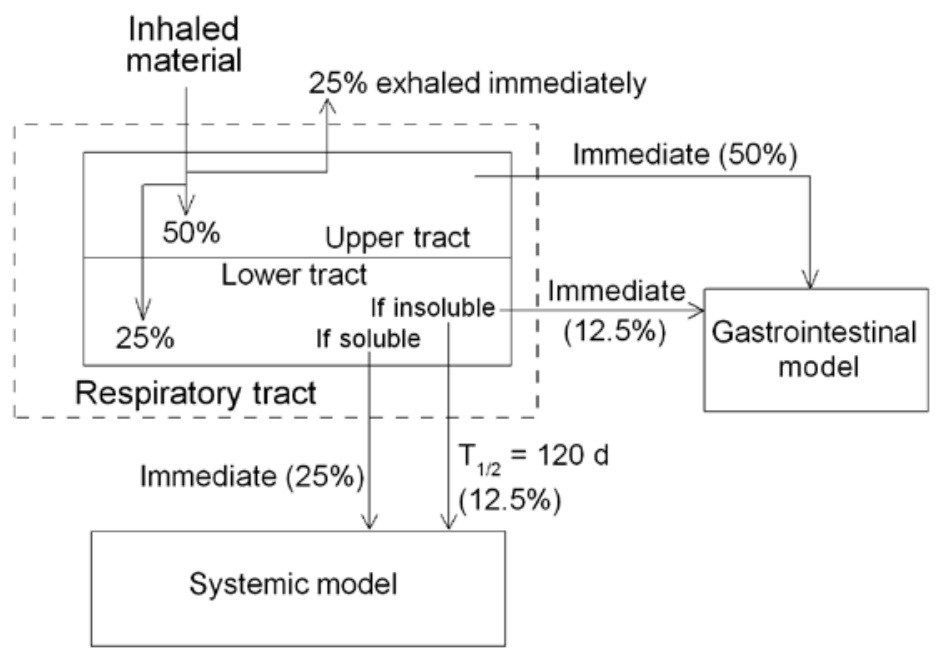

Figure 2.4. Modification of the Pub2 respiratory model used in NRC77. In contrast to the Pub2 model, the slowly cleared fraction of insoluble activity is assigned to systemic tissues. All percentages refer to inhaled activity.

Extensions and modifications of the Pub2 system are made in NRC77 to address preadult ages, reflect updated information, and consider a small, fixed set of organs. Details of the biokinetic and dosimetric models and method of computation of doses are given in NUREG-0172 (Hoenes and Soldat, 1977).

Dose coefficients for a radionuclide are given in NRC77 for total body, LLI (as the segment of the GI tract generally estimated to receive the highest dose), and any of the following five organs that are organs of reference in the Pub2 model for that radionuclide: bone, liver, kidneys, thyroid, and lung. For example, since bone, kidneys, thyroid, and lung are not addressed in the Pub2 model for ingested ${ }^{60} \mathrm{Co}$ (Figure 2.3), dose coefficients for ingested ${ }^{60} \mathrm{Co}$ are given in NRC77 only for total body, LLI, and liver. The systemic biokinetic model applied to ingested or inhaled cobalt in NRC77 is the model shown in Figure 2.3, minus the boxes and arrows for pancreas and spleen. Dose coefficients for inhaled ${ }^{60} \mathrm{Co}$ are given in NRC77 for the same organs considered for ingestion (total body, LLI, and liver), plus lung as an organ of deposition and retention of inhaled ${ }^{60} \mathrm{Co}$. For some radionuclides (e.g.e ${ }^{137} \mathrm{Cs}$ and $\left.{ }^{131} \mathrm{I}\right)$, no inhalation dose coefficient is given for lung because inhaled material is assumed to be in soluble form and to clear quickly from the respiratory tract.

NRC77 addresses four age groups: infant (0-1 y), child (1-11 y), teen (11-17 y), and adult (17 y and older). Age-specific biological half-times for selected organs are provided for tritium, iodine, and cesium (Table 2.1). For other elements the biokinetic model for adults is applied to all four age groups. 
Table 2.1. Age-specific biological half-times applied in NRC77.

\begin{tabular}{cccccc}
\hline & & \multicolumn{4}{c}{ Half-time (d) } \\
\cline { 3 - 6 } Element & Organ & Infant & Child & Teenager & Adult \\
\hline Tritium & Total body & 3.2 & 4.5 & 7.0 & 10 \\
lodine & Total body and thyroid & 20 & 20 & 50 & 100 \\
Cesium & Total body & 10 & 20 & 60 & 115 \\
\hline
\end{tabular}

Each of the dose commitment factors in NRC77 represents the integral of the dose rate over a 50-y period, regardless of age at intake. This is the same integration period as later applied to the worker in Pub30 and to the adult member of the public in Pub72, but a dose coefficient in Pub72 for intake at a pre-adult age represents the integral from time of intake to age $70 \mathrm{y}$.

Age-specific masses of body organs are considered in NRC77 in calculation of organ doses (Table 2.2). As in Pub2, doses are calculated only for source organs identified in the biokinetic model for the radionuclide, and only self-dose of an organ is considered. The effective radius of a body organ in the adult is taken from Pub2. The effective radius of an organ at a pre-adult age is derived from the value for the adult based on the assumption that the effective radius is proportional to the cube root of the organ mass. To simplify calculations of 50-year doses for pre-adult intake of radionuclides with long biological half-times, the organ masses and radii are held fixed until a division point between age groups is reached and then are abruptly changed.

\begin{tabular}{lcccccccc}
\hline Table 2.2. Mass and effective radius of body organs for the four age groups of NRC77. \\
\hline \multirow{2}{*}{ Organ } & \multicolumn{2}{c}{ Infant } & \multicolumn{2}{c}{ Child } & \multicolumn{2}{c}{ Teenager } & \multicolumn{3}{c}{ Adult } \\
\cline { 2 - 9 } & $\begin{array}{c}\text { Mass } \\
(\mathrm{g})\end{array}$ & $\begin{array}{r}\text { Radius } \\
(\mathrm{cm})\end{array}$ & $\begin{array}{c}\text { Mass } \\
(\mathrm{g})\end{array}$ & $\begin{array}{c}\text { Radius } \\
(\mathrm{cm})\end{array}$ & $\begin{array}{c}\text { Mass } \\
(\mathrm{g})\end{array}$ & $\begin{array}{c}\text { Radius } \\
(\mathrm{cm})\end{array}$ & $\begin{array}{c}\text { Mass } \\
(\mathrm{g})\end{array}$ & $\begin{array}{c}\text { Radius } \\
(\mathrm{cm})\end{array}$ \\
\hline Total body & 7700 & 14 & 16,400 & 20 & 49,000 & 27 & 70,000 & 30 \\
Bone & 770 & 2.4 & 1640 & 3 & 4900 & 4 & 7000 & 5 \\
Liver & 200 & 5 & 530 & 7 & 1200 & 9 & 1700 & 10 \\
Thyroid & 2 & 1.4 & 5 & 2 & 15 & 2.7 & 20 & 3 \\
Kidney & 55 & 4 & 100 & 5 & 210 & 6 & 300 & 7 \\
Lung & 110 & 5 & 300 & 7 & 580 & 8 & 1000 & 10 \\
LLI & 16 & 2.4 & 35 & 3 & 100 & 4 & 150 & 5 \\
\hline
\end{tabular}

In NRC77 the mass of the contents of the GI tract in the infant, child, and teen is extrapolated from the value for adults by assuming the contents to be proportional to total-body mass. Transit of a radionuclide through the lumen of the GI tract is characterized by two values: the travel time to the lower large intestine (LLI), and the travel time through the LLI. Both values were assumed to be proportional to the mass of the total body. This assumption implies much more rapid transit through the GI tract in infants and children than in adults. Information developed since the completion of NRC77 indicates that the transit time through segments of the GI tract does not depend strongly on age (Leggett et al., 2007), suggesting that the GI transit model of NRC77 could underestimate dose to the LLI wall from activity in the contents in children and infants. Apparently in an effort to avoid underestimating the dose to the LLI walls, the 
fraction of ingested material reaching the intestinal contents is assumed to be at least 0.05 in the absence of radioactive decay, even in cases where complete absorption is assumed and 1.0 is assigned to total body. This means that $105 \%$ of the ingested activity is used in the calculation of doses in cases where absorption is assumed to be complete.

Special treatment is given to the behavior of daughter radionuclides in the GI tract in cases where the $\mathrm{f}_{1}$ value for the daughter is smaller than that of the parent, and the halflife of the daughter is relatively short but sufficiently long that a substantial portion of the atoms produced in the upper large intestine (ULI) or higher is emptied into the LLI contents. An example is ${ }^{90} \mathrm{Y}\left(\mathrm{T}_{1 / 2}=64 \mathrm{~h}, \mathrm{f}_{1}=0.0001\right.$ in NRC77) as a daughter of ${ }^{90} \mathrm{Sr}\left(\mathrm{f}_{1}\right.$ $=0.3$ in NRC77). For such cases NUREG-0172 provides a set of first-order equations for calculating the radiation absorbed in the LLI per disintegration of the parent, taking account of potentially elevated activity of daughter nuclides in the LLI contents compared with activity of the parent.

\subsection{Dosimetry system of Pub30}

\subsubsection{Concept of effective dose equivalent}

The biokinetic and dosimetric models as well as the general guidance in Pub2 were overhauled in Pub30 (ICRP, 1977, 1979, 1980, 1981, 1988). A new system was introduced in ICRP Publication 26 (1977) for controlling the risks from radiation based on improved information on the relative probabilities of inducing radiogenic cancers in different organs. The purpose of this updated scheme was to provide a more consistent basis for controlling the exposure of workers to radiation, particularly from internally deposited radionuclides, than could be achieved with the critical organ concept of Pub2.

The following tissues are addressed in Pub30: adrenals, bone surface, brain, breasts, esophagus, kidneys, liver, lung, muscle, ovaries, pancreas, red marrow, skin, spleen, testes, thymus, thyroid, urinary bladder wall, uterus, stomach wall, small intestine wall, upper large intestine wall, and lower large intestine wall.

Dosimetric guidance in Publication 26 is based mainly on a quantity called the effective dose equivalent, $\mathrm{H}_{\mathrm{E}}$. This is a weighted sum of tissue doses intended to represent the same cancer risk from a non-uniform irradiation of the body as that produced when the whole body is uniformly irradiated. It is defined as

$$
H_{E}=\sum_{T} w_{T} H_{T}
$$

where $\mathrm{w}_{\mathrm{T}}$ is a weighting factor for tissue $\mathrm{T}$ and $\mathrm{H}_{\mathrm{T}}$ is the mean dose equivalent to that tissue. Because the weighting factors are normalized to sum to 1.0, a weighting factor for tissue $\mathrm{T}$ corresponds to the fractional contribution of that tissue to the total risk of stochastic health effects when the body is uniformly irradiated. The weighting factors given in ICRP Publication 26 and used in ICRP Publication 30 (1979, 1980, 1981, 1988) are listed in Table 2.3. 


\begin{tabular}{|c|c|c|}
\hline \multirow[b]{2}{*}{ Organ or tissue } & \multicolumn{2}{|c|}{ Tissue weighting factor $\left(\mathrm{w}_{\mathrm{T}}\right)$} \\
\hline & ICRP Pub. 26 & ICRP Pub. 60 \\
\hline Gonads & 0.25 & 0.20 \\
\hline Bone marrow (red) & 0.12 & 0.12 \\
\hline Colon & -- & 0.12 \\
\hline Lung & 0.12 & 0.12 \\
\hline Stomach & -- & 0.12 \\
\hline Bladder & -- & 0.05 \\
\hline Breast & 0.15 & 0.05 \\
\hline Liver & -- & 0.05 \\
\hline Esophagus & -- & 0.05 \\
\hline Thyroid & 0.03 & 0.05 \\
\hline Skin & -- & 0.01 \\
\hline Bone surface & 0.03 & 0.01 \\
\hline Remainder & $0.30^{\mathrm{a}}$ & $0.05^{\mathrm{b}, \mathrm{c}}$ \\
\hline \multicolumn{3}{|c|}{$\begin{array}{l}\text { athe value } 0.30 \text { is applied to the average dose to the five remaining } \\
\text { tissues receiving the highest dose, excluding the skin, lens of the eye, } \\
\text { and the extremities. } \\
\text { bemainder is composed of the following tissues: adrenals, brain, } \\
\text { extrathoracic airways, small intestine, kidneys, muscle, pancreas, } \\
\text { spleen, thymus, and uterus. } \\
\text { "The value } 0.05 \text { is applied to the mass-weighted average dose to the } \\
\text { Remainder tissue group, except when the following "splitting rule" } \\
\text { applies: If a tissue of Remainder receives a dose in excess of that } \\
\text { received by any of the } 12 \text { tissues for which weighting factors are } \\
\text { specified, a weighting factor of } 0.025 \text { (half of Remainder) is applied to } \\
\text { that tissue and } 0.025 \text { to the mass-averaged committed equivalent } \\
\text { dose in the rest of the Remainder tissues. }\end{array}$} \\
\hline
\end{tabular}

\subsubsection{Respiratory tract model of Pub30}

The respiratory model used in ICRP Publication 30 is referred to as the Task Group Lung Model (TGLM). The model structure is shown in Figure 2.5. The model includes four main regions: nasal-pharynx (NP), tracheobronchial, pulmonary (P), and lymphatic (L). Inhaled material is deposited in regions NP, TB, and $\mathrm{P}$, with regional deposition depending on the size of the inspired particles. A given chemical or physical form of a radionuclide is assigned to one of three clearance classes: $\mathrm{D}$ (days), $\mathrm{W}$ (weeks), or $\mathrm{Y}$ (years). These correspond to rapid, intermediate, or slow clearance, respectively, of material deposited in the respiratory passages. Removal half-times are assumed to be independent of particle size.

Parameter values for the TGLM are given in Table 2.4 for a particle size of $1 \mu \mathrm{m}$ AMAD (activity median aerodynamic diameter), the default particle size in Pub30. For this particle size, fractional deposition of inhaled material in the total respiratory tract is assumed to be 0.63 , of which 0.30 is assigned to NP, 0.08 to TB, and 0.25 to P. For a 
long-lived radionuclide the fractions of inhaled activity eventually absorbed from the respiratory tract to blood are approximately 0.48 for Class D, 0.12 for Class W, and 0.05 for Class Y material of size $1 \mu \mathrm{m}$ AMAD. Additional absorption to blood occurs from the gastrointestinal tract after activity is escalated from the lungs and swallowed. For a long-lived radionuclide, total fractional transfer of inhaled activity to blood is estimated as $0.48+0.15 f_{1}$ for Class D, $0.12+0.51 f_{1}$ for Class $\mathrm{W}$, and $0.05+0.58 f_{1}$ for Class $\mathrm{Y}$ material, where $\mathrm{f}_{1}$ is fractional absorption of swallowed activity (paths $\mathrm{b}, \mathrm{d}, \mathrm{k}$, and $\mathrm{l}$ ).

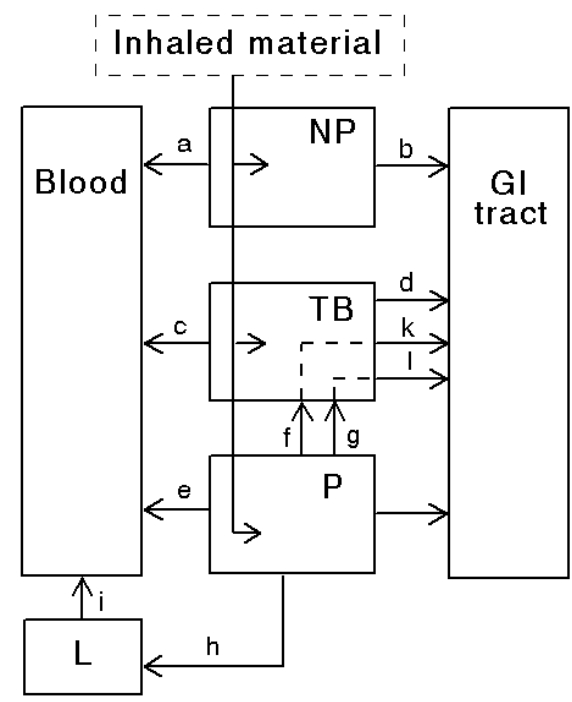

Figure 2.5. Structure of the Task Group Lung Model (TGLM) used in Pub30 (ICRP, 1979).

Table 2.4. Parameters of the TGLM for 1- $\mu \mathrm{m}$ AMAD particles. The biological halftimes, $T_{1 / 2}$, are assumed to be independent of particle size.

\begin{tabular}{cccccccc}
\hline \multirow{2}{*}{$\begin{array}{c}\text { Region and } \\
\text { fractional } \\
\text { deposition }\end{array}$} & & \multicolumn{7}{c}{ Class } \\
\cline { 2 - 8 } & Path & $\mathrm{T}_{1 / 2}$ (d) & Fraction & $\mathrm{T}_{1 / 2}$ (d) & Fraction & $\mathrm{T}_{1 / 2}$ (d) & Fraction \\
\hline NP & a & 0.01 & 0.5 & 0.01 & 0.1 & 0.01 & 0.01 \\
$(0.30)$ & b & 0.01 & 0.5 & 0.4 & 0.9 & 0.4 & 0.99 \\
TB & C & 0.01 & 0.95 & 0.01 & 0.5 & 0.01 & 0.01 \\
$(0.08)$ & d & 0.2 & 0.05 & 0.2 & 0.5 & 0.2 & 0.99 \\
P & e & 0.5 & 0.8 & 50 & 0.15 & 500 & 0.05 \\
$(0.25)$ & f & NA & NA & 1.0 & 0.4 & 1.0 & 0.4 \\
& g & NA & NA & 50 & 0.4 & 500 & 0.4 \\
& h & 0.5 & 0.2 & 50 & 0.05 & 500 & 0.15 \\
L & i & 0.5 & 1.0 & 50 & 1.0 & 1000 & 0.9 \\
\hline
\end{tabular}


The dose to the lungs is based on the assumption that the total activity in the TB, P, and $\mathrm{LN}$ regions is uniformly distributed in the total blood-filled lungs.

NRC77 lists only one inhalation dose coefficient for each radionuclide, while Pub30 generally gives multiple inhalation dose coefficients corresponding to different chemical forms of an inhaled radionuclide. The models recommended in Pub30 allow calculation of different coefficients for different sizes of inhaled particles.

For comparison of inhalation dose estimates based on NRC77 and Pub30, a single dose coefficient from Pub30 is selected for each radionuclide. Selections are made by element and are based on the following criteria: the form should be one of the forms addressed in Pub30; a commonly encountered solubility level should be considered where such information is available (e.g., soluble forms of strontium, iodine, or cesium); and, in the absence of information on forms likely to be encountered, an intermediate solubility level should be used (Class W in Pub30). Except for tritium and carbon, each radionuclide is assumed to be inhaled as a particulate aerosol. The assumed particle size is $1 \mu \mathrm{m}$ AMAD, the default particle size in Pub30. The following forms are selected for determination of a single set of inhalation dose coefficients based on Pub30:

- tritium as tritiated water;

- carbon as carbon dioxide;

- $\quad \mathrm{Ba}, \mathrm{Cs}, \mathrm{I}$, and Sr as Class D (relatively soluble material) (less soluble forms of Ba are not considered in Pub30);

- $\mathrm{Co}, \mathrm{Cr}, \mathrm{Cu}, \mathrm{Fe}, \mathrm{La}, \mathrm{Mn}, \mathrm{Nb}, \mathrm{Ni}, \mathrm{Np}, \mathrm{Ru}, \mathrm{Tc}, \mathrm{Y}$, and Zr as Class W (moderately soluble material);

- Mo and Zn as Class Y (relatively insoluble material) (Class W is not considered in Pub30 for these two elements).

\subsubsection{Gastrointestinal tract model of Pub30}

The model of GI transit applied in Pub30 is shown in Figure 2.6. As in Pub2, the GI tract is divided into four segments: stomach (St), small intestine (SI), upper large intestine (ULI), and lower large intestine (LLI). In contrast to Pub2, the Pub30 GI tract model depicts first-order transfer of material from one segment to the next. Transfer rates are reference values for a worker. Absorption of ingested activity to blood is assumed to occur in the small intestine (SI) and is described by an element-specific $\mathrm{f}_{1}$ value representing fractional absorption of the stable element to blood. If $\mathrm{f}_{1}=1$, the element is assumed to transfer directly from the stomach to blood.

For a few of the radionuclides addressed here, Pub30 as well as Pub72 provide alternate sets of dose coefficients corresponding to alternate GI uptake values ( $f_{1}$ values) for some forms of an element. For example, the $\mathrm{f}_{1}$ value 0.01 is recommended in Pub30 for ${ }^{90} \mathrm{Sr}$ ingested as $\mathrm{SrTiO}_{3}$, and the value 0.3 is recommended for all other forms of strontium. These two $f_{1}$ values give rise to different dose coefficients for ingestion of ${ }^{90} \mathrm{Sr}$. When multiple $\mathrm{f}_{1}$ values are given in Pub30 or Pub72, the $\mathrm{f}_{1}$ value applied in the present report is the one that agrees with, or most closely matches, the $f_{1}$ value given for drinking water in Federal Guidance Report No. 13 (EPA, 1999). For example, the value 0.3 is applied in 
Federal Guidance Report No.13 to strontium in drinking water and thus is applied here to strontium.

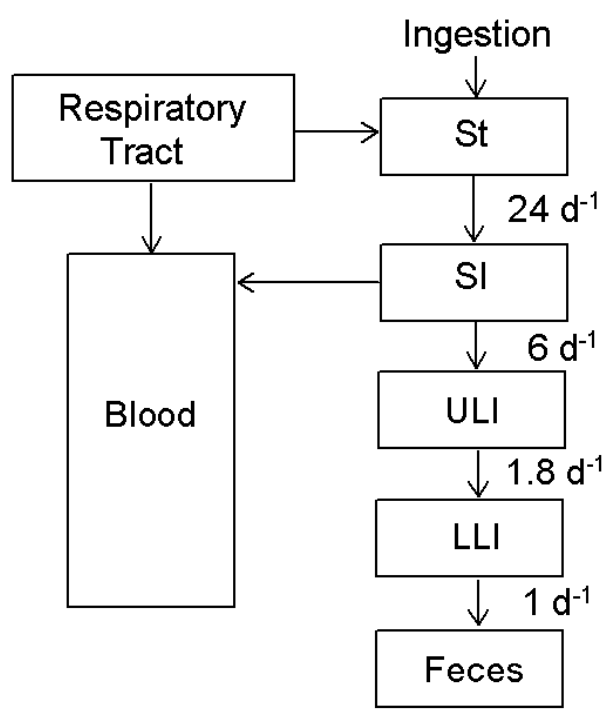

Figure 2.6. The GI tract model used in Pub30 and Pub72. In Pub72, age-specific $f_{1}$ values are assigned, but transit rates through the lumen of the tract are independent of age.

\subsubsection{Systemic biokinetic models of Pub30}

The systemic biokinetic models of Pub30 are described in Appendix B for each of the radionuclides addressed in this report. The general modeling approach is summarized in this section and illustrated for cobalt.

As a rule, an effort was made in Pub30 to provide a more detailed and complete description of the distribution and retention of a radionuclide in organs over time than was accomplished in Pub2 and NRC77. In contrast to many of the models of Pub2 and NRC77, the biokinetic models of Pub30 account for the distribution and retention of all of the activity absorbed to blood. In most cases this is accomplished by assigning the balance of the absorbed portion, after assignment of deposition fractions for explicitly identified pools, to a compartment called “Other". This compartment represents the remainder of the body or remainder of soft tissues, depending on the element, after exclusion of explicitly identified source organs. For some elements, however, large portions of the body are not addressed in the systemic model. For example, the Pub30 systemic model for neptunium accounts for $100 \%$ of absorbed neptunium but assigns no activity to soft tissues other than liver and gonads (ICRP, 1988).

Little attempt is made in Pub30 to provide a physiologically realistic description of the movement of a radionuclide in the body or along excretion pathways. Absorbed material is depicted as entering blood, from which it transfers to source organs with a specified half-time, typically $0.25 \mathrm{~d}$. Retention of a radionuclide in an organ is usually described in 
terms of a small set of first-order retention components, with multiple biological halftimes representing retention in multiple hypothetical compartments. Feedback of material from tissues to blood is not treated explicitly with the exception of the model for iodine. In general, it is assumed that material leaving an organ moves directly to a collective excretion compartment ("excreta"), so that dose along an actual route of excretion is not assessed. The systemic model for cobalt used in Pub30 illustrates this modeling scheme (Figure 2.7). In this model, $50 \%$ of the activity entering blood moves directly to excreta and the rest moves to excreta after residence in liver or "other".

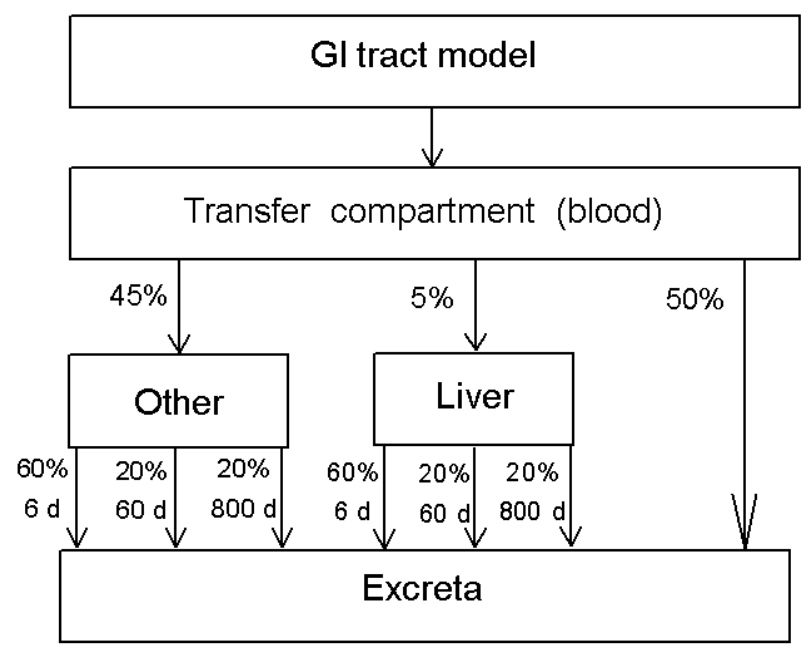

Figure 2.7. Systemic biokinetic model for cobalt used in Pub30.

\subsubsection{Approach to internal dosimetry in Pub30}

Relatively sophisticated dosimetric models and methods were introduced in Pub30 to replace the simplistic approach in Pub2 and NRC77 involving the representation of organs as spheres and considering only self dose to organs. Dosimetry in Pub30 is based on a mathematical phantom with anatomical features represented as combinations of standard geometrical shapes such as cylinders and ellipsoids that approximate the actual shapes of organs. Masses and volumes of organs are based on features of the ICRP's Reference Man (ICRP, 1975). This phantom is used to address cross irradiation of organs by penetrating radiations. In contrast to Pub2 where doses are calculated only for source organs, the methods of Pub30 allow dose calculations for a standard list of target organs representing all the major organs of the body.

Major changes in the dosimetric model of the skeleton were made in Pub30. In Pub2 the dose to bone is averaged over $7000 \mathrm{~g}$ of marrow-free skeleton, and the dose to bone marrow is not estimated. In Pub30 doses are calculated to the osteogenic cells near the anatomical surfaces of bone and to the active marrow within the cavities of trabecular bone. In the biokinetic models of Pub30, activity entering bone is assigned either to bone surface or to bone volume, based on available information from the literature or 
consideration of the radiological half-life. In Pub 2 the difference between surfaceseeking radionuclides and volume-seeking radionuclides is addressed indirectly by applying a relative damage factor of 5, i.e., a fivefold increase in the dose coefficient for bone, for skeletal deposits of alpha and beta emitters other than radium. This gives some basis for comparison of a bone dose in Pub2 with a bone surface dose in Pub30.

In Pub30, estimates of dose to tissues of the GI tract from non-penetrating radiations emitted in the contents of the tract are based on simplistic assumptions expected to overestimate doses to radiosensitive cells in the tract walls. These assumptions are essentially the same as applied in Pub2 and NRC77. For example, for alpha emitters the dose is taken as $1 \%$ of the dose at the surface of the contents.

\subsection{Dosimetry system of Pub72}

\subsubsection{Concept of effective dose}

The dosimetry system of Pub72 is a modification and extension of the Pub30 system rather than a replacement of that system. The main changes from Pub30 are (1) a modification of the concept of effective dose equivalent, (2) adoption of age-specific mathematical phantoms for calculation of age-specific doses from inhaled or ingested radionuclides, and (3) adoption of more sophisticated biokinetic models, including agespecific models, for a number of radionuclides.

The following tissues are addressed in Pub72: adrenals, bone surface, brain, breasts, gallbladder wall, heart, kidneys, liver, lungs, muscle, ovaries, pancreas, red marrow, skin, spleen, testes, thymus, thyroid, urinary bladder wall, uterus, stomach wall, small intestine wall, upper large intestine wall, and lower large intestine wall.

ICRP Publication 26 (1977) was superseded by Publication 60 (1991), which introduced a generalization of the effective dose equivalent called the effective dose, E. The effective dose is also a weighted sum of doses to radiosensitive tissues:

$$
E=\sum_{T} w_{T} H_{T}
$$

In contrast to the definition of the effective dose equivalent $\mathrm{H}_{\mathrm{E}}$, the tissue weighting factors $\mathrm{w}_{\mathrm{T}}$ in the equation for the effective dose $\mathrm{E}$ are not specified as part of the definition of $\mathrm{E}$ but can have any assigned values. Thus, the effective dose equivalent, $\mathrm{H}_{\mathrm{E}}$, used in Pub30 may be interpreted as a special case of the effective dose, E.

Values recommended in ICRP Publication 60 for the tissue weighting factors $\mathrm{w}_{\mathrm{T}}$ are compared in Table 2.3 with values used in ICRP Publication 26. The tissue weighting factors recommended in Publication 60 reflect updated information on tissues at risk as well as risk per unit dose and include values for the following tissues not addressed explicitly in ICRP Publication 26: colon, stomach, urinary bladder wall, liver, esophagus, and skin. The largest changes to previous weighting factors are a threefold reduction for bone surface, a 67\% increase for the thyroid, and a six-fold reduction of the 
weight to remaining tissues in conjunction with an increase in the number of radiosensitive tissues assigned a specific factor. These changes by themselves (i.e., in the absence of other changes between Pub30 and Pub72 such as in biokinetic models) generally result in only modest differences between $\mathrm{H}_{\mathrm{E}}$ and $\mathrm{E}$ with the main exception of radionuclides that accumulate largely in bone tissues or the thyroid gland.

\subsubsection{ICRP series on age-specific dose coefficients}

In a series of reports published between 1989 and 1995 (ICRP, 1989, 1993, 1995a, 1995b), the ICRP provided its first recommendations of age-specific biokinetic and dosimetric models and dose coefficients for intake of radionuclides by members of the public. These documents give dose coefficients for acute inhalation or ingestion of radionuclides for each of the following ages at intake: infant (age $100 \mathrm{~d}$ ), 1 y, $5 \mathrm{y}, 10 \mathrm{y}$, $15 \mathrm{y}$, and adult (18 y and greater). The dose coefficients in Pub72 are based on an integration period of $50 \mathrm{y}$ for adults and to age $70 \mathrm{y}$ for intake by children. The radionuclides addressed in these documents are selected isotopes of hydrogen, carbon, sulfur, calcium, iron, cobalt, nickel, zinc, selenium, strontium, zirconium, niobium, molybdenum, technetium, ruthenium, silver, antimony, tellurium, iodine, cesium, barium, cerium, lead, polonium, radium, thorium, uranium, neptunium, plutonium, americium, and curium. The biokinetic database for each of these 31 elements was reviewed, physiological processes determining the behavior of the element in the body were considered, and an effort was made to develop age-specific biokinetic models on the basis of this information.

ICRP Publication 56 (1989) was the first report in the series but was completed before the adoption of either ICRP Publication 60 (1991), which provided updated tissueweighting factors, or ICRP Publication 66 (1994), which described the updated respiratory tract model. Thus, inhalation dose coefficients in Publication 56 are based on the respiratory tract model of Pub30, and the effective dose coefficients given in Publication 56 are based on tissue weighting factors recommended in ICRP Publication 26. All of the dose coefficients given in Publication 56 were replaced later in the Pub72 series to reflect the updated recommendations of the ICRP. The dose coefficients tabulated in Publication 56 are updated in ICRP Publication 67 (1993) for ingestion and ICRP Publication 71 (1995a) for inhalation, to reflect the updated recommendations of ICRP Publication 60 as well as updates of some of the systemic biokinetic models used in Publication 56. Some of the models in Publication 56 are replaced in Publications 67 and 71 with much different models, but all of the ICRP models for workers or members of the public applied after the appearance of ICRP Publication 60 include explicit excretion pathways. This is done to improve dose estimates to the urinary bladder wall and the colon, both of which are assigned tissue weighting factors in Publication 60.

ICRP Publication 72 (1996) provides age-specific committed effective dose coefficients for inhalation and ingestion for approximately 800 radionuclides. For many but not all of these radionuclides, age-specific committed equivalent doses to specific tissues are tabulated in ICRP Publication 67 (1993), Publication 69 (1995a), or Publication 71 (1995b). All of the dose coefficients in Publications 67, 69, and 71 reflect consideration 
of changes with age in biokinetics as well as changes with age in organ masses and dimensions. For those radionuclides addressed in Publication 72 but not addressed in Publications 67, 69, or 71, effective dose coefficients in Publication 72 are based on the age-specific mathematical phantoms used in Publications 67, 69, and 71 and higher $\mathrm{f}_{1}$ values for infants than for ages $1 \mathrm{y}$ and greater, but the systemic biokinetic models applied are those for workers as summarized in ICRP Publication 68 (1994b).

\subsubsection{Respiratory tract model of Pub72}

The structure of the respiratory tract model used in Pub72 is shown in Figure 2.8. The model divides the respiratory system into extrathoracic (ET) and thoracic regions. The airways of the ET region are further divided into two categories: the anterior nasal passages, in which deposits are removed by extrinsic means such as nose blowing, and the posterior nasal passages including the nasopharynx, oropharynx, and the larynx, from which deposits are swallowed. The airways of the thorax include the bronchi (compartments labeled $\mathrm{BB}_{\mathrm{i}}$ ), bronchioles (compartments labeled $\mathrm{bb}_{\mathrm{i}}$ ), and alveolar region (compartments labeled $\mathrm{AI}_{\mathrm{i}}$ ). Material deposited in the thoracic airways may be cleared into blood by absorption, to the GI tract by mechanical processes (that is, transported upward and swallowed), and to the regional lymph nodes via lymphatic channels.

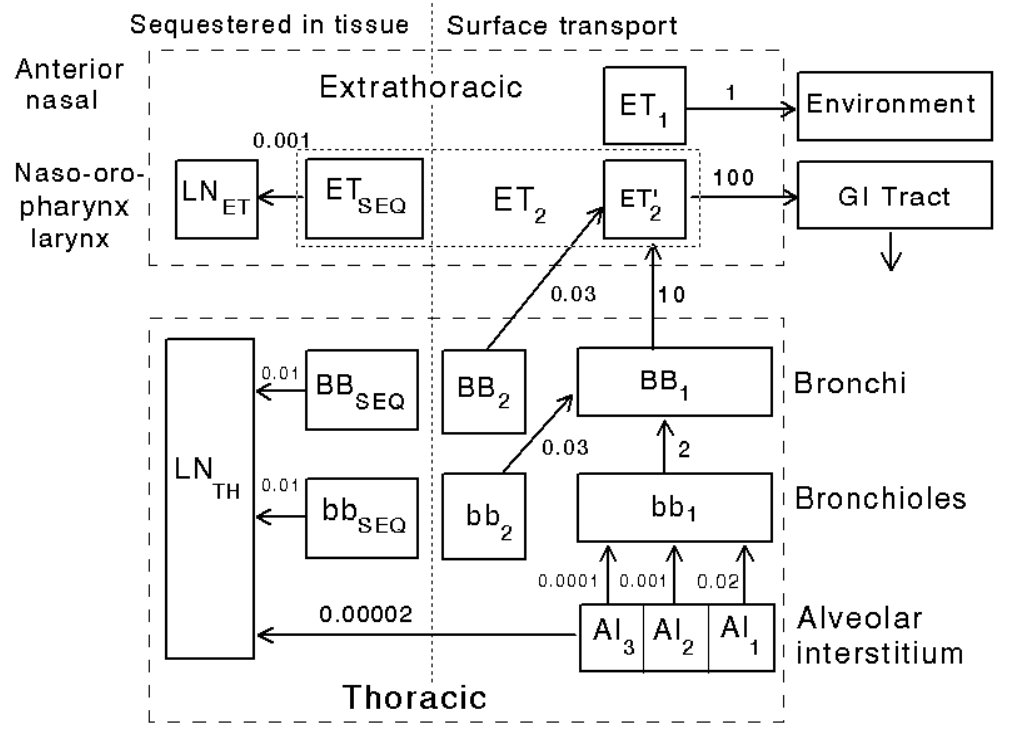

Figure 2.8. Structure of the respiratory model of Pub72 (ICRP, 1994b).

The number of compartments in each region was chosen to allow duplication of the different kinetic phases observed in humans or laboratory animals. Particle transport rates shown beside the arrows in Figure 2.8 are reference values in units of $\mathrm{d}^{-1}$. For example, particle transport from $b_{1}$ to $\mathrm{BB}_{1}$ is assumed to occur at a fractional rate of $2 \mathrm{~d}^{-1}$, and particle transport from $\mathrm{ET}_{2}$ ' to the gastrointestinal tract is assumed to occur at a fractional rate of $100 \mathrm{~d}^{-1}$. 
For an inhaled compound, the mechanical clearances of particles indicated in Figure 2.8 are in addition to dissolution rates and absorption to blood, which depend on the element and the chemical and physical form in which it is inhaled. Although the model permits consideration of compound-specific dissolution rates, a particulate is generally assigned to one of three default absorption types: Type F, representing fast dissolution and a high level of absorption to blood; Type $\mathrm{M}$, representing an intermediate rate of dissolution and an intermediate level of absorption to blood; and Type S, representing slow dissolution and a low level of absorption to blood. The fractional rates of absorption $\left(\mathrm{d}^{-1}\right)$ assigned to the default types are

Type F: 100 ,

Type M: $10 \mathrm{e}^{-100 \mathrm{t}}+0.005 \mathrm{e}^{-0.005 \mathrm{t}}$,

Type S: $0.1 \mathrm{e}^{-100 \mathrm{t}}+0.0001 \mathrm{e}^{-0.0001 \mathrm{t}}$,

where $t$ is time (days) since deposition.

In contrast to the respiratory model of Pub30, dosimetry for the Pub72 model addresses the heterogeneous distribution of radiosensitive cells in the respiratory tract. Six target tissues are considered: keratinized epithelium of the skin in the anterior part of the nose $\left(\mathrm{ET}_{1}\right)$; stratified squamous epithelium of the main extrathoracic airways $\left(\mathrm{ET}_{2}\right)$; ciliated epithelium of the bronchi (BB); ciliated epithelium of the bronchioles (bb); alveolarinterstitium (AI); and thoracic and extrathoracic lymph nodes $\left(\mathrm{LN}_{\mathrm{TH}}\right.$ and $\mathrm{LN}_{\mathrm{ET}}$, respectively).

The lung dose is defined as a weighted average of the doses to different regions of the lungs. The following weights are assigned: bronchial region, 0.333 , divided evenly between the basal and secretory cells; secretory cells of the bronchiolar region, 0.333 ; the alveolar-interstitial region, 0.333; and the thoracic lymph nodes, 0.001 . The dose to the extrathoracic regions, including its lymph nodes, is considered as part of Remainder tissue.

As is the case for Pub30, multiple sets of inhalation dose coefficients are given in Pub72 for most radionuclides, corresponding to different forms of an inhaled radionuclide. For comparison of dose estimates based on Pub72 and NRC77, attention is restricted in this report to a single inhalation dose coefficient from Pub72 for each radionuclide. The selection of a single inhalation dose coefficient for each radionuclide follows the scheme described earlier for Pub30. That is, selections are made by element and are based on the following criteria: the form should be one of the forms addressed in Pub72; a commonly encountered solubility level should be considered where such information is available; and, in the absence of information on forms likely to be encountered, an intermediate solubility level should be used (Type M in Pub72). Except for tritium and carbon, each radionuclide is assumed to be inhaled as a particulate aerosol. The assumed particle size is $1 \mu \mathrm{m}$ AMAD, the default particle size in Pub72. The following forms are selected for determination of a single set of inhalation dose coefficients based on Pub72: 
- tritium as tritiated water;

- carbon as carbon dioxide;

- Cs, I, and Sr as Type F (relatively soluble material);

- $\mathrm{Ba}, \mathrm{Co}, \mathrm{Cr}, \mathrm{Cu}, \mathrm{Fe}, \mathrm{La}, \mathrm{Mn}, \mathrm{Nb}, \mathrm{Ni}, \mathrm{Np}, \mathrm{Ru}, \mathrm{Tc}, \mathrm{Y}$, and $\mathrm{Zr}$ as Type M (moderately soluble material).

\subsubsection{Gastrointestinal tract model of Pub72}

The age-independent GI tract model of Pub30 describing transit of material through the lumen of the GI tract is applied in Pub72 to all age groups, but age-specific $f_{1}$ values are used in Pub72 (Appendix A). For most elements a higher $f_{1}$ value is applied to the infant than for ages $1 \mathrm{y}$ and greater. For a few elements including cobalt, strontium, and barium, the $\mathrm{f}_{1}$ values applied to all pre-adult ages are higher than the value for adults.

Although the text and tables in Pub72 documents sometimes indicate complete absorption of a radionuclide from the GI tract to blood, the maximum $\mathrm{f}_{1}$ value used in calculations of dose in Pub72 is 0.99 . Thus, in the absence of radioactive decay, at least $1 \%$ of the ingested amount is transferred through the ULI and LLI.

\subsubsection{Systemic biokinetic models of Pub72}

The ICRP's series of documents on doses to members of the public provide physiologically based, age-specific models for several elements, including some of the elements considered in the present report (iron, strontium, barium, neptunium). As illustrations, the model structure applied in Pub72 to strontium, barium, and some other bone-volume-seeking elements is shown in Figure 2.9, and the structure applied to neptunium and some other bone-surface-seeking elements is shown in Figure 2.10. These models depict feedback of material from organs to blood plasma, loss of material by specific excretion pathways, and certain physiological processes such as bone remodeling that influence the biokinetics of radionuclides. These physiological based models are considerably different in structure from the mathematically convenient models of Pub30 and provide an appropriate logical foundation for development of age-specific parameter values. For example, uptake and retention of calcium-like elements such as strontium or barium in bone in adults can be related to the bone remodeling rate, allowing extension of parameter values to pre-adult ages based on age-specific bone remodeling rates reported in the literature. Although the many of the biokinetic models of Pub30 yield dose estimates that are reasonably consistent with predictions of the Pub72 models for adults, it would have been difficult to extend the models of Pub30 to pre-adult ages due to lack of physiologically meaningful structure. 


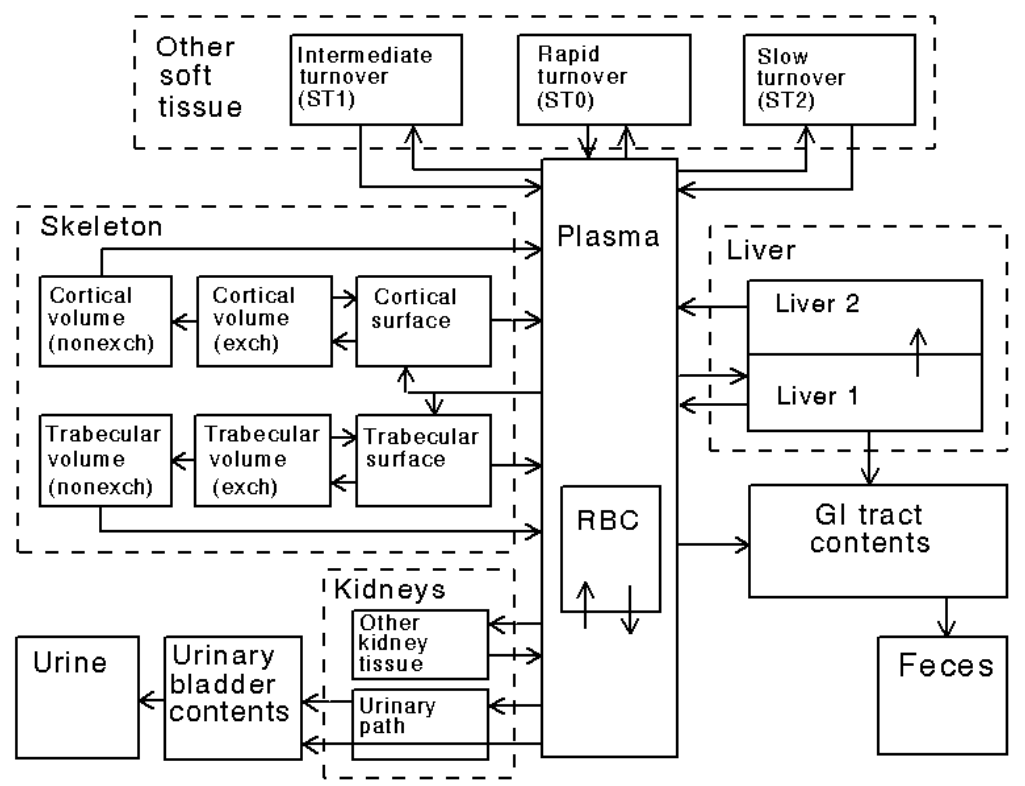

Figure 2.9. Generic model structure for bone-volume-seeking radionuclides applied in Pub72.

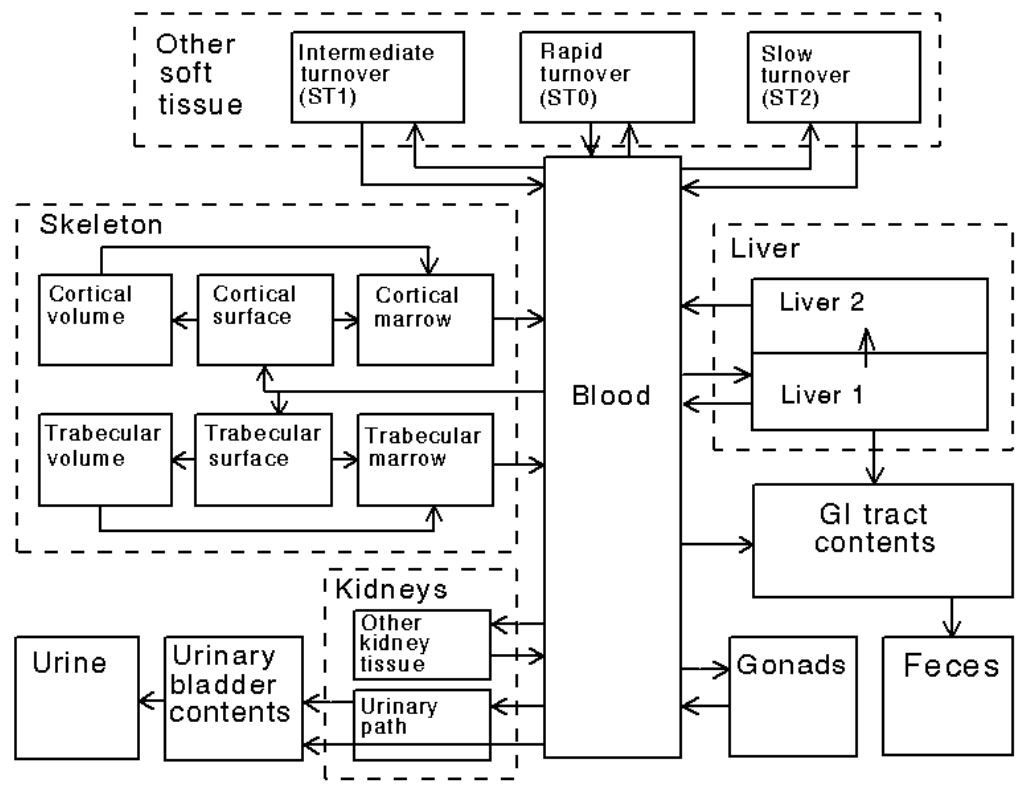

Figure 2.10. Generic model structure for bone-surface-seeking radionuclides applied in Pub72. 
Despite the trend toward physiological realism in the ICRP's models, many of the biokinetic models used in Pub72 are similar in format to the models of ICRP Publication 30. For example, simplistic retention functions in the form of a sum of exponential terms are applied to hydrogen (tritium), cobalt, nickel, zinc, zirconium, niobium, molybdenum, technetium, ruthenium, and cesium. For some but not all elements, age-specific coefficients or half-times in the retention functions are used to represent expected changes in distribution or retention of radionuclides during growth. In contrast to the biokinetic models of Pub30, the retention functions in Pub72 depict transfer of systemic activity to the urinary bladder and upper large intestine prior to excretion, with relative quantities going to bladder and intestines based on an element-specific urinary to fecal excretion ratio. This feature became standard in ICRP models for workers or the public after the introduction of explicit tissue weighting factors for the urinary bladder wall and colon in ICRP Publication 60 (1991).

For example, the model for cobalt used in Pub30 was applied in Pub72 to all age groups, but each of the transfers to excreta shown in Figure 2.7 was divided into transfers to urinary bladder contents and upper large intestine contents (Figure 2.11). A urinary to fecal ratio of 6:1 was applied to cobalt.

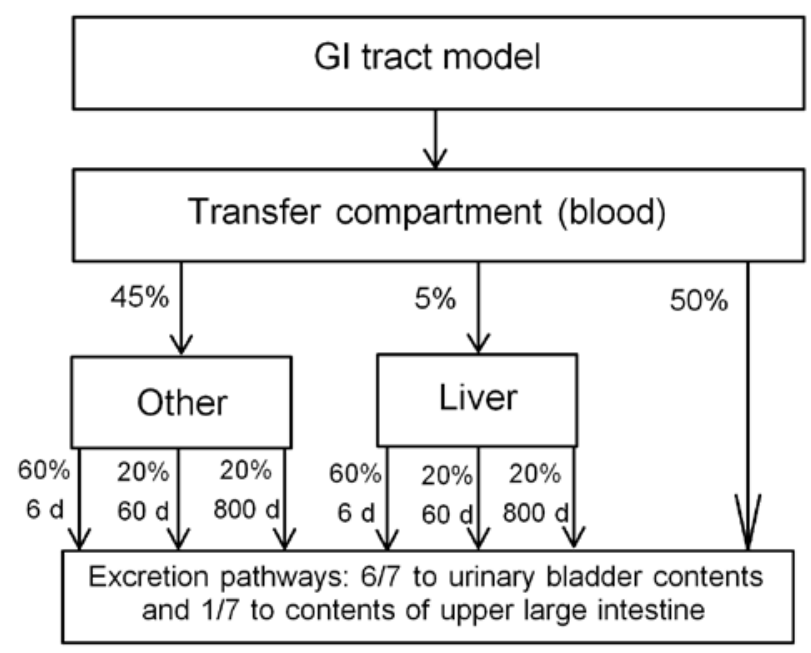

Figure 2.11. Systemic biokinetic model for cobalt used in Pub72. The same parameter values were applied to all age groups.

\subsubsection{Approach to internal dosimetry in Pub72}

The approach to internal dosimetry in Pub72 is conceptually the same as that in Pub30, but age-specific mathematical phantoms were applied in Pub72. In contrast to the methods of NRC77, the dosimetric models are changed continuously with age in Pub72 based on changes in total body mass. 


\section{COMPARISON OF IMPORTANT PARAMETERS IN DOSIMETRY MODELS}

\subsection{Gastrointestinal absorption fractions}

Table 3.1 lists the gastrointestinal uptake fractions ( $f_{1}$ values) applied in NRC77, Pub30, and Pub72 to elements addressed in this report. The values are the same in NRC77 as in Pub2. Values are independent of age in NRC77 and Pub30. In Pub72, $\mathrm{f}_{1}$ values are higher for infants than for other age groups unless virtually complete absorption is assumed for all age groups. For some radionuclides including isotopes of iron, cobalt, and strontium, elevated uptake of radionuclides during childhood and adolescence is assumed in Pub72.

\begin{tabular}{|c|c|c|c|c|c|}
\hline \multicolumn{6}{|c|}{$\begin{array}{l}\text { Table 3.1. Summary of gastrointestinal uptake fractions ( } f_{1} \text { values) } \\
\text { applied in comparisons of doses from intake of radionuclides. }\end{array}$} \\
\hline \multirow[b]{2}{*}{ Element } & \multirow[b]{2}{*}{ Pub2 and NRC77 } & \multirow[b]{2}{*}{ Pub30 } & \multicolumn{3}{|c|}{$\begin{array}{l}\text { Pub72 } \\
\end{array}$} \\
\hline & & & Infant & Ages 1-15 y & Adult \\
\hline Hydrogen $\left({ }^{3} \mathrm{H}\right)$ & 1.0 & 1.0 & 0.99 & 0.99 & 0.99 \\
\hline Carbon & 1.0 & 1.0 & 0.99 & 0.99 & 0.99 \\
\hline Phosphorus & 0.75 & 0.8 & 0.99 & 0.8 & 0.8 \\
\hline Chromium & 0.005 & 0.1 & 0.2 & 0.1 & 0.1 \\
\hline Manganes & 0.1 & 0.1 & 0.2 & 0.1 & 0.1 \\
\hline Iron $^{a}$ & 0.1 & 0.1 & 0.6 & 0.2 & 0.1 \\
\hline Cobalt $^{\mathrm{a}}$ & 0.3 & 0.05 & 0.6 & 0.3 & 0.1 \\
\hline Nickel & 0.3 & 0.05 & 0.1 & 0.05 & 0.05 \\
\hline Copper & 0.28 & 0.5 & 0.99 & 0.5 & 0.5 \\
\hline Zinc $^{a}$ & 0.1 & 0.5 & 0.99 & 0.5 & 0.5 \\
\hline Strontium & 0.3 & 0.3 & 0.6 & 0.4 & 0.3 \\
\hline Yttrium & 0.0001 & 0.0001 & 0.001 & 0.0001 & 0.0001 \\
\hline Zirconium $^{b}$ & 0.0001 & 0.002 & 0.02 & 0.01 & 0.01 \\
\hline Niobium & 0.0001 & 0.01 & 0.02 & 0.01 & 0.01 \\
\hline Molybdenum $^{\mathrm{a}, \mathrm{c}}$ & 0.8 & 0.8 & 0.99 & 0.99 & 0.99 \\
\hline Technetium $^{\mathrm{a}}$ & 0.5 & 0.8 & 0.99 & 0.5 & 0.5 \\
\hline Ruthenium & 0.03 & 0.05 & 0.1 & 0.05 & 0.05 \\
\hline Silver & 0.01 & 0.05 & 0.1 & 0.05 & 0.05 \\
\hline lodine & 1.0 & 1.0 & 0.99 & 0.99 & 0.99 \\
\hline Cesium & 1.0 & 1.0 & 0.99 & 0.99 & 0.99 \\
\hline Barium $^{\mathrm{a}}$ & 0.05 & 0.1 & 0.6 & 0.3 & 0.2 \\
\hline Lanthanum & 0.0001 & 0.001 & 0.005 & 0.0005 & 0.0005 \\
\hline Neptunium & 0.0001 & 0.01 & 0.005 & 0.0005 & 0.0005 \\
\hline \multicolumn{6}{|c|}{$\begin{array}{l}\text { In Pub72, } 0.2 \text { is applied to infants and } 0.1 \text { to other ages for inhalation of this element in the form } \\
\text { addressed in this report. } \\
\text { bIn Pub72, } 0.002 \text { is applied to adults for inhalation of this element in the form addressed in this } \\
\text { report. } \\
\text { cIn Pub30, } 0.05 \text { is applied to inhalation of this element in the form addressed in this report. }\end{array}$} \\
\hline
\end{tabular}




\subsection{Respiratory Models}

The general features of the respiratory models of Pub2, NRC77, Pub30, Pub68 and Pub72 have been discussed above. Schematic representations of the respiratory models of NRC77, Pub30, and Pub72 are show in Figures 2.4, 2.5, and 2.8, respectively. Some specific features of these models are described below.

With the exception of the model of Pub2 the fractional deposition in the lung of inhaled particulate matter is taken to be dependent on the aerosol size as characterized by the activity (or mass) median aerodynamic diameter. The physical diameter of the dispersing particles is typically distributed in a log-normal manner and the radionuclide is assumed to be uniformly distributed within the particles. The fractional depositions of the inhaled particles in Pub30 were based largely on experimental studies and thus were more representative of mouth breathing than nasal breathing. Both nasal and mouth breathing were considered in the respiratory tract model of ICRP Publication 66 used in Pub68 and Pub72. The deposition in the lung also depends on the breathing patterns (breath frequency and volume) and thus on the assumed physical activity of the exposed subject. In NRC77 it was assumed that $75 \%$ of the inhaled activity was deposited in the lung with $25 \%$ deposited in the "deep" lung. That model did not allow consideration of different aerosol sizes or breathing patterns. For an aerosol characterized by an AMAD of $1 \mu \mathrm{m}$ (the default assumption), the total deposition in the respiratory tract of an adult is 75, 63 and $51 \%$ and in the deep lung is 12.5, 33 and 14\% for the models of NRC77, Pub30 and Pub72, respectively (Fig 3.1). The relatively low deposition in the deep lung assumed in the NRC77 model is a consequence of assuming that an additional $12.5 \%$ of the inhaled activity deposited in the deep lung was immediately transferred to blood. The low Pub72 deep lung value reflects the filtering action of the anterior nasal passages.
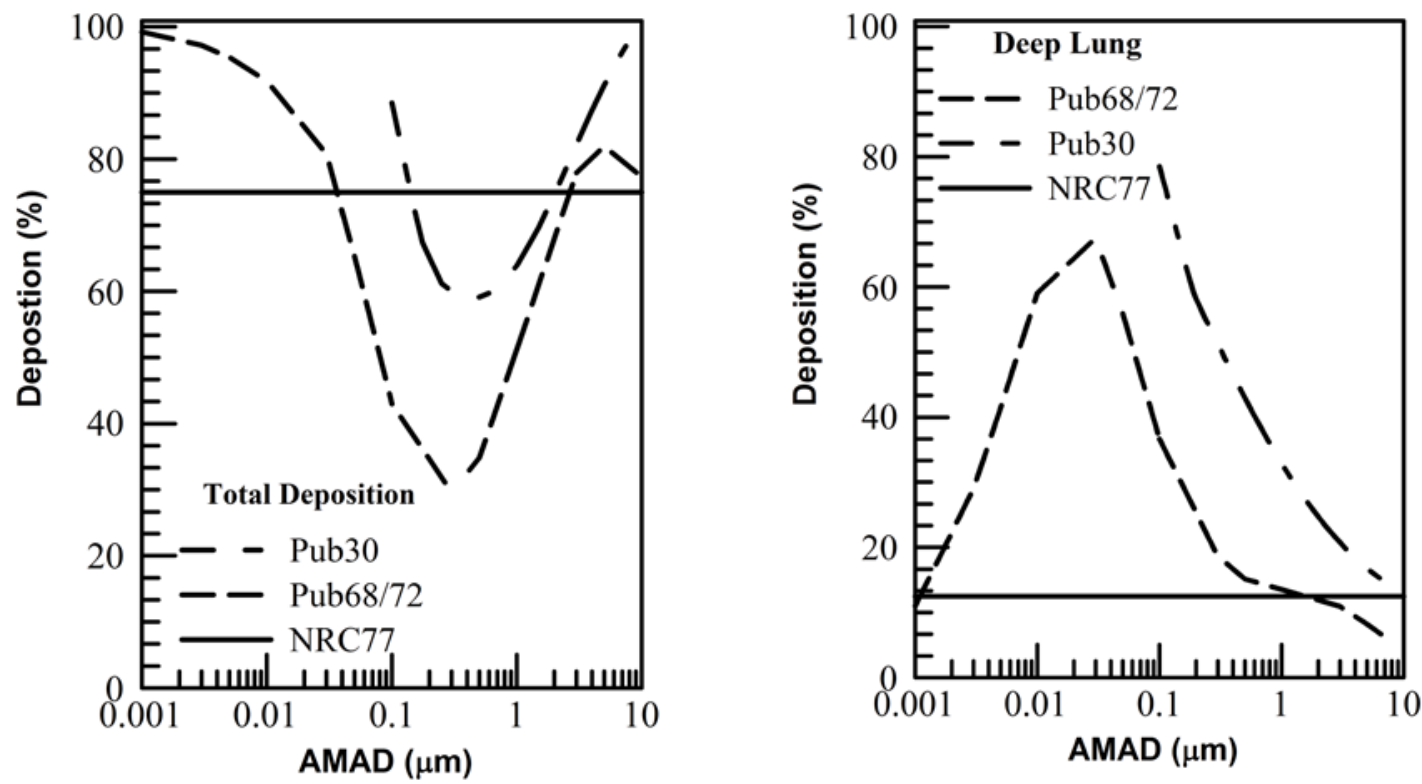

Fig. 3.1. Depositions predicted by the respiratory models used in NRC77, Pub30 and Pub68/72. Total deposition is shown in the left panel and deposition in the deep lung in the right panel. 
The fate of the deposited activity depends on its chemical form. If the radionuclide readily escapes the particle matrix (referred to as a soluble aersosol) it may be directly absorbed from the lung to blood. The deposited particles are subject to mechanical clearance from the airways and swallowing. A fraction of the swallowed activity, denoted as $f_{1}$, is assumed to be absorbed to blood from the gastrointestinal tract. The potential uptake of inhaled activity can be expresses as $a+b f_{1}$, where $a$ denotes the fraction of the inhaled activity entering blood directly from the lung, $b$ is the fraction entering the gastrointestinal tract, and $f_{1}$ is the fractional uptake to blood of activity entering the gastrointestinal tract. The potential uptake indicated by the various models is shown in Table 3.2 for the default aerosol size of $1 \mu \mathrm{m}$. The chemical forms considered in NRC77 were limited to soluble and insoluble forms, in Pub30 to Classes D, W, and Y corresponding to clearance times of days, weeks and years, respectively from the deep lung, and in Pub72 as Types F, M and S representing fast, moderate and slow absorption to blood, respectively.

\begin{tabular}{lll}
\hline \multicolumn{2}{c}{ Table 3.2 Fractional uptake of inhaled activity to blood. } \\
\hline Publication & Chemical form & Uptake to blood \\
\hline NRC77 & Soluble & $0.25+0.50 f_{1}$ \\
& Insoluble & $0.125+0.625 f_{1}$ \\
Pub30* & Class D & $0.48+0.15 f_{1}$ \\
& Class W & $0.12+0.51 f_{1}$ \\
& Class Y & $0.054+0.576 f_{1}$ \\
Pub72 ${ }^{*}$ & Type F & $0.241+0.106 f_{1}$ \\
& Type M & $0.089+0.257 f_{1}$ \\
& Type S & $0.012+0.334 f_{1}$ \\
\hline${ }^{*}$ Assuming an aerosol characterized by an AMAD of $1 \mu \mathrm{m.}$. \\
\hline
\end{tabular}

The information in Table 3.2 provides insight into the potential total absorption to blood, but the time-dependence of the absorption and radioactive decay is not considered. For long-lived radioisotopes considered as soluble in NRC77 and as Class D or Type F in Pub30 and Pub72, respectively, with $f_{1}$ values of 1.0 (e.g., Cs-137 and I-129) the fractional uptake to blood is 0.75, 0.63, 35 for the NRC77, Pub30, Pub68/72 models, respectively. The uptake of these materials is largely complete within a few days post intake. The relatively low uptake for deposited radionuclides predicted by the model of Pub72 is largely due to deposition in the anterior nasal passages, from which no direct absorption takes place and the cleared material is not swallowed.

The cumulative fraction of the inhaled activity entering blood is shown in Fig. 3.2. Panel (a) compares the uptake for soluble forms in NRC77 with Class D and Type F chemical forms in Pub30 and Pub72. The kinetics associated with the gastrointestinal-tract (absorption from the small intestine with an $f_{1}$ value of 1.0) is included in curves of panel (a) and the uptake is completed within a 5 day period post the intake. Again the lower cumulative uptake indicated by the Pub72 model as largely due to the deposition model. 
Panels (b) and (c) compare the uptake for insoluble forms in NRC77 with those of Class W / Type M and Class Y / Type S, respectively. In these panels $f_{1}$ values of 0.1 and 0.001 were assumed. The best agreement of the three models seems to indicate in panel (b). In all comparisons the NRC77 and Pub30 models overestimate the uptake to blood relative to that predicted by in Pub72.
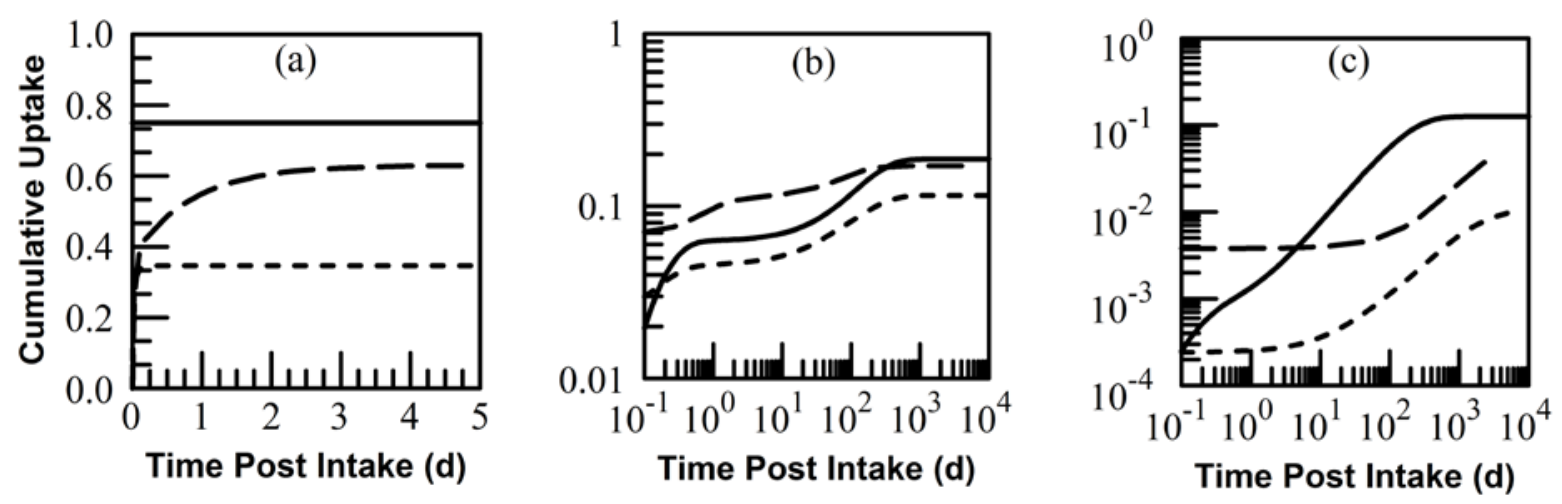

Fig. 3.2. Cumulative fractional absorption to blood of inhaled radionuclides. Solid line is the absorption predicted by the model of NRC77, short dash line is that of Pub72 and the long dash response is Pub30. Panel (a) addresses soluble isotopes (Class D/Type F) with an $f_{1}$ of 1.0, panel (b) is insoluble isotopes (Class W/Type M) with an $f_{1}$ of 0.1 and panel (c) is insoluble isotopes (Class Y/Type S) with an $f_{1}$ values of 0.001 .

For a selected set of radionuclides, the lung dose coefficients of NRC77, Pub30 and Pub72 (adult member of public) are tabulated in Table 3.3. The NRC77 and Pub30 values are shown relative to the Pub72 value. Coefficients for similar classification of the radionuclides were compared with the form specified in the Pub72 entry being the default form assumed in the absence of other information. The H-3 entry, however, is for HTO vapor and the Pub30 C-14 value is for organic compounds rather than particulate matter. The respiratory tract model of NRC77 provides lung dose estimates only for insoluble forms of the radionuclide; hence, no entry is given for radioiodines. As discussed in Section 2.4.3 the lung dose quantity of Pub72 addresses the heterogeneous distribution of the radiosensitive cells in the respiratory tract and hence differs from the lung dose quantity of NRC77 and Pub30, the latter being the quotient of the absorbed energy and the mass assigned to the lung.

The dose coefficients of Pub30 were developed for chemical forms of the radionuclides considered to be relevant to occupational exposure. Thus, the Pub30 vs. Pub72 comparison is hampered in some instances by coefficients not available for the comparable chemical forms. The order of magnitude difference in the radioiodine coefficients is due to differences in the deposition for occupational and environmental exposure and differences in the definition of the lung dose in Pub30 and Pub72.

The respiratory tract model used in Pub72 is the current state-of-the-art reflecting efforts toward physiological realism in its separate characterization of the mechanical clearance and the influence of chemical form on absorption to blood. In addition, the deposition of particulate matter includes consideration of the extrathoracic airways and the influence of the subject's physical activity on the frequency and depth of breathing on the deposition. 
For example, the daily deposition in the lung differs for an adult worker and an adult member of the public as daily energy expenditure differs. Finally, the Pub72 model is capable of addressing the inhalation of vapors and gas, which are forms of interest in some instances; e.g., radioiodine vapors forms.

\begin{tabular}{|c|c|c|c|}
\hline \multirow[b]{2}{*}{ Nuclide } & \multirow{2}{*}{$\begin{array}{l}\text { Pub72 Lung Dose } \\
\text { (Sv/Bq-inhaled) }\end{array}$} & \multicolumn{2}{|c|}{ Value Relative to Pub72 } \\
\hline & & NRC77 & Pub30 \\
\hline H-3 & $1.8 \mathrm{E}-11(\mathrm{~V})$ & 1.35 & $0.96(\mathrm{~V})$ \\
\hline C-14 & 2.0E-10 (F) & 0.58 & $2.82(\mathrm{O})$ \\
\hline Co-60 & 5.2E-08 (M) & 3.88 & $0.69(\mathrm{~W})$ \\
\hline Sr-90 & 2.1E-07 (M) & 1.54 & $0.02(\mathrm{D})$ \\
\hline Zr-95 & 3.1E-08 (M) & 1.93 & 0.60 (D) \\
\hline Ru-106 & 2.0E-07 (M) & 1.58 & $1.06(\mathrm{~W})$ \\
\hline I-131 & $6.0 \mathrm{E}-11(\mathrm{~F})$ & -(b) & 10.95 (D) \\
\hline I-135 & 4.0E-11 (F) & -(b) & 11.03 (D) \\
\hline Cs-134 & 6.0E-09 (F) & 0.55 & 1.97 (D) \\
\hline Cs-137 & 4.3E-09 (F) & 0.59 & 2.05 (D) \\
\hline Ba-140 & 3.5E-08 (M) & 1.23 & $0.05(\mathrm{D})$ \\
\hline Ce-141 & 2.4E-08 (M) & 0.51 & $0.47(\mathrm{~W})$ \\
\hline Ce-144 & 1.9E-07 (M) & 1.38 & $0.96(\mathrm{~W})$ \\
\hline Np-239 & 6.3E-09 (M) & 0.20 & $0.37(\mathrm{~W})$ \\
\hline \multicolumn{4}{|c|}{$\begin{array}{l}\text { (a) For Pub30 and Pub72 the chemical form V denotes HTO vapor. F and } \\
\text { M are the absorption types for the Pub72 model and D and W are the } \\
\text { clearance classes of the Pub30 coefficients; O denotes organic } \\
\text { compounds of C-14. } \\
\text { (b) No lung dose derived for soluble chemical forms. }\end{array}$} \\
\hline
\end{tabular}




\subsection{Systemic biokinetic models}

\subsubsection{Hydrogen (as tritium)}

Pub2 model: The form of ${ }^{3} \mathrm{H}$ addressed in Pub2 is tritiated water. Absorbed ${ }^{3} \mathrm{H}$ is assumed to be uniformly distributed in body water and removed from the body with a biological half-time of $12 \mathrm{~d}$. Tritium removed from tissues is transferred directly to excreta.

NRC77 model: The Pub2 model was modified by reducing the biological half-time for adults to $10 \mathrm{~d}$ and introducing age-specific values: teenager, $7 \mathrm{~d}$; child, $4.5 \mathrm{~d}$, infant, 3.2 d. These age-specific values were based on the hypothetical rate of turnover of body water, assuming body water is a uniformly mixed pool with outflow rate determined by the rate of water intake.

Pub30 model: The biokinetic model adopted in Pub30 for ingestion of tritiated water by a worker is essentially the same as the model of of NRC77, i.e., ${ }^{3} \mathrm{H}$ is completely and instantaneously absorbed, it is uniformly distributed in the body, and it is removed from the body with a biological half-time of $10 \mathrm{~d}$. Pub30 was intended for application to occupational intakes and hence did not address intake at pre-adult ages.

Pub72 model: Tritium ingested as tritiated water is assumed to be nearly completely $\left(\mathrm{f}_{1}=\right.$ 0.99) absorbed from the GI tract and uniformly distributed in tissues and fluids. Estimated doses to GI tract tissues are higher than those to other tissues because residence in the GI tract is considered, i.e., absorption of ${ }^{3} \mathrm{H}$ is not assumed to be instantaneous and complete as in Pub2 and Pub30. Whole-body retention of absorbed ${ }^{3} \mathrm{H}$ at $t$ days after injection is described by a sum of two exponential terms:

$$
R(t)=0.97 \exp \left(-0.693 t / T_{1}\right)+0.03 \exp \left(-0.693 t / T_{2}\right) .
$$

The coefficients (0.97 and 0.03) are assumed to be independent of age, but the half-times $\mathrm{T}_{1}$ and $\mathrm{T}_{2}$ are assumed to decrease with decreasing age, based on an assumed equivalence of tritium turnover and body water turnover. For the adult, $\mathrm{T}_{1}=10 \mathrm{~d}$, and $\mathrm{T}_{2}=40 \mathrm{~d}$. The theoretical model predicts that the short-term half-time of tritium, representing $97 \%$ of the amount of tritiated water consumed, is 3.0, 3.5, 4.6, 5.7, 7.9, and $10 \mathrm{~d}$ at ages $3 \mathrm{mo}, 1$ y, $5 \mathrm{y}, 10 \mathrm{y}, 15 \mathrm{y}$, and adulthood, respectively. The long-term half-times at these ages are assumed to be $8,15,19,26,32$, and $40 \mathrm{~d}$, respectively.

\subsubsection{Carbon}

Pub2 model: The organs of reference are total body, fat, and bone. Deposition fractions for these organs are 1.0, 0.5 , and 0.025 , respectively. The biological half-times for these organs are $10 \mathrm{~d}, 12 \mathrm{~d}$, and $40 \mathrm{~d}$, respectively.

NRC77 model: The organs of reference are total body, bone, liver, thyroid, kidneys, and lung. The deposition fractions for total body and bone are 1.0 and 0.02 , respectively. 
The total body dose is applied is applied to each of the other organs; hence deposition fractions are not required. This model is applied to all four age groups.

Pub30 model: The ICRP's model for dietary carbon depicts the body as a single wellmixed pool. A removal half-time of $40 \mathrm{~d}$ is based on balance of carbon intake and excretion, assuming daily intake of $0.3 \mathrm{~kg}$ and a total-body content of $16 \mathrm{~kg}$ :

$$
\mathrm{T}_{1 / 2}=(\ln 2) \times 16 \mathrm{~kg} / 0.3 \mathrm{~kg} \mathrm{~d}^{-1}=40 \mathrm{~d} \text {. }
$$

Carbon inhaled as carbon dioxide is rapidly absorbed from the lungs and distributed uniformly throughout the body. Retention, $\mathrm{R}(\mathrm{t})$, is described by the sum of three terms:

$$
R(t)=0.18 \exp (-0.693 t / 5)+0.81 \exp (-0693 t / 60)+0.01 \exp \left(-0.693 t / T_{b}\right) \text {, }
$$

where $t$ is in minutes and $\mathrm{T}_{\mathrm{b}}$ is the half-time used in the ingestion model.

Pub72 model: For adults, the models for ingested carbon and inhaled carbon dioxide are the same as in Pub30. The following age-specific values are assigned to the single halftime in the ingestion model and to the long-term half-time $\mathrm{T}_{\mathrm{b}}$ in the carbon dioxide inhalation model: $8,15,19,26$, and $32 \mathrm{~d}$ for ages 3 mo and $1,5,10$, and $15 \mathrm{y}$, respectively. Other parameters in the models are age invariant.

\subsubsection{Phosphorus}

Pub2 model: The organs of reference are total body, liver, bone, and brain. Deposition fractions for these organs are 1.0, 0.07, 0.2, and 0.007 , respectively. Biological halftimes are $257 \mathrm{~d}, 18 \mathrm{~d}, 1155 \mathrm{~d}$, and $257 \mathrm{~d}$, respectively.

NRC77 model: The Pub2 biokinetic model for the adult is modified by omitting brain. The modified model is applied to all age groups.

Pub30 model: Phosphorus leaves blood with a half-time of $0.5 \mathrm{~d}$. It is assumed that $15 \%$ of activity leaving blood goes direction to excretion, $30 \%$ goes to mineral bone where it is permanently retained, $15 \%$ is uniformly distributed in soft tissues and removed from the body with a half-time of $2 \mathrm{~d}$, and $40 \%$ is uniformly distributed in soft tissues and removed with a half-time of $19 \mathrm{~d}$. Phosphorous isotopes with half-life less than $15 \mathrm{~d}$ are assumed to be uniformly distributed on bone surfaces, and all others are distributed in bone volume.

Pub72 model: The Pub30 model is modified by assigning specific excretion pathways. Activity that is promptly excreted or removed from tissues transfers directly to the urinary bladder contents or upper large intestine contents. A urinary to fecal excretion ratio of 9:1 is assigned. 


\subsubsection{Chromium}

Pub2 model: The organs of reference are total body, lungs, prostate, thyroid, and kidneys. Deposition fractions for these organs are 1.0, 0.04, 0.0009, 0.0009, and 0.0027, respectively. The biological half-time for each organ is $616 \mathrm{~d}$.

NRC77 model: The Pub2 model is modified by removing the prostate as an organ of reference. The modified model is applied to all four age groups.

Pub30 model: Chromium leaves blood with a half-time of $0.5 \mathrm{~d}$, with fractions 0.3 and 0.05 going to excretion pathways and bone, respectively, and 0.65 distributing uniformly in other tissues. Activity removed from tissues is transferred directly to excreta. The removal half-time from bone is $1000 \mathrm{~d}$. Other tissues are divided into two retention components representing fractions 0.4 and 0.25 of activity leaving blood and having removal half-times of 6 and $80 \mathrm{~d}$, respectively. Chromium isotopes with half-life less than $15 \mathrm{~d}$ are assumed to be uniformly distributed on bone surfaces, and all others are distributed in bone volume.

Pub72 model: The biokinetic model for chromium is modified by assigning activity removed from tissues to specific excretion pathways, beginning with the urinary bladder contents and upper large intestine contents. A urinary to fecal excretion ratio of 1:1 is assigned; this is the default ratio applied in Pub72 when information on the urinary to fecal ratio is limited. The systemic model for the adult is applied to all age groups.

\subsubsection{Manganese}

Pub2 model: The organs of reference are total body, pancreas, liver, and kidneys. Deposition fractions for these organs are 1.0, 0.03, 0.24, and 0.05, respectively. Biological half-times are $17 \mathrm{~d}, 5.7 \mathrm{~d}, 25 \mathrm{~d}$, and $6.8 \mathrm{~d}$, respectively.

NRC77 model: The Pub2 biokinetic model for the adult is modified by omitting the pancreas. This modified model is applied to all age groups.

Pub30 model: Activity leaves blood with a half-time of $0.25 \mathrm{~d}$ and deposits on bone surface (deposition fraction 0.35), in liver (0.25), and in other (0.4). Biological halftimes are $40 \mathrm{~d}$ for bone surface, $4 \mathrm{~d}$ for $40 \%$ of the liver deposition, $40 \mathrm{~d}$ for $60 \%$ of the liver deposition, $4 \mathrm{~d}$ for $50 \%$ of the deposition in other, and $40 \mathrm{~d}$ for the other $50 \%$ deposited in other. Manganese removed from tissues is assigned to excreta.

Pub72 model: The manganese model of Pub30 is modified by adding explicit excretion pathways, i.e., activity lost from tissues is excreted in urine after residence in the urinary bladder contents and in feces after residence in the upper and lower large intestines. A urinary to fecal ratio of 1:1 is assigned. The modified systemic model is applied to all age groups. 


\subsubsection{Iron}

Pub2 model: The organs of reference are total body, spleen, lungs, liver, and bone. Deposition fractions for these organs are 1.0, 0.02, 0.02, 0.13, and 0.1, and biological half-times are 800 d, 600 d, 3200 d, 554 d, and 1680 d, respectively.

NRC77 model: The Pub2 biokinetic model for the adult is modified by omitting the spleen. This modified model is applied to all four age groups.

Pub30 model: Activity leaves blood with a half-time of $0.25 \mathrm{~d}$ and deposits in the liver (deposition fraction 0.08), spleen (0.013), and other (0.907). The biological half-time is $2000 \mathrm{~d}$ for all compartments. Iron removed from tissues is assigned to excreta.

Pub72 model: A relatively sophisticated, physiologically realistic, age-specific systemic biokinetic model is applied. The reader is referred to ICRP Publication 69 (1995) for details of the model, including a schematic of the model structure and a tabulation of agespecific parameter values. The model describes three main aspects of iron metabolism: (1) the hemoglobin cycle, including uptake of transferrin-bound iron by the erythroid marrow for incorporation into hemoglobin, subsequent appearance of iron in red blood cells, uptake of old and damaged red blood cells by the reticuloendothelial system, and eventual return of iron to plasma; (2) removal of transferrin-bound iron from plasma to the extravascular spaces and return to plasma via the lymphatic system; and (3) uptake and retention of iron by the parenchymal tissues. The soft tissues include a pool of extravascular iron that exchanges rapidly with plasma iron. Storage iron is divided among liver, spleen, red marrow, and other soft tissues. Destruction of red blood cells is viewed as occurring in the red marrow. The liver is viewed as consisting of two pools: a transit pool representing parenchymal tissues that exchange iron with plasma, and a storage pool associated with the reticuloendothelial system. Excretion of iron is depicted as occurring through exfoliation of skin, losses of plasma iron in urine, and leakage of red blood cells into the intestines and subsequent removal in feces. Age-specific parameter values are based mainly on consideration of iron balance and reported changes with age in the sizes of various iron pools in the body.

\subsubsection{Copper}

Pub2 model: The organs of reference are total body, spleen, kidneys, liver, heart, and brain. Deposition fractions for these organs are 1.0, 0.07, 0.05, 0.08, 0.01, and 0.1, and biological half-times are 80 d, 2 d, 16 d, 150 d, 80 d, and 800 d, respectively.

NRC77 model: The Pub2 biokinetic model for the adult is modified by omitting spleen, heart, and brain. Also, it appears that fractions of ingested ${ }^{64} \mathrm{Cu}$ assigned to organs are rounded to one significant digit except for total body. For example, the Pub2 model implies fractional deposition of $0.28 \times 0.08=0.224$ in liver, but in NRC77 this is rounded to 0.2 . The modified model is applied to all four age groups. 
Pub30 model: Activity leaves blood with a half-time of $0.25 \mathrm{~d}$ and deposits in liver, brain, pancreas, and other. Deposition fractions are 0.1, 0.1, 0.006, and 0.794, respectively. A biological half-time of $40 \mathrm{~d}$ is applied to each compartment. Copper removed from tissues is assigned to excreta.

Pub72 model: The copper model of Pub30 is modified by adding explicit excretion pathways, i.e., activity lost from tissues is excreted in urine after residence in the urinary bladder contents and in feces after residence in the upper and lower large intestines. A urinary to fecal ratio of 1:1 is assigned.

\subsubsection{Cobalt}

Pub2 model: The organs of reference are total body, liver, spleen, and pancreas. Deposition fractions for these organs are 1.0, 0.04, 0.0014, and 0.002, and the biological half-time for each organ is $9.5 \mathrm{~d}$.

NRC77 model: The Pub2 biokinetic model for the adult is modified by omitting spleen and pancreas. The modified model is applied to all four age groups.

Pub30 model: Cobalt leaves blood with a half-time of $0.5 \mathrm{~d}$, with fractions 0.5 and 0.05 going to excretion and liver, respectively, and 0.45 uniformly distributed among the other organs and tissues. Fractions $0.6,0.2$, and 0.2 of activity translocated from blood to tissues are retained with biological half-times of 6, 60, and $800 \mathrm{~d}$, respectively, and are assumed to be lost directly to excreta.

Pub72 model: The cobalt model of Pub30 is modified by adding explicit excretion pathways, i.e., activity lost from tissues is excreted in urine after residence in the urinary bladder contents and in feces after residence in the upper and lower large intestines. A urinary to fecal ratio of 6:1 is assigned. The modified model is applied to all age groups.

\subsubsection{Nickel}

Pub2 model: The organs of reference are total body, bone, and liver. Deposition fractions for these organs are 1.0, 0.5, and 0.07, and biological half-times are $667 \mathrm{~d}, 800 \mathrm{~d}$, and 500 d, respectively.

NRC77 model: This Pub2 model is applied to all four age groups.

Pub30 model: Activity leaves blood with a half-time of $0.25 \mathrm{~d}$ and deposits in excretion pathways (0.68), kidneys (0.02), and body tissues (0.3). Body tissues represents the whole body including kidneys, but excludes contents of the GI tract, urinary bladder, and heart (blood). The biological half-time in all compartments is $1200 \mathrm{~d}$. Nickel leaving tissues is assigned to excreta.

Pub72 model: The nickel model of Pub30 is modified by adding explicit excretion pathways, i.e., activity lost from tissues is excreted in urine after residence in the urinary 
bladder contents and in feces after residence in the upper and lower large intestines. A urinary to fecal ratio of 20:1 is assigned. The modified model is applied to all age groups.

\subsubsection{Zinc}

Pub2 model: The organs of reference are total body, prostate, bone, kidneys, muscle, liver, pancreas, testes, and ovaries. Deposition fractions for these organs are 1.0, 0.06, $0.15,0.04,0.3,0.35,0.03,0.0009$, and 0.0004, respectively. Biological half-times are 933 d, 14 d, 1300 d, 149 d, 1959 d, 91 d, 25 d, 270 d, and 107 d, respectively.

NRC77 model: The Pub2 model for zinc was modified by removing prostate, liver, pancreas, testes, and ovaries. The modified model is applied to all four age groups.

Pub30 model: Activity leaves blood with a half-time of $0.25 \mathrm{~d}$ and is divided between skeleton (0.2) and other (0.8). The biological half-time in the skeleton is $400 \mathrm{~d}$. Two retention components are assigned to other: $20 \mathrm{~d}$ (30\%) and $400 \mathrm{~d}$ (70\%). Zinc isotopes with half-life less than $15 \mathrm{~d}$ are assumed to be uniformly distributed on bone surfaces,

and all others (e.g., ${ }^{65} \mathrm{Zn}$ ) are assumed to be distributed in bone volume. Activity removed from bone or other tissues is assumed to be lost immediately in excreta.

Pub72 model: The model of Pub30 is modified by adding a long-term retention component in the skeleton, assigning age-specific biological half-times to this component, and adding explicit excretion pathways. Activity leaves blood with a halftime of $0.25 \mathrm{~d}$ with the fraction 0.2 depositing in the skeleton, where 0.195 is retained with a biological half-time of $400 \mathrm{~d}$ and 0.005 with an age-specific half-time: adult, 10,000 d; 15 y, 1500 d; 10 y, 1000 d; 5 y, 500 d; 1 y, 300 d; infants, 100 d. The remaining 0.8 is uniformly distributed throughout other tissues and retained with biological halftimes of $20 \mathrm{~d}(30 \%)$ and $400 \mathrm{~d}$ (70\%). Zinc isotopes with half-life less than $15 \mathrm{~d}$ are assumed to be uniformly distributed on bone surfaces, and all others (e.g., ${ }^{65} \mathrm{Zn}$ ) are assumed to be distributed in bone volume. A urinary to fecal ratio of 1:4 is assigned.

\subsubsection{Strontium}

Pub2 model: The organs of reference are total body and bone. Deposition fractions for these organs are 1.0 and 0.3 , respectively. Biological half-times in these organs are $13,000 \mathrm{~d}$ and 18,000 d, respectively.

NRC77 model: The Pub2 model for the adult is applied to all four age groups.

Pub30 model: The alkaline earth model introduced in ICRP Publication 20 (1973) is applied in Pub30 to strontium, calcium, barium, and radium. Whole-body retention $\mathrm{R}(\mathrm{t})$ at time $t$ days after injection is described by the equation:

$$
\mathrm{R}(\mathrm{t})=(1-\mathrm{p}) \exp (-\mathrm{mt})+\mathrm{pE}^{\mathrm{b}}(\mathrm{t}+\mathrm{E})^{-\mathrm{b}}[\mathrm{Bexp}(-\mathrm{rLt})+(1-\mathrm{B}) \exp (-\mathrm{srLt})]
$$

Some of the parameters are element dependent, and some are related to processes rather than specific elements. The parameter $\mathrm{L}$ is the rate of apposition and resorption in compact bone, $\mathrm{s}$ is the ratio of turnover rates of trabecular and compact bone, $\mathrm{B}$ is the 
fraction of bone volume activity deposited in compact bone, and $\mathrm{r}$ is an element-specific factor that corrects for redeposition of activity in new bone at sites of resorption long after injection. The power function slope, $b$, is related to diffusion of activity from bone but is element specific. The element-specific parameter values $\mathrm{E}$ (a small time related to the turnover of an initial pool), $\mathrm{m}$ (the rate constant of a small early exponential in R), and $\mathrm{p}$ (the fraction of $\mathrm{R}$ not in the early exponential) are not clearly related to processes.

Pub72 model: The structure of the ICRP's biokinetic model for strontium (ICRP 1993) is the ICRP's generic, physiologically based structure for calcium-like elements. Agespecific parameter values were based on a combination of physiological information such as bone turnover rates at different ages and a relatively large database on the age-specific behavior of ${ }^{90} \mathrm{Sr}$ in humans and laboratory animals. The reader is referred to ICRP Publication 67 (1993) for a description of the model.

\subsubsection{Yttrium}

Pub2 model: The organs of reference are total body and bone. Deposition fractions for these organs are 1.0 and 0.75 , respectively. Biological half-times are 14,000 $\mathrm{d}$ and $18,000 \mathrm{~d}$, respectively.

NRC77 model: The Pub2 model for the adult is applied to all four age groups.

Pub30 model: Yttrium leaves blood with a half-time of $0.25 \mathrm{~d}$, with fractions 0.25 assigned to excreta, 0.5 to bone, 0.15 to liver, and 0.1 to other. Yttrium entering tissues is permanently retained. Yttrium deposited in the skeleton is uniformly distributed on bone surfaces.

Pub72 model: The yttrium model of Pub30 is modified by adding explicit excretion pathways, i.e., activity lost from tissues is excreted in urine after residence in the urinary bladder contents and in feces after residence in the upper and lower large intestines. A urinary to fecal ratio of 1:1 is assigned. The modified model is applied to all age groups.

\subsubsection{Molybdenum}

Pub2 model: The organs of reference are total body, liver, and kidneys. Deposition fractions for these organs are 1.0, 0.1 and 0.08, respectively. Biological half-times are 5 d, $45 \mathrm{~d}$ and $3 \mathrm{~d}$, respectively.

NRC77 model: The Pub2 model for the adult is applied to all four age groups.

Pub30 model: Activity leaves blood with a half-time of $0.25 \mathrm{~d}$ and is distributed as follows: liver, 0.3; bone, 0.15 , kidney, 0.05 ; other, 0.5 . The removal half-time from bone is $10,000 \mathrm{~d}$. Retention in any region is divided into two components with fractions 0.1 and 0.9 removed with biological half-times of 1 and $50 \mathrm{~d}$, respectively. Activity removed from tissues transfers directly to excreta. Molybdenum isotopes with half-life less than 15 
$\mathrm{d}$ are uniformly distributed on bone surfaces, and all others are distributed in bone volume.

Pub72 model: The systemic model for molybdenum is also independent of age. Activity leaves blood with a half-time of $0.25 \mathrm{~d}$ and is distributed as follows: bone, 0.1 ; liver, 0.25 ; kidney, 0.05 , other, 0.6 . The removal half-time from bone is $10,000 \mathrm{~d}$. Retention in other regions is divided into two components with fractions 0.1 and 0.9 removed with half-times of 1 and $50 \mathrm{~d}$, respectively. Activity lost from tissues is excreted in urine after residence in the urinary bladder contents and in feces after residence in the upper and lower large intestines. A urinary to fecal excretion ratio of 8:1 is assigned. Molybdenum isotopes of half-life less than $15 \mathrm{~d}$ are uniformly distributed on bone surfaces, and all others are distributed in bone volume.

\subsubsection{Technetium}

Pub2 model: The organs of reference are total body, kidneys, lungs, skin, liver, and bone. Deposition fractions for these organs are 1.0, 0.01, 0.0009, 0.01, 0.003, and 0.002, respectively. Biological half-times are $1 \mathrm{~d}, 20 \mathrm{~d}, 5 \mathrm{~d}, 10 \mathrm{~d}, 30 \mathrm{~d}$, and $25 \mathrm{~d}$, respectively.

NRC77 model: The Pub2 model for the adult is modified by removing lungs and skin. The modified model is applied to all four age groups.

Pub30 model: Activity leaves blood with a half-time of $0.02 \mathrm{~d}$ and is divided among tissues as follows: thyroid, 0.04 ; stomach wall, 0.1 ; liver, 0.03 ; other, 0.83 . The removal half-time from thyroid is $0.5 \mathrm{~d}$. Retention in other regions is divided into three components with fractions $0.75,0.20$, and 0.05 removed with half-times of 1.6, 3.7, and $22 \mathrm{~d}$, respectively. Activity removed from tissues transfers directly to excreta.

Pub72 model: The technetium model of Pub30 is modified by adding explicit excretion pathways, i.e., activity lost from tissues is excreted in urine after residence in the urinary bladder contents and in feces after residence in the upper and lower large intestines. A urinary to fecal excretion ratio of 1:1 is assigned.

\subsubsection{Zirconium}

Pub2 model: The organs of reference are total body, bone, kidneys, lungs, spleen, and liver. Deposition fractions for these organs are 1.0, 0.36, 0.02, 0.006, and 0.07, respectively. Biological half-times are 450 d, 1000 d, 900 d, 900 d, and 320 d, respectively.

NRC77 model: The Pub2 model for the adult is modified by removing lungs and spleen. The modified model is applied to all four age groups.

Pub30 model: Activity leaves blood with a half-time of $0.25 \mathrm{~d}$ with fractions 0.5 depositing uniformly on bone surfaces and 0.5 depositing uniformly in remaining tissues. 
The half-time of removal from tissues to excretion pathways is 8,000 $\mathrm{d}$ for bone and $7 \mathrm{~d}$ for other tissues. Zirconium removed from tissues is assigned to excreta.

Pub72 model: The systemic model is based on the Pub30 model, but the biological halftime in bone is age-dependent: infant, $100 \mathrm{~d}$; age $1 \mathrm{y}, 300 \mathrm{~d}$; age $5 \mathrm{y}, 500 \mathrm{~d}$; age $10 \mathrm{y}$, $1000 \mathrm{~d}$; age $15 \mathrm{y}, 1500 \mathrm{~d}$; adult, 10,000 d. Activity lost from tissues is excreted in urine after residence in the urinary bladder contents and in feces after residence in the upper and lower large intestines. A urinary to fecal excretion ratio of 5:1 is assigned.

\subsubsection{Niobium}

Pub2 model: The organs of reference are total body, bone, spleen, kidneys, and liver. Deposition fractions for these organs are $1.0,0.38,0.008,0.02$, and 0.09 , respectively. Biological half-times are 760 d, 1000 d, 950 d, 760 d, and 845 d, respectively.

NRC77 model: The Pub2 model for the adult is modified by omitting spleen. The modified model is applied to all four age groups.

Pub30 model: Activity leaves blood with a half-time of $0.25 \mathrm{~d}$, with fractions 0.71 , $0.018,0.01,0.002$, and 0.26 assigned to bone, kidneys, spleen, testes, and other, respectively. For each of these regions, half of the deposited activity is removed with a half-time of $6 \mathrm{~d}$ and half is removed with a half-time of $200 \mathrm{~d}$. For bone dosimetry, niobium-93m and ${ }^{94} \mathrm{Nb}$ are assigned to bone volume and shorter-lived niobium isotopes including ${ }^{95} \mathrm{Nb}$ are assigned to bone surface. Niobium removed from tissues is assigned to excreta.

Pub72 model: Activity leaves blood with a half-time of $0.25 \mathrm{~d}$. The initial distribution depends on age. At ages $10 \mathrm{y}$ or greater, fractions $0.4,0.2,0.03$, and 0.37 deposit in bone, liver, kidneys, and other, respectively. At ages $1-5 \mathrm{y}$, deposition fractions are 0.5 , $0.18,0.02$, and 0.3 , respectively. In infants, deposition fractions are $0.6,0.15,0.02$, and 0.23 , respectively. For each region, half of the deposited activity is removed with a halftime of $6 \mathrm{~d}$ and half is removed with a half-time of $200 \mathrm{~d}$. For bone dosimetry, ${ }^{93 \mathrm{~m}} \mathrm{Nb}$ and ${ }^{94} \mathrm{Nb}$ are assigned to bone volume and shorter-lived niobium isotopes including ${ }^{95} \mathrm{Nb}$ are assigned to bone surface. Activity lost from tissues is excreted in urine after residence in the urinary bladder contents and in feces after residence in the upper and lower large intestines. A urinary to fecal excretion ratio of 5:1 is assigned.

\subsubsection{Ruthenium}

Pub2 model: The organs of reference are total body, kidneys, and bone. Deposition fractions in these organs are 1.0, 0.2, and 0.08, respectively. Biological half-times are 7.3 d, $2.5 \mathrm{~d}$, and $16 \mathrm{~d}$, respectively.

NRC77 model: The Pub2 model is applied to all four age groups. 
Pub30 model: Activity leaves blood with a half-time of $0.3 \mathrm{~d}$, with the fraction 0.15 being promptly excreted and 0.85 distributing uniformly throughout the body. The retained fraction (0.85) is divided into three retention components representing fractions $0.35,0.3$, and 0.2 of outflow from blood and having removal half-times of 8, 35, and $1000 \mathrm{~d}$, respectively. Activity removed from tissues transfers directly to excreta.

Pub72 model: The systemic biokinetic model of Pub30 is modified by addition of explicit excretion pathways; i.e., activity lost from tissues is excreted in urine after residence in the urinary bladder contents and in feces after residence in the upper and lower large intestines. A urinary to fecal excretion ratio of 4:1 is assigned.

\subsubsection{Silver}

Pub2 model: The organs of reference are total body, bone, liver, and kidneys. Deposition fractions in these organs are 1.0, 0.05, 0.03, and 0.02, respectively. Biological half-times are $5 \mathrm{~d}, 30 \mathrm{~d}, 15 \mathrm{~d}$, and $10 \mathrm{~d}$, respectively.

NRC77 model: The Pub2 model is applied to all four age groups.

Pub30 model: Activity leaves blood with a half-time of $0.25 \mathrm{~d}$, with fractions 0.8 and 0.2 depositing in liver and all other tissues, respectively. Fractions 0.1 and 0.9 of deposited activity are removed from the body with biological half-times of $3.5 \mathrm{~d}$ and $50 \mathrm{~d}$, respectively.

Pub72 model: The model of Pub30 is modified by assuming three rather than two components of retention in tissues and assigning specific excretion pathways. Fractions $0.1,0.8$, and 0.1 are assumed to be removed from the body with biological half-times of $3.5 \mathrm{~d}, 50 \mathrm{~d}$, and $500 \mathrm{~d}$, respectively. Activity lost from tissues is excreted in urine after residence in the urinary bladder contents and in feces after residence in the upper and lower large intestines. A urinary to fecal excretion ratio of 4:1 is assigned.

\subsubsection{Iodine}

Pub2 model: The organs of reference are total body, thyroid, kidneys, liver, spleen, testes, and bone. Deposition fractions for these organs are 1.0, 0.3, 0.04, 0.12, 0.005, 0.005, and 0.07, respectively. Biological half-times are $138 \mathrm{~d}$ for total body and thyroid; $7 \mathrm{~d}$ for kidneys, liver, spleen, and testes; and $14 \mathrm{~d}$ for bone.

NRC77 model: The Pub2 model is modified by removing spleen and testes and by introducing age-specific biological half-times for total body and thyroid: infant and child, $20 \mathrm{~d}$; teenager, $50 \mathrm{~d}$; adult, $100 \mathrm{~d}$.

Pub30 model. The systemic model for iodine is a recycling model that depicts different distributions of absorbed and recycled iodine, i.e., immediately after absorption to blood and after loss from the thyroid gland to blood. The structure of the model is similar to the Pub72 model (Figure 23 of main text), except that the excretion pathways are not as 
clearly identified in the Pub30 model. The removal half-time from blood is $0.25 \mathrm{~d}$. Of iodine atoms entering blood for the first time, the fraction 0.3 is deposited in the thyroid gland and 0.7 is lost directly in excretion. Iodine is removed from the thyroid gland in the form of organic iodine with a biological half-time of $120 \mathrm{~d}$. Organic iodine returning to blood from the thyroid is taken up and metabolized in tissues (other) and is returned to the blood pool as inorganic iodide with a half-time of $12 \mathrm{~d}$. One-tenth of the outflow from other is assumed to be lost directly in excretion and the rest is assumed to be returned to the transfer compartment as inorganic iodine, which follows the same paths of movement as the initial input to blood.

Pub72 model: The removal half-time from blood is $0.25 \mathrm{~d}$. Of iodine atoms entering blood for the first time, the fraction 0.3 is deposited in the thyroid gland and 0.7 moves to the urinary bladder contents. Iodine is removed from the thyroid gland with an agespecific biological half-time: infant, 11.2 d; age 1 y, 15 d; age 5 y, 23 d; age 10 y, 58 d; age $15 \mathrm{y}, 67 \mathrm{~d}$; and adult, $80 \mathrm{~d}$. Organic iodine returning to blood from the thyroid is taken up and metabolized in tissues (Other) and is returned to the plasma pool as inorganic iodide with an age-specific half-time: infant, $1.12 \mathrm{~d}$; age $1 \mathrm{y}, 1.5 \mathrm{~d}$; age $5 \mathrm{y}, 2.3$ d; age $10 \mathrm{y}, 5.8 \mathrm{~d}$; age $15 \mathrm{y}, 6.7 \mathrm{~d}$; and adult, $12 \mathrm{~d}$. Of iodine entering blood from Other, the fraction 0.2 moves to the upper large intestine contents, 0.24 returns to the thyroid gland, and 0.56 moves to the urinary bladder contents.

\subsubsection{Cesium}

Pub2 model: The organs of reference are total body, muscle, lungs, kidneys, spleen, liver, and bone. Deposition fractions for these organs are 1.0, 0.4, 0.003, 0.01, 0.005, 0.07, and 0.04, respectively. Biological half-times are 70 d, 140 d, 140 d, 42 d, 98 d, 90 $\mathrm{d}$, and $140 \mathrm{~d}$, respectively.

NRC77 model. The systemic model used in Pub2 is modified by removing muscle, lungs, and spleen, and by introducing age-specific biological half-times for total body: infant, 10 d; child, 20 d; teenager, 60 d; adult, 115 d.

Pub30 model: Activity leaves blood with a half-time of $0.25 \mathrm{~d}$ and is uniformly distributed in the body. Whole-body retention $t$ days post injection is described by a sum of two exponential terms:

$$
R(t)=0.1 \exp (-0.693 \mathrm{t} / 2)+0.9 \exp (-0.693 \mathrm{t} / 110) \text {. }
$$

Activity removed from tissues is assumed to transfer immediately to excreta.

Pub72 model: As in Pub30, whole-body retention of absorbed cesium is described by a sum of two exponential terms:

$$
R(t)=a \exp \left(-0.693 t / T_{1}\right)+(1-a) \exp \left(-0.693 t / T_{2}\right),
$$

where $t$ is time in days after uptake. The values $a, T_{1}$, and $T_{2}$ vary with age, based on observations of more rapid turnover of cesium in children than in adults and established relations between the parameter values and total-body potassium. For the adult, $\mathrm{a}=0.1$, $\mathrm{T}_{1}=2 \mathrm{~d}$, and $\mathrm{T}_{2}=110 \mathrm{~d}$, as in Pub30. For ages $100 \mathrm{~d}$ and $1 \mathrm{y}$, the model has only one term, with half-times of $16 \mathrm{~d}$ and $13 \mathrm{~d}$, respectively. For ages 5,10 , and $15 \mathrm{y}$, the 
coefficient a is $0.45,0.30$, and 0.13 , respectively; the short-term half-time $T_{1}$ is $9.1,5.8$, and $2.2 \mathrm{~d}$, respectively; and the long-term half-time $\mathrm{T}_{2}$ is 30,50 , and $93 \mathrm{~d}$, respectively. Activity lost from tissues is excreted in urine after residence in the urinary bladder contents and in feces after residence in the upper and lower large intestines. A urinary to fecal excretion ratio of 4:1 is assigned.

\subsubsection{Barium}

Pub 2 model: The organs of reference are total body, bone, lungs, muscle, kidneys, spleen, liver, testes, and ovaries. Deposition fractions for these organs are 1.0, 0.7, $0.0002,0.003,0.0001,0.00005,0.0006,0.001$, and 0.0004 , respectively. Biological halftimes are 65 d, 65 d, 6500 d, 2000 d, 8.5 d, 13 d, 975 d, 6.2 d, and 4.9 d, respectively.

NRC77 model: The Pub2 model is modified by removing lungs, muscle, spleen, testes, and ovaries. The modified model is applied to all four age groups.

Pub30 model: The alkaline earth model introduced in ICRP Publication 20 (1973) is applied in Pub30 to barium as well as strontium, calcium, and radium. The model is described earlier in the section on ${ }^{90} \mathrm{Sr}$.

Pub72 model: The structure of the ICRP's biokinetic model for barium (ICRP 1993) is the ICRP's generic, physiologically based structure for calcium-like elements. Agespecific parameter values were based on a combination of physiological information such as bone turnover rates at different ages and information on the age-specific behavior of barium or other alkaline earth elements in laboratory animals and humans. The reader is referred to ICRP Publication 67 (1993) for a description of the model.

\subsubsection{Lanthanum}

Pub2 model. The organs of reference are total body, bone, and liver. Deposition fractions for these organs are 1.0, 0.4, and 0.15, respectively. Biological half-times are $500 \mathrm{~d}$, $1000 \mathrm{~d}$, and $400 \mathrm{~d}$, respectively.

NRC77 model: The Pub2 model is applied to all four age groups.

Pub30 model: Activity leaves blood with a half-time of $0.25 \mathrm{~d}$, with $60 \%$ going to liver, $20 \%$ to bone, and $20 \%$ to other tissues. The removal half-time from all tissues is $3500 \mathrm{~d}$. Lanthanum isotopes deposited in bone are uniformly distributed on bone surfaces. Activity removed from tissues is transferred directly to excreta.

Pub72 model: The systemic biokinetic model of Pub30 is modified by addition of explicit excretion pathways; i.e., activity lost from tissues is excreted in urine after residence in the urinary bladder contents and in feces after residence in the upper and lower large intestines. A urinary to fecal excretion ratio of 1:1 is assigned. 


\subsubsection{Neptunium}

Pub2 model: The organs of reference are total body, bone, kidneys, and liver. Deposition fractions for these organs are 1.0, 0.45, 0.03, and 0.05, respectively. Biological half-times are 39,000 d, 73,000 d, 64,000 d, and 54,000 d, respectively.

NRC77 model: The Pub2 model is applied to all four age groups.

Pub30 model: Neptunium leaving blood is divided among tissues and excreta as follows: bone surface, 0.75; liver, 0.15; testes, 0.00035; ovaries, 0.00011; excreta, 0.09954 . Assigned removal half-times are $50 \mathrm{y}$ for bone and $20 \mathrm{y}$ for liver. Neptunium assigned to gonads is assumed to be permanently retained.

Pub72 model: A relatively sophisticated, physiologically realistic, age-specific systemic biokinetic model was applied to neptunium in Pub72. The model structure is a generic structure applied in Pub72 to a set of radionuclides that deposit heavily on bone surfaces (Figure 8). Age-specific parameter values for neptunium can be found in ICRP Publication 67 (1993). The model depicts recycling of material between blood and tissues and gradual burial of neptunium in bone after deposition on bone surfaces. 


\section{COMPARISON OF INGESTION AND INHALATION DOSE COEFFICIENTS FOR EACH DOSIMETRY SYSTEM}

\subsection{Dose quantities addressed}

This section compares dose estimates for annual intake of each of 28 radionuclides in drinking water and air based on each of three dosimetry systems: NRC77 (i.e., the Pub2 system as modified and applied in NRC77), Pub30, and Pub72. The base case involves derivation of annual doses from inhalation of each of these radionuclides using dose coefficients and drinking water intake rates given in NRC77. Reference values for annual consumption of drinking water used in NRC77 are $330 \mathrm{~L}$ for infants, $510 \mathrm{~L}$ for children and teenagers, and $730 \mathrm{~L}$ for adults. Reference values for annual intake of air given in NRC77 are $1400 \mathrm{~m}^{3}$ for infants, $3700 \mathrm{~m}^{3}$ for children, and $8000 \mathrm{~m}^{3}$ for teenagers and adults. A unit activity concentration of the radionuclide or mixture of radionuclides in drinking water $(1 \mathrm{pCi} / \mathrm{L}$ or $0.037 \mathrm{~Bq} / \mathrm{L})$ and air $\left(1 \mathrm{pCi} / \mathrm{m}^{3}\right.$ or $\left.0.037 \mathrm{~Bq} / \mathrm{m}^{3}\right)$ is assumed. The analysis is repeated using ingestion and inhalation dose coefficients based on Pub30 and Pub72. For comparison between NRC77 and Pub30, estimates based on NRC77 for the infant, child, teen, and adult are compared with the age-independent ingestion and inhalation dose coefficients for the worker based on Pub30 multiplied by the age-specific intake rates given in NRC77. For comparison between NRC77 and Pub72, estimates based on NRC77 for the infant, child, teen, and adult are compared with estimates based on Pub72 for the infant, age $5 \mathrm{y}$, age $15 \mathrm{y}$, and adult, respectively, assuming annual drinking water intake is $330 \mathrm{~L}$ for infants, $510 \mathrm{~L}$ for age 5 and $15 \mathrm{y}$, and $730 \mathrm{~L}$ for adults and annual air intake of $1400 \mathrm{~m}^{3}$ for infants, $3700 \mathrm{~m}^{3}$ for age $5 \mathrm{y}$, and $8000 \mathrm{~m}^{3}$ for age $15 \mathrm{y}$ and adults.

Comparison of doses to individual organs based on the three systems is complicated by a lack of uniformity across systems in the organs addressed and in some of the dose quantities derived. Because the only organs addressed in NRC77 are LLI and some subset of the organs bone, liver, kidneys, thyroid, and lungs for a given radionuclide, comparisons of doses to individual tissues are necessarily limited to those organs. As discussed earlier, a dose estimate for bone based on NRC77 does not correspond precisely to any dose quantity generated by the Pub30 or Pub72 systems but is compared here with the bone surface dose defined by those systems as the most closely related value.

The total body dose based on NRC77 is compared here with the effective dose quantities $\mathrm{H}_{\mathrm{E}}$ and $\mathrm{E}$. The quantities $\mathrm{H}_{\mathrm{E}}$ and $\mathrm{E}$ are most closely related to total body dose in cases where they are determined largely by doses from absorbed activity, particularly in cases where the radionuclide is modeled in all three systems as uniformly distributed in the body. The relation between total body dose and the effective dose quantities is particularly weak for poorly absorbed and relatively short-lived radionuclides such as

${ }^{239} \mathrm{~Np}$ for which $\mathrm{H}_{\mathrm{E}}$ and $\mathrm{E}$ are dominated by the unabsorbed portion of ingested activity.

Comparisons are also made between the primary dose quantities in the two age-specific systems, NRC77 and Pub72. That is, the maximum across age groups of the dose to the 
critical organ based on NRC77 is compared with the maximum across age groups of the effective dose E based on Pub72.

\subsection{Comparisons of dose estimates for adults}

\subsubsection{Ingestion}

Base case dose estimates for an adult were derived using dose coefficients from NRC77, assuming a one-year intake of each radionuclide in drinking water (730 L) and an activity concentration of $1 \mathrm{pCi} / \mathrm{L}(0.037 \mathrm{~Bq} / \mathrm{L})$. Base case dose estimates are listed in Table B.1 of Appendix B. Base case estimates for a given radionuclide are provided for each of the organs addressed in NRC77 for that radionuclide, i.e., for total body, lower large intestine, and some subset of the organs bone, liver, thyroid, kidney, and lung.

The base case dose estimates for each organ addressed in NRC77 were compared with dose estimates for adults based on Pub30 or Pub72. Comparisons for all cases, i.e., all 28 radionuclides and all organs addressed in NRC77 for each of these radionuclides, are listed in Table B.2 of Appendix B. The comparisons are illustrated in Figures 4.1-4.3, which show organ-specific dose estimates based on Pub30 and Pub72 as multiples of the dose estimate for the same organ based on NRC77, for ${ }^{55} \mathrm{Fe},{ }^{95} \mathrm{Nb}$, and ${ }^{137} \mathrm{Cs}$, respectively.

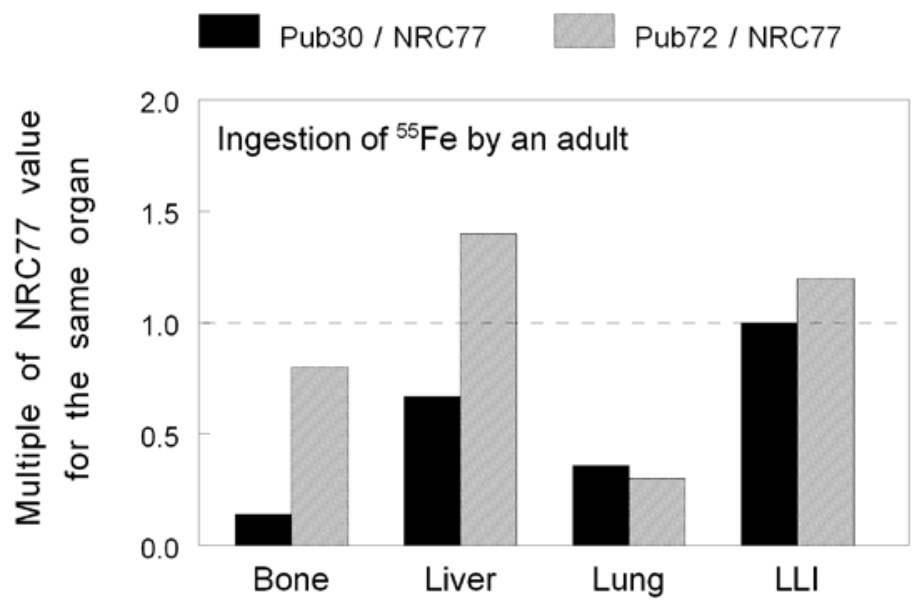

Figure 4.1. For intake of ${ }^{55} \mathrm{Fe}$ in drinking water by an adult, organ dose estimates based on Pub30 and Pub72, as multiples of corresponding values based on NRC77. 


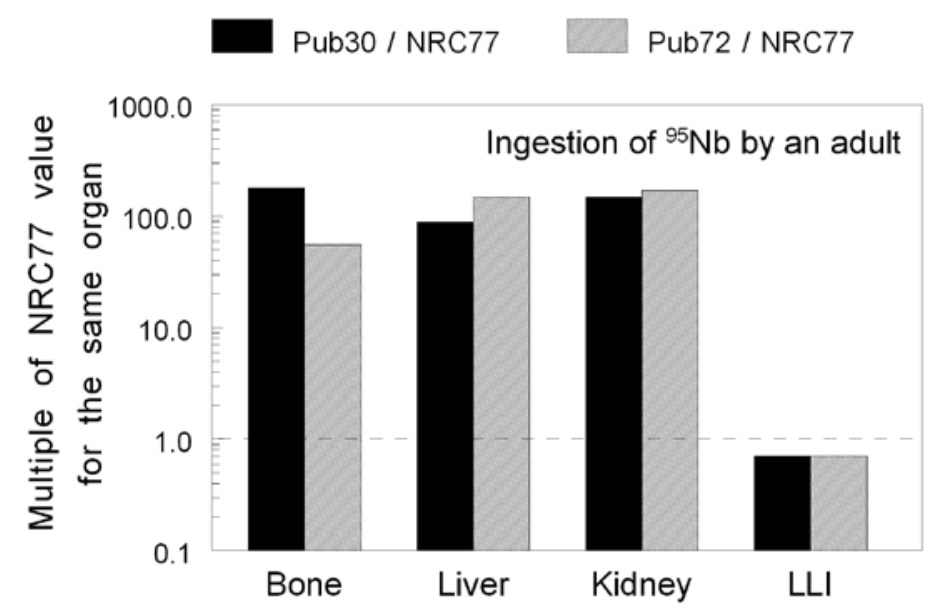

Figure 4.2. For intake of ${ }^{95} \mathrm{Nb}$ in drinking water by an adult, organ dose estimates based on Pub30 and Pub72, as multiples of corresponding values based on NRC77.

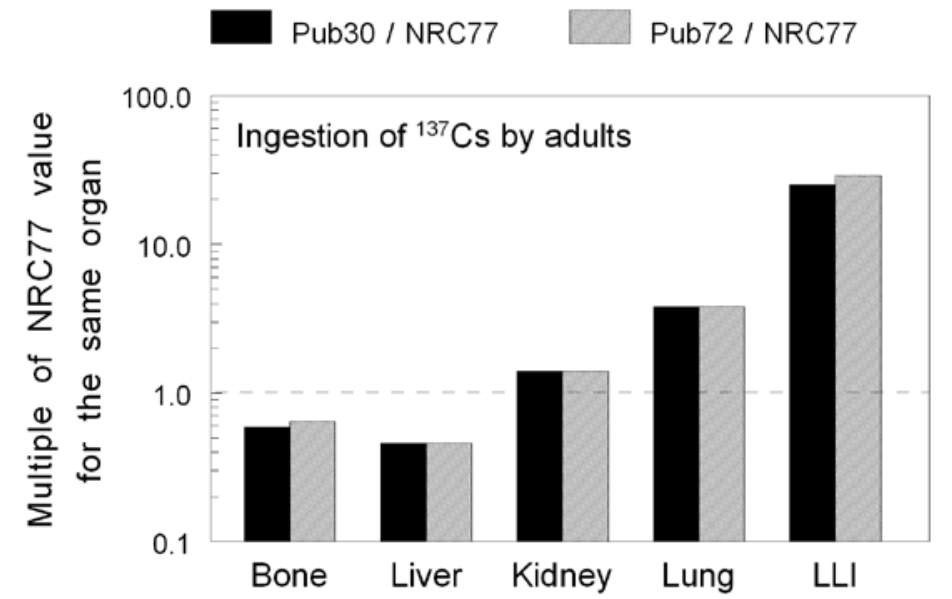

Figure 4.3. For intake of ${ }^{137} \mathrm{Cs}$ in drinking water by an adult, organ dose estimates based on Pub30 and Pub72, as multiples of corresponding values based on NRC77. 
Dose estimates for adults based on Pub30 were found to be broadly consistent with values for adults based on Pub72. Largest relative differences in dose estimates based on Pub30 and Pub72 (factors of 2-6 in a few cases) are due to differences in $\mathrm{f}_{1}$ values, systemic models, or some combination of these in the two. For example, for ${ }^{55} \mathrm{Fe}$ the dose to bone surface based on Pub72 is nearly 6 times higher than the value based on Pub30, resulting mainly from replacement of the systemic biokinetic model of Pub30 with a more detailed and realistic model in Pub72.

Considerably less consistency is found between NRC77 and the later systems. Estimates for some organs based on NRC77 differ by a factor of 10-500 from estimates based on Pub72 or Pub30 for several radionuclides including ${ }^{51} \mathrm{Cr},{ }^{63} \mathrm{Ni},{ }^{95} \mathrm{Zr},{ }^{95} \mathrm{Nb},{ }^{99 \mathrm{~m}} \mathrm{Tc},{ }^{131} \mathrm{I}$, ${ }^{134} \mathrm{Cs},{ }^{137} \mathrm{Cs},{ }^{140} \mathrm{Ba},{ }^{140} \mathrm{La}$, and ${ }^{239} \mathrm{~Np}$. Reasonably good agreement between NRC77 and the later systems is found for some radionuclides, e.g., ${ }^{3} \mathrm{H},{ }^{54} \mathrm{Mn},{ }^{59} \mathrm{Fe}$, and ${ }^{106} \mathrm{Ru}$. In these four cases, dose estimates agree within a factor of two for organs addressed in all three systems.

Factors that contribute to sizable differences in calculated dose for adults based on NRC77 and later systems include:

- differences in $\mathrm{f}_{1}$ values;

- use of more sophisticated systemic biokinetic models in Pub30 and Pub72 than in NRC77;

- use of more sophisticated dosimetric models in Pub30 and Pub72 than in NRC77, including consideration of cross irradiation of tissues and more realistic geometries of organs;

- application of a relative damage factor of 5 in NRC77 for some radionuclides in bone;

- application of an RBE of 1.7 in NRC77 to low-energy beta radiation.

The organ for which calculated doses for adults based on NRC77 are most nearly consistent with estimates based on Pub30 or Pub72 for the full set of radionuclides considered here is the LLI, i.e., the wall of the lower large intestine. Consistency of dose estimates for LLI is an important consideration when comparing the three systems because the LLI appears on the basis of current as well as older models to be the most highly irradiated tissue in many cases of ingestion of radionuclides. For example, for ingestion of ${ }^{239} \mathrm{~Np}$, the large differences in doses estimates to bone, liver, or kidneys based on NRC77 and the later systems may be of little importance for regulatory purposes because the dose estimate for LLI is orders of magnitude greater than dose estimates to those tissues.

The broadly similar estimates of dose to LLI for most of the radionuclides addressed here are attributed mainly to the following factors: (1) reasonably similar GI transit models are used in NRC77 (Figure 2.2) and the later systems (Figure 2.6); (2) assumptions concerning the fraction of emissions from the contents of the GI tract that deposit in the walls of the tract are reasonably consistent across the three dosimetry systems; and (3) the dose to the LLI as estimated by the sophisticated dosimetry systems of Pub30 or Pub72 often is dominated or strongly influenced by emissions in the contents of the LLI. 
The largest discrepancies between NRC77 and later systems in estimated doses to LLI are found for ${ }^{134} \mathrm{Cs}$ and ${ }^{137} \mathrm{Cs}$, for which dose estimates based on Pub30 and Pub72 are 25-32 times higher than estimates based on NRC77. These large discrepancies arise because the absorbed portion of ingested ${ }^{134} \mathrm{Cs}$ or ${ }^{137} \mathrm{Cs}$ is estimated by the Pub30 and Pub72 systems to account for nearly all the dose to the LLI wall. In NRC77 it is assumed that the dose to the LLI wall arises entirely from activity in the LLI contents.

\subsubsection{Inhalation}

Base case dose estimates for an adult were derived using dose coefficients from NRC77, assuming a one-year intake of each radionuclide in air $\left(8000 \mathrm{~m}^{3}\right)$ and an activity concentration of $1 \mathrm{pCi} / \mathrm{m}^{3}\left(0.037 \mathrm{~Bq} / \mathrm{m}^{3}\right)$. Base case dose estimates are listed in Table C.1 of Appendix C. Base case estimates for a given radionuclide are provided for each of the organs addressed in NRC77 for that radionuclide, i.e., for total body, lower large intestine, and some subset of the organs bone, liver, thyroid, kidney, and lung.

The base case dose estimates for each organ addressed in NRC77 were compared with dose estimates for adults based on Pub30 or Pub72. Comparisons for all cases, i.e., all 28 radionuclides and all organs addressed in NRC77 for each of these radionuclides, are listed in Table C.2 of Appendix C. The comparisons are illustrated in Figures 4.4-4.7, which show organ-specific dose estimates based on Pub30 and Pub72 as multiples of the dose estimate for the same organ based on NRC77, for ${ }^{60} \mathrm{Co},{ }^{95} \mathrm{Zr}$, and ${ }^{239} \mathrm{~Np}$, respectively.

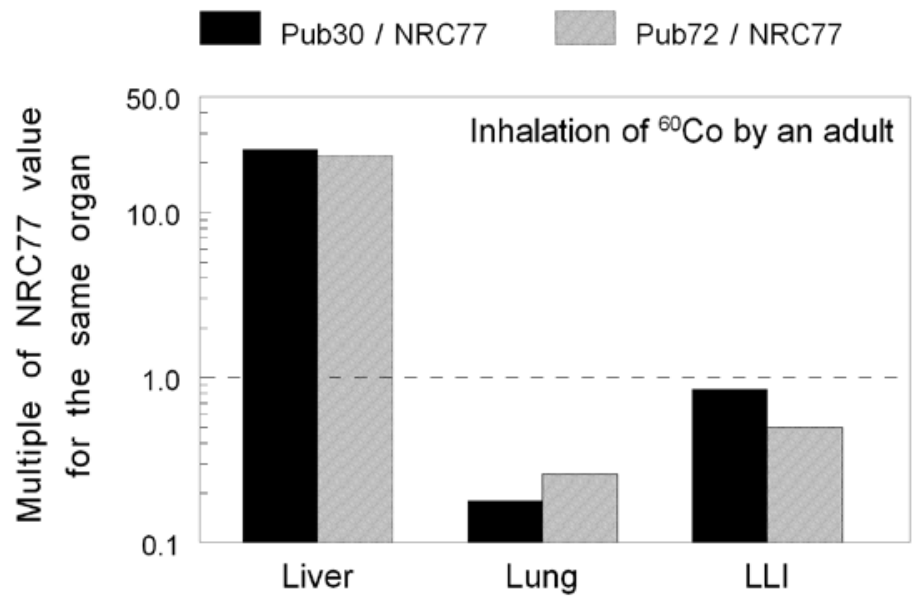

Figure 4.4. For inhalation of ${ }^{60} \mathrm{Co}$ by an adult, organ dose estimates based on Pub30 and Pub72, as multiples of corresponding values based on NRC77. 


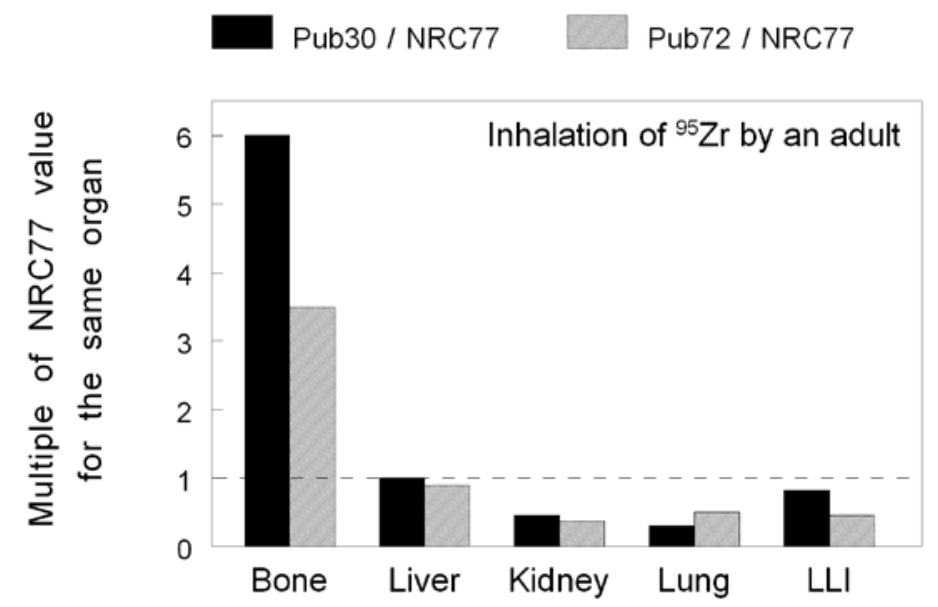

Figure 4.5. For inhalation of ${ }^{95} \mathrm{Zr}$ by an adult, organ dose estimates based on Pub30 and Pub72, as multiples of corresponding values based on NRC77.

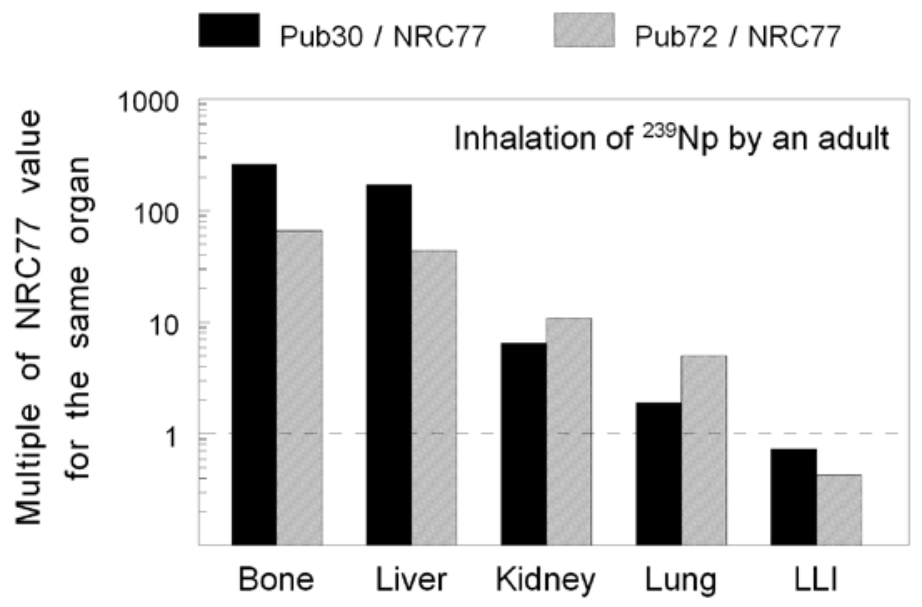

Figure 4.6. For inhalation of ${ }^{239} \mathrm{~Np}$ by an adult, organ dose estimates based on Pub30 and Pub72, as multiples of corresponding values based on NRC77.

In most but not all cases, dose estimates for adults based on Pub30 were broadly consistent with values for adults based on Pub72. The largest relative difference between Pub30 and Pub72 is a 20-fold higher lung dose for ${ }^{140}$ Ba based on Pub72. This large difference results from a mismatch in the solubility types being compared. That is, soluble barium (Class D) was assumed in the Pub30 calculation because this is the only form of inhaled barium addressed in Pub30, while moderately soluble barium (Type M) was assumed in the Pub72 calculation. Otherwise, the largest relative differences in dose estimates based on Pub30 and Pub72 are factors of 3-8 in a few cases, resulting from 
some combination of differences in $\mathrm{f}_{1}$ values, fractional absorption from the respiratory tract to blood, and systemic models in the two systems.

Considerably less consistency is found between NRC77 and the later systems. Estimates for some organs based on NRC77 differ by 2-5 orders of magnitude from estimates based on Pub72 or Pub30 for some radionuclides including ${ }^{14} \mathrm{C},{ }^{63} \mathrm{Ni},{ }^{90} \mathrm{Sr},{ }^{99 \mathrm{~m}} \mathrm{Tc},{ }^{131} \mathrm{I},{ }^{140} \mathrm{Ba}$, ${ }^{140} \mathrm{La}$, and ${ }^{239} \mathrm{~Np}$.

Factors contributing to sizable differences in calculated dose for adults based on NRC77 and later systems include:

- differences in $\mathrm{f}_{1}$ values;

- use of more sophisticated systemic biokinetic models and respiratory model in Pub30 and Pub72 than in NRC77;

- use of more sophisticated dosimetric models in Pub30 and Pub72 than in NRC77, including consideration of cross irradiation of tissues and more realistic geometries of organs;

- application of a relative damage factor of 5 in NRC77 for some radionuclides in bone;

- application of an RBE of 1.7 in NRC77 to low-energy beta radiation.

\subsection{Comparison of age-specific dose estimates}

\subsubsection{Ingestion}

NRC77 provides separate ingestion dose coefficients for the infant, child, teen, and adult. Pub30 provides dose coefficients for the adult only, but these are applied in this report to all four of the NRC77 age groups by multiplying dose coefficients for the adult by agespecific drinking water intake rates. Pub72 provides dose coefficients for six ages, but for purposes of this comparison only four ages at intake are considered: age $100 \mathrm{~d}$, age $5 \mathrm{y}$, age $15 \mathrm{y}$, and adult, corresponding to the infant, child, teen, and adult, respectively, in NRC77.

To examine differences in dose estimates with age group as well as dosimetry system, it is useful to normalize all estimates for a given radionuclide to the dose to the critical organ of the adult (bold-faced values in Table D.1 of Appendix D). For example, all dose estimates for ${ }^{54} \mathrm{Mn}$ are normalized by dividing by the estimated critical organ dose to the adult of $1.0 \times 10^{-2} \mathrm{mrem}\left(1.0 \times 10^{-7} \mathrm{~Sv}\right)$ for LLI based on NRC77. This normalization approach allows the calculation of the relative dose to any of the target tissues considered in Pub30 or Pub72, whether or not the tissue is addressed in a biokinetic model used in NRC77.

The full set of normalized age-specific dose estimates for all 28 radionuclides and all organs considered in NRC77 is given in Table D.3 of Appendix D. Results are illustrated in Figures 4.7-4.11 for selected radionuclides and organs. 
Figure 4.7 compares estimated age-specific doses for ingestion of ${ }^{3} \mathrm{H}$ in drinking water based on NRC77, Pub30, and Pub72. The comparison applies to any organ because ${ }^{3} \mathrm{H}$ ingested as tritiated water is assumed in all three systems to deliver a uniform dose to the body. The comparisons also apply to total body dose based on NRC77, effective dose equivalent based on Pub30, and effective dose based on Pub72, as these values are the same as the dose to any organ due to the assumed uniformity of doses from ${ }^{3} \mathrm{H}$ in each system. Differences in dose estimates based on the three systems are essentially the net result of three factors:

- $\quad$ application of RBE $=1.7$ for low-energy beta radiation in NRC77 compared with a value of 1.0 in Pub30 and Pub72;

- differences in the three biokinetic models, i.e., no age dependence in the biokinetic model of Pub30 and moderately different age-specific biokinetic models in NRC77 and Pub72;

- differences in tissues masses, i.e., use of adult tissue masses for all ages for application of Pub30, and moderately different age-specific tissue masses applied in NRC77 and Pub72.

Because ${ }^{3} \mathrm{H}$ does not emit penetrating radiations, there are no important differences among the three systems in conversion of retained activity to dose.

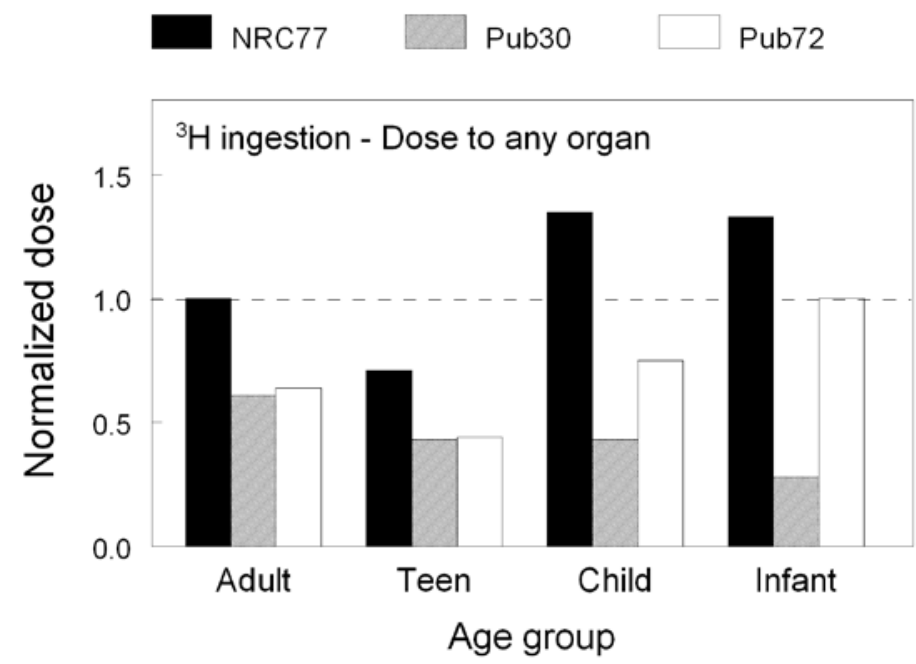

Figure 4.7. Comparison of annual dose estimates to any organ from ingestion of ${ }^{3} \mathrm{H}$ in drinking water based on NRC77, Pub30, and Pub72. Values are normalized to the uniform dose to the adult based on NRC77.

Figure 4.8 compares estimated doses to LLI from intake of ${ }^{60} \mathrm{Co}$ in drinking water based on NCR77, Pub30, and Pub72. Differences in estimated doses following intake by adults result mainly from:

- differences in the fraction of ingested activity assumed to reach the LLI;

- a shorter residence time assigned to the LLI in NRC77 than in Pub30 and Pub72;

- consideration of cross-irradiation of tissues in Pub30 and Pub72 but not in NRC77. 
Differences among the three sets of dose estimates increase with decreasing age because of different patterns of change with age in estimated dose to LLI in the three systems:

- Pub72 predicts increasing dose to LLI with decreasing age as a result agedependent tissue mass but age-independent transit rates through the GI tract.

- Pub30 predicts decreasing estimates of dose to LLI with decreasing age because water intake is assumed to be the only factor that changes with age.

- NRC77 gives decreasing estimates of LLI dose with decreasing age because the assumed decrease in transit time through the LLI at younger ages offsets the assumed decrease in tissue mass, so that water intake also determines the differences with age in estimated LLI doses in this system.

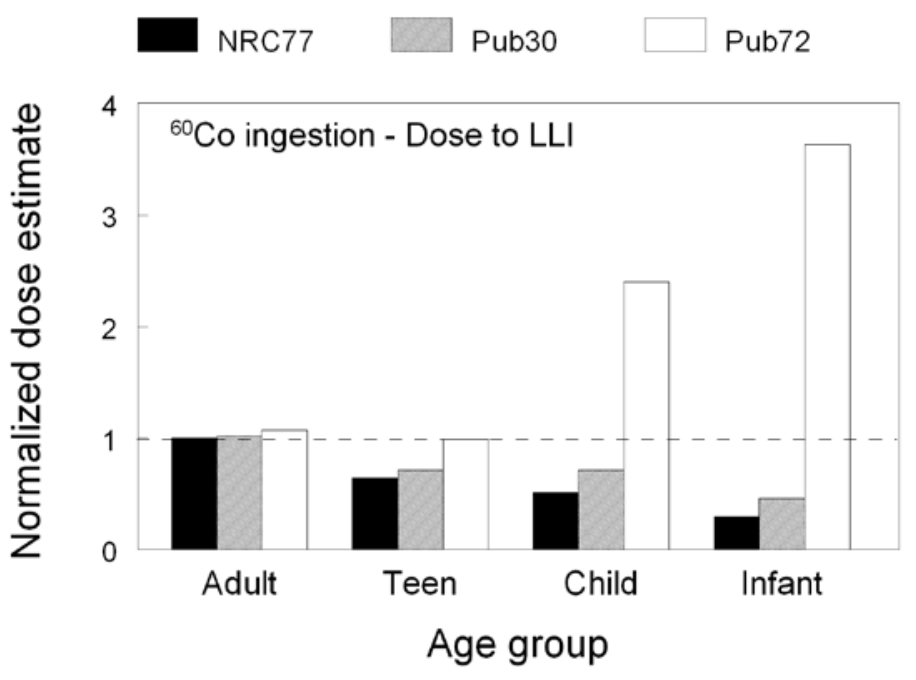

Figure 4.8. Comparison of estimated annual dose to LLI from ingestion of ${ }^{60} \mathrm{Co}$ in drinking water based on NRC77, Pub30, and Pub72. Values are normalized to the dose to the critical organ in the adult based on NRC77 (LLI).

Figure 4.9 compares estimated doses to liver from intake of ${ }^{60} \mathrm{Co}$ in drinking water based on NRC77, Pub30, and Pub72. Differences in estimates based on Pub30 and Pub72 result mainly from the following factors:

- higher gastrointestinal absorption fractions ( $\mathrm{f}_{1}$ values) for cobalt in Pub72;

- application of age-dependent organ masses in Pub72.

Differences in dose estimates based on NRC77 and Pub72 are mainly the net result of the following factors:

- the Pub72 biokinetic model has a long retention component (800 d) in liver, while the NRC77 model predicts relatively fast turnover of cobalt by the liver;

- Pub72 addresses cross irradiation of tissues, but NRC77 does not;

- different $\mathrm{f}_{1}$ values are applied. 


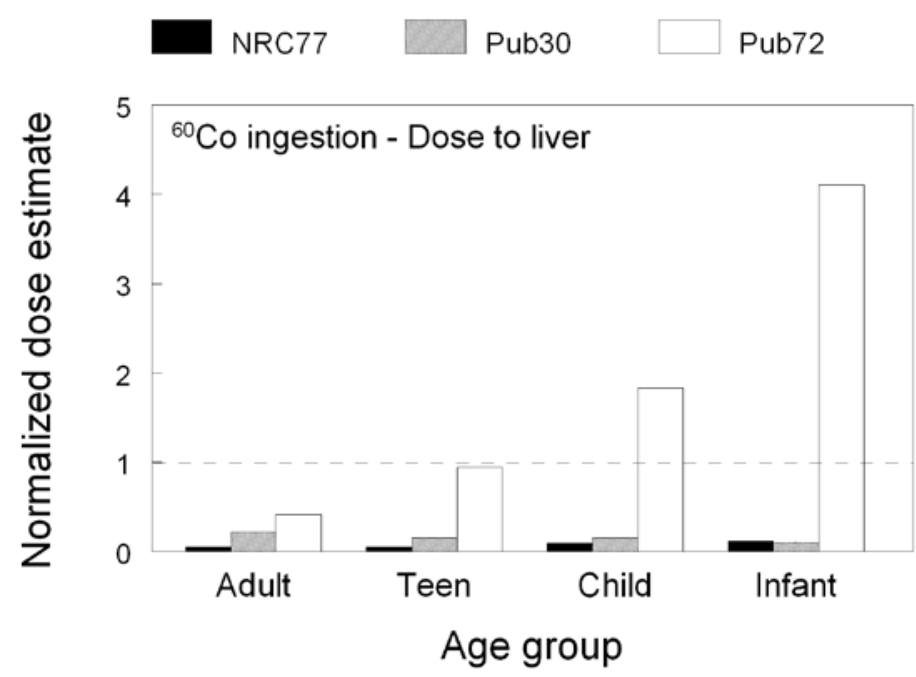

Figure 4.9. Comparison of estimated annual dose to liver from ingestion of ${ }^{60} \mathrm{Co}$ in drinking water based on NRC77, Pub30, and Pub72. Values are normalized to the dose to the critical organ in the adult (LLI) based on NRC77.

Figure 4.10 compares estimated doses to bone tissues (bone in NRC77 and bone surface in Pub30 or Pub72) from intake of ${ }^{63} \mathrm{Ni}$ in drinking water. NRC77 predicts much higher doses to bone tissues than Pub72 and Pub30 mainly because:

- the biokinetic model for nickel in NRC77 depicts high uptake by bone, while the Pub30 and Pub72 models do not single out bone as an important repository for nickel;

- NRC77 assigns a "relative damage factor" of 5 to bone for pure beta emitters, including ${ }^{63} \mathrm{Ni}$;

- Pub30 does not address changes with age in tissue masses. Because ${ }^{63} \mathrm{Ni}$ does not emit penetrating radiations, there are no important differences among the three dosimetry systems in conversion of retained activity to bone dose in this case. For example, the assumed shape of bone is irrelevant, and there is no cross irradiation from other tissues. 


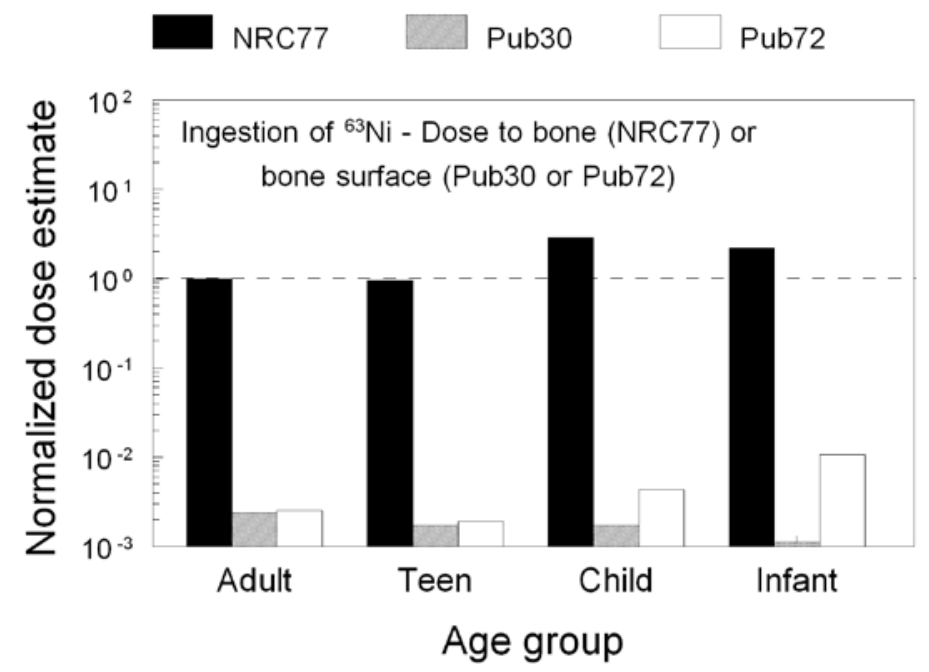

Figure 4.10. Comparison of annual dose estimates from ingestion of ${ }^{63} \mathrm{Ni}$ in drinking water based on NRC77 (bone), Pub30 (bone surface), and Pub72 (bone surface). Values are normalized to the dose to the critical organ in the adult (bone) based on NRC77.

Figure 4.11 compares estimated doses to thyroid from intake of ${ }^{131}$ I in drinking water based on NCR77, Pub30, and Pub72. The three systems give reasonably similar estimates for adults and teens, and NRC77 and Pub72 give similar estimates for all four age groups. For the adult and teen the reasonable agreement in dose estimates results mainly from:

- the assumption of complete absorption of iodine to blood in all three systems;

- assignment of a deposition fraction of 0.3 to thyroid in all three systems;

- in all three systems, assignment of a biological half-time to thyroid that is long compared with the radiological half-life of ${ }^{131} \mathrm{I}(\sim 8 \mathrm{~d})$, so that the number of decays in the thyroid is broadly similar for each systems

- assignment of reasonably similar values for thyroid mass in all three systems. The first two factors (complete absorption and a deposition fraction of 0.3 ) also apply to the child and infant, but in these two cases the biological half-times in NRC77 and Pub72 are of the same order as the 8-d radiological half-time of ${ }^{131} \mathrm{I}$ (e.g., for the infant, $20 \mathrm{~d}$ in NRC77 and $11.2 \mathrm{~d}$ in Pub72) and the assigned thyroid masses are noticeably different in these two systems (e.g., for the infant, $2 \mathrm{~g}$ in NRC77 and $1.29 \mathrm{~g}$ in Pub72). For these ages the reasonable agreement in estimated doses to the thyroid based on NRC77 and Pub72 is due partly to offsetting differences in biological half-times and thyroid masses in the two systems. The large discrepancies between Pub30 and the other two systems for the child and infant mainly result from the age-independent biokinetics and organ masses in Pub30. 


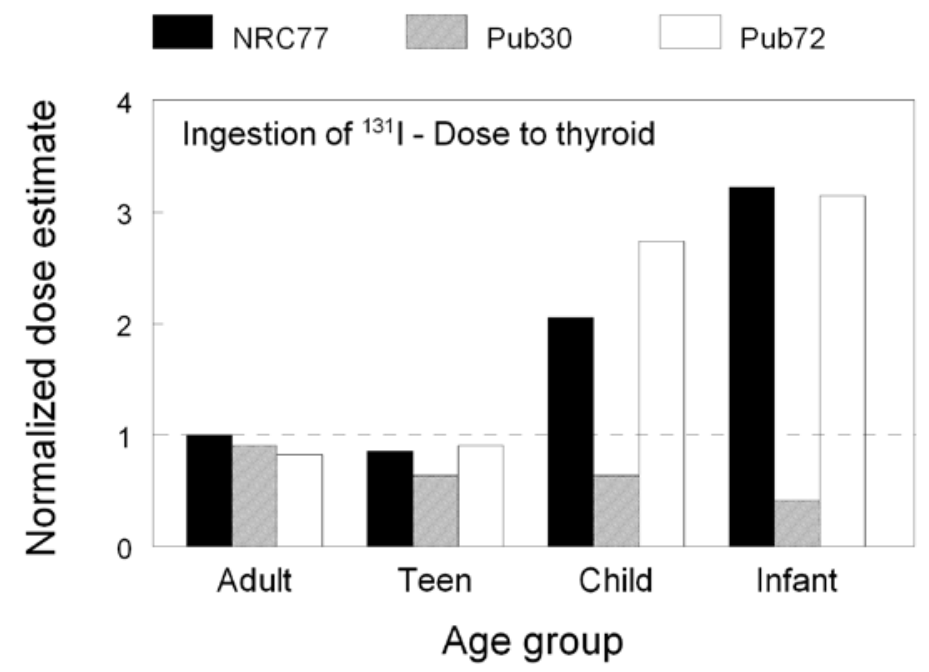

Figure 4.11. Comparison of estimates of dose to thyroid from ingestion of
${ }_{131}$ I in drinking water based on NRC77, Pub30, and Pub72. Values are
normalized to the dose to thyroid in the adult based on NRC77.

Pub30 rarely yields the highest dose estimates of the three systems for any radionuclide or organ (Appendix D, Table D.1). For each of the 28 radionuclides addressed, either NRC77 or Pub72, or both systems, give a higher maximum organ dose across all ages than does Pub30. Also, for every radionuclide addressed, the maximum effective dose $\mathrm{E}$ based on Pub72 is higher than the maximum effective dose equivalent $\mathrm{H}_{\mathrm{E}}$ based on Pub30. In the following, comparisons of age-specific dose estimates for individual radionuclides are restricted to NRC77 and Pub72.

\subsubsection{Inhalation}

As in the analysis for drinking water, comparison of age-specific dose estimates based on the different systems was facilitated by normalization of all dose estimates for a given inhaled radionuclide to the dose to the critical organ of the adult (bold-faced values in Table E.1 of Appendix E). The full set of normalized age-specific dose estimates for all 28 radionuclides and all organs considered in NRC77 is given in Table E.3 of Appendix E. Results are illustrated in Figures 4.12-4.16 for selected radionuclides and organs.

Figure 4.12 compares estimated age-specific doses for inhalation of ${ }^{3} \mathrm{H}$ based on NRC77, Pub30, and Pub72. The comparison applies to any organ because ${ }^{3} \mathrm{H}$ inhaled as tritiated water is assumed in all three systems to deliver a uniform dose to the body. Differences in dose estimates based on the three systems are mainly the net result of the following factors:

- inclusion of skin absorption of ${ }^{3} \mathrm{H}$ in the inhalation dose coefficient of NRC77 (representing a 50\% increase in dose over the inhaled amount alone) but not in the inhalation dose coefficients of Pub30 or Pub72; 
- application of RBE $=1.7$ for low-energy beta radiation in NRC77 compared with $\mathrm{RBE}=1.0$ in Pub30 and Pub72;

- differences in the three biokinetic models, i.e., no age dependence in the biokinetic model of Pub30 and moderately different age-specific biokinetic models in NRC77 and Pub72;

- differences in tissues masses, i.e., use of adult tissue masses for all ages for application of Pub30, and moderately different age-specific tissue masses applied in NRC77 and Pub72.

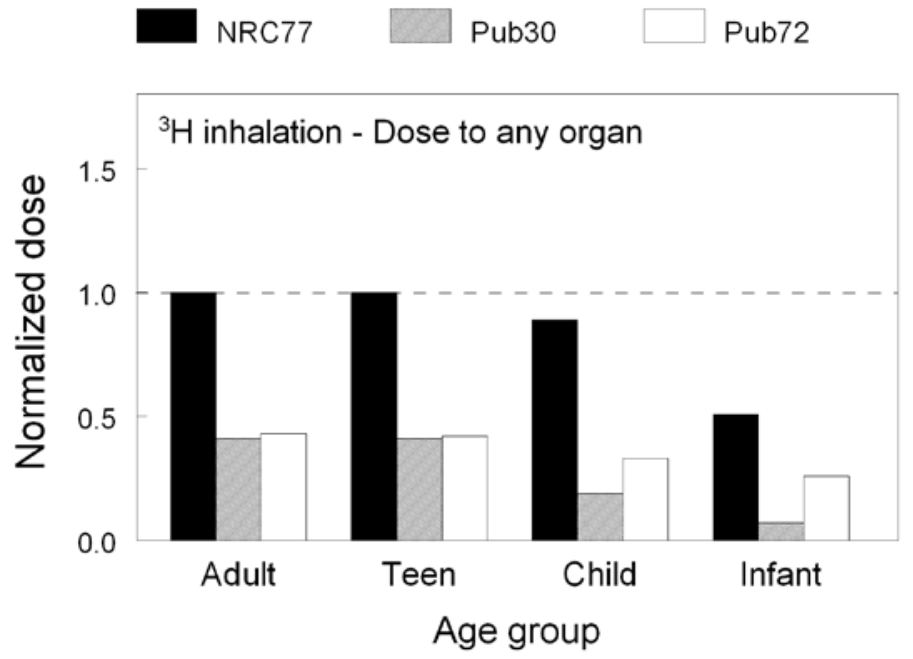

\section{Figure 4.12. Comparison of annual dose estimates to any organ from inhalation of ${ }^{3} \mathrm{H}$ based on NRC77, Pub30, and Pub72. Values are normalized to the uniform dose to the adult based on NRC77.}

Figure 4.13 compares estimated age-specific lung doses from inhalation of ${ }^{60} \mathrm{Co}$ based on NCR77, Pub30, and Pub72. As discussed earlier, NRC77 provides only one set of inhalation dose coefficients for each radionuclide while Pub30 and Pub72 generally provide multiple sets of inhalation dose coefficients corresponding to different forms of the radionuclide. The forms of ${ }^{60} \mathrm{Co}$ chosen from Pub30 and Pub72 for comparison of dose estimates across the three systems are Class $\mathrm{W}$ and Type $\mathrm{M}$, respectively, i.e., moderately soluble forms of ${ }^{60} \mathrm{Co}$. For any age group the estimated annual dose to lungs based on Pub30 or Pub72 for moderately soluble forms of ${ }^{60} \mathrm{Co}$ is substantially lower than estimated lung doses based on NRC77. Differences between NRC77 and Pub30 in dose estimates result mainly from:

- a shorter removal half-time from deep lungs (a few weeks for Class W material) in Pub30 than in NRC77 (120 d);

- lack of age-specific biokinetics and dosimetry in Pub30.

Differences between NRC77 and Pub72 in dose estimates result mainly from:

- relatively low deposition in the long-term compartment of deep lungs in the Pub72 model; 
- differences in the way that lung dose is calculated in NRC77 and Pub72 (uniform dose to lung tissue in NRC77 and a weighted sum of doses to different regions of the lungs in Pub72.

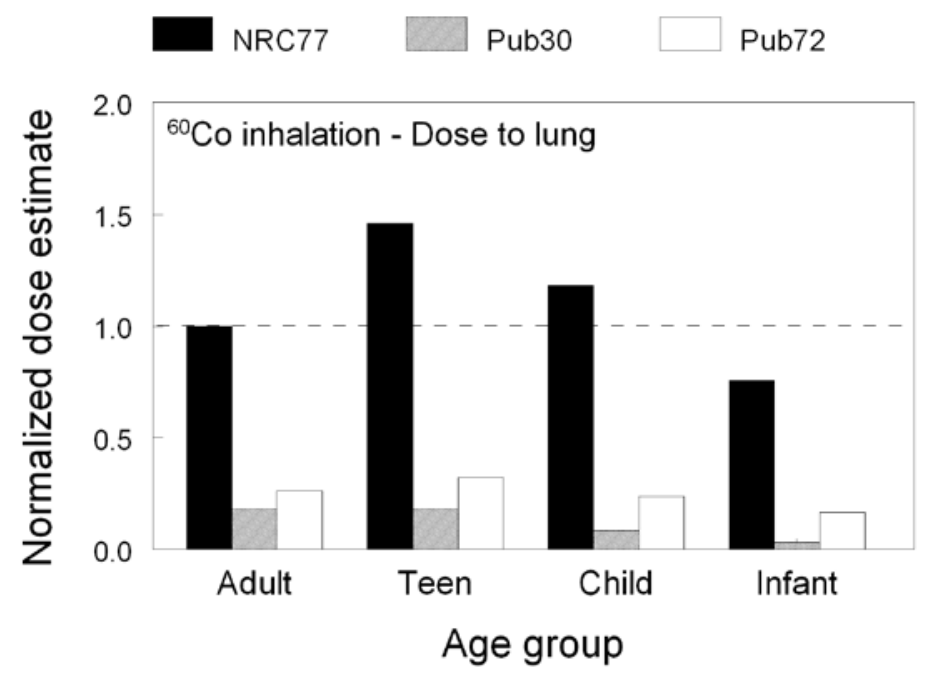

Figure 4.13. Comparison of estimated annual dose to lung from inhalation of ${ }^{60} \mathrm{Co}$ based on NRC77, Pub30 (Class W, $1 \mu \mathrm{m}$ AMAD), and Pub72 (Type M, $1 \mu \mathrm{m}$ AMAD). Values are normalized to the dose to the critical organ in the adult (lung) based on NRC77.

Figure 4.14 compares doses to liver following inhalation of ${ }^{60}$ Co based on NRC77, Pub30, and Pub72. Differences in estimates based on Pub30 and Pub72 result mainly from the application of age-dependent organ masses in Pub72. Differences in dose estimates based on NRC77 and Pub72 result mainly from the following factors:

- the Pub72 biokinetic model has a long retention component (800 d) in liver, while the NRC77 model predicts relatively fast turnover of cobalt by the liver;

- Pub72 addresses cross irradiation of tissues, but NRC77 does not;

- different $\mathrm{f}_{1}$ values are applied. 


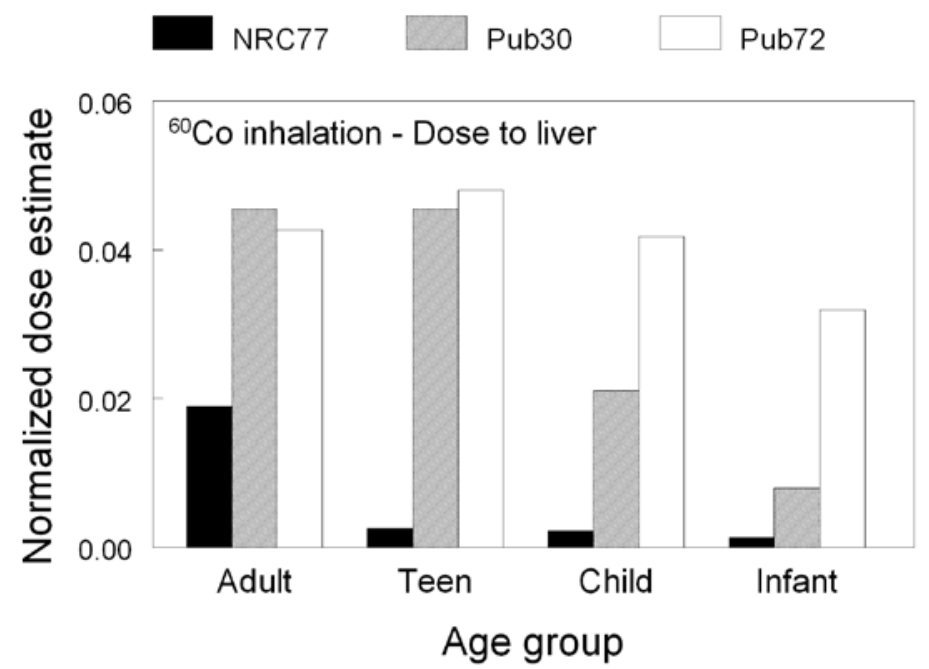

Figure 4.14. Comparison of estimated annual dose to liver from inhalation of ${ }^{60} \mathrm{Co}$ based on NRC77, Pub30 (Class W, $1 \mu \mathrm{m}$ AMAD), and Pub72 (Type M, $1 \mu \mathrm{m}$ AMAD). Values are normalized to the dose to the critical organ in the adult (lung) based on NRC77.

Figure 4.15 compares lung dose from inhalation of ${ }^{239} \mathrm{~Np}$ based on NRC77, Pub30, and Pub72. The forms of ${ }^{239} \mathrm{~Np}$ chosen from Pub30 and Pub72 for comparison of inhalation doses with NRC77 are Class W and Type M, respectively, i.e., moderately soluble forms of ${ }^{239} \mathrm{~Np}$. Estimates based on Pub72 are much higher than estimates based on NRC77 or Pub30. This differs from the pattern discussed above for inhalation of a moderately soluble form of ${ }^{60} \mathrm{Co}$, for which estimated annual lung doses based on either Pub30 or Pub72 are substantially lower than estimates based on NRC77. The different pattern for ${ }^{239} \mathrm{~Np}$ results mainly from its short physical half-life of $2.36 \mathrm{~d}$. For short-lived radionuclides inhaled in moderately soluble or relatively insoluble form, the Pub72 respiratory model (HRTM) typically yields higher dose estimates than the Pub30 model (TGLM) or NRC77 model because:

- lung dose as defined in the HRTM is a weighted sum of doses to different regions of the lung;

- the HRTM predicts a relatively long retention time of material in the small mass of sensitive tissue in the bronchi and bronchioles, which are given high weight in the dose calculation;

- lung dose calculations based on the TGLM and model of NRC77 assume uniform distribution of activity throughout the lung mass. 


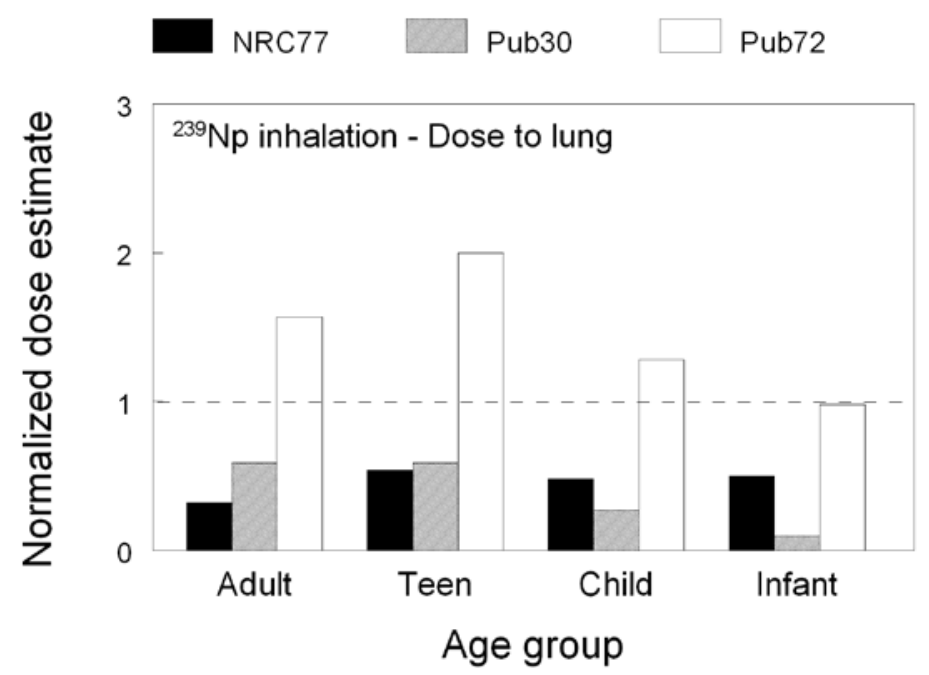

Figure 4.15. Comparison of estimated annual dose to lung from inhalation of ${ }^{239} \mathrm{~Np}$ based on NRC77, Pub30 (Class W, $1 \mu \mathrm{m}$ AMAD ), and Pub72 (Type M, $1 \mu \mathrm{m}$ AMAD). Values are normalized to the dose to the critical organ in the adult (LLI) based on NRC77.

Figure 4.16 compares dose to liver from inhalation of ${ }^{239} \mathrm{~Np}$ based on NRC77, Pub30, and Pub72. NRC77 predicts much lower dose to liver than either Pub30 or Pub72 due mainly to two factors:

- larger fractional transfer from lungs and gastrointestinal tract to blood in Pub30 and Pub72 than in NRC77;

- consideration of cross irradiation of tissues in Pub30 and Pub72 but not in NRC77.

Regarding the second factor, the Pub30 and Pub72 dosimetric models predict that penetrating radiations emitted from the contents of the gastrointestinal tract and respiratory tract contribute significantly to the total dose received from inhaled ${ }^{239} \mathrm{~Np}$. 


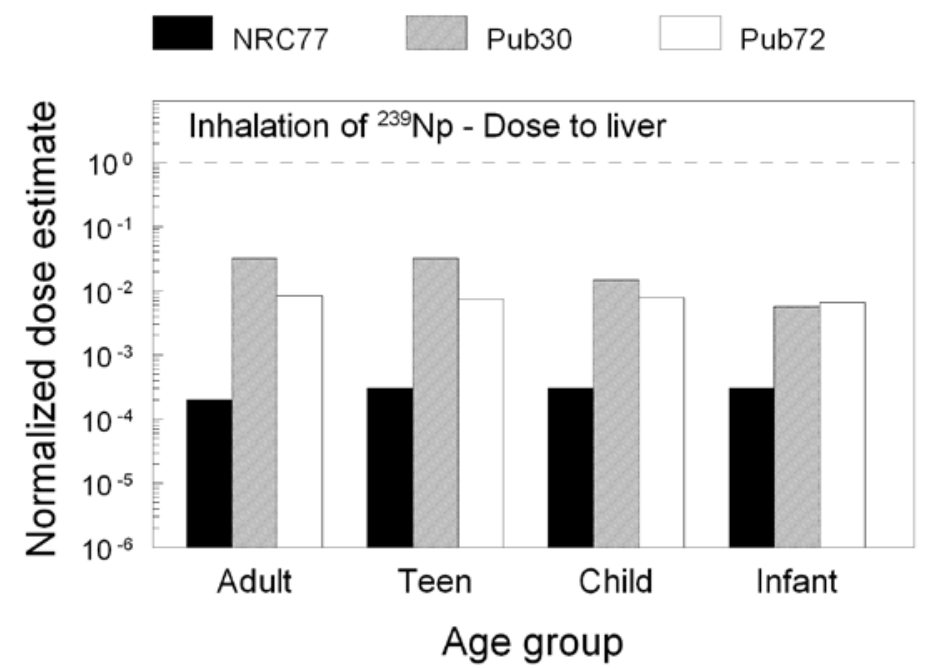

Figure 4.16. Comparison of estimated annual dose to liver from inhalation of ${ }^{239} \mathrm{~Np}$ based on NRC77, Pub30 (Class W, $1 \mu \mathrm{m}$ AMAD ), and Pub72 (Type M, $1 \mu \mathrm{m}$ AMAD). Values are normalized to the dose to the critical organ in the adult (LLI) based on NRC77.

\subsection{Comparison of key dose quantities}

\subsubsection{Ingestion}

Table 4.1 compares maximum organ doses across all ages for intake of individual radionuclides in drinking water based on the two age-dependent dosimetry systems, NRC77 and Pub72. The maximum organ dose based on Pub72 refers to the maximum for all organs addressed in Pub72 rather than just the maximum over the smaller set of organs addressed in NRC77. Organ doses for a given radionuclide based on either NRC77 or Pub72 are normalized to the dose to the critical organ of the adult based on NRC77. For example, for ingestion of ${ }^{55} \mathrm{Fe}$ in drinking water: the table entry in the second column of Table 4.1 indicates that the maximum organ dose based on NRC77 is for intake by a child and is 2.92 times the dose to the critical organ of the adult based on NRC77; the value in the third column indicates that the highest organ dose based on Pub72 is to the spleen (an organ not addressed in NRC77) in the infant and is 30 times the dose to the critical organ of the adult based on NRC77; and the value in the fourth column is the ratio of values in columns three (Pub72) and two (NRC77): 30/2.92 = 10 (rounded to two significant digits). Pub72 gives a higher maximum organ dose for 18 of the 28 radionuclides. The ratio Pub72 : NRC77 ranges from 0.04 to 10 . The ratios Pub72 : NRC77 for the 28 individual radionuclides are shown in increasing order in Figure 4.17. 


\begin{tabular}{|c|c|c|c|}
\hline Radionuclide & NRC77 & Pub72 & $\begin{array}{c}\text { Ratio } \\
\text { Pub72 : NRC77 }\end{array}$ \\
\hline $\mathrm{H}-3$ & 1.35 (Child, All) & 1.00 (Infant, All) & 0.74 \\
\hline C-14 & 3.77 (Infant, Bone) & 0.88 (Child, All) & 0.23 \\
\hline P-32 & 3.98 (Infant, Bone) & 1.43 (Infant, Red marrow) & 0.36 \\
\hline Cr-51 & 1.00 (Adult, LLI) & 7.18 (Infant, LLI) & 7.2 \\
\hline$M n-54$ & 1.00 (Adult, LLI) & 1.85 (Infant, LLI) & 1.9 \\
\hline Fe-55 & 2.92 (Child, Bone) & 30.0 (Infant, Spleen) & 10 \\
\hline Fe-59 & 1.00 (Adult, LLI) & 6.30 (Infant, Spleen) & 6.3 \\
\hline Co-58 & 1.00 (Adult, LLI) & 2.32 (Infant, LLI) & 2.3 \\
\hline Co-60 & 1.00 (Adult, LLI) & 4.11 (Infant, Liver) & 4.1 \\
\hline $\mathrm{Ni}-63$ & 2.89 (Child, Bone) & 0.13 (Infant, LLI) & 0.04 \\
\hline Cu-64 & 1.13 (Child, LLI) & 0.99 (Child, LLI) & 0.88 \\
\hline Zn-65 & 1.85 (Infant, Liver) & 5.65 (Infant, Bone Surf) & 3.1 \\
\hline Sr-89 & 1.57 (Child, Bone) & 0.88 (Teen, Bone Surf) & 0.56 \\
\hline Sr-90 & 1.57 (Child, Bone) & 0.62 (Teen, Bone Surf) & 0.40 \\
\hline Y-90 & 1.00 (Adult, LLI) & 5.93 (Infant, LLI) & 5.9 \\
\hline Zr-95 & 1.00 (Adult, LLI) & 4.22 (Infant, LLI) & 4.2 \\
\hline $\mathrm{Nb}-95$ & 1.00 (Adult, LLI) & 2.81 (Infant, LLI) & 2.8 \\
\hline Mo-99 & 2.30 (Infant, Kidney) & 4.02 (Infant, Liver) & 1.8 \\
\hline Tc-99m & 1.74 (Child, LLI) & 5.19 (Infant, Thyroid) & 3.0 \\
\hline Ru-106 & 1.00 (Adult, LLI) & 7.43 (Infant, LLI) & 7.4 \\
\hline $\mathrm{Ag}-110 \mathrm{~m}$ & 1.00 (Adult, LLI) & 2.58 (Infant, LLI) & 2.58 \\
\hline I-131 & 3.22 (Infant, Thyroid) & 3.14 (Infant, Thyroid) & 0.98 \\
\hline $\mathrm{I}-133$ & 4.12 (Infant, Thyroid) & 4.43 (Infant, Thyroid) & 1.08 \\
\hline Cs-134 & 2.15 (Infant, Liver) & 0.57 (Adult, LLI) & 0.26 \\
\hline Cs-137 & 2.53 (Infant, Liver) & 0.74 (Infant, LLI) & 0.29 \\
\hline Ba-140 & 1.85 (Infant, Bone) & 8.85 (Infant, LLI) & 4.8 \\
\hline La-140 & 1.00 (Adult, LLI) & 3.31 (Infant, LLI) & 3.3 \\
\hline Np-239 & 1.00 (Adult, LLI) & 6.82 (Infant, LLI) & 6.8 \\
\hline
\end{tabular}




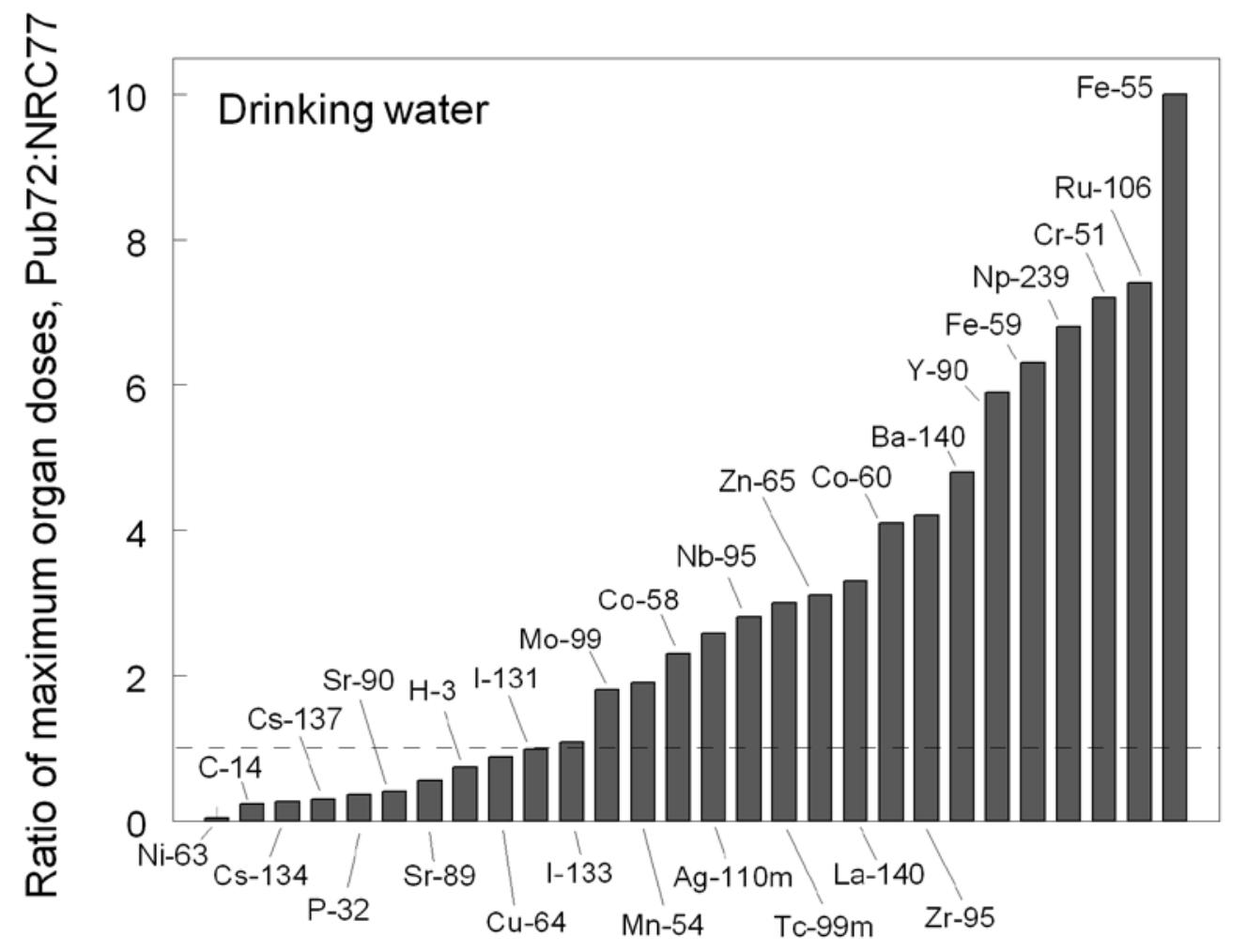

Figure 4.17. For ingestion of radionuclides in drinking water, comparison of maximum organ doses across all age groups based on NRC77 and Pub72.

Table 4.2 compares the maximum total body dose based on NRC77 with the maximum effective dose based on Pub72 for ingestion of individual radionuclides in drinking water. Dose values for a given radionuclide are normalized to the dose to the critical organ of the adult based on NRC77. For example, for ingestion of ${ }^{55} \mathrm{Fe}$ in drinking water: the table entry in the second column of Table 4.2 indicates that the maximum total body dose based on NRC77 is for intake by a child and is 0.48 times the dose to the critical organ of the adult based on NRC77; the value in the third column indicates that the highest effective dose based on Pub72 is for intake by an infant and is 4.56 times the dose to the critical organ of the adult based on NRC77; and the value in the fourth column is the ratio of values in columns three (Pub72) and two (NRC77): 4.56/0.48 =9.5. The ratios for individual radionuclides are shown in increasing order in Figure 4.18.

In most cases, the maximum effective dose based on Pub72 is greater than the maximum total body dose based on NRC77. The two values are reasonably similar for radionuclides that are assumed in both systems to be completely absorbed to blood and fairly uniformly distributed in the body (e.g. ${ }^{3} \mathrm{H}$ or ${ }^{137} \mathrm{Cs}$ ) but are not closely related for poorly absorbed or non-uniformly distributed radionuclides (e.g., ${ }^{95} \mathrm{Zr}$ or ${ }^{239} \mathrm{~Np}$ ). 


\begin{tabular}{|c|c|c|c|}
\hline \multicolumn{4}{|c|}{$\begin{array}{l}\text { Table 4.2. For ingestion of individual radionuclides in drinking water, } \\
\text { maximum total body doses based on NRC77 and maximum effective dose } \\
\text { based on Pub72. Dose values for a give radionuclide are normalized to the } \\
\text { dose to the critical organ of the adult based on NRC77. }\end{array}$} \\
\hline Radionuclide & $\begin{array}{l}\text { Highest total body } \\
\text { dose for any age group } \\
\text { based on NRC } 77\end{array}$ & $\begin{array}{l}\text { Highest effective dose } \\
\text { for any age group } \\
\text { based on Pub72 }\end{array}$ & $\begin{array}{l}\text { Ratio } \\
\text { Pub72 : NRC77 }\end{array}$ \\
\hline $\mathrm{H}-3$ & 1.35 (Child) & 1.00 (Infant) & 0.74 \\
\hline C-14 & 0.81 (Infant) & 0.88 (Child) & 1.1 \\
\hline $\mathrm{P}-32$ & 0.15 (Infant) & 0.27 (Infant) & 1.8 \\
\hline Cr-51 & 0.01 (Infant) & 0.86 (Infant) & 91 \\
\hline $\mathrm{Mn}-54$ & 0.15 (Infant) & 0.66 (Infant) & 4.5 \\
\hline Fe-55 & 0.48 (Child) & 4.56 (Infant) & 9.5 \\
\hline Fe-59 & 0.28 (Infant) & 1.94 (Infant) & 6.9 \\
\hline Co-58 & 0.27 (Infant) & 0.81 (Infant) & 3.1 \\
\hline Co-60 & 0.29 (Infant) & 2.26 (Infant) & 7.9 \\
\hline $\mathrm{Ni}-63$ & 0.10 (Child) & 0.02 (Infant) & 0.20 \\
\hline Cu-64 & 0.02 (Infant) & 0.15 (Child) & 8.6 \\
\hline Zn-65 & 1.03 (Child) & 3.95 (Infant) & 3.8 \\
\hline Sr-89 & 0.11 (Infant) & 0.20 (Infant) & 1.8 \\
\hline Sr-90 & 0.40 (Child) & 0.05 (Infant) & 0.13 \\
\hline Y-90 & 0.00001 (Infant) & 0.51 (Infant) & 50,000 \\
\hline Zr-95 & 0.0005 (Infant) & 0.46 (Infant) & 890 \\
\hline $\mathrm{Nb}-95$ & 0.0002 (Infant) & 0.36 (Infant) & 1700 \\
\hline Mo-99 & 0.30 (Infant) & 0.92 (Infant) & 3.1 \\
\hline Tc-99m & 0.06 (Infant) & 0.83 (Infant) & 15 \\
\hline Ru-106 & 0.01 (Infant) & 0.79 (Infant) & 100 \\
\hline $\mathrm{Ag}-110 \mathrm{~m}$ & 0.0036 (Infant) & 0.67 (Infant) & 190 \\
\hline $\mid-131$ & 0.004 (Infant) & 0.16 (Infant) & 37 \\
\hline I-133 & 0.0066 (Infant) & 0.23 (Infant) & 34 \\
\hline Cs-134 & 0.82 (Adult) & 0.48 (Adult) & 0.59 \\
\hline Cs-137 & 0.66 (Adult) & 0.46 (Adult) & 0.71 \\
\hline Ba-140 & 0.10 (Infant) & 1.27 (Infant) & 13 \\
\hline La-140 & 0.00001 (Infant) & 0.35 (Infant) & 34,000 \\
\hline Np-239 & 0.00001 (Infant) & 0.62 (Infant) & 58,000 \\
\hline
\end{tabular}




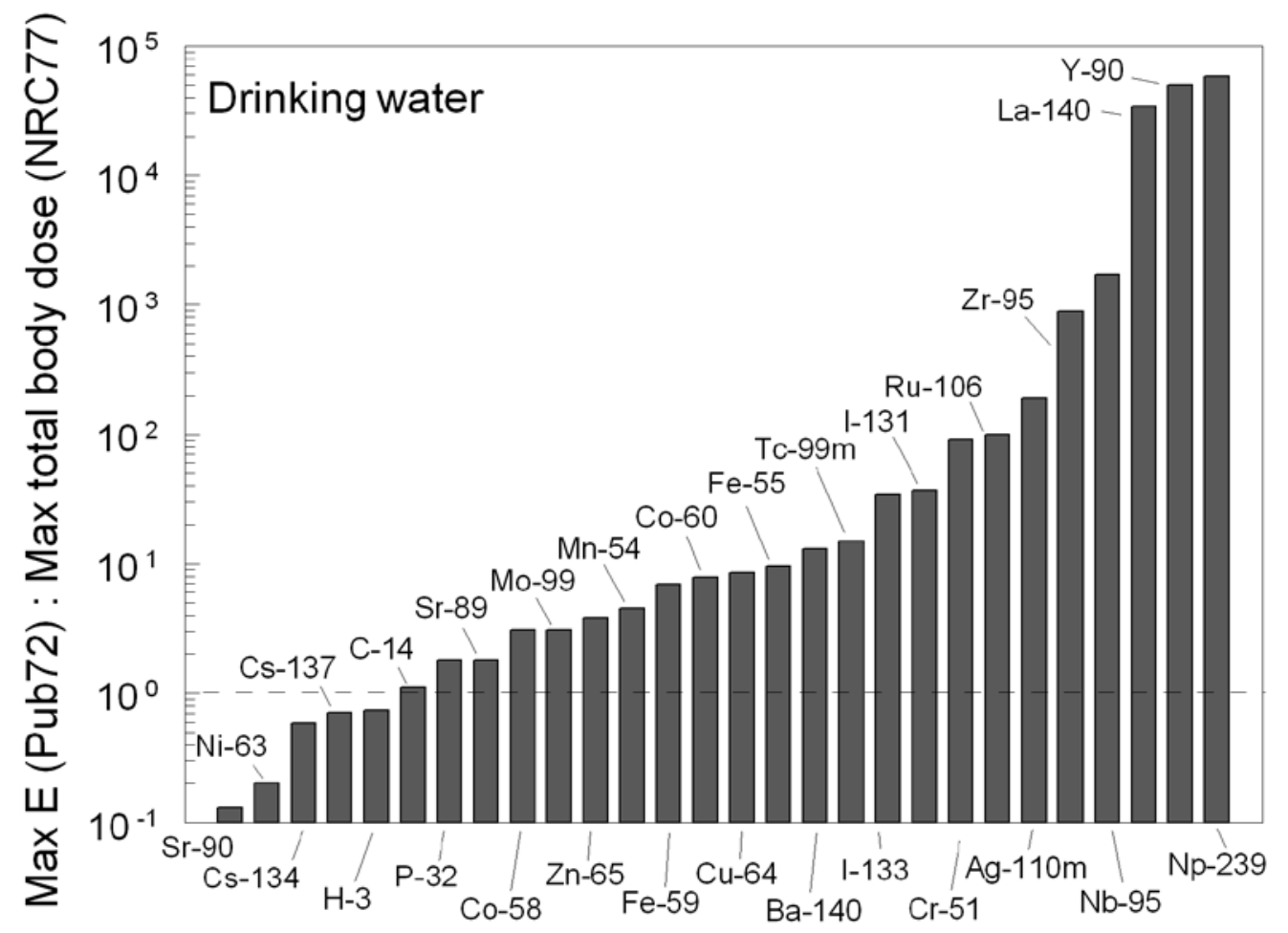

Figure 4.18. For ingestion of radionuclides in drinking water, ratio of maximum effective dose E (Pub72) to maximum total body dose (NRC77).

Comparisons of dose estimates were also made in terms of the primary dose quantities in NRC77 and Pub72. That is, for intake of each of the 28 radionuclides in drinking water, the maximum dose to the critical organ across all age groups based on NRC77 was compared with the maximum effective dose E across all age groups based on Pub72. Results are summarized in Figure 4.19. For 24 of the 28 radionuclides the maximum critical organ dose based on NRC77 was greater than the maximum effective dose E based on Pub72. For the other four radionuclides the maximum effective dose E based on Pub72 was 1.6 to 2.3 times the maximum critical organ dose based on NRC77. 


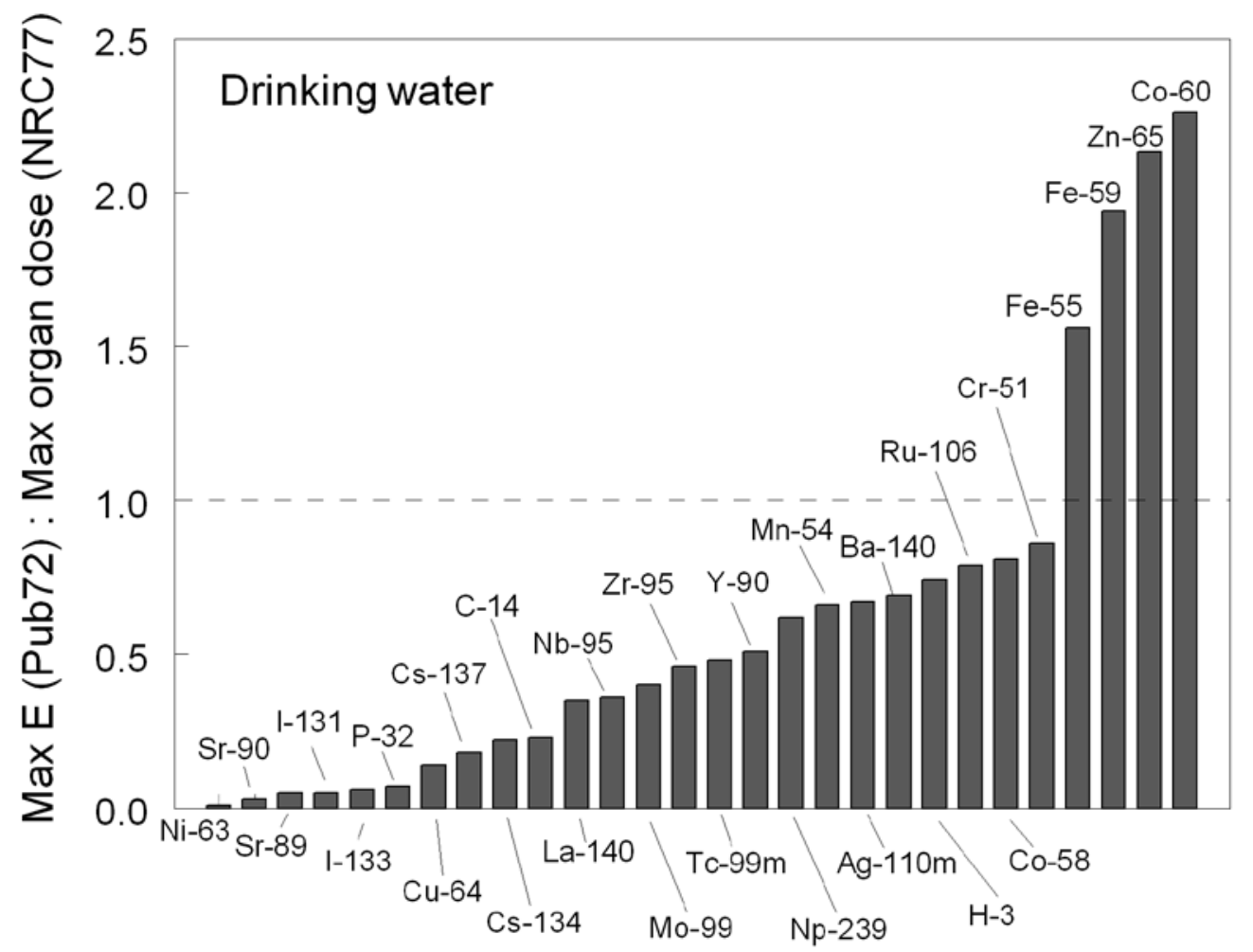

Figure 4.19. For ingestion of radionuclides in drinking water, the ratio of the maximum effective dose $\mathrm{E}$ (Pub72) to the maximum critical organ dose (NRC77).

\subsubsection{Inhalation}

Table 4.3 compares maximum organ doses across all age groups for inhalation of individual radionuclides in drinking water based on the two age-dependent dosimetry systems NRC77 and Pub72. The maximum organ dose based on Pub72 refers to the maximum for all organs addressed in Pub72 rather than just the maximum over the smaller set of organs addressed in NRC77. Organ doses for a given radionuclide based on either NRC77 or Pub72 are normalized to the dose to the critical organ of the adult based on NRC77. For example, for inhalation of ${ }^{137} \mathrm{Cs}$ : the table entry in the second column indicates that the maximum organ dose based on NRC77 is the dose to bone from intake by a child and is 1.46 times the dose to the critical organ of the adult based on NRC77; the value in the third column indicates that the highest organ dose based on Pub72 is to the LLI in the adult and is 0.27 times the dose to the critical organ of the adult based on NRC77; and the value in the fourth column is the ratio of values in columns three (Pub72) and two (NRC77): 0.27/1.46 =0.18. (The ratios were calculated before rounding and are not reproduced precisely in some cases by the quotient of the the rounded values shown in the table.) NRC77 gives a higher maximum organ dose than Pub72 for 27 of the 28 radionuclides. The ratio NRC77 : Pub72 ranges from 0.005 to 1.8. The ratios Pub72 : NRC77 for the 28 individual radionuclides are shown in increasing order in Figure 4.20. 


\begin{tabular}{|c|c|c|c|}
\hline \multicolumn{4}{|c|}{$\begin{array}{l}\text { Table 4.3. For inhalation of individual radionuclides, comparison of } \\
\text { maximum organ doses based on NRC77 and Pub72. Organ doses for a } \\
\text { given radionuclide are normalized to the dose to the critical organ of the } \\
\text { adult based on NRC77. }\end{array}$} \\
\hline \multirow[b]{2}{*}{ Radionuclide } & \multicolumn{2}{|c|}{ Highest organ dose for any age group } & \multirow{2}{*}{$\begin{array}{c}\text { Ratio } \\
\text { Pub72 : NRC77 }\end{array}$} \\
\hline & NRC77 & Pub72 & \\
\hline $\mathrm{H}-3$ & 1.01 (Teen, All) & 0.43 (Infant, All) & 0.43 \\
\hline C-14 & 1.98 (Child, Bone) & 0.01 (Adult, All) & 0.005 \\
\hline P-32 & 1.97 (Child, Bone) & 0.63 (Teen, Lung) & 0.32 \\
\hline Cr-51 & 1.46 (Teen, Lung) & 0.35 (Teen, Lung) & 0.24 \\
\hline $\mathrm{Mn}-54$ & 1.42 (Teen, Lung) & 0.17 (Teen, Lung ) & 0.12 \\
\hline Fe-55 & 1.72 (Teen, Lung) & 1.27 (Teen, Spleen) & 0.74 \\
\hline Fe-59 & 1.50 (Teen, Lung) & 0.83 (Teen, Lung) & 0.55 \\
\hline Co-58 & 1.45 (Teen, Lung) & 0.36 (Teen, Lung) & 0.25 \\
\hline Co-60 & 1.46 (Teen, Lung) & 0.32 (Teen, Lung) & 0.22 \\
\hline $\mathrm{Ni}-63$ & 1.90 (Child, Bone) & 0.19 (Teen, Lung) & 0.10 \\
\hline Cu-64 & 1.25 (Teen, LLI) & 0.44 (Teen, Lung) & 0.35 \\
\hline Zn-65 & 1.44 (Teen, Lung) & 0.22 (Teen, Lung) & 0.15 \\
\hline Sr-89 & 1.73 (Lung, Teen) & 0.33 (Infant, Lung) & 0.19 \\
\hline Sr-90 & 1.09 (Teen, Bone) & 0.36 (Teen, Bone Surf) & 0.33 \\
\hline Y-90 & 1.11 (Teen, LLI) & 1.0 (Infant, LLI) & 0.93 \\
\hline Zr-95 & 1.52 (Teen, Lung) & 0.65 (Teen, Lung) & 0.42 \\
\hline $\mathrm{Nb}-95$ & 1.49 (Teen, Lung) & 0.70 (Teen, Lung) & 0.47 \\
\hline Mo-99 & 1.08 (Teen, LLI) & 0.79 (Teen, Lung) & 0.73 \\
\hline Tc-99m & 1.47 (Teen, LLI) & 0.70 (Teen, Lung) & 0.47 \\
\hline Ru-106 & 1.72 (Teen, Lung) & 0.69 (Teen, Lung) & 0.40 \\
\hline $\mathrm{Ag}-110 \mathrm{~m}$ & 1.46 (Teen, Lung) & 0.28 (Teen, Lung) & 0.19 \\
\hline I-131 & 1.36 (Child, Thyroid) & 0.84 (Child, Thyroid) & 0.62 \\
\hline $\mathrm{l}-133$ & 1.79 (Child, Thyroid) & 1.04 (Child, Thyroid) & 0.58 \\
\hline Cs-134 & 1.33 (Teen, Liver) & 0.27 (Adult, LLI) & 0.20 \\
\hline Cs-137 & 1.46 (Child, Bone) & 0.27 (Adult, LLI) & 0.18 \\
\hline Ba-140 & 1.60 (Teen, Lung) & 1.00 (Teen, Lung) & 0.63 \\
\hline La-140 & 1.06 (Teen, LLI) & 0.56 (Infant, LLI) & 0.53 \\
\hline Np-239 & 1.11 (Teen, LLI) & 2.0 (Teen, Lung) & 1.8 \\
\hline
\end{tabular}




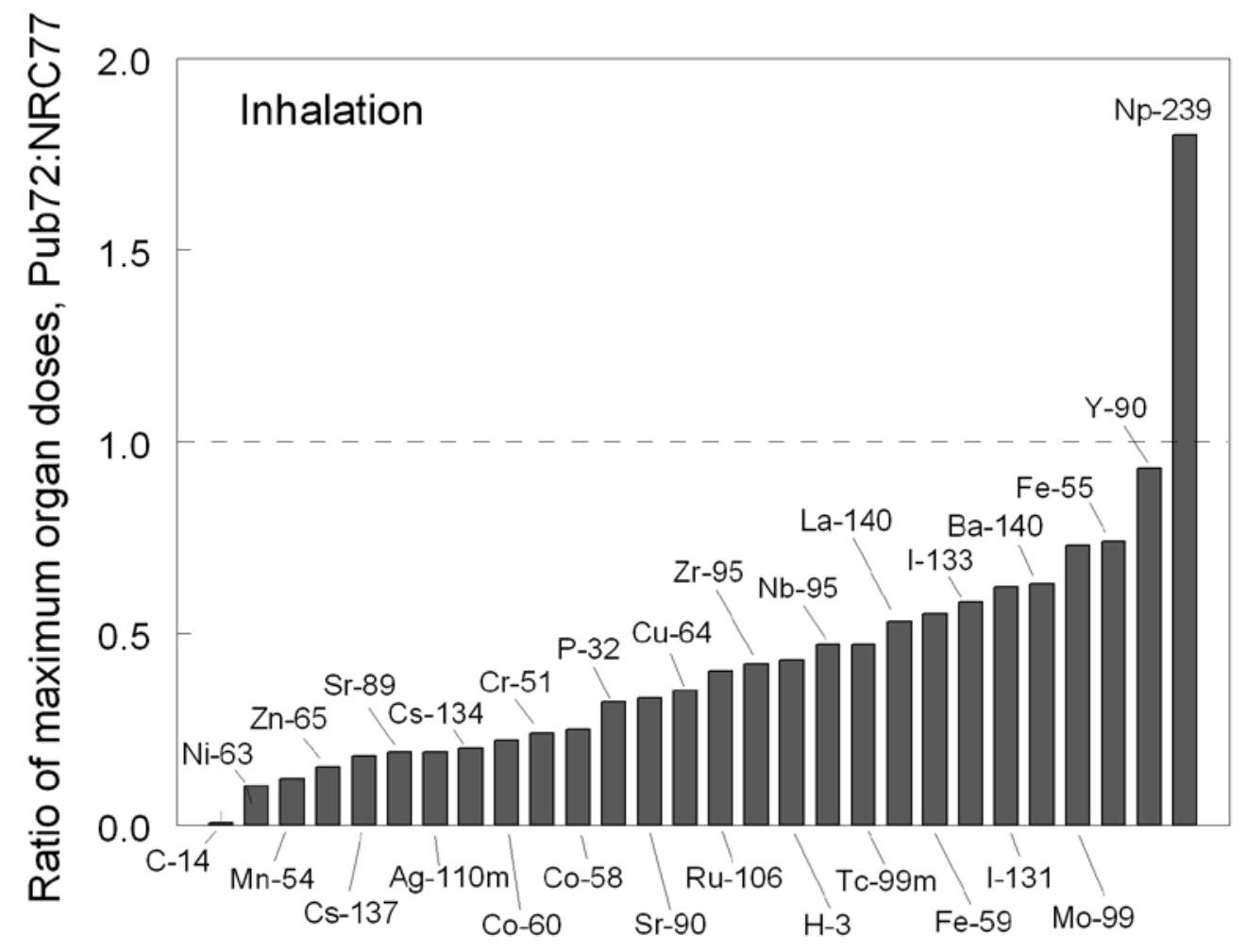

Figure 4.20. For inhalation of radionuclides, comparison of maximum organ doses across all age groups based on NRC77 and Pub72.

Table 4.4 compares the maximum total body dose (across all age groups) based on NRC77 with the maximum effective dose based on Pub72 for inhalation of individual radionuclides. All values for a given radionuclide are normalized to the dose to the critical organ of the adult based on NRC77. For example, for inhalation of ${ }^{137} \mathrm{Cs}$ : the table entry in the second column indicates that the maximum total body dose based on NRC77 is for intake by an adult and is 0.69 times the dose to the critical organ of the adult based on NRC77; the value in the third column indicates that the maximum effective dose based on Pub72 is for intake by an adult and is 0.22 times the dose to the critical organ of the adult based on NRC77; and the value in the fourth column is the ratio of values in columns three (Pub72) and two (NRC77): $0.22 / 0.69=0.32$. The ratios for individual radionuclides are shown in increasing order in Figure 4.21.

In 21 of the 28 cases, the maximum effective dose based on Pub72 is greater than the maximum total body dose based on NRC77. The two values are of the same order for radionuclides that are assumed in both systems to have high fractional absorption to blood and to be fairly uniformly distributed in the body (e.g., ${ }^{3} \mathrm{H}$ or ${ }^{137} \mathrm{Cs}$ ) but are not closely related overall. 


\begin{tabular}{|c|c|c|c|}
\hline Radionuclide & $\begin{array}{l}\text { Highest total body } \\
\text { dose for any age group } \\
\text { based on NRC77 }\end{array}$ & $\begin{array}{l}\text { Highest effective dose } \\
\text { for any age group } \\
\text { based on Pub72 }\end{array}$ & $\begin{array}{c}\text { Ratio } \\
\text { Pub72 : NRC77 }\end{array}$ \\
\hline $\mathrm{H}-3$ & 1.01 (Teen) & 0.43 (Adult) & 0.43 \\
\hline C-14 & 0.37 (Child) & 0.01 (Adult) & 0.03 \\
\hline P-32 & 0.075 (Child) & 0.091 (Teen) & 1.2 \\
\hline Cr-51 & 0.01 (Child) & 0.10 (Child) & 8.9 \\
\hline Mn-54 & 0.01 (Child) & 0.04 (Teen) & 5.9 \\
\hline Fe-55 & 0.11 (Child) & 0.19 (Child) & 1.7 \\
\hline Fe-59 & 0.02 (Child) & 0.13 (Teen) & 8.1 \\
\hline Co-58 & 0.003 (Child) & 0.06 (Teen) & 18 \\
\hline Co-60 & 0.004 (Child) & 0.06 (Teen) & 16 \\
\hline $\mathrm{Ni}-63$ & 0.06 (Child) & 0.04 (Teen) & 0.56 \\
\hline Cu-64 & 0.00002 (Child) & 0.08 (Teen) & 3800 \\
\hline Zn-65 & 0.08 (Child) & 0.06 (Teen) & 0.79 \\
\hline Sr-89 & 0.012 (Child) & 0.057 (Infant) & 4.8 \\
\hline Sr-90 & 0.07 (Teen) & 0.02 (Teen) & 0.23 \\
\hline Y-90 & 0.0002 (Child) & 0.13 (Infant) & 590 \\
\hline Zr-95 & 0.02 (Child) & 0.10 (Teen) & 4.7 \\
\hline $\mathrm{Nb}-95$ & 0.01 (Child) & 0.11 (Teen) & 8.3 \\
\hline Mo-99 & 0.0002 (Child) & 0.13 (Teen) & 770 \\
\hline Tc-99m & 0.00001 (Child) & 0.17 (Teen) & 12,000 \\
\hline Ru-106 & 0.002 (Child) & 0.10 (Teen) & 54 \\
\hline $\mathrm{Ag}-110 \mathrm{~m}$ & 0.002 (Child) & 0.059 (Teen) & 30 \\
\hline I-131 & 0.002 (Child) & 0.04 (Child) & 18 \\
\hline I-133 & 0.003 (Child) & 0.053 (Child) & 18 \\
\hline Cs-134 & 0.86 (Adult) & 0.23 (Adult) & 0.27 \\
\hline Cs-137 & 0.69 (Adult) & 0.22 (Adult) & 0.32 \\
\hline Ba-140 & 0.003 (Child) & 0.15 (Teen) & 43 \\
\hline La-140 & 0.0002 (Child) & 0.10 (Infant) & 600 \\
\hline Np-239 & 0.0002 (Child) & 0.29 (Teen) & 1500 \\
\hline
\end{tabular}




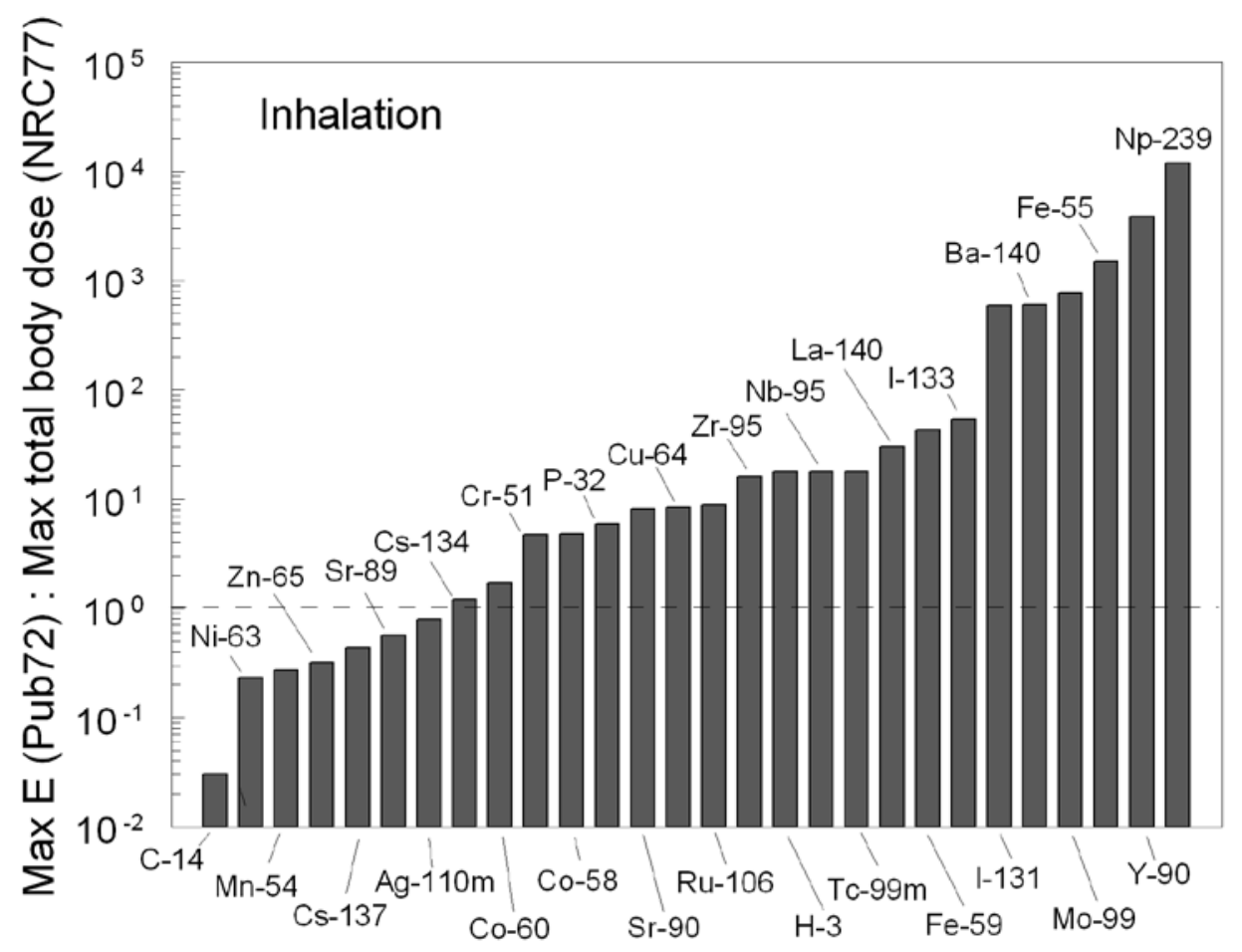

Figure 4.21. For inhalation of radionuclides, ratio of maximum effective dose $E$ (Pub72) to maximum total body dose (NRC77).

Comparisons of dose estimates were also made in terms of the primary dose quantities in NRC77 and Pub72. That is, for inhalation of each of the 28 radionuclides, the maximum dose to the critical organ across all age groups based on NRC77 was compared with the maximum effective dose E across all age groups based on Pub72. Results are summarized in Figure 4.22. For all 28 radionuclides the maximum critical organ dose based on NRC77 was greater than the maximum effective dose E based on Pub72. 


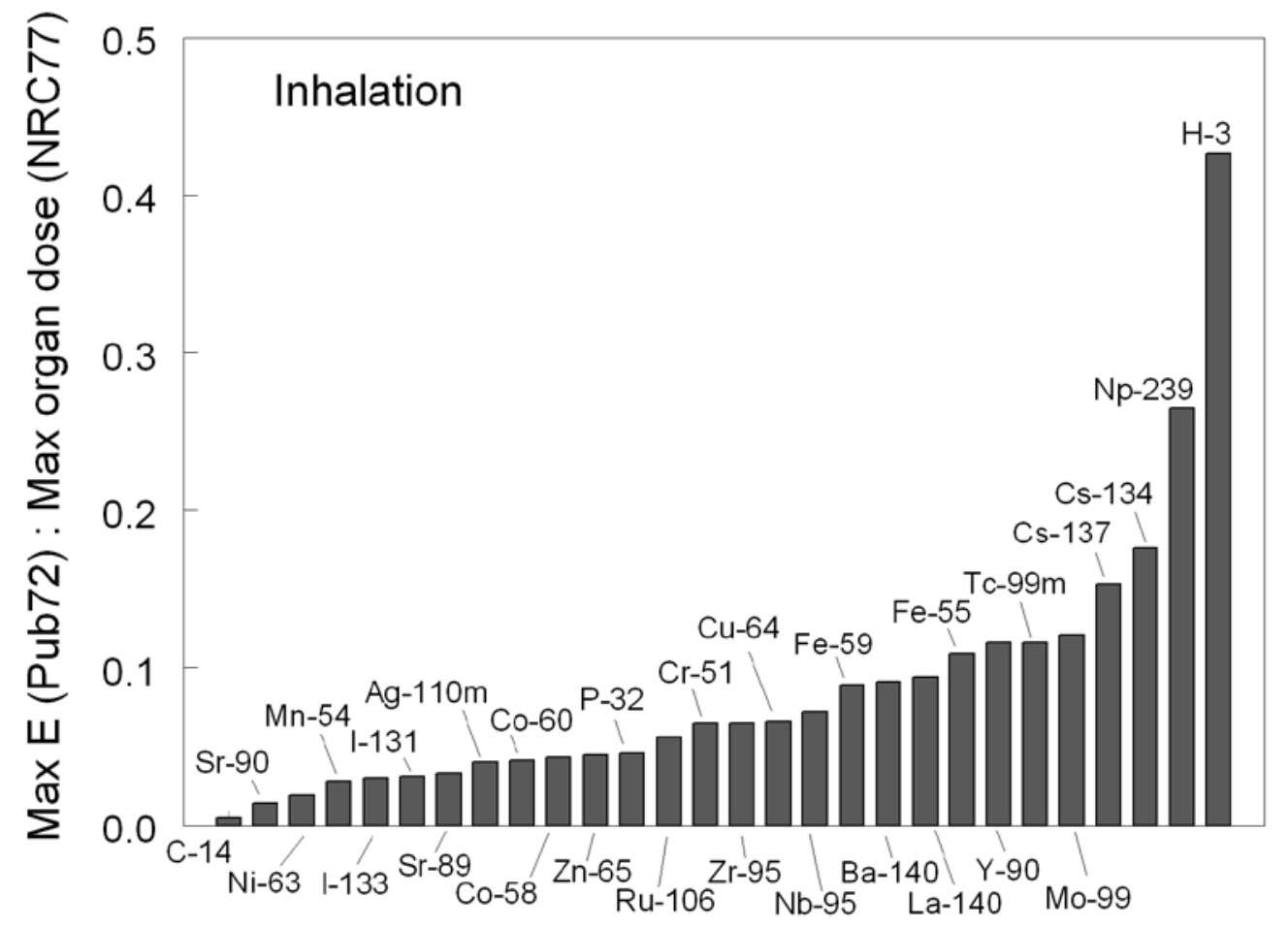

Figure 4.22. For inhalation of radionuclides, the ratio of the maximum effective dose $E$ (Pub72) to the maximum critical organ dose (NRC77). 


\section{COMPARISON OF EXTERNAL DOSE COEFFICIENTS FROM NRC77 WITH UPDATED COEFFICIENTS}

Table B-1 of RG 1.109 provides dose rate coefficients for assessment of doses from each of 14 noble gas radionuclides with half-life of at least a few minutes. Nuclear decay data for these radionuclides given in ICRP Publication 38 (1983) are summarized in Table 5.1. Dose rate coefficients computed using the methods of Federal Guidance Report 12 (1993) and the decay date of ICRP Publication 38 are compared in this section with coefficients in RG 1.109.

\begin{tabular}{|c|c|c|c|c|c|c|}
\hline \multirow{3}{*}{ Nuclide } & \multirow[b]{3}{*}{$\mathrm{T}_{1 / 2}$} & \multirow{3}{*}{$\begin{array}{l}\text { Decay } \\
\text { Mode }^{a}\end{array}$} & \multicolumn{4}{|c|}{ Energy (MeV / nuclear transformation) } \\
\hline & & & \multirow[t]{2}{*}{ Total photon } & \multicolumn{2}{|c|}{ Prominent photon } & \multirow{2}{*}{$\begin{array}{l}\text { Total } \\
\text { electron }\end{array}$} \\
\hline & & & & Yield (\%) & Energy & \\
\hline Ar-41 & $1.827 \mathrm{~h}$ & $\beta^{-}$ & 1.28 & 99.2 & 1.294 & 0.464 \\
\hline $\mathrm{Kr}-83 \mathrm{~m}$ & $1.83 \mathrm{~h}$ & IT & 0.00268 & 9.22 & 0.0126 & 0.0387 \\
\hline Kr-85m & $4.48 \mathrm{~h}$ & $\mathrm{IT}, \beta^{-}$ & 0.158 & 14.0 & 0.3049 & 0.256 \\
\hline Kr-85 & $10.72 y$ & $\beta^{-}$ & 0.00221 & 0.430 & 0.5140 & 0.250 \\
\hline $\mathrm{Kr}-87$ & $76.3 \mathrm{~m}$ & $\beta^{-}$ & 0.794 & 49.5 & 0.4026 & 1.32 \\
\hline Kr-88 & $2.84 \mathrm{~h}$ & $\beta^{-}$ & 1.96 & 13.0 & 0.8348 & 0.364 \\
\hline $\mathrm{Kr}-89^{\mathrm{b}}$ & $3.15 \mathrm{~m}$ & $\beta^{-}$ & 1.93 & 20.1 & 0.2209 & 1.37 \\
\hline $\mathrm{Xe}-131 \mathrm{~m}$ & $11.9 \mathrm{~d}$ & IT & 0.0200 & 1.91 & 0.1639 & 0.144 \\
\hline Xe-133m & $2.188 d$ & IT & 0.0407 & 9.99 & 0.2332 & 0.192 \\
\hline Xe-133 & $5.245 d$ & $\beta^{-}$ & 0.0460 & 37.4 & 0.0810 & 0.135 \\
\hline Xe-135m & $15.29 \mathrm{~m}$ & $\mathrm{IT}, \beta^{-}$ & 0.429 & 80.7 & 0.5266 & 0.0975 \\
\hline Xe-135 & $9.09 \mathrm{~h}$ & $\beta^{-}$ & 0.249 & 90.1 & 0.2498 & 0.317 \\
\hline $\mathrm{Xe}-137^{\mathrm{b}}$ & $3.818 \mathrm{~m}$ & $\beta^{-}$ & 0.191 & 31.2 & 0.4555 & 1.69 \\
\hline Xe-138 & $14.17 \mathrm{~m}$ & $\beta^{-}$ & 1.13 & 31.5 & 0.2583 & 0.672 \\
\hline
\end{tabular}

Dose rate coefficients are provided in RG 1.109 for submersion in air contaminated with each of these noble gas radionuclides. The coefficients address:

(1) $\beta$-Air = air dose from beta minus, beta plus, and internal conversion electrons;

(2) $\gamma$-Air = air dose from photons (gamma-rays, x-rays, and annihilation photons);

(3) $\beta$-Skin = beta component of the skin dose;

(4) $\gamma$-Body $=$ dose from photons at a depth of $5 \mathrm{~cm}$ into the body.

The $\beta$-Air and $\gamma$-Air coefficients given in Table B-1 of RG 1.109 are compared in Table 5.2 with values derived using the decay data of ICRP Publications 38 (1983). The $\beta$-Air and $\gamma$-Air coefficients are calculated as one-half the equilibrium dose coefficient in air (semi-infinite cloud) and thus are determined completely from nuclear decay data (energies and intensities of the emitted radiations), i.e., without consideration of transport of radiation in the atmosphere. In the derivation of the "current" coefficients, the density of the air at sea level is taken to be $1.3 \mathrm{~kg} / \mathrm{m}^{3}$. As seen from Table 5.2 , the dose coefficients of Table B-1 of RG 1.109 are in reasonable agreement with current values. 
The ratio of the $\beta$-Air coefficients (Table B-1: Current) ranges from 0.98 to 1.12 and the ratio of the $\gamma$-Air coefficients range from 1.01 to 1.24. These results reflect the fact that the nuclear decay data used in deriving the values of Table B-1 (Martin, 1973) apparently did not differ greatly from the data of ICRP Publication 38.

\begin{tabular}{|c|c|c|c|c|}
\hline \multicolumn{5}{|c|}{$\begin{array}{c}\text { Table 5.2. Comparison of air dose rate coefficients of } \\
\text { Table B-1 of RG } 1.109 \text { with values based on the decay data of } \\
\text { ICRP Publication } 38 \text {. }\end{array}$} \\
\hline & \multicolumn{4}{|c|}{ Air dose rate coefficient (mrad- $\left.\mathrm{m}^{3} / \mathrm{pCi}-\mathrm{yr}\right)$} \\
\hline & \multicolumn{2}{|c|}{$\beta$-Air } & \multicolumn{2}{|c|}{ Y-Air } \\
\hline Nuclide $^{a}$ & Table B-1 & Current & Table B-1 & Current \\
\hline Ar-41 & $3.28 \mathrm{E}-03$ & 3.33E-03 & $9.30 \mathrm{E}-03$ & 9.19E-03 \\
\hline $\mathrm{Kr}-83 \mathrm{~m}$ & 2.88E-04 & 2.78E-04 & 1.93E-05 & 1.92E-05 \\
\hline $\mathrm{Kr}-85 \mathrm{~m}$ & 1.97E-03 & 1.84E-03 & 1.23E-03 & 1.13E-03 \\
\hline Kr-85 & 1.95E-03 & $1.80 \mathrm{E}-03$ & 1.72E-05 & $1.59 \mathrm{E}-05$ \\
\hline $\mathrm{Kr}-87$ & 1.03E-02 & 9.48E-03 & $6.17 \mathrm{E}-03$ & 5.70E-03 \\
\hline $\mathrm{Kr}-88$ & 2.93E-03 & 2.61E-03 & 1.52E-02 & 1.41E-02 \\
\hline Kr-89 & 1.06E-02 & 9.84E-03 & 1.73E-02 & 1.39E-02 \\
\hline Xe-131m & 1.11E-03 & 1.03E-03 & 1.56E-04 & $1.44 \mathrm{E}-04$ \\
\hline Xe-133m & 1.48E-03 & 1.38E-03 & 3.27E-04 & 2.92E-04 \\
\hline Xe-133 & $1.05 E-03$ & 9.69E-04 & 3.53E-04 & 3.30E-04 \\
\hline Xe-135m & 7.39E-04 & 7.00E-04 & 3.36E-03 & $3.08 \mathrm{E}-03$ \\
\hline Xe-135 & 2.46E-03 & 2.28E-03 & 1.92E-03 & $1.79 \mathrm{E}-03$ \\
\hline Xe-137 & 1.27E-02 & 1.21E-02 & 1.51E-03 & 1.37E-03 \\
\hline Xe-138 & 4.75E-03 & 4.83E-03 & $9.21 \mathrm{E}-03$ & 8.11E-03 \\
\hline
\end{tabular}

Dose rate coefficients for skin and total body of the exposed individual for the noble gas nuclides of Table B-1 of RG 1.109 are compared in Table 5.3 with values based on ICRP Publication 38 as described in Federal Guidance Report 12 (FGR-12) (EPA, 1993). The skin values from Table B-1 range from 0.82 (Ar-41) to 1.02 (Xe-135m) times the values based on FGR-12. The total body values of Table B-1 range from 0.54 (Kr-83m) to 2.24 (Xe-135m) times the values based on FGR-12. The discrepancies between the two sets of total body coefficients in Table 5.3 appear to result mainly from differences in definitions of total body dose quantity itself. The $\gamma$-Body quantity of Table B-1 of RG 1.109 is reported to be a depth dose (at $5 \mathrm{~cm}$ into the body) which may have been derived assuming a slab geometry. The FGR-12 value is the effective dose (ICRP 60 tissue weighting factors) and thus is computed as the weighted sum of the tissue/organ doses derived using an anthropomorphic computational phantom. Also, in contrast to the Table B-1 coefficients, the FGR-12 coefficients reflect the down-scattered photon spectrum and its angular distribution incident on the phantom. 


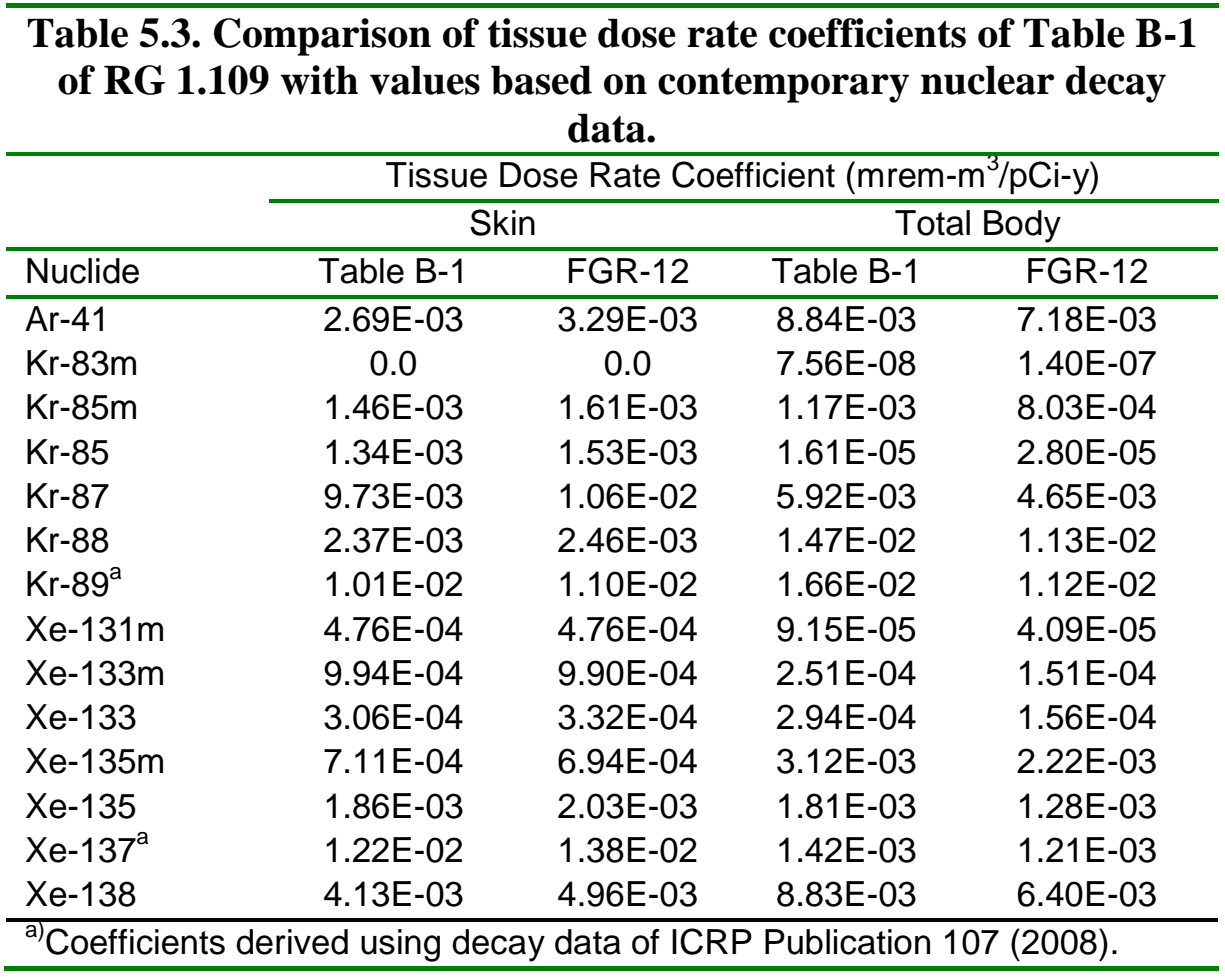

Dose rate coefficients for skin and the total body are given in Table E-6 of RG 1.109 for exposures to contaminated ground surfaces. The coefficients listed in RG 1.109 are compared with values from Federal Guidance Report 12 in Table 5.4. For both the skin and total body, large differences are seen for some radionuclides. In most instances the values of RG 1.109 are lower than those of FGR-12. For skin the values of Table E-6 range from more than five orders of magnitude lower (Sr-89) to a factor of 23 (Te-131) higher than the corresponding FGR-12 coefficients. Similarly the values for the total body in Table E-6 range from more than three orders of magnitude lower (Sr-89) to a factor of 1.6 (Zr-97) higher than the corresponding FGR-12 coefficients. The differences arise in part from the use of different models of radiation transport in the body, but largest differences result from the fact that the FGR-12 approach includes the contribution from bremsstrahlung and the values in Table E-6 do not. For example, for ${ }^{90} \mathrm{Y}$ the total body coefficient is increased by three orders of magnitude by inclusion of bremsstrahlung. Bremsstrahlung also contributes to the increased skin coefficients of FGR-12. The Sr-89 value of Table E-6 appears to be in error. 


\begin{tabular}{|c|c|c|c|c|}
\hline \multirow[b]{3}{*}{ Nuclide } & \multirow{2}{*}{\multicolumn{2}{|c|}{ Skin }} & \multirow{2}{*}{\multicolumn{2}{|c|}{ Total Body }} \\
\hline & & & & \\
\hline & Table E-6 & FGR-12 & Table E-6 & FGR-12 \\
\hline $\mathrm{H}-3$ & 0.0 & 0.0 & 0.0 & 0.0 \\
\hline C-14 & 0.0 & 9.96E-13 & 0.0 & 1.70E-13 \\
\hline $\mathrm{Na}-24$ & 2.90E-08 & $1.37 \mathrm{E}-07$ & 2.50E-08 & 4.78E-08 \\
\hline P-32 & 0.0 & 1.10E-07 & 0.0 & 1.13E-09 \\
\hline Cr-51 & $2.60 E-10$ & $4.90 \mathrm{E}-10$ & $2.20 E-10$ & $3.96 \mathrm{E}-10$ \\
\hline$M n-54$ & 6.80E-09 & $1.29 E-08$ & 5.80E-09 & $1.05 \mathrm{E}-08$ \\
\hline Mn-56 & 1.30E-08 & 1.29E-08 & 5.80E-09 & 1.05E-09 \\
\hline Fe-55 & 0.0 & 0.0 & 0.0 & 0.0 \\
\hline Fe-59 & 9.40E-09 & $1.78 \mathrm{E}-08$ & 8.00E-09 & 1.47E-08 \\
\hline Co-58 & 8.20E-09 & $1.52 \mathrm{E}-08$ & 7.00E-09 & $1.23 \mathrm{E}-08$ \\
\hline Co-60 & 2.00E-08 & 3.68E-08 & 1.70E-08 & 3.06E-08 \\
\hline $\mathrm{Ni}-63$ & 0.0 & 0.0 & 0.0 & 0.0 \\
\hline $\mathrm{Ni}-65$ & 4.30E-09 & 9.63E-08 & 3.70E-09 & 7.57E-09 \\
\hline Cu-64 & 1.70E-09 & 5.23E-09 & 1.50E-09 & 2.44E-09 \\
\hline Zn-65 & 4.60E-09 & 8.68E-09 & 4.00E-09 & 7.18E-09 \\
\hline Zn-69 & 0.0 & 2.69E-08 & 0.0 & 2.77E-10 \\
\hline $\mathrm{Br}-83$ & 9.30E-11 & $2.78 \mathrm{E}-08$ & $6.40 \mathrm{E}-11$ & $3.81 E-10$ \\
\hline $\mathrm{Br}-84$ & 1.40E-08 & 1.70E-07 & $1.20 \mathrm{E}-08$ & $2.22 E-08$ \\
\hline $\mathrm{Br}-85$ & 0.0 & - & 0.0 & - \\
\hline $\mathrm{Rb}-86$ & 7.20E-10 & $1.03 \mathrm{E}-07$ & 6.30E-10 & 2.22E-09 \\
\hline $\mathrm{Rb}-88$ & 4.00E-09 & $2.22 \mathrm{E}-07$ & 3.50E-09 & 9.87E-09 \\
\hline $\mathrm{Rb}-89$ & 1.80E-08 & $1.61 \mathrm{E}-07$ & 1.50E-08 & 2.62E-08 \\
\hline Sr-89 & $6.50 \mathrm{E}-13$ & 8.87E-08 & $5.60 \mathrm{E}-13$ & $9.14 \mathrm{E}-10$ \\
\hline Sr-90 & $0.0^{\mathrm{a}}$ & 1.86E-09 & $0.0^{\mathrm{a}}$ & $2.18 \mathrm{E}-11$ \\
\hline Sr-91 & 8.30E-09 & $1.00 \mathrm{E}-07$ & 7.10E-09 & 9.66E-09 \\
\hline Sr-92 & 1.00E-08 & 2.48E-08 & 9.00E-09 & 1.63E-08 \\
\hline Y-90 & $2.60 \mathrm{E}-12$ & $1.40 \mathrm{E}-07$ & 2.20E-12 & 1.47E-09 \\
\hline Y-91m & 4.40E-09 & $1.27 \mathrm{E}-08$ & 3.80E-09 & 6.78E-09 \\
\hline Y-91 & 2.70E-11 & $9.22 \mathrm{E}-08$ & 2.40E-11 & 9.94E-10 \\
\hline Y-92 & 1.90E-09 & $1.85 \mathrm{E}-07$ & 1.60E-09 & 5.10E-09 \\
\hline Y-93 & $7.80 \mathrm{E}-10$ & 1.64E-07 & $5.70 \mathrm{E}-10$ & 2.81E-09 \\
\hline Zr-95 & 5.80E-09 & 1.19E-08 & 5.00E-09 & 9.35E-09 \\
\hline Zr-97 & 6.40E-09 & 1.10E-07 & 5.50E-09 & 3.33E-09 \\
\hline Nb-95 & 6.00E-09 & $1.21 \mathrm{E}-08$ & 5.10E-09 & 9.68E-09 \\
\hline Mo-99 & 2.20E-09 & 5.01E-08 & 1.90E-09 & 2.37E-09 \\
\hline Tc-99m & 1.10E-09 & 1.92E-09 & $9.60 \mathrm{E}-10$ & 1.52E-09 \\
\hline Tc-99 & $0.0^{\mathrm{C}}$ & $3.25 E-12$ & $0.0^{\mathrm{C}}$ & 8.64E-13 \\
\hline Tc-101 & 3.00E-09 & 7.01E-08 & 2.70E-09 & 4.86E-09 \\
\hline Ru-103 & 4.20E-09 & 8.21E-09 & 3.60E-09 & 5.97E-09 \\
\hline Ru-105 & 5.10E-09 & 5.97E-08 & 4.50e-09 & 1.04E-08 \\
\hline Ru-106 & 1.80E-09 & $1.89 \mathrm{E}-07$ & 1.50E-09 & 4.60E-09 \\
\hline Rh-106 & $0.0^{\mathrm{b}}$ & $1.89 \mathrm{E}-07$ & $0.0^{\mathrm{b}}$ & 4.60E-09 \\
\hline
\end{tabular}




\begin{tabular}{|c|c|c|c|c|}
\hline \multicolumn{5}{|c|}{ Table 5.4 (continued) } \\
\hline \multirow[b]{2}{*}{ Nuclide } & \multicolumn{2}{|c|}{ Skin } & \multicolumn{2}{|c|}{ Total Body } \\
\hline & Table E-6 & FGR-12 & Table E-6 & FGR-12 \\
\hline $\mathrm{Ag}-110 \mathrm{~m}$ & $2.10 \mathrm{E}-08$ & $4.29 \mathrm{E}-08$ & 1.80E-08 & $3.44 \mathrm{E}-08$ \\
\hline Te-125m & $4.80 \mathrm{E}-11$ & - & $3.50 \mathrm{E}-11$ & - \\
\hline Te-127m & 1.30E-12 & 6.93E-10 & 1.10E-12 & 1.15E-10 \\
\hline Te-127 & 1.10E-11 & 7.19E-09 & $1.00 \mathrm{E}-11$ & 1.37E-10 \\
\hline Te-129m & 9.00E-10 & 3.02E-08 & 7.70E-10 & 7.58E-10 \\
\hline Te-129 & 8.40E-10 & 7.65E-08 & 7.10E-10 & 1.52E-09 \\
\hline Te-131m & 9.90E-09 & 2.93E-08 & 8.40E-09 & 1.78E-08 \\
\hline Te-131 & 2.60E-06 & 1.11E-07 & $2.20 \mathrm{e}-09$ & $6.31 e-09$ \\
\hline Te-132 & 2.00E-09 & 3.98E-09 & 1.70E-09 & 2.84E-09 \\
\hline $1-129$ & $0.0^{\mathrm{C}}$ & $7.73 E-10$ & $0.0^{\mathrm{C}}$ & 2.61E-10 \\
\hline I-130 & 1.70E-08 & 5.71E-08 & $1.40 \mathrm{E}-08$ & 2.73E-08 \\
\hline |-131 & 3.40E-09 & 8.56E-09 & 2.80E-09 & 4.85E-09 \\
\hline |-132 & 2.00E-08 & 1.00E-07 & 1.70E-08 & 2.93E-08 \\
\hline I-133 & 4.50E-09 & 6.06E-08 & 3.70E-09 & 8.21E-09 \\
\hline I-134 & $1.90 \mathrm{E}-08$ & 1.31E-07 & $1.60 \mathrm{E}-08$ & 3.37E-08 \\
\hline I-135 & 1.40E-08 & 6.43E-08 & $1.20 E-08$ & 1.96E-08 \\
\hline Cs-134 & $1.40 \mathrm{E}-08$ & 2.89E-08 & $1.20 \mathrm{E}-08$ & 1.97E-08 \\
\hline Cs-136 & 1.70E-08 & 3.38E-08 & $1.50 \mathrm{E}-08$ & 2.70E-08 \\
\hline Cs-137 & 4.90E-09 & 3.66E-09 & 4.20E-09 & 3.98E-11 \\
\hline Cs-138 & 2.40E-08 & 2.02E-07 & 2.10E-08 & 3.01E-08 \\
\hline $\mathrm{Ba}-137 \mathrm{~m}$ & $0.0^{\mathrm{b}}$ & $2.20 \mathrm{E}-08$ & $0.0^{\mathrm{b}}$ & 7.70E-09 \\
\hline Ba-139 & 2.70E-09 & $1.37 \mathrm{E}-07$ & 2.40E-09 & 1.94E-09 \\
\hline Ba-140 & 2.40E-09 & 2.60E-08 & 2.10E-09 & 2.53E-09 \\
\hline Ba-141 & 4.90E-09 & $1.41 \mathrm{E}-07$ & 4.30E-09 & 1.18E-08 \\
\hline Ba-142 & 9.00E-09 & 6.39E-08 & 7.90E-09 & 1.35E-08 \\
\hline La-140 & 1.70E-08 & 1.10E-07 & $1.50 \mathrm{E}-08$ & $2.88 \mathrm{E}-08$ \\
\hline La-142 & 1.80E-08 & $1.56 \mathrm{E}-07$ & $1.50 \mathrm{E}-08$ & 3.32E-08 \\
\hline Ce-141 & $6.20 E-10$ & 1.76E-09 & 5.50E-10 & $9.23 E-10$ \\
\hline Ce-143 & 2.50E-09 & 5.31E-08 & 2.20E-09 & 4.01E-09 \\
\hline Ce-144 & 3.70E-10 & $3.48 \mathrm{E}-10$ & 3.20E-10 & $2.45 \mathrm{E}-10$ \\
\hline Pr-143 & 0.0 & 2.66E-08 & 0.0 & $2.74 \mathrm{E}-10$ \\
\hline Pr-144 & $2.30 \mathrm{E}-10$ & 1.69E-07 & 2.00E-10 & 2.17E-09 \\
\hline Nd-147 & 1.20E-09 & 1.47E-08 & 1.00E-09 & 1.86E-09 \\
\hline W-187 & 3.60E-09 & 2.70E-08 & 3.10E-09 & 6.23E-09 \\
\hline Np-239 & 1.10E-09 & 3.50E-09 & 9.50E-10 & 2.05E-09 \\
\hline
\end{tabular}




\section{EVALUATION OF THE IMPACT OF USING ICRP 103 RECOMMENDATIONS}

The biokinetic and dosimetric models in Pub72 are being updated in ICRP Publication 103 (Pub103). Development of the gastrointestinal tract, inhalation, and systemic models are ongoing, so an exact dose comparison between Pub103 and Pub72 cannot be made. The tissue weighting factors have been updated in Pub103 and are listed along with Pub72 weighting factors in Table 6.1.

\begin{tabular}{lcc}
\hline \multicolumn{2}{c}{ Table 6.1. Tissue weighting factors given in Pub72 and } \\
Pub103
\end{tabular}

The salivary glands were not a target region in Pub72, and the Brain was considered part of remainder in Pub72. In Pub103, both were given a tissue weighting factor of 0.01 . The gonads tissue weighting factor decreased from 0.2 to 0.08 . The breast tissue weighting factor increased from 0.05 to 0.12 . The tissue weighting factors of urinary bladder, liver, esophagus, and thyroid all decreased from 0.05 to 0.04 . 
The ICRP revised the alimentary tract biokinetic model in ICRP 100. For H-2, C-14, I131, Cs-137, and Ru-106, the gut to blood transfer factors $\left(\mathrm{f}_{1}\right)$ are unchanged. A comparison of the transit times of the material through the alimentary tract in Pub72 and Pub103 are listed in Table 6.2. There is no significant change in transit times, and the added short transit times for the mouth and esophagus are not expected to be significant dose contributors. Based on the changes to tissue weighting factors and alimentary tract model, a significant change in dose is not expected for power plant radionuclides. For a more complete comparison, the updated inhalation and systemic models are needed.

\begin{tabular}{|c|c|c|}
\hline \multicolumn{3}{|c|}{$\begin{array}{l}\text { Table 6.2. Recommended Transit Times through the Alimentary Tract in } \\
\text { Pub72 and Pub103 }\end{array}$} \\
\hline Compartment & Pub72 & Pub103 \\
\hline Mouth & Not Applicable & $2 \mathrm{sec}$ (infants), $12 \mathrm{sec}$ (>1 year) \\
\hline Esophagus & Not Applicable & $<40 \mathrm{sec}$ \\
\hline \multirow[t]{4}{*}{ Stomach } & 60 minutes & 75 min (infant) \\
\hline & & 70 min (1-15 years) \\
\hline & & 70 min (adult male) \\
\hline & & 75 min (adult female) \\
\hline Small Intestine & 4 hours & 4 hours (all groups) \\
\hline \multirow{5}{*}{ Colon (entire length) } & 13 hours, ULI & 28 hours (infant) \\
\hline & 24 hours, LLI & 32 hours (child) \\
\hline & & 34 hours (teen) \\
\hline & & 36 hours (adult male) \\
\hline & & 48 hours (adult female) \\
\hline
\end{tabular}




\section{COMPARATIVE DOSE ASSESSMENTS FOR NUCLEAR POWER PLANT LIQUID AND GASEOUS EFFLUENTS BASED ON DIFFERENT DOSE COEFFICIENTS}

Dose estimates based on Pub2 and Pub72 were compared for typical gaseous and liquid effluents for next generation nuclear reactor designs. The liquid and gaseous effluent data for the Advanced Boiling Water Reactor (ABWR), Economically Simplified Bowling Water Reactor (ESBWR), Advanced Passive 1000 (AP1000), Advanced Pressurized Water Reactor (APWR), and U.S. Evolutionary Power Reactor (U.S. EPR) standardized designs were acquired from the design control documents (GE Nuclear Energy, 1997; GE-Hitachi, 2009; Westinghouse, 2008; Mitsubishi, 2009; Areva, 2009). The dose coefficients from NRC77 for the adult, teen, child, and infant were compared with those from Pub72 for the adult, 15-year-old teen, 5-year-old child, and 3-month-old infant. Federal Guidance Report No. 13 (EPA, 1999) was used when Pub72 lacked data for some radionuclides. Fate, transport, and usage parameters were acquired from combined license (COL) applications for new reactors (reference the NRC website with COLAs), and the assumptions for discharges and parameters used in dispersion mechanisms for liquid and gaseous effluent releases were left unchanged.

Exposure pathways for liquid and gaseous effluents that were evaluated in design certifications are listed in Table 7.1 and 7.2. The listed assumptions describing offsite dose receptors, locations, and associated exposure pathways assumed in applications for design certifications were left unchanged.

\begin{tabular}{|c|c|c|c|c|c|c|c|}
\hline \multicolumn{8}{|c|}{ Table 7.1. Liquid exposure pathways assumed in design certifications } \\
\hline Reactor & $\begin{array}{c}\text { Fresh } \\
\text { Water } \\
\text { Fish } \\
\text { Ingestion }\end{array}$ & $\begin{array}{l}\text { Saltwater } \\
\text { Fish } \\
\text { Ingestion }\end{array}$ & $\begin{array}{l}\text { Invertebrate } \\
\text { Ingestion }\end{array}$ & $\begin{array}{l}\text { Drinking } \\
\text { Water }\end{array}$ & $\begin{array}{l}\text { Shoreline } \\
\text { Exposure }\end{array}$ & $\begin{array}{l}\text { Swimming } \\
\text { and } \\
\text { Boating }\end{array}$ & $\begin{array}{l}\text { Irrigation } \\
\text { Pathways }\end{array}$ \\
\hline ABWR & $\mathrm{X}$ & & & & $x$ & & \\
\hline ESBWR & $x$ & & $x$ & $x$ & $x$ & $x$ & \\
\hline AP1000 & $x$ & & & $x$ & $x$ & & X \\
\hline APWR & $x$ & & & & $\mathrm{X}$ & & $\mathrm{X}$ \\
\hline U.S. EPR & & $x$ & $x$ & & $x$ & $x$ & \\
\hline
\end{tabular}

\begin{tabular}{lcccccc}
\hline \multicolumn{6}{c}{ Table 7.2. Gaseous exposure pathways assumed in design certifications } \\
\hline Reactor & Plume & $\begin{array}{c}\text { Ground } \\
\text { Shine }\end{array}$ & $\begin{array}{c}\text { Vegetable } \\
\text { Ingestion }\end{array}$ & $\begin{array}{c}\text { Milk } \\
\text { Ingestion }\end{array}$ & $\begin{array}{c}\text { Meat } \\
\text { Ingestion }\end{array}$ & Inhalation \\
\hline ABWR & $\mathrm{X}$ & $\mathrm{X}$ & $\mathrm{X}$ & $\mathrm{X}$ & $\mathrm{X}$ & $\mathrm{X}$ \\
ESBWR & $\mathrm{X}$ & $\mathrm{X}$ & $\mathrm{X}$ & & $\mathrm{X}$ & $\mathrm{X}$ \\
AP1000 & $\mathrm{X}$ & $\mathrm{X}$ & $\mathrm{X}$ & $\mathrm{X}$ & $\mathrm{X}$ & $\mathrm{X}$ \\
APWR & $\mathrm{X}$ & $\mathrm{X}$ & $\mathrm{X}$ & $\mathrm{X}$ & $\mathrm{X}$ & $\mathrm{X}$ \\
U.S. EPR & $\mathrm{X}$ & $\mathrm{X}$ & $\mathrm{X}$ & & $\mathrm{X}$ & $\mathrm{X}$ \\
\hline
\end{tabular}

Dose estimates for liquid effluents for the five reactors based on Pub2 and Pub72 are compared in Table 7.3. For the plants on freshwater sites (ABWR, ESBWR, AP1000, and APWR), the total body/effective dose decreased 3\% to 34\% using the Pub72 dosimetry, and maximum organ dose decreased by about a factor of six. For the U.S. EPR on a 
saltwater site, the total body/effective dose increased by a factor of three and the maximum organ dose increased by a factor of 13 using the Pub72 dosimetry as compared to Pub2. No site exceeded Part 50, Appendix I criteria using either dosimetry system.

\begin{tabular}{|c|c|c|c|c|}
\hline \multicolumn{5}{|c|}{ Table 7.3. Liquid Effluent Dose Comparison } \\
\hline Reference Case & Dose Type & $\begin{array}{c}\text { Pub2 } \\
\text { (mrem) }\end{array}$ & $\begin{array}{c}\text { Pub72 } \\
\text { (mrem) }\end{array}$ & $\begin{array}{l}\text { Appendix I } \\
\text { Design } \\
\text { Objective } \\
\text { (mrem) }\end{array}$ \\
\hline ABWR & $\begin{array}{l}\text { Total Body or Effective } \\
\text { Maximum Organ }\end{array}$ & $\begin{array}{c}0.90-\text { adult } \\
1.4-\text { teen liver }\end{array}$ & $\begin{array}{c}0.59 \text { - adult } \\
0.77 \text { - adult LLI }\end{array}$ & $\begin{array}{c}3 \\
10\end{array}$ \\
\hline ESBWR & $\begin{array}{l}\text { Total Body or Effective } \\
\text { Maximum Organ }\end{array}$ & $\begin{array}{l}0.10 \text { - adult } \\
1.4-\text { child bone }\end{array}$ & $\begin{array}{c}0.096 \text { - adult } \\
0.25 \text { - child LLI }\end{array}$ & $\begin{array}{c}3 \\
10\end{array}$ \\
\hline AP1000 & $\begin{array}{l}\text { Total Body or Effective } \\
\text { Maximum Organ }\end{array}$ & $\begin{array}{c}0.070 \text { - adult } \\
0.10-\text { child liver }\end{array}$ & $\begin{array}{c}0.065 \text { - adult } \\
0.14 \text { - child LLI }\end{array}$ & $\begin{array}{c}3 \\
10\end{array}$ \\
\hline APWR & $\begin{array}{l}\text { Total Body or Effective } \\
\text { Maximum Organ }\end{array}$ & $\begin{array}{c}0.95 \text { - adult } \\
1.37 \text { - teen liver }\end{array}$ & $\begin{array}{c}0.68 \text { - adult } \\
0.85 \text { - adult LLI }\end{array}$ & $\begin{array}{c}3 \\
10\end{array}$ \\
\hline U.S. EPR & $\begin{array}{l}\text { Total Body or Effective } \\
\text { Maximum Organ }\end{array}$ & $\begin{array}{c}0.0072 \text { - adult } \\
0.0087 \text { - adult liver }\end{array}$ & $\begin{array}{c}0.020 \text { - child } \\
0.11-\text { child LLI }\end{array}$ & $\begin{array}{c}3 \\
10\end{array}$ \\
\hline
\end{tabular}

When comparing gaseous effluents, the maximum organ dose increased by a factor of $33 \%$ for the ESBWR and decreased for the remaining four sites when using Pub72 dosimetry. Using the Pub72 dosimetry system for the ESBWR causes the maximum estimated organ dose from gaseous effluent to exceed the Appendix I design objective. The maximum organ doses for gaseous effluents are shown in Table 7.4.

\begin{tabular}{|c|c|c|c|c|}
\hline \multicolumn{5}{|c|}{ Table 7.4. Gaseous Effluent Dose Comparison } \\
\hline Reference Case & Dose Type & $\begin{array}{c}\text { Pub2 } \\
\text { (mrem) }\end{array}$ & $\begin{array}{c}\text { Pub72 } \\
\text { (mrem) }\end{array}$ & $\begin{array}{l}\text { Appendix I } \\
\text { Design } \\
\text { Objective } \\
\text { (mrem) }\end{array}$ \\
\hline ABWR & Maximum Organ & 8.4 - infant thyroid & 8.3 - infant thyroid & 15 \\
\hline ESBWR & Maximum Organ & 12 - child thyroid & 16 - child thyroid & 15 \\
\hline AP1000 & Maximum Organ & 4.8 - infant thyroid & 4.8 - infant thyroid & 15 \\
\hline APWR & Maximum Organ & 1.2 - child bone & 0.56 - infant thyroid & 15 \\
\hline U.S. EPR & Maximum Organ & 1.0 - child bone & 0.81 - child thyroid & 15 \\
\hline
\end{tabular}

The differences observed in dose estimates between the Pub2 and Pub72 dosimetry systems are further explained in Tables 7.5 and 7.6 by considering the dose contributions of major radionuclides ( $>5 \%$ of overall dose) from liquid and gaseous effluents. 


\begin{tabular}{|c|c|c|c|c|c|}
\hline \multirow[t]{2}{*}{$\begin{array}{c}\text { Reference } \\
\text { Case }\end{array}$} & \multirow[t]{2}{*}{ Dose Type } & \multicolumn{2}{|c|}{ Pub2 } & \multicolumn{2}{|c|}{ Pub72 } \\
\hline & & Radionuclide & $\%$ & Radionuclide & $\%$ \\
\hline \multirow[t]{3}{*}{ ABWR } & Total Body/Effective & $\begin{array}{l}\text { Cs-134 } \\
\text { Cs-137 }\end{array}$ & $\begin{array}{l}20 \\
80\end{array}$ & $\begin{array}{l}\text { Cs-134 } \\
\text { Cs-137 }\end{array}$ & $\begin{array}{l}15 \\
85\end{array}$ \\
\hline & Maximum Organ & Cs-134 & 15 & Cs-134 & 15 \\
\hline & & Cs-137 & 85 & Cs-137 & 85 \\
\hline \multirow[t]{2}{*}{ ESBWR } & Total Body/Effective & $\begin{array}{l}\text { Cs-134 } \\
\text { Cs-137 }\end{array}$ & $\begin{array}{l}20 \\
35\end{array}$ & $\begin{array}{l}\text { Cs-134 } \\
\text { Cs-137 }\end{array}$ & $\begin{array}{l}15 \\
25\end{array}$ \\
\hline & & P-32 & 40 & P-32 & 50 \\
\hline \multirow[t]{6}{*}{ AP1000 } & Total Body/Effective & $\begin{array}{c}\mathrm{H}-3 \\
\mathrm{Cs}-134\end{array}$ & $\begin{array}{l}30 \\
40\end{array}$ & $\begin{array}{c}\mathrm{H}-3 \\
\mathrm{Cs}-134\end{array}$ & $\begin{array}{l}45 \\
25\end{array}$ \\
\hline & & Cs-137 & 30 & Cs-137 & 25 \\
\hline & Maximum Organ & $\mathrm{H}-3$ & 30 & $\mathrm{H}-3$ & 35 \\
\hline & & Cs-134 & 35 & Cs-134 & 25 \\
\hline & & Cs-137 & 35 & Cs-137 & 25 \\
\hline & & & & Ru-106 & 15 \\
\hline \multirow[t]{5}{*}{ APWR } & Total Body/Effective & $\begin{array}{c}\mathrm{H}-3 \\
\mathrm{Cs}-134\end{array}$ & $\begin{array}{l}10 \\
10\end{array}$ & $\begin{array}{c}\mathrm{H}-3 \\
\mathrm{Cs}-134\end{array}$ & $\begin{array}{c}20 \\
5\end{array}$ \\
\hline & & Cs-137 & 80 & Cs-137 & 75 \\
\hline & Maximum Organ & $\mathrm{H}-3$ & 10 & $\mathrm{H}-3$ & 15 \\
\hline & & Cs-134 & 5 & Cs-134 & 10 \\
\hline & & Cs-137 & 85 & Cs-137 & 75 \\
\hline \multirow[t]{10}{*}{ U.S. EPR } & Total Body/Effective & $\begin{array}{c}\mathrm{H}-3 \\
\mathrm{Cs}-137\end{array}$ & $\begin{array}{l}60 \\
20\end{array}$ & $\begin{array}{c}\mathrm{H}-3 \\
\mathrm{Cs}-137\end{array}$ & $\begin{array}{c}30 \\
5\end{array}$ \\
\hline & & Xn-65 & 15 & Ru-106 & 40 \\
\hline & & & & I-131 & 15 \\
\hline & & & & $\mathrm{Ag}-110 \mathrm{~m}$ & 5 \\
\hline & Maximum Organ & $\mathrm{H}-3$ & 55 & Ru-106 & 80 \\
\hline & & Zn-65 & 25 & $\mathrm{H}-3$ & 5 \\
\hline & & Fe-55 & 5 & & \\
\hline & & Fe-59 & 5 & & \\
\hline & & Cs-134 & 5 & & \\
\hline & & Cs-137 & 5 & & \\
\hline
\end{tabular}


Cs-137 and Cs-134 dominate for liquid effluents in freshwater due to the biomagnification of cesium in fish, based on bioaccumulation factors given in Regulatory Guide 1.109. In the case of saltwater (U.S. EPR), other radionuclides such as zinc, iron, iodine, and ruthenium also bio-magnify in saltwater fish and invertebrates; therefore, the dose generally is not dominated by Cs-137 and Cs-134. Tritium is also an important radionuclide due to the significant quantity of tritium released in PWR liquid effluents ( $\sim 1000 \mathrm{Ci} / \mathrm{yr}$ per reactor). For gaseous effluents, I-131, I-133, and C-14 are the most prevalent radionuclides. Radioiodine is a significant dose contributor due to its affinity to concentrate in the thyroid gland, and C-14 is important because of its large relative release rate ( $\sim 10 \mathrm{Ci} / \mathrm{yr}$ per reactor). The maximum organ dose is to the thyroid in some cases due to the contribution from radioiodine and to bone in some cases due to the contribution from C-14.

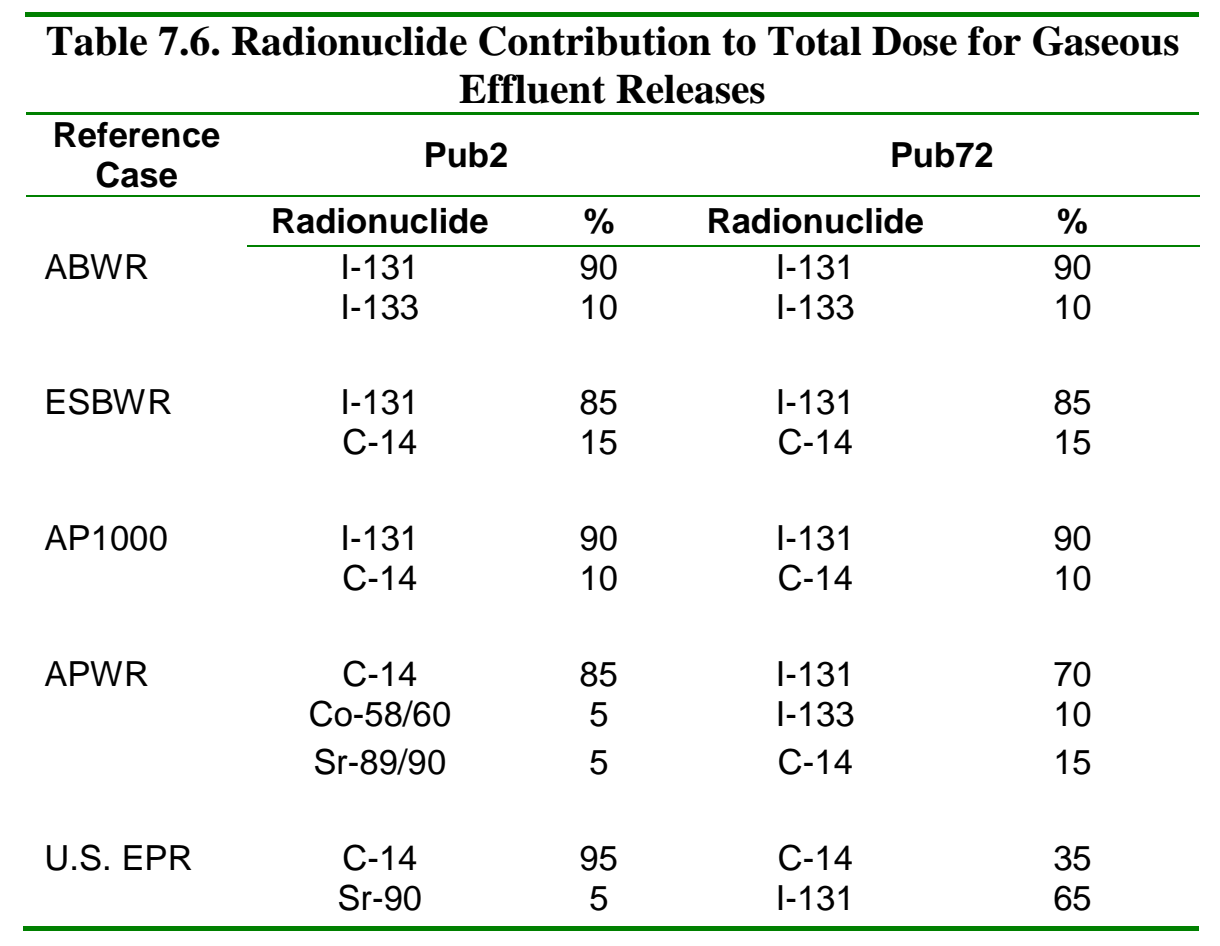

The change in overall dose obtained by using Pub72 compared to Pub2 is presented in Table 7.7. The body and organ doses for liquid effluents on freshwater sites decreased under Pub72 except for the cases of the maximum organ dose for the AP1000. This increase is due to a five-fold increase in dose to the large intestine of the child from $\mathrm{Ru}$ 106 under the Pub72 dosimetry system. The dose from liquid effluents of the U.S. EPR greatly increases under Pub72 treatment due to its location on a saltwater site and invertebrate ingestions, where the biological uptake and accumulation of Ru-106 and I131 are significant based on Regulatory guide 1.109 assumptions. The dose coefficients for Ru-106 in Pub72 are five times greater than those in Pub2, and the dose factor for I131 for the lower large intestine of the child is twice as large in Pub72. Ru-106 is not typically present in effluents from operating reactors; therefore, the five-fold increase in dose coefficient is not expected to affect operating reactors. 
For gaseous effluents, the Pub72 maximum organ dose was less than or equal to the Pub2 dose in all cases besides the ESBWR. This increase is due to the dose coefficient for I131 doubling under the Pub72 methodology, increasing the gaseous effluent dose to exceed the 15 mrem design objective in 10 CFR 50, Appendix I.

\begin{tabular}{lccc}
\hline \multicolumn{4}{c}{ Table 7.7. Change in overall dose using Pub72 versus Pub2 } \\
dosimetry methods \\
\hline $\begin{array}{c}\text { Reference } \\
\text { Case }\end{array}$ & \multicolumn{2}{c}{ Liquid Effluents } & Gaseous Effluents \\
\hline & $\begin{array}{c}\text { Body Dose } \\
\text { (Pub72/Pub2) }\end{array}$ & $\begin{array}{c}\text { Organ Dose } \\
\text { (Pub72/Pub2) }\end{array}$ & $\begin{array}{c}\text { Organ Dose } \\
\text { (Pub72/Pub2) }\end{array}$ \\
ABWR & 0.66 & 0.55 & 0.99 \\
ESBWR & 0.96 & 0.18 & 1.33 \\
AP1000 & 0.93 & 1.4 & 1.0 \\
APWR & 0.72 & 0.62 & 0.47 \\
U.S. EPR & 2.8 & 13 & 0.81 \\
\hline
\end{tabular}

The use of the Pub72 dose methodology has the greatest impact on sites characterized by marine environment pathways, leading to increased total body and organ doses. In instances where the evaluation showed dose results in excess of the Part 50, Appendix I criteria when using Pub72 concepts, these isolated observations are attributed to the licensing proce-ss which forces the use of conservative assumptions in developing radioactive effluent source terms, identifying dose receptors and modeling exposure pathways, and methods used in calculating doses to members of the public. 


\section{APPENDIX A: SUMMARY OF NUCLEAR DECAY DATA FOR RADIONUCLIDES ADDRESSED IN INTAKE SCENARIOS}

Half-lives and other basic nuclear decay properties of the 28 parent radionuclides addressed in this report and their important progeny are summarized in Table A.1. The decay properties of these radionuclides have been reasonably well determined for many years and do not represent a significant source of discrepancy in dose estimates based on NRC77, Pub30, and Pub72.

\begin{tabular}{|c|c|c|c|c|c|c|}
\hline \multicolumn{7}{|c|}{$\begin{array}{l}\text { Table A.1. Summary of decay data for radionuclides addressed in the dose } \\
\text { comparisons for ingested or inhaled radionuclides. }\end{array}$} \\
\hline \multirow[b]{3}{*}{ Nuclide } & \multirow[b]{3}{*}{$\mathrm{T}_{1 / 2}$} & \multirow{3}{*}{$\begin{array}{l}\text { Decay } \\
\text { Mode }^{\text {b }}\end{array}$} & \multicolumn{4}{|c|}{ Energy (MeV / nuclear transformation) } \\
\hline & & & \multirow{2}{*}{$\begin{array}{c}\text { Total } \\
\text { photon }\end{array}$} & \multicolumn{2}{|c|}{ Prominent photon } & \multirow{2}{*}{$\begin{array}{c}\text { Total } \\
\text { electron }\end{array}$} \\
\hline & & & & Yield (\%) & Energy & \\
\hline $\mathrm{H}-3$ & $12.3 \mathrm{y}$ & $\beta-$ & - & - & - & 0.00568 \\
\hline C-14 & 5730 y & $\beta-$ & - & - & - & 0.0495 \\
\hline P-32 & $14.29 \mathrm{~h}$ & $\beta-$ & - & - & - & 0.695 \\
\hline Cr-51 & $27.704 \mathrm{~d}$ & EC & 0.0326 & 13.3 & 0.0050 & 0.00386 \\
\hline Mn-54 & $312.5 \mathrm{~d}$ & EC & 0.836 & 99.9 & 0.8348 & 0.00422 \\
\hline Fe-55 & $2.7 \mathrm{y}$ & EC & 0.00169 & 16.6 & 0.0059 & 0.00420 \\
\hline Fe-59 & $44.529 \mathrm{~d}$ & $\beta-$ & 1.191 & 56.1 & 1.0992 & 0.118 \\
\hline Co-58 & $70.80 \mathrm{~d}$ & $E C, \beta+$ & 0.976 & 99.4 & 0.8108 & 0.0342 \\
\hline Co-60 & $5.271 y$ & $\beta-$ & 2.50 & 99.9 & 1.3325 & 0.0966 \\
\hline $\mathrm{Ni}-63$ & $96 y$ & $\beta-$ & - & - & - & 0.0171 \\
\hline Cu-64 & $12.701 \mathrm{~h}$ & $E C, \beta+, \beta-$ & 0.191 & 35.8 & 0.5110 & 0.123 \\
\hline Zn-65 & $243.9 d$ & $E C, \beta+$ & 0.584 & 50.8 & 1.1155 & 0.00687 \\
\hline Sr-89 & $50.5 d$ & $\beta-$ & $<10^{-4}$ & 0.009 & 0.9091 & 0.583 \\
\hline Sr-90 & 29.12 y & $\beta-$ & - & - & - & 0.196 \\
\hline$Y-90^{C}$ & $64.0 \mathrm{~h}$ & $\beta-$ & $<10^{-5}$ & 0.006 & 0.0158 & 0.935 \\
\hline Zr-95 & $63.98 d$ & $\beta-$ & 0.739 & 55.0 & 0.7567 & 0.116 \\
\hline$(\mathrm{Nb}-95 \mathrm{~m})^{\mathrm{d}}$ & $86.6 \mathrm{~h}$ & IT & 0.0683 & 25.9 & 0.2347 & 0.166 \\
\hline $\mathrm{Nb}-95^{\mathrm{C}}$ & $35.15 \mathrm{~d}$ & $\beta-$ & 0.766 & 100.0 & 0.7658 & 0.0444 \\
\hline Mo-99 & $66.0 \mathrm{~h}$ & $\beta-$ & 0.150 & 12.2 & 0.7395 & 0.392 \\
\hline Tc- $99 m^{c}$ & $6.02 \mathrm{~h}$ & IT & 0.126 & 88.9 & 0.1405 & 0.0163 \\
\hline Ru-106 & $368.2 \mathrm{~d}$ & $\beta-$ & - & - & - & 0.0100 \\
\hline$(\mathrm{Rh}-106)^{\mathrm{d}}$ & $29.9 \mathrm{~s}$ & $\beta-$ & 0.205 & 20.6 & 0.5118 & 1.41 \\
\hline $\mathrm{Ag}-110 \mathrm{~m}$ & $249.9 d$ & IT, $\beta-$ & 2.75 & 94.7 & 0.6557 & 0.0722 \\
\hline |-131 & $8.04 d$ & $\beta-$ & 0.382 & 81.2 & 0.3645 & 0.192 \\
\hline |-133 & $20.8 \mathrm{~h}$ & $\beta-$ & 0.607 & 86.3 & 0.5299 & 0.411 \\
\hline Cs-134 & $2.062 \mathrm{y}$ & $\beta-, E C$ & 1.56 & 97.6 & 0.6047 & 0.164 \\
\hline Cs-137 & $30.0 y$ & $\beta-$ & - & - & - & 0.187 \\
\hline$(B a-137 m)^{d}$ & $2.552 \mathrm{~m}$ & IT & 0.597 & 89.8 & 0.6616 & 0.0651 \\
\hline Ba-140 & $12.74 \mathrm{~d}$ & $\beta-$ & 0.183 & 24.4 & 0.5373 & 0.313 \\
\hline La- $140^{c}$ & $40.272 \mathrm{~h}$ & $\beta-$ & 2.31 & 95.4 & 1.5962 & 0.537 \\
\hline Np-239 & $2.355 d$ & $\beta-$ & 0.173 & 23.4 & 0.1038 & 0.260 \\
\hline \multicolumn{7}{|c|}{$\begin{array}{l}\text { a From ICRP Publication } 38 \text { (1983) } \\
\text { bEC = electron capture, IT = isomeric transition } \\
{ }^{c} \text { Considered in dosimetric calculations in this report as both a parent and a daughter nuclide } \\
\text { d Considered as a daughter but not as a parent radionuclide }\end{array}$} \\
\hline
\end{tabular}




\section{APPENDIX B: DETAILED TABULATIONS OF COMPARATIVE DOSE ESTIMATES FOR RADIONUCLIDES IN DRINKING WATER}

The starting place for the comparative analysis for intake of radionuclides in drinking water was derivation of base case dose estimates for adults using dose coefficients and water consumption rates given in NRC77. These base case estimates are listed in Table B.1. Estimates for a radionuclide are based on a one-year intake of the radionuclide in drinking water using dose coefficients from NRC77 and assuming an activity concentration of $1 \mathrm{pCi} / \mathrm{L}(0.037 \mathrm{~Bq} / \mathrm{L})$. The dose estimate for a tissue is calculated as 730 pCi times the dose coefficient for adults given in NRC77 (in units of mrem/pCi ingested), assuming annual intake of $730 \mathrm{~L}$ of drinking water. Dose estimates for a given radionuclide are provided for each of the organs addressed in NRC77 for that radionuclide, i.e., for total body, lower large intestine, and some subset of the organs bone, liver, thyroid, kidney, and lung. The highest dose to any organ from ingestion of the radionuclide in drinking water is in bold-faced type. This value is referred to in Pub2 and NRC77 as the dose to the critical organ.

Table B.1. Base-case values for the adult: Estimated committed doses from one-year intake of drinking water with radionuclide concentration of $1 \mathrm{pCi} / \mathrm{L}$ based on NRC77 ${ }^{\mathrm{a}}$.

\begin{tabular}{|c|c|c|c|c|c|c|c|}
\hline \multirow[b]{2}{*}{ Nuclide } & \multicolumn{7}{|c|}{ Estimated committed dose (mrem $\left.{ }^{\mathrm{a}}\right)$} \\
\hline & Bone & Liver & T Body & Thyroid & Kidney & Lung & LLI \\
\hline $\mathrm{H}-3$ & $\mathrm{~b}$ & 7.7E-05 & 7.7E-05 & 7.7E-05 & 7.7E-05 & 7.7E-05 & 7.7E-05 \\
\hline C-14 & 2.1E-03 & 4.1E-04 & 4.1E-04 & 4.1E-04 & 4.1E-04 & 4.1E-04 & 4.1E-04 \\
\hline P-32 & 1.4E-01 & 8.8E-03 & $5.4 \mathrm{E}-03$ & b & b & b & 1.6E-02 \\
\hline Cr-51 & b & b & 1.9E-06 & 1.2E-06 & 4.3E-07 & $2.6 \mathrm{E}-06$ & 4.9E-04 \\
\hline Mn-54 & b & 3.3E-03 & 6.4E-04 & b & $9.9 \mathrm{E}-04$ & b & $1.0 \mathrm{E}-02$ \\
\hline Fe-55 & 2.0E-03 & 1.4E-03 & 3.2E-04 & b & b & 7.7E-04 & 8.0E-04 \\
\hline Fe-59 & $3.2 \mathrm{E}-03$ & 7.5E-03 & $2.9 \mathrm{E}-03$ & b & b & $2.1 \mathrm{E}-03$ & $2.5 \mathrm{E}-02$ \\
\hline Co-58 & b & $5.4 \mathrm{E}-04$ & $1.2 \mathrm{E}-03$ & b & b & b & 1.1E-02 \\
\hline Co-60 & b & 1.6E-03 & $3.5 \mathrm{E}-03$ & b & b & b & $2.9 \mathrm{E}-02$ \\
\hline $\mathrm{Ni}-63$ & 9.5E-02 & $6.6 \mathrm{E}-03$ & $3.2 \mathrm{E}-03$ & b & b & b & 1.4E-03 \\
\hline Cu-64 & b & 6.1E-05 & 2.9E-05 & b & 1.5E-04 & b & 5.2E-03 \\
\hline Zn-65 & $3.5 \mathrm{E}-03$ & 1.1E-02 & 5.1E-03 & b & 7.5E-03 & b & 7.1E-03 \\
\hline Sr-89 & 2.2E-01 & b & 6.5E-03 & b & b & b & 3.6E-02 \\
\hline Sr-90 & $5.5 E+00$ & b & $1.4 \mathrm{E}+00$ & b & b & b & 1.6E-01 \\
\hline Y-90 & 7.0E-06 & b & 1.9E-07 & b & b & b & 7.5E-02 \\
\hline Zr-95 & $2.2 \mathrm{E}-05$ & 7.1E-06 & 4.8E-06 & b & 1.1E-05 & b & 2.3E-02 \\
\hline $\mathrm{Nb}-95$ & $4.5 \mathrm{E}-06$ & $2.5 \mathrm{E}-06$ & 1.4E-06 & b & $2.5 \mathrm{E}-06$ & b & $1.5 \mathrm{E}-02$ \\
\hline Mo-99 & b & $3.2 \mathrm{E}-03$ & 6.0E-04 & b & 7.1E-03 & b & 7.3E-03 \\
\hline Tc-99m & 1.8E-07 & 5.1E-07 & $6.5 \mathrm{E}-06$ & b & 7.7E-06 & $2.5 \mathrm{E}-07$ & 3.0E-04 \\
\hline Ru-106 & 2.0E-03 & b & $2.5 \mathrm{E}-04$ & b & $3.9 \mathrm{E}-03$ & b & 1.3E-01 \\
\hline $\mathrm{Ag}-110 \mathrm{~m}$ & $1.2 \mathrm{E}-04$ & 1.1E-04 & 6.4E-05 & b & 2.1E-04 & b & 4.4E-02 \\
\hline I-131 & 3.0E-03 & 4.3E-03 & $2.5 \mathrm{E}-03$ & $1.4 \mathrm{E}+00$ & 7.5E-03 & b & 1.2E-03 \\
\hline I-133 & 1.0E-03 & $1.8 \mathrm{E}-03$ & 5.5E-04 & 2.6E-01 & 3.1E-03 & b & 1.6E-03 \\
\hline Cs-134 & 4.5E-02 & 1.1E-01 & 8.8E-02 & b & 3.5E-02 & $1.2 \mathrm{E}-02$ & 1.9E-03 \\
\hline Cs-137 & $5.8 \mathrm{E}-02$ & 8.0E-02 & $5.2 \mathrm{E}-02$ & b & 2.7E-02 & 9.0E-03 & $1.5 \mathrm{E}-03$ \\
\hline Ba-140 & 1.5E-02 & 1.9E-05 & 9.7E-04 & b & 6.3E-06 & 1.1E-05 & 3.1E-02 \\
\hline La-140 & 1.8E-06 & $9.2 \mathrm{E}-07$ & 2.4E-07 & b & b & b & 6.8E-02 \\
\hline Np-239 & 8.7E-07 & 8.5E-08 & 4.7E-08 & b & 2.7E-07 & b & $1.8 \mathrm{E}-02$ \\
\hline
\end{tabular}


Base case dose estimates for each organ listed in Table B.1 are compared in Table B.2 with estimates for adults based on Pub30 or Pub72. Comparisons are given as ratios D30 : D77 and D72 : D77, where D30 and D72 are dose estimates for a given radionuclide and organ based on Pub30 or Pub72, respectively, and D77 is the dose given in Table B.2 for the same radionuclide and organ.

\begin{tabular}{|c|c|c|c|c|c|c|c|}
\hline Nuclide & ICRP Pub & Bone $^{\mathrm{a}}$ & Liver & Thyroid & Kidney & Lung & LLI \\
\hline \multirow[t]{2}{*}{$\mathrm{H}-3$} & Pub30 & $\mathrm{b}$ & 0.61 & 0.61 & 0.61 & 0.61 & 0.61 \\
\hline & Pub72 & $\mathrm{b}$ & 0.64 & 0.64 & 0.64 & 0.64 & 0.64 \\
\hline \multirow[t]{2}{*}{ C-14 } & Pub30 & 0.74 & 3.7 & 3.7 & 3.7 & 3.7 & 3.7 \\
\hline & Pub72 & 0.75 & 3.7 & 3.7 & 3.7 & 3.7 & 3.7 \\
\hline \multirow[t]{2}{*}{ P-32 } & Pub30 & 0.15 & 0.2 & $\mathrm{~b}$ & $\mathrm{~b}$ & $\mathrm{~b}$ & 1.24 \\
\hline & Pub72 & 0.16 & 0.21 & $\mathrm{~b}$ & $\mathrm{~b}$ & $\mathrm{~b}$ & 1.44 \\
\hline \multirow[t]{2}{*}{ Cr-51 } & Pub30 & $\mathrm{b}$ & $\mathrm{b}$ & 8.6 & 53 & 4.6 & 1.4 \\
\hline & Pub72 & $\mathrm{b}$ & $\mathrm{b}$ & 9.8 & 56 & 4.7 & 1.7 \\
\hline \multirow[t]{2}{*}{ Mn-54 } & Pub30 & $\mathrm{b}$ & 0.81 & $\mathrm{~b}$ & 1 & $\mathrm{~b}$ & 0.58 \\
\hline & Pub72 & $\mathrm{b}$ & 0.85 & $b$ & 1.2 & $\mathrm{~b}$ & 0.65 \\
\hline \multirow[t]{2}{*}{ Fe-55 } & Pub30 & 0.14 & 0.67 & $\mathrm{~b}$ & $\mathrm{~b}$ & 0.36 & 1 \\
\hline & Pub72 & 0.8 & 1.4 & $\mathrm{~b}$ & $\mathrm{~b}$ & 0.3 & 1.2 \\
\hline \multirow[t]{2}{*}{ Fe-59 } & Pub30 & 0.56 & 0.56 & $b$ & $\mathrm{~b}$ & 0.83 & 0.92 \\
\hline & Pub72 & 0.91 & 1.1 & $b$ & $\mathrm{~b}$ & 0.89 & 0.91 \\
\hline \multirow[t]{2}{*}{ Co-58 } & Pub30 & $\mathrm{b}$ & 1.2 & $\mathrm{~b}$ & $\mathrm{~b}$ & $\mathrm{~b}$ & 0.97 \\
\hline & Pub72 & $\mathrm{b}$ & 2.0 & $b$ & $\mathrm{~b}$ & $\mathrm{~b}$ & 0.98 \\
\hline \multirow[t]{2}{*}{ Co-60 } & Pub30 & $\mathrm{b}$ & 7.8 & $\mathrm{~b}$ & $\mathrm{~b}$ & $\mathrm{~b}$ & 1.1 \\
\hline & Pub72 & $\mathrm{b}$ & 7.8 & $\mathrm{~b}$ & $\mathrm{~b}$ & $\mathrm{~b}$ & 1.1 \\
\hline \multirow[t]{2}{*}{$\mathrm{Ni}-63$} & Pub30 & $<0.01$ & 0.03 & $b$ & $\mathrm{~b}$ & $b$ & 1.8 \\
\hline & Pub72 & $<0.01$ & 0.04 & $\mathrm{~b}$ & $\mathrm{~b}$ & $\mathrm{~b}$ & 1.8 \\
\hline \multirow[t]{2}{*}{ Cu-64 } & Pub30 & $\mathrm{b}$ & 1.7 & $\mathrm{~b}$ & 0.34 & $\mathrm{~b}$ & 0.39 \\
\hline & Pub72 & $\mathrm{b}$ & 1.7 & $b$ & 0.35 & $b$ & 0.39 \\
\hline \multirow[t]{2}{*}{ Zn-65 } & Pub30 & 3.4 & 0.89 & $b$ & 1.4 & $\mathrm{~b}$ & 1.9 \\
\hline & Pub72 & 4.2 & 0.88 & $\mathrm{~b}$ & 1.4 & $\mathrm{~b}$ & 2.0 \\
\hline \multirow[t]{2}{*}{ Sr-89 } & Pub30 & 0.06 & $\mathrm{~b}$ & $b$ & $\mathrm{~b}$ & $b$ & 1.6 \\
\hline & Pub72 & 0.07 & $b$ & $b$ & $\mathrm{~b}$ & $b$ & 1.7 \\
\hline \multirow[t]{2}{*}{ Sr-90 } & Pub30 & 0.2 & $b$ & $b$ & $\mathrm{~b}$ & $b$ & 0.33 \\
\hline & Pub72 & 0.2 & $b$ & $b$ & $b$ & $b$ & 0.37 \\
\hline \multirow[t]{2}{*}{ Y-90 } & Pub30 & 0.14 & $b$ & $b$ & $\mathrm{~b}$ & $b$ & 1.2 \\
\hline & Pub72 & 0.14 & $\mathrm{~b}$ & $b$ & $\mathrm{~b}$ & $b$ & 1.1 \\
\hline \multirow[t]{2}{*}{ Zr-95 } & Pub30 & 59 & 30 & $b$ & 27 & $b$ & 0.94 \\
\hline & Pub72 & 270 & 41 & $b$ & 40 & $b$ & 0.94 \\
\hline \multirow[t]{2}{*}{$\mathrm{Nb}-95$} & Pub30 & 180 & 89 & $b$ & 150 & $\mathrm{~b}$ & 0.71 \\
\hline & Pub72 & 56 & 150 & $b$ & 170 & $b$ & 0.71 \\
\hline \multirow[t]{2}{*}{ Mo-99 } & Pub30 & $\mathrm{b}$ & 2.3 & $b$ & 0.94 & $b$ & 1.2 \\
\hline & Pub72 & $\mathrm{b}$ & 2.4 & $b$ & 1.2 & $\mathrm{~b}$ & 0.21 \\
\hline \multirow[t]{2}{*}{ Tc-99m } & Pub30 & 61 & 25 & $b$ & 1.8 & 34 & 0.23 \\
\hline & Pub72 & 78 & 23 & $b$ & 1.9 & 23 & 0.48 \\
\hline \multirow[t]{2}{*}{ Ru-106 } & Pub30 & 1.9 & $\mathrm{~b}$ & $\mathrm{~b}$ & 1 & $\mathrm{~b}$ & 1.5 \\
\hline & Pub72 & 2 & $\mathrm{~b}$ & $b$ & 1 & $\mathrm{~b}$ & 1.5 \\
\hline \multirow[t]{2}{*}{$\mathrm{Ag}-110 \mathrm{~m}$} & Pub30 & 11.4 & 216 & $\mathrm{~b}$ & 19.1 & $\mathrm{~b}$ & 0.66 \\
\hline & Pub72 & 20.0 & 190 & $\mathrm{~b}$ & 20.8 & $\mathrm{~b}$ & 0.71 \\
\hline
\end{tabular}




\begin{tabular}{|c|c|c|c|c|c|c|c|}
\hline \multicolumn{8}{|c|}{ Table B.2 (continued) } \\
\hline Nuclide & ICRP Pub & Bone $^{a}$ & Liver & Thyroid & Kidney & Lung & LLI \\
\hline \multirow[t]{2}{*}{$\mathrm{I}-131$} & Pub30 & 0.08 & 0.03 & 0.9 & 0.02 & $\mathrm{~b}$ & 0.1 \\
\hline & Pub72 & 0.12 & 0.03 & 0.82 & 0.02 & $\mathrm{~b}$ & 0.38 \\
\hline \multirow[t]{2}{*}{$\mathrm{I}-133$} & Pub30 & 0.11 & 0.06 & 0.93 & 0.03 & $\mathrm{~b}$ & 0.06 \\
\hline & Pub72 & 0.13 & 0.06 & 0.84 & 0.04 & $\mathrm{~b}$ & 0.22 \\
\hline \multirow[t]{2}{*}{ Cs-134 } & Pub30 & 1 & 0.5 & $\mathrm{~b}$ & 1.6 & 4.1 & 31 \\
\hline & Pub72 & 1.2 & 0.5 & $\mathrm{~b}$ & 1.5 & 4.1 & 32 \\
\hline \multirow[t]{2}{*}{ Cs-137 } & Pub30 & 0.59 & 0.46 & $\mathrm{~b}$ & 1.4 & 3.8 & 25 \\
\hline & Pub72 & 0.64 & 0.46 & $\mathrm{~b}$ & 1.4 & 3.8 & 29 \\
\hline \multirow[t]{2}{*}{ Ba-140 } & Pub30 & 0.1 & 17 & $\mathrm{~b}$ & 65 & 16.8 & 2.3 \\
\hline & Pub72 & 0.3 & 22 & $\mathrm{~b}$ & 97 & 27 & 2.5 \\
\hline \multirow[t]{2}{*}{ La-140 } & Pub30 & 140 & 500 & $\mathrm{~b}$ & $\mathrm{~b}$ & $\mathrm{~b}$ & 0.7 \\
\hline & Pub72 & 172 & 470 & $\mathrm{~b}$ & $\mathrm{~b}$ & $\mathrm{~b}$ & 0.7 \\
\hline \multirow[t]{2}{*}{ Np-239 } & Pub30 & 110 & 490 & $\mathrm{~b}$ & 210 & $\mathrm{~b}$ & 1.4 \\
\hline & Pub72 & 80 & 430 & $\mathrm{~b}$ & 210 & $\mathrm{~b}$ & 1.3 \\
\hline
\end{tabular}

To facilitate comparison of dose estimates across different ages as well different dosimetry systems, all dose estimates for a given radionuclide were normalized to the dose to the critical organ of the adult based on NRC77. Normalized dose estimates for ingestion of individual radionuclides in drinking water are listed in Table B.3. 


\section{Table B.3. Dose estimates for 1-y intake of radionuclide in drinking water based on NRC77,}

Pub30, and Pub72, normalized to the NRC77 critical organ dose for the adult.

\begin{tabular}{|c|c|c|c|c|c|c|c|c|c|}
\hline \multirow[b]{2}{*}{ Nuclide } & \multirow{2}{*}{$\begin{array}{l}\text { Age } \\
\text { group }\end{array}$} & \multirow{2}{*}{$\begin{array}{l}\text { Dose } \\
\text { system }\end{array}$} & \multicolumn{7}{|c|}{ Normalized dose commitment } \\
\hline & & & Bone $^{a}$ & Liver & Thyroid & Kidney & Lung & LLI & Tbody or eff $^{b}$ \\
\hline \multirow[t]{12}{*}{$\mathrm{H}-3$} & Adult & NRC77 & $\mathrm{C}$ & 1.00 & 1.00 & 1.00 & 1.00 & 1.00 & 1.00 \\
\hline & & Pub30 & 0.61 & 0.61 & 0.61 & 0.61 & 0.61 & 0.61 & 0.61 \\
\hline & & Pub72 & 0.64 & 0.64 & 0.64 & 0.64 & 0.64 & 0.64 & 0.64 \\
\hline & Teen & NRC77 & C & 0.71 & 0.71 & 0.71 & 0.71 & 0.71 & 0.71 \\
\hline & & Pub30 & 0.43 & 0.43 & 0.43 & 0.43 & 0.43 & 0.43 & 0.43 \\
\hline & & Pub72 & 0.44 & 0.44 & 0.44 & 0.44 & 0.44 & 0.44 & 0.44 \\
\hline & Child & NRC77 & C & 1.35 & 1.35 & 1.35 & 1.35 & 1.35 & 1.35 \\
\hline & & Pub30 & 0.43 & 0.43 & 0.43 & 0.43 & 0.43 & 0.43 & 0.43 \\
\hline & & Pub72 & 0.75 & 0.75 & 0.75 & 0.75 & 0.75 & 0.75 & 0.75 \\
\hline & Infant & NRC77 & C & 1.33 & 1.33 & 1.33 & 1.33 & 1.33 & 1.33 \\
\hline & & Pub30 & 0.28 & 0.28 & 0.28 & 0.28 & 0.28 & 0.28 & 0.28 \\
\hline & & Pub72 & 1.00 & 1.00 & 1.00 & 1.00 & 1.00 & 1.00 & 1.00 \\
\hline \multirow[t]{12}{*}{ C-14 } & Adult & NRC77 & 1.00 & 0.20 & 0.20 & 0.20 & 0.20 & 0.20 & 0.20 \\
\hline & & Pub30 & 0.74 & 0.74 & 0.74 & 0.74 & 0.74 & 0.74 & 0.74 \\
\hline & & Pub72 & 0.75 & 0.75 & 0.75 & 0.75 & 0.75 & 0.75 & 0.75 \\
\hline & Teen & NRC77 & 1.00 & 0.20 & 0.20 & 0.20 & 0.20 & 0.20 & 0.20 \\
\hline & & Pub30 & 0.51 & 0.51 & 0.51 & 0.51 & 0.51 & 0.51 & 0.51 \\
\hline & & Pub72 & 0.51 & 0.51 & 0.51 & 0.51 & 0.51 & 0.51 & 0.51 \\
\hline & Child & NRC77 & 2.98 & 0.60 & 0.60 & 0.60 & 0.60 & 0.60 & 0.60 \\
\hline & & Pub30 & 0.51 & 0.51 & 0.51 & 0.51 & 0.51 & 0.51 & 0.51 \\
\hline & & Pub72 & 0.88 & 0.88 & 0.88 & 0.88 & 0.88 & 0.88 & 0.88 \\
\hline & Infant & NRC77 & 3.77 & 0.81 & 0.81 & 0.81 & 0.81 & 0.81 & 0.81 \\
\hline & & Pub30 & 0.33 & 0.33 & 0.33 & 0.33 & 0.33 & 0.33 & 0.33 \\
\hline & & Pub72 & 0.78 & 0.78 & 0.78 & 0.78 & 0.78 & 0.78 & 0.78 \\
\hline \multirow[t]{12}{*}{ P-32 } & Adult & NRC77 & 1.00 & 0.06 & C & $\mathrm{C}$ & C & 0.11 & 0.04 \\
\hline & & Pub30 & 0.15 & 0.01 & 0.01 & 0.01 & 0.01 & 0.14 & 0.05 \\
\hline & & Pub72 & 0.16 & 0.01 & 0.01 & 0.01 & 0.01 & 0.16 & 0.05 \\
\hline & Teen & NRC77 & 1.00 & 0.06 & C & C & C & 0.08 & 0.04 \\
\hline & & Pub30 & 0.11 & 0.01 & 0.01 & 0.01 & 0.01 & 0.10 & 0.03 \\
\hline & & Pub72 & 0.11 & 0.01 & 0.01 & 0.01 & 0.01 & 0.14 & 0.04 \\
\hline & Child & NRC77 & 2.99 & 0.14 & C & C & C & 0.08 & 0.12 \\
\hline & & Pub30 & 0.11 & 0.01 & 0.01 & 0.01 & 0.01 & 0.10 & 0.03 \\
\hline & & Pub72 & 0.36 & 0.03 & 0.03 & 0.03 & 0.03 & 0.41 & 0.13 \\
\hline & Infant & NRC77 & 3.98 & 0.23 & C & C & C & 0.05 & 0.15 \\
\hline & & Pub30 & 0.07 & 0.01 & 0.01 & 0.01 & 0.01 & 0.06 & 0.02 \\
\hline & & Pub72 & 0.54 & 0.08 & 0.08 & 0.08 & 0.08 & 0.25 & 0.27 \\
\hline \multirow[t]{12}{*}{ Cr-51 } & Adult & NRC77 & C & $\mathrm{C}$ & $<0.005$ & $<0.005$ & 0.01 & 1.00 & $<0.005$ \\
\hline & & Pub30 & 0.04 & 0.04 & 0.02 & 0.05 & 0.02 & 1.37 & 0.22 \\
\hline & & Pub72 & 0.06 & 0.04 & 0.02 & 0.05 & 0.02 & 1.70 & 0.21 \\
\hline & Teen & NRC77 & C & C & $<0.005$ & $<0.005$ & 0.01 & 0.63 & $<0.005$ \\
\hline & & Pub30 & 0.03 & 0.03 & 0.01 & 0.03 & 0.02 & 0.96 & 0.15 \\
\hline & & Pub72 & 0.05 & 0.03 & 0.02 & 0.04 & 0.02 & 1.46 & 0.19 \\
\hline & Child & NRC77 & C & C & 0.01 & $<0.005$ & 0.01 & 0.49 & 0.01 \\
\hline & & Pub30 & 0.03 & 0.03 & 0.01 & 0.03 & 0.02 & 0.96 & 0.15 \\
\hline & & Pub72 & 0.11 & 0.09 & 0.05 & 0.10 & 0.05 & 4.06 & 0.48 \\
\hline & Infant & NRC77 & C & C & 0.01 & $<0.005$ & 0.01 & 0.28 & 0.01 \\
\hline & & Pub30 & 0.02 & 0.02 & 0.01 & 0.02 & 0.01 & 0.62 & 0.10 \\
\hline & & Pub72 & 0.28 & 0.22 & 0.16 & 0.21 & 0.16 & 7.18 & 0.86 \\
\hline
\end{tabular}




\begin{tabular}{|c|c|c|c|c|c|c|c|c|c|}
\hline \multicolumn{10}{|c|}{ Table B.3 (continued) } \\
\hline \multirow[b]{2}{*}{ Nuclide } & \multirow{2}{*}{$\begin{array}{l}\text { Age } \\
\text { group }\end{array}$} & \multirow{2}{*}{$\begin{array}{c}\text { Dose } \\
\text { system }\end{array}$} & \multicolumn{7}{|c|}{ Normalized dose commitment } \\
\hline & & & Bone $^{a}$ & Liver & Thyroid & Kidney & Lung & LLI & Tbody or eff $^{\mathrm{D}}$ \\
\hline \multirow{12}{*}{ Mn-54 } & \multirow[t]{3}{*}{ Adult } & NRC77 & $\mathrm{C}$ & 0.33 & $\mathrm{c}$ & 0.10 & $\mathrm{c}$ & 1.00 & 0.06 \\
\hline & & Pub30 & 0.15 & 0.26 & 0.04 & 0.10 & 0.06 & 0.58 & 0.20 \\
\hline & & Pub72 & 0.19 & 0.28 & 0.04 & 0.11 & 0.07 & 0.65 & 0.19 \\
\hline & \multirow[t]{3}{*}{ Teen } & NRC77 & $\mathrm{C}$ & 0.29 & $\mathrm{C}$ & 0.09 & $\mathrm{C}$ & 0.60 & 0.06 \\
\hline & & Pub30 & 0.11 & 0.18 & 0.02 & 0.07 & 0.04 & 0.41 & 0.14 \\
\hline & & Pub72 & 0.15 & 0.23 & 0.04 & 0.09 & 0.06 & 0.54 & 0.16 \\
\hline & \multirow[t]{3}{*}{ Child } & NRC77 & C & 0.53 & C & 0.15 & C & 0.45 & 0.14 \\
\hline & & Pub30 & 0.11 & 0.18 & 0.02 & 0.07 & 0.04 & 0.41 & 0.14 \\
\hline & & Pub72 & 0.36 & 0.46 & 0.08 & 0.20 & 0.12 & 1.23 & 0.35 \\
\hline & \multirow[t]{3}{*}{ Infant } & NRC77 & $\mathrm{C}$ & 0.64 & $\mathrm{C}$ & 0.14 & $\mathrm{C}$ & 0.24 & 0.15 \\
\hline & & Pub30 & 0.07 & 0.12 & 0.02 & 0.05 & 0.03 & 0.26 & 0.09 \\
\hline & & Pub72 & 0.90 & 1.14 & 0.22 & 0.45 & 0.34 & 1.85 & 0.66 \\
\hline \multirow[t]{12}{*}{ Fe-55 } & \multirow[t]{3}{*}{ Adult } & NRC77 & 1.00 & 0.69 & $\mathrm{C}$ & $\mathrm{C}$ & 0.39 & 0.40 & 0.16 \\
\hline & & Pub30 & 0.14 & 0.46 & 0.15 & 0.14 & 0.14 & 0.41 & 0.22 \\
\hline & & Pub72 & 0.80 & 0.99 & 0.12 & 0.12 & 0.12 & 0.49 & 0.45 \\
\hline & \multirow[t]{3}{*}{ Teen } & NRC77 & 0.96 & 0.68 & C & C & 0.43 & 0.29 & 0.16 \\
\hline & & Pub30 & 0.10 & 0.32 & 0.10 & 0.10 & 0.10 & 0.29 & 0.15 \\
\hline & & Pub72 & 1.66 & 1.39 & 0.18 & 0.18 & 0.18 & 0.47 & 0.72 \\
\hline & \multirow[t]{3}{*}{ Child } & NRC77 & 2.92 & 1.55 & C & C & 0.88 & 0.29 & 0.48 \\
\hline & & Pub30 & 0.10 & 0.32 & 0.10 & 0.10 & 0.10 & 0.29 & 0.15 \\
\hline & & Pub72 & 4.23 & 3.01 & 0.43 & 0.43 & 0.43 & 1.30 & 1.64 \\
\hline & \multirow[t]{3}{*}{ Infant } & NRC77 & 2.28 & 1.48 & C & C & 0.72 & 0.19 & 0.39 \\
\hline & & Pub30 & 0.06 & 0.21 & 0.07 & 0.06 & 0.06 & 0.19 & 0.10 \\
\hline & & Pub72 & 12.7 & 9.74 & 1.55 & 1.55 & 1.55 & 2.61 & 4.56 \\
\hline \multirow[t]{12}{*}{ Fe-59 } & \multirow[t]{3}{*}{ Adult } & NRC77 & 0.13 & 0.30 & $\mathrm{C}$ & $\mathrm{C}$ & 0.08 & 1.00 & 0.12 \\
\hline & & Pub30 & 0.07 & 0.17 & 0.07 & 0.10 & 0.07 & 0.92 & 0.20 \\
\hline & & Pub72 & 0.12 & 0.33 & 0.06 & 0.11 & 0.07 & 0.91 & 0.20 \\
\hline & \multirow[t]{3}{*}{ Teen } & NRC77 & 0.12 & 0.28 & C & C & 0.09 & 0.67 & 0.11 \\
\hline & & Pub30 & 0.05 & 0.12 & 0.05 & 0.07 & 0.05 & 0.64 & 0.14 \\
\hline & & Pub72 & 0.22 & 0.47 & 0.10 & 0.16 & 0.12 & 0.75 & 0.23 \\
\hline & \multirow[t]{3}{*}{ Child } & NRC77 & 0.34 & 0.55 & C & C & 0.16 & 0.57 & 0.27 \\
\hline & & Pub30 & 0.05 & 0.12 & 0.05 & 0.07 & 0.05 & 0.64 & 0.14 \\
\hline & & Pub72 & 0.61 & 1.08 & 0.25 & 0.37 & 0.27 & 2.01 & 0.57 \\
\hline & Infant & NRC77 & 0.41 & 0.72 & $\mathrm{C}$ & $\mathrm{C}$ & 0.21 & 0.34 & 0.28 \\
\hline & & Pub30 & 0.03 & 0.08 & 0.03 & 0.04 & 0.03 & 0.42 & 0.09 \\
\hline & & Pub72 & 3.62 & 3.85 & 1.14 & 1.38 & 1.18 & 2.79 & 1.94 \\
\hline Co-58 & Adult & NRC77 & $\mathrm{C}$ & 0.05 & $\mathrm{C}$ & $\mathrm{C}$ & $\mathrm{C}$ & 1.00 & 0.11 \\
\hline & & Pub30 & 0.03 & 0.06 & 0.02 & 0.05 & 0.02 & 0.97 & 0.20 \\
\hline & & Pub72 & 0.05 & 0.10 & 0.03 & 0.07 & 0.04 & 0.98 & 0.18 \\
\hline & Teen & NRC77 & $\mathrm{C}$ & 0.05 & $\mathrm{C}$ & $\mathrm{C}$ & $\mathrm{C}$ & 0.62 & 0.10 \\
\hline & & Pub30 & 0.02 & 0.04 & 0.01 & 0.04 & 0.01 & 0.68 & 0.14 \\
\hline & & Pub72 & 0.10 & 0.21 & 0.08 & 0.11 & 0.09 & 0.72 & 0.19 \\
\hline & Child & NRC77 & C & 0.08 & C & C & $\mathrm{C}$ & 0.49 & 0.25 \\
\hline & & Pub30 & 0.02 & 0.04 & 0.01 & 0.04 & 0.01 & 0.68 & 0.14 \\
\hline & & Pub72 & 0.21 & 0.44 & 0.20 & 0.26 & 0.19 & 1.83 & 0.44 \\
\hline & Infant & NRC77 & C & 0.11 & $\mathrm{C}$ & C & C & 0.27 & 0.27 \\
\hline & & Pub30 & 0.01 & 0.03 & 0.01 & 0.02 & 0.01 & 0.44 & 0.09 \\
\hline & & Pub72 & 0.58 & 1.13 & 0.58 & 0.64 & 0.54 & 2.32 & 0.81 \\
\hline
\end{tabular}




\begin{tabular}{|c|c|c|c|c|c|c|c|c|c|}
\hline \multicolumn{10}{|c|}{ Table B.3 (continued) } \\
\hline \multirow[b]{2}{*}{ Nuclide } & \multirow{2}{*}{$\begin{array}{l}\text { Age } \\
\text { group }\end{array}$} & \multirow{2}{*}{$\begin{array}{c}\text { Dose } \\
\text { system }\end{array}$} & \multicolumn{7}{|c|}{ Normalized dose commitment } \\
\hline & & & Bone $^{a}$ & Liver & Thyroid & Kidney & Lung & LLI & Tbody or eff $^{b}$ \\
\hline \multirow{12}{*}{ Co-60 } & \multirow[t]{3}{*}{ Adult } & NRC77 & $\mathrm{C}$ & 0.05 & $\mathrm{C}$ & $\mathrm{C}$ & $\mathrm{c}$ & 1.00 & 0.12 \\
\hline & & Pub30 & 0.09 & 0.21 & 0.07 & 0.12 & 0.08 & 1.02 & 0.26 \\
\hline & & Pub72 & 0.19 & 0.41 & 0.16 & 0.22 & 0.16 & 1.07 & 0.32 \\
\hline & \multirow[t]{3}{*}{ Teen } & NRC77 & $\mathrm{C}$ & 0.05 & $\mathrm{C}$ & $\mathrm{C}$ & $\mathrm{C}$ & 0.64 & 0.11 \\
\hline & & Pub30 & 0.06 & 0.15 & 0.05 & 0.09 & 0.06 & 0.71 & 0.18 \\
\hline & & Pub72 & 0.41 & 0.94 & 0.37 & 0.47 & 0.39 & 0.99 & 0.51 \\
\hline & \multirow[t]{3}{*}{ Child } & NRC77 & $\mathrm{C}$ & 0.09 & $\mathrm{C}$ & $\mathrm{C}$ & C & 0.51 & 0.27 \\
\hline & & Pub30 & 0.06 & 0.15 & 0.05 & 0.09 & 0.06 & 0.71 & 0.18 \\
\hline & & Pub72 & 0.85 & 1.83 & 0.86 & 0.98 & 0.79 & 2.40 & 1.09 \\
\hline & \multirow[t]{3}{*}{ Infant } & NRC77 & $\mathrm{C}$ & 0.12 & C & $\mathrm{C}$ & C & 0.29 & 0.29 \\
\hline & & Pub30 & 0.04 & 0.10 & 0.03 & 0.06 & 0.04 & 0.46 & 0.12 \\
\hline & & Pub72 & 1.99 & 4.11 & 2.08 & 2.21 & 1.89 & 3.63 & 2.26 \\
\hline \multirow[t]{12}{*}{$\mathrm{Ni}-63$} & \multirow[t]{3}{*}{ Adult } & NRC77 & 1.00 & 0.07 & $\mathrm{C}$ & $\mathrm{C}$ & C & 0.01 & 0.03 \\
\hline & & Pub30 & $<0.005$ & $<0.005$ & $<0.005$ & $<0.005$ & $<0.005$ & 0.03 & $<0.005$ \\
\hline & & Pub72 & $<0.005$ & $<0.005$ & $<0.005$ & $<0.005$ & $<0.005$ & 0.03 & $<0.005$ \\
\hline & \multirow[t]{3}{*}{ Teen } & NRC77 & 0.95 & 0.07 & C & C & C & 0.01 & 0.03 \\
\hline & & Pub30 & $<0.005$ & $<0.005$ & $<0.005$ & $<0.005$ & $<0.005$ & 0.02 & $<0.005$ \\
\hline & & Pub72 & $<0.005$ & $<0.005$ & $<0.005$ & $<0.005$ & $<0.005$ & 0.02 & $<0.005$ \\
\hline & \multirow[t]{3}{*}{ Child } & NRC77 & 2.89 & 0.15 & C & C & C & 0.01 & 0.10 \\
\hline & & Pub30 & $<0.005$ & $<0.005$ & $<0.005$ & $<0.005$ & $<0.005$ & 0.02 & $<0.005$ \\
\hline & & Pub72 & $<0.005$ & $<0.005$ & $<0.005$ & $<0.005$ & $<0.005$ & 0.07 & 0.01 \\
\hline & \multirow[t]{3}{*}{ Infant } & NRC77 & 2.20 & 0.14 & C & C & C & 0.01 & 0.08 \\
\hline & & Pub30 & $<0.005$ & $<0.005$ & $<0.005$ & $<0.005$ & $<0.005$ & 0.01 & $<0.005$ \\
\hline & & Pub72 & 0.01 & 0.01 & 0.01 & 0.01 & 0.01 & 0.13 & 0.02 \\
\hline \multirow[t]{12}{*}{ Cu-64 } & \multirow[t]{3}{*}{ Adult } & NRC77 & $\mathrm{C}$ & 0.01 & $\mathrm{C}$ & 0.03 & $\mathrm{C}$ & 1.00 & 0.01 \\
\hline & & Pub30 & 0.01 & 0.02 & 0.01 & 0.01 & 0.01 & 0.39 & 0.07 \\
\hline & & Pub72 & 0.01 & 0.02 & 0.01 & 0.01 & 0.01 & 0.39 & 0.06 \\
\hline & \multirow[t]{3}{*}{ Teen } & NRC77 & $\mathrm{C}$ & 0.01 & $\mathrm{C}$ & 0.03 & $\mathrm{C}$ & 0.88 & 0.01 \\
\hline & & Pub30 & 0.01 & 0.01 & 0.00 & 0.01 & 0.00 & 0.27 & 0.05 \\
\hline & & Pub72 & 0.01 & 0.02 & 0.01 & 0.01 & 0.01 & 0.34 & 0.06 \\
\hline & \multirow[t]{3}{*}{ Child } & NRC77 & $\mathrm{C}$ & 0.02 & $\mathrm{C}$ & 0.06 & C & 1.13 & 0.01 \\
\hline & & Pub30 & 0.01 & 0.01 & 0.00 & 0.01 & 0.00 & 0.27 & 0.05 \\
\hline & & Pub72 & 0.02 & 0.04 & 0.01 & 0.02 & 0.02 & 0.99 & 0.15 \\
\hline & Infant & NRC77 & $\mathrm{C}$ & 0.04 & $\mathrm{C}$ & 0.07 & $\mathrm{C}$ & 0.80 & 0.02 \\
\hline & & Pub30 & 0.00 & 0.01 & 0.00 & 0.00 & 0.00 & 0.18 & 0.03 \\
\hline & & Pub72 & 0.06 & 0.14 & 0.06 & 0.06 & 0.06 & 0.12 & 0.12 \\
\hline Zn-65 & Adult & NRC77 & 0.31 & 1.00 & $\mathrm{C}$ & 0.67 & $\mathrm{C}$ & 0.63 & 0.45 \\
\hline & & Pub30 & 1.08 & 0.89 & 0.77 & 0.93 & 0.74 & 1.20 & 0.94 \\
\hline & & Pub72 & 1.32 & 0.88 & 0.85 & 0.93 & 0.79 & 1.27 & 0.95 \\
\hline & Teen & NRC77 & 0.26 & 0.91 & C & 0.58 & C & 0.38 & 0.42 \\
\hline & & Pub30 & 0.76 & 0.62 & 0.54 & 0.65 & 0.52 & 0.84 & 0.66 \\
\hline & & Pub72 & 1.04 & 0.71 & 0.69 & 0.75 & 0.65 & 0.96 & 0.76 \\
\hline & Child & NRC77 & 0.62 & 1.66 & C & 1.04 & C & 0.29 & 1.03 \\
\hline & & Pub30 & 0.76 & 0.62 & 0.54 & 0.65 & 0.52 & 0.84 & 0.66 \\
\hline & & Pub72 & 2.25 & 1.55 & 1.60 & 1.64 & 1.38 & 2.22 & 1.64 \\
\hline & Infant & NRC77 & 0.54 & 1.85 & $\mathrm{C}$ & 0.90 & C & 1.56 & 0.85 \\
\hline & & Pub30 & 0.49 & 0.40 & 0.35 & 0.42 & 0.33 & 0.54 & 0.42 \\
\hline & & Pub72 & 5.65 & 3.98 & 4.10 & 4.21 & 3.65 & 4.34 & 3.95 \\
\hline
\end{tabular}




\begin{tabular}{|c|c|c|c|c|c|c|c|c|c|}
\hline \multicolumn{10}{|c|}{ Table B.3 (continued) } \\
\hline \multirow[b]{2}{*}{ Nuclide } & \multirow{2}{*}{$\begin{array}{l}\text { Age } \\
\text { group }\end{array}$} & \multirow{2}{*}{$\begin{array}{l}\text { Dose } \\
\text { system }\end{array}$} & \multicolumn{7}{|c|}{ Normalized dose commitment } \\
\hline & & & Bone $^{a}$ & Liver & Thyroid & Kidney & Lung & LLI & Tbody or eff $^{b}$ \\
\hline \multirow[t]{12}{*}{ Sr-89 } & Adult & NRC77 & 1.00 & $\mathrm{C}$ & $\mathrm{C}$ & $\mathrm{C}$ & $\mathrm{C}$ & 0.16 & 0.03 \\
\hline & & Pub30 & 0.06 & $<0.005$ & $<0.005$ & $<0.005$ & $<0.005$ & 0.25 & 0.03 \\
\hline & & Pub72 & 0.07 & $<0.005$ & $<0.005$ & $<0.005$ & $<0.005$ & 0.27 & 0.03 \\
\hline & Teen & NRC77 & 1.00 & c & c & c & c & 0.12 & 0.03 \\
\hline & & Pub30 & 0.04 & $<0.005$ & $<0.005$ & $<0.005$ & $<0.005$ & 0.17 & 0.02 \\
\hline & & Pub72 & 0.18 & $<0.005$ & $<0.005$ & $<0.005$ & $<0.005$ & 0.19 & 0.03 \\
\hline & Child & NRC77 & 2.99 & C & C & C & C & 0.12 & 0.09 \\
\hline & & Pub30 & 0.04 & $<0.005$ & $<0.005$ & $<0.005$ & $<0.005$ & 0.17 & 0.02 \\
\hline & & Pub72 & 0.26 & 0.01 & 0.01 & 0.01 & 0.01 & 0.61 & 0.07 \\
\hline & Infant & NRC77 & 3.68 & C & C & C & C & 0.08 & 0.11 \\
\hline & & Pub30 & 0.03 & $<0.005$ & $<0.005$ & $<0.005$ & $<0.005$ & 0.11 & 0.01 \\
\hline & & Pub72 & 0.88 & 0.02 & 0.02 & 0.02 & 0.02 & 0.83 & 0.20 \\
\hline \multirow[t]{12}{*}{ Sr-90 } & Adult & NRC77 & 1.00 & $\mathrm{C}$ & $\mathrm{C}$ & $\mathrm{C}$ & C & 0.03 & 0.25 \\
\hline & & Pub30 & 0.20 & $<0.005$ & $<0.005$ & $<0.005$ & $<0.005$ & 0.01 & 0.02 \\
\hline & & Pub72 & 0.20 & $<0.005$ & $<0.005$ & $<0.005$ & $<0.005$ & 0.01 & 0.01 \\
\hline & Teen & NRC77 & 0.77 & C & C & C & C & 0.02 & 0.19 \\
\hline & & Pub30 & 0.14 & $<0.005$ & $<0.005$ & $<0.005$ & $<0.005$ & 0.01 & 0.01 \\
\hline & & Pub72 & 0.62 & $<0.005$ & $<0.005$ & $<0.005$ & $<0.005$ & 0.01 & 0.03 \\
\hline & Child & NRC77 & 1.57 & C & C & C & C & 0.02 & 0.40 \\
\hline & & Pub30 & 0.14 & $<0.005$ & $<0.005$ & $<0.005$ & $<0.005$ & 0.01 & 0.01 \\
\hline & & Pub72 & 0.22 & $<0.005$ & $<0.005$ & $<0.005$ & $<0.005$ & 0.03 & 0.02 \\
\hline & Infant & NRC77 & 1.10 & $\mathrm{C}$ & c & C & C & 0.01 & 0.28 \\
\hline & & Pub30 & 0.09 & $<0.005$ & $<0.005$ & $<0.005$ & $<0.005$ & 0.00 & 0.01 \\
\hline & & Pub72 & 0.50 & $<0.005$ & $<0.005$ & $<0.005$ & $<0.005$ & 0.04 & 0.05 \\
\hline \multirow[t]{12}{*}{ Y-90 } & Adult & NRC77 & $<0.005$ & C & C & $\mathrm{C}$ & C & 1.00 & $<0.005$ \\
\hline & & Pub30 & $<0.005$ & $<0.005$ & $<0.005$ & $<0.005$ & $<0.005$ & 1.15 & 0.11 \\
\hline & & Pub72 & $<0.005$ & $<0.005$ & $<0.005$ & $<0.005$ & $<0.005$ & 1.14 & 0.10 \\
\hline & Teen & NRC77 & $<0.005$ & C & C & C & C & 0.77 & $<0.005$ \\
\hline & & Pub30 & $<0.005$ & $<0.005$ & $<0.005$ & $<0.005$ & $<0.005$ & 0.80 & 0.07 \\
\hline & & Pub72 & $<0.005$ & $<0.005$ & $<0.005$ & $<0.005$ & $<0.005$ & 0.99 & 0.08 \\
\hline & Child & NRC77 & $<0.005$ & C & C & C & C & 0.80 & $<0.005$ \\
\hline & & Pub30 & $<0.005$ & $<0.005$ & $<0.005$ & $<0.005$ & $<0.005$ & 0.80 & 0.07 \\
\hline & & Pub72 & $<0.005$ & $<0.005$ & $<0.005$ & $<0.005$ & $<0.005$ & 2.94 & 0.25 \\
\hline & Infant & NRC77 & $<0.005$ & C & C & C & C & 0.53 & $<0.005$ \\
\hline & & Pub30 & $<0.005$ & $<0.005$ & $<0.005$ & $<0.005$ & $<0.005$ & 0.52 & 0.05 \\
\hline & & Pub72 & $<0.005$ & $<0.005$ & $<0.005$ & $<0.005$ & $<0.005$ & 5.93 & 0.51 \\
\hline \multirow[t]{12}{*}{ Zr-95 } & Adult & NRC77 & $<0.005$ & $<0.005$ & $\mathrm{C}$ & $<0.005$ & $\mathrm{C}$ & 1.00 & $<0.005$ \\
\hline & & Pub30 & 0.06 & 0.01 & $<0.005$ & 0.01 & $<0.005$ & 0.94 & 0.12 \\
\hline & & Pub72 & 0.27 & 0.01 & 0.01 & 0.02 & 0.01 & 0.94 & 0.12 \\
\hline & Teen & NRC77 & $<0.005$ & $<0.005$ & C & $<0.005$ & C & 0.68 & $<0.005$ \\
\hline & & Pub30 & 0.04 & 0.01 & $<0.005$ & 0.01 & $<0.005$ & 0.65 & 0.09 \\
\hline & & Pub72 & 0.18 & 0.01 & $<0.005$ & 0.02 & 0.01 & 0.81 & 0.10 \\
\hline & Child & NRC77 & $<0.005$ & $<0.005$ & C & $<0.005$ & C & 0.60 & $<0.005$ \\
\hline & & Pub30 & 0.04 & 0.01 & $<0.005$ & 0.01 & $<0.005$ & 0.65 & 0.09 \\
\hline & & Pub72 & 0.52 & 0.03 & 0.01 & 0.04 & 0.01 & 2.24 & 0.26 \\
\hline & Infant & NRC77 & $<0.005$ & $<0.005$ & $\mathrm{C}$ & $<0.005$ & $\mathrm{C}$ & 0.37 & $<0.005$ \\
\hline & & Pub30 & 0.03 & $<0.005$ & $<0.005$ & 0.01 & $<0.005$ & 0.42 & 0.06 \\
\hline & & Pub72 & 0.81 & 0.05 & 0.02 & 0.05 & 0.03 & 4.22 & 0.46 \\
\hline
\end{tabular}




\begin{tabular}{|c|c|c|c|c|c|c|c|c|c|}
\hline \multicolumn{10}{|c|}{ Table B.3 (continued) } \\
\hline \multirow[b]{2}{*}{ Nuclide } & \multirow{2}{*}{$\begin{array}{l}\text { Age } \\
\text { group }\end{array}$} & \multirow{2}{*}{$\begin{array}{l}\text { Dose } \\
\text { system }\end{array}$} & \multicolumn{7}{|c|}{ Normalized dose commitment } \\
\hline & & & Bone $^{a}$ & Liver & Thyroid & Kidney & Lung & LLI & Tbody or eff $^{b}$ \\
\hline \multirow{12}{*}{$\mathrm{Nb}-95$} & Adult & NRC77 & $<0.005$ & $<0.005$ & $\mathrm{c}$ & $<0.005$ & $\mathrm{C}$ & 1.00 & $<0.005$ \\
\hline & & Pub30 & 0.05 & 0.01 & $<0.005$ & 0.02 & $<0.005$ & 0.71 & 0.12 \\
\hline & & Pub72 & 0.02 & 0.03 & $<0.005$ & 0.03 & 0.01 & 0.71 & 0.10 \\
\hline & Teen & NRC77 & $<0.005$ & $<0.005$ & c & $<0.005$ & C & 0.65 & $<0.005$ \\
\hline & & Pub30 & 0.04 & 0.01 & $<0.005$ & 0.02 & $<0.005$ & 0.49 & 0.09 \\
\hline & & Pub72 & 0.01 & 0.02 & $<0.005$ & 0.02 & 0.01 & 0.61 & 0.09 \\
\hline & Child & NRC77 & $<0.005$ & $<0.005$ & C & $<0.005$ & $\mathrm{C}$ & 0.54 & $<0.005$ \\
\hline & & Pub30 & 0.04 & 0.01 & $<0.005$ & 0.02 & $<0.005$ & 0.49 & 0.09 \\
\hline & & Pub72 & 0.03 & 0.06 & 0.01 & 0.05 & 0.01 & 1.59 & 0.22 \\
\hline & Infant & NRC77 & $<0.005$ & $<0.005$ & C & $<0.005$ & C & 0.31 & $<0.005$ \\
\hline & & Pub30 & 0.02 & 0.01 & $<0.005$ & 0.01 & $<0.005$ & 0.32 & 0.06 \\
\hline & & Pub72 & 0.07 & 0.11 & 0.01 & 0.09 & 0.03 & 2.81 & 0.36 \\
\hline \multirow[t]{12}{*}{ Mo-99 } & Adult & NRC77 & $\mathrm{C}$ & 0.43 & $\mathrm{C}$ & 0.98 & $\mathrm{C}$ & 1.00 & 0.08 \\
\hline & & Pub30 & 0.29 & 0.99 & 0.06 & 0.92 & 0.07 & 1.16 & 0.30 \\
\hline & & Pub72 & 0.38 & 1.03 & 0.09 & 1.15 & 0.10 & 0.21 & 0.22 \\
\hline & Teen & NRC77 & $\mathrm{C}$ & 0.42 & $\mathrm{C}$ & 0.97 & $\mathrm{C}$ & 0.76 & 0.08 \\
\hline & & Pub30 & 0.20 & 0.69 & 0.04 & 0.64 & 0.05 & 0.81 & 0.21 \\
\hline & & Pub72 & 0.28 & 0.92 & 0.08 & 1.00 & 0.09 & 0.18 & 0.20 \\
\hline & Child & NRC77 & C & 1.28 & C & 1.99 & C & 0.77 & 0.23 \\
\hline & & Pub30 & 0.20 & 0.69 & 0.04 & 0.64 & 0.05 & 0.81 & 0.21 \\
\hline & & Pub72 & 0.85 & 2.16 & 0.22 & 2.13 & 0.23 & 0.52 & 0.46 \\
\hline & Infant & NRC77 & $\mathrm{C}$ & 1.54 & C & 2.30 & C & 0.51 & 0.30 \\
\hline & & Pub30 & 0.13 & 0.45 & 0.03 & 0.42 & 0.03 & 0.53 & 0.14 \\
\hline & & Pub72 & 1.17 & 4.02 & 0.43 & 3.96 & 0.45 & 1.03 & 0.92 \\
\hline \multirow[t]{12}{*}{ Tc-99m } & Adult & NRC77 & $<0.005$ & $<0.005$ & $\mathrm{C}$ & 0.03 & $<0.005$ & 1.00 & 0.02 \\
\hline & & Pub30 & 0.04 & 0.04 & 0.76 & 0.05 & 0.03 & 0.23 & 0.15 \\
\hline & & Pub72 & 0.05 & 0.04 & 0.43 & 0.05 & 0.02 & 0.48 & 0.20 \\
\hline & Teen & NRC77 & $<0.005$ & $<0.005$ & $\mathrm{C}$ & 0.02 & $<0.005$ & 1.03 & 0.02 \\
\hline & & Pub30 & 0.03 & 0.03 & 0.53 & 0.03 & 0.02 & 0.16 & 0.11 \\
\hline & & Pub72 & 0.04 & 0.04 & 0.46 & 0.04 & 0.02 & 0.42 & 0.18 \\
\hline & Child & NRC77 & $<0.005$ & $<0.005$ & C & 0.04 & $<0.005$ & 1.74 & 0.05 \\
\hline & & Pub30 & 0.03 & 0.03 & 0.53 & 0.03 & 0.02 & 0.16 & 0.11 \\
\hline & & Pub72 & 0.08 & 0.10 & 1.55 & 0.09 & 0.04 & 1.12 & 0.45 \\
\hline & Infant & NRC77 & $<0.005$ & $<0.005$ & $\mathrm{C}$ & 0.05 & $<0.005$ & 1.26 & 0.06 \\
\hline & & Pub30 & 0.02 & 0.02 & 0.34 & 0.02 & 0.01 & 0.10 & 0.07 \\
\hline & & Pub72 & 0.17 & 0.15 & 5.19 & 0.13 & 0.12 & 0.43 & 0.83 \\
\hline \multirow[t]{12}{*}{ Ru-106 } & Adult & NRC77 & 0.02 & $\mathrm{C}$ & $\mathrm{C}$ & 0.03 & $\mathrm{C}$ & 1.00 & $<0.005$ \\
\hline & & Pub30 & 0.03 & 0.03 & 0.03 & 0.03 & 0.03 & 1.48 & 0.15 \\
\hline & & Pub72 & 0.03 & 0.03 & 0.03 & 0.03 & 0.03 & 1.49 & 0.15 \\
\hline & Teen & NRC77 & 0.02 & C & C & 0.03 & C & 0.74 & $<0.005$ \\
\hline & & Pub30 & 0.02 & 0.02 & 0.02 & 0.02 & 0.02 & 1.03 & 0.11 \\
\hline & & Pub72 & 0.03 & 0.03 & 0.03 & 0.03 & 0.03 & 1.29 & 0.13 \\
\hline & Child & NRC77 & 0.05 & C & $\mathrm{C}$ & 0.06 & C & 0.71 & 0.01 \\
\hline & & Pub30 & 0.02 & 0.02 & 0.02 & 0.02 & 0.02 & 1.03 & 0.11 \\
\hline & & Pub72 & 0.07 & 0.07 & 0.07 & 0.07 & 0.07 & 3.84 & 0.37 \\
\hline & Infant & NRC77 & 0.06 & $\mathrm{C}$ & C & 0.07 & $\mathrm{C}$ & 0.46 & 0.01 \\
\hline & & Pub30 & 0.01 & 0.01 & 0.01 & 0.01 & 0.01 & 0.67 & 0.07 \\
\hline & & Pub72 & 0.22 & 0.22 & 0.22 & 0.22 & 0.21 & 7.43 & 0.79 \\
\hline
\end{tabular}




\begin{tabular}{|c|c|c|c|c|c|c|c|c|c|}
\hline \multicolumn{10}{|c|}{ Table B.3 (continued) } \\
\hline \multirow[b]{2}{*}{ Nuclide } & \multirow{2}{*}{$\begin{array}{l}\text { Age } \\
\text { group }\end{array}$} & \multirow{2}{*}{$\begin{array}{c}\text { Dose } \\
\text { system }\end{array}$} & \multicolumn{7}{|c|}{ Normalized dose commitment } \\
\hline & & & Bone $^{a}$ & Liver & Thyroid & Kidney & Lung & LLI & Tbody or eff $^{b}$ \\
\hline \multirow[t]{12}{*}{$\mathrm{Ag}-110 \mathrm{~m}$} & \multirow[t]{3}{*}{ Adult } & NRC77 & $<0.005$ & $<0.005$ & $\mathrm{c}$ & $<0.005$ & $\mathrm{C}$ & 1.00 & $<0.005$ \\
\hline & & Pub30 & 0.03 & 0.53 & 0.01 & 0.09 & 0.05 & 0.66 & 0.18 \\
\hline & & Pub72 & 0.05 & 0.47 & 0.03 & 0.10 & 0.06 & 0.71 & 0.17 \\
\hline & \multirow[t]{3}{*}{ Teen } & NRC77 & $<0.005$ & $<0.005$ & C & $<0.005$ & C & 0.63 & $<0.005$ \\
\hline & & Pub30 & 0.02 & 0.37 & 0.01 & 0.06 & 0.04 & 0.46 & 0.13 \\
\hline & & Pub72 & 0.04 & 0.38 & 0.02 & 0.08 & 0.05 & 0.60 & 0.15 \\
\hline & \multirow[t]{3}{*}{ Child } & NRC77 & 0.01 & $<0.005$ & $\mathrm{C}$ & 0.01 & $\mathrm{C}$ & 0.50 & $<0.005$ \\
\hline & & Pub30 & 0.02 & 0.37 & 0.01 & 0.06 & 0.04 & 0.46 & 0.13 \\
\hline & & Pub72 & 0.10 & 0.77 & 0.06 & 0.19 & 0.11 & 1.51 & 0.34 \\
\hline & \multirow[t]{3}{*}{ Infant } & NRC77 & 0.01 & 0.01 & $\mathrm{C}$ & 0.01 & $\mathrm{C}$ & 0.28 & $<0.005$ \\
\hline & & Pub30 & 0.01 & 0.24 & 0.01 & 0.04 & 0.02 & 0.30 & 0.08 \\
\hline & & Pub72 & 0.26 & 1.98 & 0.18 & 0.40 & 0.31 & 2.58 & 0.67 \\
\hline \multirow[t]{12}{*}{$1-131$} & \multirow[t]{3}{*}{ Adult } & NRC77 & $<0.005$ & $<0.005$ & 1.00 & 0.01 & C & $<0.005$ & $<0.005$ \\
\hline & & Pub30 & $<0.005$ & $<0.005$ & 0.90 & $<0.005$ & $<0.005$ & $<0.005$ & 0.03 \\
\hline & & Pub72 & $<0.005$ & $<0.005$ & 0.82 & $<0.005$ & $<0.005$ & $<0.005$ & 0.04 \\
\hline & \multirow[t]{3}{*}{ Teen } & NRC77 & $<0.005$ & $<0.005$ & 0.86 & 0.01 & C & $<0.005$ & $<0.005$ \\
\hline & & Pub30 & $<0.005$ & $<0.005$ & 0.63 & $<0.005$ & $<0.005$ & $<0.005$ & 0.02 \\
\hline & & Pub72 & $<0.005$ & $<0.005$ & 0.90 & $<0.005$ & $<0.005$ & $<0.005$ & 0.05 \\
\hline & \multirow[t]{3}{*}{ Child } & NRC77 & 0.01 & 0.01 & 2.05 & 0.01 & C & $<0.005$ & $<0.005$ \\
\hline & & Pub30 & $<0.005$ & $<0.005$ & 0.63 & $<0.005$ & $<0.005$ & $<0.005$ & 0.02 \\
\hline & & Pub72 & $<0.005$ & $<0.005$ & 2.73 & $<0.005$ & $<0.005$ & $<0.005$ & 0.14 \\
\hline & \multirow[t]{3}{*}{ Infant } & NRC77 & 0.01 & 0.01 & 3.22 & 0.01 & C & $<0.005$ & $<0.005$ \\
\hline & & Pub30 & $<0.005$ & $<0.005$ & 0.41 & $<0.005$ & $<0.005$ & $<0.005$ & 0.01 \\
\hline & & Pub72 & $<0.005$ & $<0.005$ & 3.14 & $<0.005$ & $<0.005$ & $<0.005$ & 0.16 \\
\hline \multirow[t]{12}{*}{$\mathrm{I}-133$} & \multirow[t]{3}{*}{ Adult } & NRC77 & $<0.005$ & 0.01 & 1.00 & 0.01 & $\mathrm{C}$ & 0.01 & $<0.005$ \\
\hline & & Pub30 & $<0.005$ & $<0.005$ & 0.93 & $<0.005$ & $<0.005$ & $<0.005$ & 0.03 \\
\hline & & Pub72 & $<0.005$ & $<0.005$ & 0.84 & $<0.005$ & $<0.005$ & $<0.005$ & 0.04 \\
\hline & \multirow[t]{3}{*}{ Teen } & NRC77 & $<0.005$ & 0.01 & 0.92 & 0.01 & C & 0.01 & $<0.005$ \\
\hline & & Pub30 & $<0.005$ & $<0.005$ & 0.65 & $<0.005$ & $<0.005$ & $<0.005$ & 0.02 \\
\hline & & Pub72 & $<0.005$ & $<0.005$ & 0.94 & $<0.005$ & $<0.005$ & $<0.005$ & 0.05 \\
\hline & \multirow[t]{3}{*}{ Child } & NRC77 & 0.01 & 0.01 & 2.62 & 0.02 & C & 0.01 & 0.01 \\
\hline & & Pub30 & $<0.005$ & $<0.005$ & 0.65 & $<0.005$ & $<0.005$ & $<0.005$ & 0.02 \\
\hline & & Pub72 & $<0.005$ & $<0.005$ & 3.25 & $<0.005$ & $<0.005$ & $<0.005$ & 0.17 \\
\hline & Infant & NRC77 & 0.02 & 0.02 & 4.12 & 0.03 & C & $<0.005$ & 0.01 \\
\hline & & Pub30 & $<0.005$ & $<0.005$ & 0.42 & $<0.005$ & $<0.005$ & $<0.005$ & 0.01 \\
\hline & & Pub72 & $<0.005$ & $<0.005$ & 4.43 & $<0.005$ & $<0.005$ & 0.01 & 0.23 \\
\hline Cs-134 & Adult & NRC77 & 0.42 & 1.00 & $\mathrm{C}$ & 0.32 & 0.11 & 0.02 & 0.82 \\
\hline & & Pub30 & 0.44 & 0.50 & 0.44 & 0.50 & 0.44 & 0.55 & 0.50 \\
\hline & & Pub72 & 0.50 & 0.50 & 0.47 & 0.49 & 0.44 & 0.57 & 0.48 \\
\hline & Teen & NRC77 & 0.40 & 0.93 & C & 0.30 & 0.11 & 0.01 & 0.43 \\
\hline & & Pub30 & 0.30 & 0.35 & 0.31 & 0.35 & 0.31 & 0.38 & 0.35 \\
\hline & & Pub72 & 0.34 & 0.34 & 0.33 & 0.34 & 0.31 & 0.36 & 0.33 \\
\hline & Child & NRC77 & 1.10 & 1.81 & C & 0.56 & 0.20 & 0.01 & 0.38 \\
\hline & & Pub30 & 0.30 & 0.35 & 0.31 & 0.35 & 0.31 & 0.38 & 0.35 \\
\hline & & Pub72 & 0.22 & 0.23 & 0.23 & 0.22 & 0.20 & 0.36 & 0.23 \\
\hline & Infant & NRC77 & 1.15 & 2.15 & C & 0.55 & 0.23 & 0.01 & 0.22 \\
\hline & & Pub30 & 0.20 & 0.23 & 0.20 & 0.23 & 0.20 & 0.25 & 0.22 \\
\hline & & Pub72 & 0.27 & 0.28 & 0.29 & 0.28 & 0.25 & 0.52 & 0.29 \\
\hline
\end{tabular}




\begin{tabular}{|c|c|c|c|c|c|c|c|c|c|}
\hline \multicolumn{10}{|c|}{ Table B.3 (continued) } \\
\hline \multirow[b]{2}{*}{ Nuclide } & \multirow{2}{*}{$\begin{array}{c}\text { Age } \\
\text { group }\end{array}$} & \multirow{2}{*}{$\begin{array}{l}\text { Dose } \\
\text { system }\end{array}$} & \multicolumn{7}{|c|}{ Normalized dose commitment } \\
\hline & & & Bone $^{a}$ & Liver & Thyroid & Kidney & Lung & LLI & Tbody or eff $^{b}$ \\
\hline \multirow{12}{*}{ Cs-137 } & Adult & NRC77 & 0.73 & 1.00 & $\mathrm{C}$ & 0.34 & 0.11 & 0.02 & 0.66 \\
\hline & & Pub30 & 0.43 & 0.46 & 0.43 & 0.47 & 0.43 & 0.49 & 0.46 \\
\hline & & Pub72 & 0.47 & 0.46 & 0.45 & 0.46 & 0.43 & 0.57 & 0.46 \\
\hline & Teen & NRC77 & 0.72 & 0.96 & C & 0.33 & 0.13 & 0.01 & 0.33 \\
\hline & & Pub30 & 0.30 & 0.32 & 0.30 & 0.33 & 0.30 & 0.34 & 0.32 \\
\hline & & Pub72 & 0.32 & 0.32 & 0.31 & 0.32 & 0.30 & 0.39 & 0.32 \\
\hline & Child & NRC77 & 2.10 & 2.01 & $\mathrm{C}$ & 0.65 & 0.24 & 0.01 & 0.30 \\
\hline & & Pub30 & 0.30 & 0.32 & 0.30 & 0.33 & 0.30 & 0.34 & 0.32 \\
\hline & & Pub72 & 0.21 & 0.21 & 0.21 & 0.21 & 0.20 & 0.46 & 0.23 \\
\hline & Infant & NRC77 & 2.16 & 2.53 & C & 0.68 & 0.28 & 0.01 & 0.18 \\
\hline & & Pub30 & 0.19 & 0.21 & 0.19 & 0.21 & 0.20 & 0.22 & 0.21 \\
\hline & & Pub72 & 0.29 & 0.29 & 0.29 & 0.28 & 0.27 & 0.74 & 0.32 \\
\hline \multirow[t]{12}{*}{ Ba-140 } & Adult & NRC77 & 0.49 & $<0.005$ & $\mathrm{C}$ & $<0.005$ & $<0.005$ & 1.00 & 0.03 \\
\hline & & Pub30 & 0.05 & 0.01 & $<0.005$ & 0.01 & 0.01 & 2.34 & 0.23 \\
\hline & & Pub72 & 0.15 & 0.01 & 0.01 & 0.02 & 0.01 & 2.53 & 0.23 \\
\hline & Teen & NRC77 & 0.47 & $<0.005$ & C & $<0.005$ & $<0.005$ & 0.73 & 0.03 \\
\hline & & Pub30 & 0.03 & 0.01 & $<0.005$ & 0.01 & $<0.005$ & 1.63 & 0.16 \\
\hline & & Pub72 & 0.59 & 0.03 & 0.03 & 0.04 & 0.03 & 1.93 & 0.23 \\
\hline & Child & NRC77 & 1.39 & $<0.005$ & c & $<0.005$ & $<0.005$ & 0.70 & 0.08 \\
\hline & & Pub30 & 0.03 & 0.01 & $<0.005$ & 0.01 & $<0.005$ & 1.63 & 0.16 \\
\hline & & Pub72 & 0.74 & 0.04 & 0.03 & 0.06 & 0.04 & 6.10 & 0.57 \\
\hline & Infant & NRC77 & 1.85 & $<0.005$ & $\mathrm{C}$ & $<0.005$ & $<0.005$ & 0.45 & 0.10 \\
\hline & & Pub30 & 0.02 & $<0.005$ & $<0.005$ & 0.01 & $<0.005$ & 1.06 & 0.10 \\
\hline & & Pub72 & 4.17 & 0.20 & 0.15 & 0.27 & 0.23 & 8.85 & 1.27 \\
\hline \multirow[t]{12}{*}{ La-140 } & Adult & NRC77 & $<0.005$ & $<0.005$ & $\mathrm{C}$ & $\mathrm{C}$ & $\mathrm{C}$ & 1.00 & $<0.005$ \\
\hline & & Pub30 & $<0.005$ & 0.01 & $<0.005$ & 0.01 & $<0.005$ & 0.70 & 0.09 \\
\hline & & Pub72 & $<0.005$ & 0.01 & $<0.005$ & 0.01 & $<0.005$ & 0.70 & 0.08 \\
\hline & Teen & NRC77 & $<0.005$ & $<0.005$ & C & C & C & 0.74 & $<0.005$ \\
\hline & & Pub30 & $<0.005$ & $<0.005$ & $<0.005$ & 0.01 & $<0.005$ & 0.49 & 0.06 \\
\hline & & Pub72 & $<0.005$ & 0.01 & $<0.005$ & 0.01 & $<0.005$ & 0.60 & 0.07 \\
\hline & Child & NRC77 & $<0.005$ & $<0.005$ & C & $\mathrm{C}$ & C & 0.74 & $<0.005$ \\
\hline & & Pub30 & $<0.005$ & $<0.005$ & $<0.005$ & 0.01 & $<0.005$ & 0.49 & 0.06 \\
\hline & & Pub72 & 0.01 & 0.02 & $<0.005$ & 0.02 & $<0.005$ & 1.71 & 0.19 \\
\hline & Infant & NRC77 & $<0.005$ & $<0.005$ & C & C & C & 0.48 & $<0.005$ \\
\hline & & Pub30 & $<0.005$ & $<0.005$ & $<0.005$ & $<0.005$ & $<0.005$ & 0.32 & 0.04 \\
\hline & & Pub72 & 0.02 & 0.03 & $<0.005$ & 0.02 & 0.01 & 3.31 & 0.35 \\
\hline \multirow[t]{12}{*}{ Np-239 } & Adult & NRC77 & $<0.005$ & $<0.005$ & $\mathrm{C}$ & $<0.005$ & $\mathrm{C}$ & 1.00 & $<0.005$ \\
\hline & & Pub30 & 0.01 & $<0.005$ & $<0.005$ & $<0.005$ & $<0.005$ & 1.35 & 0.14 \\
\hline & & Pub72 & $<0.005$ & $<0.005$ & $<0.005$ & $<0.005$ & $<0.005$ & 1.34 & 0.12 \\
\hline & Teen & NRC77 & $<0.005$ & $<0.005$ & C & $<0.005$ & C & 0.78 & $<0.005$ \\
\hline & & Pub30 & $<0.005$ & $<0.005$ & $<0.005$ & $<0.005$ & $<0.005$ & 0.94 & 0.10 \\
\hline & & Pub72 & $<0.005$ & $<0.005$ & $<0.005$ & $<0.005$ & $<0.005$ & 1.16 & 0.11 \\
\hline & Child & NRC77 & $<0.005$ & $<0.005$ & C & $<0.005$ & C & 0.81 & $<0.005$ \\
\hline & & Pub30 & $<0.005$ & $<0.005$ & $<0.005$ & $<0.005$ & $<0.005$ & 0.94 & 0.10 \\
\hline & & Pub72 & 0.01 & 0.01 & $<0.005$ & 0.01 & $<0.005$ & 3.43 & 0.31 \\
\hline & Infant & NRC77 & $<0.005$ & $<0.005$ & C & $<0.005$ & C & 0.54 & $<0.005$ \\
\hline & & Pub30 & $<0.005$ & $<0.005$ & $<0.005$ & $<0.005$ & $<0.005$ & 0.61 & 0.06 \\
\hline & & Pub72 & 0.03 & 0.01 & $<0.005$ & 0.01 & $<0.005$ & 6.82 & 0.62 \\
\hline
\end{tabular}




\section{APPENDIX C: DETAILED TABULATIONS OF COMPARATIVE DOSE ESTIMATES FOR INHALED RADIONUCLIDES}

The starting place for the comparative analysis for inhalation of radionuclides was derivation of base case dose estimates for adults using dose coefficients and air intake rates given in NRC77. These base case estimates are listed in Table C.1. Estimates for a radionuclide are based on a one-year intake of the radionuclide in air using dose coefficients from NRC77 and assuming an activity concentration of $1 \mathrm{pCi} / \mathrm{m}^{3}(0.037$ $\mathrm{Bq} / \mathrm{m}^{3}$ ). The dose estimate for a tissue is calculated as $8000 \mathrm{pCi}$ times the dose coefficient for adults given in NRC77 (in units of mrem/pCi ingested), assuming annual intake of $8000 \mathrm{~m}^{3}$ of air. Dose estimates for a given radionuclide are provided for each of the organs addressed in NRC77 for that radionuclide, i.e., for total body, lower large intestine, and some subset of the organs bone, liver, thyroid, kidney, and lung. The highest dose to any organ from annual intake of the radionuclide in air is in bold-faced type. This value is referred to in Pub2 and NRC77 as the dose to the critical organ.

\begin{tabular}{|c|c|c|c|c|c|c|c|}
\hline \multirow[b]{2}{*}{ Nuclide } & \multicolumn{7}{|c|}{ Estimated committed dose $\left(\mathrm{mrem}^{\mathrm{a}}\right)$} \\
\hline & Bone & Liver & T Body & Thyroid & Kidney & Lung & LLI \\
\hline $\mathrm{H}-3$ & $\mathrm{~b}$ & $1.3 \mathrm{E}-03$ & 1.3E-03 & 1.3E-03 & 1.3E-03 & 1.3E-03 & 1.3E-03 \\
\hline C-14 & 1.8E-02 & 3.4E-03 & $3.4 \mathrm{E}-03$ & $3.4 \mathrm{E}-03$ & 3.4E-03 & $3.4 \mathrm{E}-03$ & $3.4 \mathrm{E}-03$ \\
\hline P-32 & $1.3 E+00$ & 7.7E-02 & $5.0 \mathrm{E}-02$ & b & $\mathrm{b}$ & b & 8.6E-02 \\
\hline Cr-51 & b & b & 1.0E-04 & 6.0E-05 & 2.3E-05 & 1.4E-02 & 3.3E-03 \\
\hline Mn-54 & b & 4.0E-02 & $6.3 \mathrm{E}-03$ & b & 9.8E-03 & $1.4 \mathrm{E}+00$ & 7.7E-02 \\
\hline Fe-55 & 2.5E-02 & 1.7E-02 & 3.9E-03 & b & b & 7.2E-02 & $6.0 \mathrm{E}-03$ \\
\hline $\mathrm{Fe}-59$ & $1.2 \mathrm{E}-02$ & $2.8 \mathrm{E}-02$ & 1.1E-02 & b & b & $1.0 \mathrm{E}+00$ & 1.9E-01 \\
\hline Co-58 & b & 1.6E-03 & 2.1E-03 & b & b & 9.3E-01 & 1.1E-01 \\
\hline Co-60 & b & $1.2 \mathrm{E}-02$ & 1.5E-02 & b & b & $6.0 \mathrm{E}+00$ & 2.9E-01 \\
\hline $\mathrm{Ni}-63$ & 4.3E-01 & 3.1E-02 & 1.5E-02 & b & b & 1.8E-01 & 1.3E-02 \\
\hline Cu-64 & b & $1.5 \mathrm{E}-06$ & $6.2 \mathrm{E}-07$ & b & 4.6E-06 & $6.8 \mathrm{E}-03$ & 4.9E-02 \\
\hline Zn-65 & 3.2E-02 & $1.0 \mathrm{E}-01$ & 4.7E-02 & b & $6.9 \mathrm{E}-02$ & 8.6E-01 & 5.3E-02 \\
\hline Sr-89 & 3.0E-01 & b & 8.7E-03 & b & b & 1.4E+00 & 3.5E-01 \\
\hline Sr-90 & 9.9E+01 & b & $6.1 E+00$ & b & b & $9.6 \mathrm{E}+00$ & 7.2E-01 \\
\hline Y-90 & 2.1E-03 & b & 5.6E-05 & b & b & 1.7E-01 & 5.1E-01 \\
\hline Zr-95 & 1.1E-01 & 3.4E-02 & 2.3E-02 & b & 5.4E-02 & $1.8 \mathrm{E}+00$ & $1.5 \mathrm{E}-01$ \\
\hline $\mathrm{Nb}-95$ & 1.4E-02 & 7.8E-03 & $4.2 \mathrm{E}-03$ & b & 7.7E-03 & 5.1E-01 & 1.0E-01 \\
\hline Mo-99 & B & $1.2 \mathrm{E}-04$ & 2.3E-05 & b & 2.9E-04 & 9.1E-02 & 2.5E-01 \\
\hline Tc-99m & 1.0E-09 & 2.9E-09 & 3.7E-08 & b & 4.4E-08 & 7.6E-04 & 4.2E-03 \\
\hline Ru-106 & $6.9 \mathrm{E}-02$ & b & 8.7E-03 & b & 1.3E-01 & $9.4 \mathrm{E}+00$ & 9.1E-01 \\
\hline $\mathrm{Ag}-110 \mathrm{~m}$ & 1.1E-02 & 1.0E-02 & 5.9E-03 & b & 2.0E-02 & $4.6 E+00$ & 3.0E-01 \\
\hline I-131 & $2.5 \mathrm{E}-02$ & 3.6E-02 & 2.1E-02 & $1.2 E+01$ & 6.1E-02 & b & 6.3E-03 \\
\hline |-133 & 8.6E-03 & $1.5 \mathrm{E}-02$ & 4.5E-03 & $2.2 E+00$ & 2.6E-02 & $b$ & 8.9E-03 \\
\hline Cs-134 & 3.7E-01 & 8.5E-01 & 7.3E-01 & b & $2.9 \mathrm{E}-01$ & $9.8 \mathrm{E}-02$ & 1.0E-02 \\
\hline Cs-137 & 4.8E-01 & $6.2 \mathrm{E}-01$ & 4.3E-01 & b & 2.2E-01 & 7.5E-02 & 8.4E-03 \\
\hline Ba-140 & 3.9E-02 & 4.9E-05 & 2.6E-03 & b & 1.7E-05 & $1.3 E+00$ & 2.2E-01 \\
\hline La-140 & 3.4E-04 & 1.7E-04 & 4.6E-05 & b & b & 1.4E-01 & 4.6E-01 \\
\hline Np-239 & 2.3E-04 & 2.3E-05 & $1.2 \mathrm{E}-05$ & b & 7.0E-05 & 3.8E-02 & 1.2E-01 \\
\hline
\end{tabular}


Base case dose estimates for each organ listed in Table C.1 are compared in Table C.2 with estimates for adults based on Pub30 or Pub72. Comparisons are given as ratios D30 : D77 and D72 : D77, where D30 and D72 are dose estimates for a given radionuclide and organ based on Pub30 or Pub72, respectively, and D77 is the dose given in Table C.2 for the same radionuclide and organ.

\section{Table C.2. For adults, ratios of organ dose estimates D30 : D77 and D72 : D77 for annual intake of radionuclides in air, where D30, D72, and D77 are the doses to a given organ based on Pub30, Pub72, and NRC77, respectively.}

\begin{tabular}{|c|c|c|c|c|c|c|c|}
\hline Nuclide & ICRP Pub & Bone $^{a}$ & Liver & Thyroid & Kidney & Lung & LLI \\
\hline \multirow[t]{2}{*}{$\mathrm{H}-3$} & Pub30 & $\mathrm{b}$ & 0.41 & 0.41 & 0.41 & 0.41 & 0.41 \\
\hline & Pub72 & $\mathrm{b}$ & 0.43 & 0.43 & 0.43 & 0.43 & 0.43 \\
\hline \multirow[t]{2}{*}{ C-14 } & Pub30 & 0.01 & 0.06 & 0.06 & 0.06 & 0.06 & 0.06 \\
\hline & Pub72 & 0.01 & 0.05 & 0.05 & 0.05 & 0.05 & 0.05 \\
\hline \multirow[t]{2}{*}{ P-32 } & Pub30 & 0.09 & 0.13 & $\mathrm{~b}$ & b & b & 1.06 \\
\hline & Pub72 & 0.05 & 0.06 & $b$ & $\mathrm{~b}$ & $\mathrm{~b}$ & 0.63 \\
\hline \multirow[t]{2}{*}{ Cr-51 } & Pub30 & $\mathrm{b}$ & $\mathrm{b}$ & 5.5 & 17 & 0.78 & 1.0 \\
\hline & Pub72 & b & b & 4.4 & 11 & 0.29 & 0.65 \\
\hline \multirow[t]{2}{*}{$M n-54$} & Pub30 & b & 1.9 & $\mathrm{~b}$ & 2.7 & 0.14 & 0.51 \\
\hline & Pub72 & $\mathrm{b}$ & 1.5 & b & 2.3 & 0.14 & 0.34 \\
\hline \multirow[t]{2}{*}{ Fe-55 } & Pub30 & 0.21 & 1.0 & b & $\mathrm{b}$ & 0.44 & 1.4 \\
\hline & Pub72 & 0.8 & 1.4 & b & b & 0.16 & 0.81 \\
\hline \multirow[t]{2}{*}{ Fe-59 } & Pub30 & 2.8 & 2.9 & b & b & 0.40 & 0.71 \\
\hline & Pub72 & 2.5 & 2.8 & b & b & 0.66 & 0.34 \\
\hline \multirow[t]{2}{*}{ Co-58 } & Pub30 & $b$ & 22 & $b$ & $b$ & 0.25 & 0.56 \\
\hline & Pub72 & b & 17 & b & b & 0.29 & 0.29 \\
\hline \multirow[t]{2}{*}{ Co-60 } & Pub30 & $b$ & 24 & $b$ & $b$ & 0.18 & 0.85 \\
\hline & Pub72 & $\mathrm{b}$ & 22 & b & b & 0.26 & 0.50 \\
\hline \multirow{2}{*}{$\mathrm{Ni}-63$} & Pub30 & 0.02 & 0.23 & b & $b$ & 0.51 & 1.5 \\
\hline & Pub72 & 0.01 & 0.17 & b & b & 0.41 & 0.87 \\
\hline \multirow[t]{2}{*}{ Cu-64 } & Pub30 & $\mathrm{b}$ & 340 & b & 50 & 1.5 & 0.10 \\
\hline & Pub72 & b & 220 & b & 34 & 2.5 & 0.09 \\
\hline \multirow[t]{2}{*}{ Zn-65 } & Pub30 & 3.1 & 1.3 & b & 1.3 & 0.72 & 1.5 \\
\hline & Pub72 & 1.3 & 0.39 & b & 0.44 & 0.18 & 0.70 \\
\hline \multirow[t]{2}{*}{ Sr-89 } & Pub30 & 0.82 & $\mathrm{~b}$ & b & $\mathrm{b}$ & 0.05 & 0.3 \\
\hline & Pub72 & 0.52 & b & b & b & 0.004 & 0.29 \\
\hline \multirow[t]{2}{*}{ Sr-90 } & Pub30 & 0.22 & b & b & b & 0.01 & 0.22 \\
\hline & Pub72 & 0.11 & b & b & b & 0.002 & 0.21 \\
\hline \multirow[t]{2}{*}{ Y-90 } & Pub30 & 3.9 & b & b & b & 1.6 & 0.64 \\
\hline & Pub72 & 1.5 & b & b & b & 1.2 & 0.37 \\
\hline \multirow[t]{2}{*}{ Zr-95 } & Pub30 & 6.0 & 1.0 & b & 0.45 & 0.31 & 0.82 \\
\hline & Pub72 & 3.5 & 0.9 & b & 0.38 & 0.51 & 0.45 \\
\hline \multirow[t]{2}{*}{$\mathrm{Nb}-95$} & Pub30 & 5.1 & 2.0 & b & 2.0 & 0.32 & 0.54 \\
\hline & Pub72 & 0.68 & 2.7 & b & 1.5 & 0.56 & 0.28 \\
\hline \multirow[t]{2}{*}{ Mo-99 } & Pub30 & b & 27 & b & 9.5 & 1.4 & 0.66 \\
\hline & Pub72 & b & 36 & b & 16 & 1.7 & 0.31 \\
\hline \multirow[t]{2}{*}{ Tc-99m } & Pub30 & 51,000 & 25,000 & $b$ & 1000 & 1.2 & 0.03 \\
\hline & Pub72 & 67,000 & 17,000 & b & 950 & 3.0 & 0.10 \\
\hline \multirow[t]{2}{*}{ Ru-106 } & Pub30 & 1.7 & b & $b$ & 0.90 & 0.67 & 1.3 \\
\hline & Pub72 & 1.2 & $\mathrm{~b}$ & b & 0.61 & 0.63 & 0.66 \\
\hline \multirow{2}{*}{$\mathrm{Ag}-110 \mathrm{~m}$} & Pub30 & 5.84 & 75.9 & b & 6.81 & 0.20 & 0.58 \\
\hline & Pub72 & 7.30 & 46.5 & $b$ & 5.30 & 0.23 & 0.42 \\
\hline
\end{tabular}




\begin{tabular}{|c|c|c|c|c|c|c|c|}
\hline \multicolumn{8}{|c|}{ Table C.2 (continued) } \\
\hline Nuclide & ICRP Pub & Bone $^{a}$ & Liver & Thyroid & Kidney & Lung & LLI \\
\hline \multirow[t]{2}{*}{$\mathrm{I}-131$} & Pub30 & 0.07 & 0.03 & 0.73 & 0.01 & $\mathrm{~b}$ & 0.12 \\
\hline & Pub72 & 0.06 & 0.01 & 0.37 & 0.01 & b & 0.15 \\
\hline \multirow[t]{2}{*}{$\mathrm{I}-133$} & Pub30 & 0.09 & 0.06 & 0.67 & 0.03 & b & 0.07 \\
\hline & Pub72 & 0.07 & 0.03 & 0.39 & 0.02 & $\mathrm{~b}$ & 0.08 \\
\hline \multirow[t]{2}{*}{ Cs-134 } & Pub30 & 0.87 & 0.44 & $\mathrm{~b}$ & 1.3 & 3.6 & 39 \\
\hline & Pub72 & 0.54 & 0.23 & b & 0.69 & 1.8 & 22 \\
\hline \multirow[t]{2}{*}{ Cs-137 } & Pub30 & 0.49 & 0.41 & b & 1.2 & 3.5 & 32 \\
\hline & Pub72 & 0.29 & 0.22 & b & 0.61 & 1.7 & 20 \\
\hline \multirow[t]{2}{*}{$\mathrm{Ba}-140$} & Pub30 & 1.8 & 170 & b & 510 & 0.04 & 0.59 \\
\hline & Pub72 & 0.52 & 310 & b & 450 & 0.82 & 0.98 \\
\hline \multirow[t]{2}{*}{ La-140 } & Pub30 & 12 & 130 & b & $\mathrm{b}$ & 0.92 & 0.35 \\
\hline & Pub72 & 8.3 & 55 & b & $\mathrm{b}$ & 0.86 & 0.22 \\
\hline \multirow[t]{2}{*}{ Np-239 } & Pub30 & 260 & 170 & b & 6.5 & 1.9 & 0.73 \\
\hline & Pub72 & 66 & 44 & b & 11 & 5.0 & 0.43 \\
\hline
\end{tabular}

To facilitate comparison of dose estimates across different ages as well different dosimetry systems, all dose estimates for a given radionuclide were normalized to the dose to the critical organ of the adult based on NRC77. Normalized dose estimates for inhalation of individual radionuclides are listed in Table C.3. 


\begin{tabular}{|c|c|c|c|c|c|c|c|c|c|}
\hline \multirow[b]{2}{*}{ Nuclide } & \multirow{2}{*}{$\begin{array}{l}\text { Age } \\
\text { group }\end{array}$} & \multirow{2}{*}{$\begin{array}{c}\text { Dose } \\
\text { system }\end{array}$} & \multicolumn{7}{|c|}{ Normalized dose commitment } \\
\hline & & & Bone $^{a}$ & Liver & Thyroid & Kidney & Lung & LLI & Tbody or eff \\
\hline \multirow[t]{12}{*}{$\mathrm{H}-3$} & Adult & NRC77 & $\mathrm{c}$ & 1.00 & 1.00 & 1.00 & 1.00 & 1.00 & 1.00 \\
\hline & & Pub30 & 0.41 & 0.41 & 0.41 & 0.41 & 0.41 & 0.41 & 0.41 \\
\hline & & Pub72 & 0.43 & 0.43 & 0.43 & 0.43 & 0.43 & 0.43 & 0.43 \\
\hline & Teen & NRC77 & $\mathrm{C}$ & 1.01 & 1.01 & 1.01 & 1.01 & 1.01 & 1.01 \\
\hline & & Pub30 & 0.41 & 0.41 & 0.41 & 0.41 & 0.41 & 0.41 & 0.41 \\
\hline & & Pub72 & 0.42 & 0.42 & 0.42 & 0.42 & 0.42 & 0.42 & 0.42 \\
\hline & Child & NRC77 & C & 0.89 & 0.89 & 0.89 & 0.89 & 0.89 & 0.89 \\
\hline & & Pub30 & 0.19 & 0.19 & 0.19 & 0.19 & 0.19 & 0.19 & 0.19 \\
\hline & & Pub72 & 0.33 & 0.33 & 0.33 & 0.33 & 0.33 & 0.33 & 0.33 \\
\hline & Infant & NRC77 & C & 0.51 & 0.51 & 0.51 & 0.51 & 0.51 & 0.51 \\
\hline & & Pub30 & 0.07 & 0.07 & 0.07 & 0.07 & 0.07 & 0.07 & 0.07 \\
\hline & & Pub72 & 0.26 & 0.26 & 0.26 & 0.26 & 0.26 & 0.26 & 0.26 \\
\hline \multirow[t]{12}{*}{ C-14 } & Adult & NRC77 & 1.00 & 0.19 & 0.19 & 0.19 & 0.19 & 0.19 & 0.19 \\
\hline & & Pub30 & 0.01 & 0.01 & 0.01 & 0.01 & 0.01 & 0.01 & 0.01 \\
\hline & & Pub72 & 0.01 & 0.01 & 0.01 & 0.01 & 0.01 & 0.01 & 0.01 \\
\hline & Teen & NRC77 & 1.43 & 0.27 & 0.27 & 0.27 & 0.27 & 0.27 & 0.27 \\
\hline & & Pub30 & 0.01 & 0.01 & 0.01 & 0.01 & 0.01 & 0.01 & 0.01 \\
\hline & & Pub72 & 0.01 & 0.01 & 0.01 & 0.01 & 0.01 & 0.01 & 0.01 \\
\hline & Child & NRC77 & 1.98 & 0.37 & 0.37 & 0.37 & 0.37 & 0.37 & 0.37 \\
\hline & & Pub30 & 0.005 & 0.005 & 0.005 & 0.005 & 0.005 & 0.005 & 0.005 \\
\hline & & Pub72 & 0.01 & 0.01 & 0.01 & 0.01 & 0.01 & 0.01 & 0.01 \\
\hline & Infant & NRC77 & 1.46 & 0.29 & 0.29 & 0.29 & 0.29 & 0.29 & 0.29 \\
\hline & & Pub30 & $<0.005$ & $<0.005$ & $<0.005$ & $<0.005$ & $<0.005$ & $<0.005$ & $<0.005$ \\
\hline & & Pub72 & 0.01 & 0.01 & 0.01 & 0.01 & 0.01 & 0.01 & 0.01 \\
\hline \multirow[t]{12}{*}{ P-32 } & Adult & NRC77 & 1.00 & 0.06 & $\mathrm{C}$ & $\mathrm{C}$ & $\mathrm{C}$ & 0.07 & 0.04 \\
\hline & & Pub30 & 0.09 & 0.01 & 0.01 & 0.01 & 0.58 & 0.07 & 0.09 \\
\hline & & Pub72 & 0.05 & $<0.005$ & $<0.005$ & $<0.005$ & 0.53 & 0.04 & 0.08 \\
\hline & Teen & NRC77 & 1.43 & 0.08 & C & C & C & 0.07 & 0.05 \\
\hline & & Pub30 & 0.09 & 0.01 & 0.01 & 0.01 & 0.58 & 0.07 & 0.09 \\
\hline & & Pub72 & 0.05 & 0.01 & 0.01 & 0.01 & 0.63 & 0.05 & 0.09 \\
\hline & Child & NRC77 & 1.97 & 0.09 & C & C & C & 0.03 & 0.08 \\
\hline & & Pub30 & 0.04 & $<0.005$ & $<0.005$ & $<0.005$ & 0.27 & 0.03 & 0.04 \\
\hline & & Pub72 & 0.08 & 0.01 & 0.01 & 0.01 & 0.48 & 0.08 & 0.08 \\
\hline & Infant & NRC77 & 1.54 & 0.09 & C & C & C & 0.01 & 0.06 \\
\hline & & Pub30 & 0.02 & $<0.005$ & $<0.005$ & $<0.005$ & 0.10 & 0.01 & 0.02 \\
\hline & & Pub72 & 0.08 & 0.01 & 0.01 & 0.01 & 0.39 & 0.04 & 0.08 \\
\hline \multirow[t]{12}{*}{ Cr-51 } & Adult & NRC77 & C & C & $<0.005$ & $<0.005$ & 1.00 & 0.23 & 0.01 \\
\hline & & Pub30 & 0.03 & 0.05 & 0.02 & 0.03 & 0.78 & 0.23 & 0.15 \\
\hline & & Pub72 & 0.03 & 0.03 & 0.02 & 0.02 & 0.29 & 0.15 & 0.07 \\
\hline & Teen & NRC77 & C & C & 0.01 & $<0.005$ & 1.46 & 0.21 & 0.01 \\
\hline & & Pub30 & 0.03 & 0.05 & 0.02 & 0.03 & 0.78 & 0.23 & 0.15 \\
\hline & & Pub72 & 0.03 & 0.04 & 0.02 & 0.02 & 0.35 & 0.18 & 0.08 \\
\hline & Child & NRC77 & C & $\mathrm{C}$ & 0.01 & $<0.005$ & 1.18 & 0.08 & 0.01 \\
\hline & & Pub30 & 0.01 & 0.02 & 0.01 & 0.01 & 0.36 & 0.11 & 0.07 \\
\hline & & Pub72 & 0.03 & 0.04 & 0.03 & 0.02 & 0.34 & 0.26 & 0.10 \\
\hline & Infant & NRC77 & C & C & $<0.005$ & $<0.005$ & 0.89 & 0.02 & 0.01 \\
\hline & & Pub30 & 0.01 & 0.01 & $<0.005$ & $<0.005$ & 0.14 & 0.04 & 0.03 \\
\hline & & Pub72 & 0.03 & 0.03 & 0.02 & 0.02 & 0.29 & 0.32 & 0.09 \\
\hline
\end{tabular}




\begin{tabular}{|c|c|c|c|c|c|c|c|c|c|}
\hline \multicolumn{10}{|c|}{ Table C.3 (continued) } \\
\hline \multirow[b]{2}{*}{ Nuclide } & \multirow{2}{*}{$\begin{array}{l}\text { Age } \\
\text { group }\end{array}$} & \multirow{2}{*}{$\begin{array}{c}\text { Dose } \\
\text { system }\end{array}$} & \multicolumn{7}{|c|}{ Normalized dose commitment } \\
\hline & & & Bone $^{a}$ & Liver & Thyroid & Kidney & Lung & LLI & Tbody or eff \\
\hline \multirow[t]{12}{*}{ Mn-54 } & \multirow[t]{3}{*}{ Adult } & NRC77 & $\mathrm{C}$ & 0.03 & $\mathrm{C}$ & 0.01 & 1.00 & 0.06 & $<0.005$ \\
\hline & & Pub30 & 0.03 & 0.05 & 0.02 & 0.02 & 0.14 & 0.03 & 0.04 \\
\hline & & Pub72 & 0.02 & 0.04 & 0.01 & 0.02 & 0.14 & 0.02 & 0.03 \\
\hline & \multirow[t]{3}{*}{ Teen } & NRC77 & c & 0.04 & c & $<0.005$ & 1.42 & 0.05 & 0.01 \\
\hline & & Pub30 & 0.03 & 0.05 & 0.02 & 0.02 & 0.14 & 0.03 & 0.04 \\
\hline & & Pub72 & 0.03 & 0.05 & 0.02 & 0.02 & 0.17 & 0.02 & 0.04 \\
\hline & \multirow[t]{3}{*}{ Child } & NRC77 & c & 0.03 & $\mathrm{C}$ & 0.01 & 1.13 & 0.02 & 0.01 \\
\hline & & Pub30 & 0.01 & 0.02 & 0.01 & 0.01 & 0.07 & 0.01 & 0.02 \\
\hline & & Pub72 & 0.03 & 0.04 & 0.02 & 0.02 & 0.13 & 0.02 & 0.04 \\
\hline & \multirow{3}{*}{ Infant } & NRC77 & c & 0.02 & c & $<0.005$ & 0.71 & 0.01 & $<0.005$ \\
\hline & & Pub30 & $<0.005$ & $<0.005$ & $<0.005$ & $<0.005$ & 0.02 & $<0.005$ & 0.01 \\
\hline & & Pub72 & 0.03 & 0.04 & 0.01 & 0.02 & 0.09 & 0.02 & 0.03 \\
\hline \multirow[t]{12}{*}{ Fe-55 } & \multirow[t]{3}{*}{ Adult } & NRC77 & 0.34 & 0.24 & $\mathrm{C}$ & $\mathrm{C}$ & 1.00 & 0.08 & 0.05 \\
\hline & & Pub30 & 0.07 & 0.24 & 0.08 & 0.07 & 0.44 & 0.11 & 0.15 \\
\hline & & Pub72 & 0.27 & 0.34 & 0.04 & 0.04 & 0.16 & 0.07 & 0.16 \\
\hline & \multirow[t]{3}{*}{ Teen } & NRC77 & 0.46 & 0.33 & C & C & 1.72 & 0.09 & 0.08 \\
\hline & & Pub30 & 0.07 & 0.24 & 0.08 & 0.07 & 0.44 & 0.11 & 0.15 \\
\hline & & Pub72 & 0.37 & 0.32 & 0.04 & 0.04 & 0.19 & 0.08 & 0.18 \\
\hline & \multirow[t]{3}{*}{ Child } & NRC77 & 0.66 & 0.35 & $\mathrm{C}$ & $\mathrm{C}$ & 1.54 & 0.04 & 0.11 \\
\hline & & Pub30 & 0.03 & 0.11 & 0.04 & 0.03 & 0.20 & 0.05 & 0.07 \\
\hline & & Pub72 & 0.44 & 0.31 & 0.04 & 0.04 & 0.22 & 0.10 & 0.19 \\
\hline & \multirow[t]{3}{*}{ Infant } & NRC77 & 0.27 & 0.16 & C & C & 1.21 & 0.02 & 0.05 \\
\hline & & Pub30 & 0.01 & 0.04 & 0.01 & 0.01 & 0.08 & 0.02 & 0.03 \\
\hline & & Pub72 & 0.32 & 0.24 & 0.04 & 0.04 & 0.19 & 0.11 & 0.14 \\
\hline \multirow[t]{12}{*}{ Fe-59 } & \multirow[t]{3}{*}{ Adult } & NRC77 & 0.01 & 0.03 & $\mathrm{C}$ & $\mathrm{C}$ & 1.00 & 0.19 & 0.01 \\
\hline & & Pub30 & 0.03 & 0.08 & 0.03 & 0.04 & 0.40 & 0.13 & 0.10 \\
\hline & & Pub72 & 0.03 & 0.08 & 0.02 & 0.02 & 0.66 & 0.06 & 0.11 \\
\hline & \multirow[t]{3}{*}{ Teen } & NRC77 & 0.01 & 0.04 & $\mathrm{C}$ & $\mathrm{C}$ & 1.50 & 0.18 & 0.01 \\
\hline & & Pub30 & 0.03 & 0.08 & 0.03 & 0.04 & 0.40 & 0.13 & 0.10 \\
\hline & & Pub72 & 0.04 & 0.08 & 0.02 & 0.03 & 0.83 & 0.07 & 0.13 \\
\hline & \multirow[t]{3}{*}{ Child } & NRC77 & 0.02 & 0.03 & C & C & 1.25 & 0.07 & 0.02 \\
\hline & & Pub30 & 0.02 & 0.04 & 0.02 & 0.02 & 0.19 & 0.06 & 0.04 \\
\hline & & Pub72 & 0.05 & 0.08 & 0.03 & 0.03 & 0.57 & 0.10 & 0.11 \\
\hline & Infant & NRC77 & 0.01 & 0.02 & $\mathrm{C}$ & $\mathrm{C}$ & 1.00 & 0.02 & 0.01 \\
\hline & & Pub30 & 0.01 & 0.01 & 0.01 & 0.01 & 0.07 & 0.02 & 0.02 \\
\hline & & Pub72 & 0.07 & 0.08 & 0.03 & 0.03 & 0.43 & 0.12 & 0.09 \\
\hline Co-58 & Adult & NRC77 & $\mathrm{C}$ & $<0.005$ & $\mathrm{C}$ & $\mathrm{C}$ & 1.00 & 0.11 & $<0.005$ \\
\hline & & Pub30 & 0.02 & 0.04 & 0.02 & 0.02 & 0.25 & 0.06 & 0.05 \\
\hline & & Pub72 & 0.01 & 0.03 & 0.01 & 0.01 & 0.29 & 0.03 & 0.05 \\
\hline & Teen & NRC77 & $\mathrm{C}$ & $<0.005$ & $\mathrm{C}$ & $\mathrm{C}$ & 1.45 & 0.10 & $<0.005$ \\
\hline & & Pub30 & 0.02 & 0.04 & 0.02 & 0.02 & 0.25 & 0.06 & 0.05 \\
\hline & & Pub72 & 0.02 & 0.04 & 0.02 & 0.02 & 0.36 & 0.04 & 0.06 \\
\hline & Child & NRC77 & $\mathrm{C}$ & $<0.005$ & C & C & 1.19 & 0.04 & $<0.005$ \\
\hline & & Pub30 & 0.01 & 0.02 & 0.01 & 0.01 & 0.12 & 0.03 & 0.03 \\
\hline & & Pub72 & 0.02 & 0.03 & 0.02 & 0.02 & 0.26 & 0.05 & 0.05 \\
\hline & Infant & NRC77 & C & $<0.005$ & C & C & 0.84 & 0.01 & $<0.005$ \\
\hline & & Pub30 & $<0.005$ & 0.01 & $<0.005$ & $<0.005$ & 0.04 & 0.01 & 0.01 \\
\hline & & Pub72 & 0.02 & 0.03 & 0.02 & 0.02 & 0.19 & 0.05 & 0.04 \\
\hline
\end{tabular}




\begin{tabular}{|c|c|c|c|c|c|c|c|c|c|}
\hline \multicolumn{10}{|c|}{ Table C.3 (continued) } \\
\hline \multirow[b]{2}{*}{ Nuclide } & \multirow{2}{*}{$\begin{array}{l}\text { Age } \\
\text { group }\end{array}$} & \multirow{2}{*}{$\begin{array}{l}\text { Dose } \\
\text { system }\end{array}$} & \multicolumn{7}{|c|}{ Normalized dose commitment } \\
\hline & & & Bone $^{a}$ & Liver & Thyroid & Kidney & Lung & LLI & Tbody or eff $^{b}$ \\
\hline \multirow[t]{12}{*}{ Co-60 } & Adult & NRC77 & $\mathrm{C}$ & $<0.005$ & $\mathrm{C}$ & $\mathrm{C}$ & 1.00 & 0.05 & $<0.005$ \\
\hline & & Pub30 & 0.02 & 0.05 & 0.02 & 0.02 & 0.18 & 0.04 & 0.04 \\
\hline & & Pub72 & 0.02 & 0.04 & 0.02 & 0.02 & 0.26 & 0.02 & 0.05 \\
\hline & Teen & NRC77 & $\mathrm{C}$ & $<0.005$ & $\mathrm{C}$ & $\mathrm{C}$ & 1.46 & 0.04 & $<0.005$ \\
\hline & & Pub30 & 0.02 & 0.05 & 0.02 & 0.02 & 0.18 & 0.04 & 0.04 \\
\hline & & Pub72 & 0.02 & 0.05 & 0.02 & 0.02 & 0.32 & 0.03 & 0.06 \\
\hline & Child & NRC77 & C & $<0.005$ & C & C & 1.18 & 0.02 & $<0.005$ \\
\hline & & Pub30 & 0.01 & 0.02 & 0.01 & 0.01 & 0.08 & 0.02 & 0.02 \\
\hline & & Pub72 & 0.02 & 0.04 & 0.02 & 0.02 & 0.24 & 0.03 & 0.05 \\
\hline & Infant & NRC77 & C & $<0.005$ & C & C & 0.76 & 0.01 & $<0.005$ \\
\hline & & Pub30 & $<0.005$ & 0.01 & $<0.005$ & $<0.005$ & 0.03 & 0.01 & 0.01 \\
\hline & & Pub72 & 0.02 & 0.03 & 0.02 & 0.02 & 0.17 & 0.03 & 0.04 \\
\hline \multirow[t]{12}{*}{$\mathrm{Ni}-63$} & Adult & NRC77 & 1.00 & 0.07 & $\mathrm{C}$ & $C$ & 0.41 & 0.03 & 0.03 \\
\hline & & Pub30 & 0.02 & 0.02 & 0.02 & 0.02 & 0.21 & 0.05 & 0.04 \\
\hline & & Pub72 & 0.01 & 0.01 & 0.01 & 0.01 & 0.17 & 0.03 & 0.03 \\
\hline & Teen & NRC77 & 1.34 & 0.10 & C & C & 0.71 & 0.03 & 0.05 \\
\hline & & Pub30 & 0.02 & 0.02 & 0.02 & 0.02 & 0.21 & 0.05 & 0.04 \\
\hline & & Pub72 & 0.01 & 0.01 & 0.01 & 0.01 & 0.19 & 0.03 & 0.04 \\
\hline & Child & NRC77 & 1.90 & 0.11 & C & C & 0.64 & 0.01 & 0.06 \\
\hline & & Pub30 & 0.01 & 0.01 & 0.01 & 0.01 & 0.10 & 0.02 & 0.02 \\
\hline & & Pub72 & 0.01 & 0.01 & 0.01 & 0.01 & 0.18 & 0.04 & 0.04 \\
\hline & Infant & NRC77 & 0.78 & 0.05 & C & C & 0.48 & 0.01 & 0.03 \\
\hline & & Pub30 & $<0.005$ & $<0.005$ & $<0.005$ & $<0.005$ & 0.04 & 0.01 & 0.01 \\
\hline & & Pub72 & 0.01 & 0.01 & 0.01 & 0.01 & 0.15 & 0.04 & 0.03 \\
\hline \multirow[t]{12}{*}{ Cu-64 } & Adult & NRC77 & $\mathrm{C}$ & $<0.005$ & $\mathrm{C}$ & $<0.005$ & 0.14 & 1.00 & $<0.005$ \\
\hline & & Pub30 & $<0.005$ & 0.01 & $<0.005$ & $<0.005$ & 0.20 & 0.10 & 0.04 \\
\hline & & Pub72 & $<0.005$ & 0.01 & $<0.005$ & $<0.005$ & 0.35 & 0.09 & 0.07 \\
\hline & Teen & NRC77 & C & $<0.005$ & C & $<0.005$ & 0.23 & 1.25 & $<0.005$ \\
\hline & & Pub30 & $<0.005$ & 0.01 & $<0.005$ & $<0.005$ & 0.20 & 0.10 & 0.04 \\
\hline & & Pub72 & $<0.005$ & 0.01 & $<0.005$ & $<0.005$ & 0.44 & 0.10 & 0.08 \\
\hline & Child & NRC77 & C & $<0.005$ & C & $<0.005$ & 0.20 & 0.75 & $<0.005$ \\
\hline & & Pub30 & $<0.005$ & $<0.005$ & $<0.005$ & $<0.005$ & 0.09 & 0.04 & 0.02 \\
\hline & & Pub72 & $<0.005$ & 0.01 & $<0.005$ & 0.01 & 0.28 & 0.17 & 0.08 \\
\hline & Infant & NRC77 & C & $<0.005$ & C & $<0.005$ & 0.19 & 0.31 & $<0.005$ \\
\hline & & Pub30 & $<0.005$ & $<0.005$ & $<0.005$ & $<0.005$ & 0.04 & 0.02 & 0.01 \\
\hline & & Pub72 & 0.01 & 0.02 & 0.01 & 0.01 & 0.22 & 0.02 & 0.06 \\
\hline \multirow[t]{12}{*}{ Zn-65 } & Adult & NRC77 & 0.04 & 0.12 & $\mathrm{C}$ & 0.08 & 1.00 & 0.06 & 0.05 \\
\hline & & Pub30 & 0.12 & 0.15 & 0.10 & 0.11 & 0.72 & 0.09 & 0.19 \\
\hline & & Pub72 & 0.05 & 0.05 & 0.03 & 0.04 & 0.18 & 0.04 & 0.06 \\
\hline & Teen & NRC77 & 0.04 & 0.15 & $\mathrm{C}$ & 0.10 & 1.44 & 0.05 & 0.07 \\
\hline & & Pub30 & 0.12 & 0.15 & 0.10 & 0.11 & 0.72 & 0.09 & 0.19 \\
\hline & & Pub72 & 0.05 & 0.05 & 0.04 & 0.04 & 0.22 & 0.05 & 0.06 \\
\hline & Child & NRC77 & 0.05 & 0.13 & $\mathrm{C}$ & 0.08 & 1.15 & 0.02 & 0.08 \\
\hline & & Pub30 & 0.05 & 0.07 & 0.05 & 0.05 & 0.33 & 0.04 & 0.09 \\
\hline & & Pub72 & 0.05 & 0.05 & 0.04 & 0.04 & 0.18 & 0.05 & 0.06 \\
\hline & Infant & NRC77 & 0.02 & 0.07 & C & 0.04 & 0.75 & 0.06 & 0.04 \\
\hline & & Pub30 & 0.02 & 0.03 & 0.02 & 0.02 & 0.13 & 0.02 & 0.03 \\
\hline & & Pub72 & 0.05 & 0.04 & 0.04 & 0.04 & 0.13 & 0.05 & 0.05 \\
\hline
\end{tabular}




\begin{tabular}{|c|c|c|c|c|c|c|c|c|c|}
\hline \multicolumn{10}{|c|}{ Table C.3 (continued) } \\
\hline \multirow[b]{2}{*}{ Nuclide } & \multirow{2}{*}{$\begin{array}{l}\text { Age } \\
\text { group }\end{array}$} & \multirow{2}{*}{$\begin{array}{c}\text { Dose } \\
\text { system }\end{array}$} & \multicolumn{7}{|c|}{ Normalized dose commitment } \\
\hline & & & Bone $^{a}$ & Liver & Thyroid & Kidney & Lung & LLI & Tbody or eff \\
\hline \multirow[t]{12}{*}{ Sr-89 } & \multirow[t]{3}{*}{ Adult } & NRC77 & 0.22 & $\mathrm{C}$ & $\mathrm{C}$ & $\mathrm{C}$ & 1.00 & 0.25 & 0.01 \\
\hline & & Pub30 & 0.18 & 0.01 & 0.01 & 0.01 & 0.05 & 0.08 & 0.04 \\
\hline & & Pub72 & 0.11 & $<0.005$ & $<0.005$ & $<0.005$ & $<0.005$ & 0.07 & 0.02 \\
\hline & \multirow[t]{3}{*}{ Teen } & NRC77 & 0.31 & c & c & c & 1.73 & 0.27 & 0.01 \\
\hline & & Pub30 & 0.18 & 0.01 & 0.01 & 0.01 & 0.05 & 0.08 & 0.04 \\
\hline & & Pub72 & 0.31 & $<0.005$ & $<0.005$ & $<0.005$ & $<0.005$ & 0.06 & 0.04 \\
\hline & \multirow[t]{3}{*}{ Child } & NRC77 & 0.43 & C & C & C & 1.54 & 0.12 & 0.01 \\
\hline & & Pub30 & 0.08 & $<0.005$ & $<0.005$ & $<0.005$ & 0.02 & 0.04 & 0.02 \\
\hline & & Pub72 & 0.21 & 0.01 & 0.01 & 0.01 & 0.01 & 0.12 & 0.03 \\
\hline & \multirow[t]{3}{*}{ Infant } & NRC77 & 0.28 & c & c & c & 1.45 & 0.05 & 0.01 \\
\hline & & Pub30 & 0.03 & $<0.005$ & $<0.005$ & $<0.005$ & 0.01 & 0.01 & 0.01 \\
\hline & & Pub72 & 0.33 & 0.01 & 0.01 & 0.01 & 0.01 & 0.11 & 0.06 \\
\hline \multirow[t]{12}{*}{ Sr-90 } & \multirow[t]{3}{*}{ Adult } & NRC77 & 1.00 & $\mathrm{C}$ & $\mathrm{C}$ & $\mathrm{C}$ & 0.10 & 0.01 & 0.06 \\
\hline & & Pub30 & 0.22 & $<0.005$ & $<0.005$ & $<0.005$ & $<0.005$ & $<0.005$ & 0.02 \\
\hline & & Pub72 & 0.11 & $<0.005$ & $<0.005$ & $<0.005$ & $<0.005$ & $<0.005$ & 0.01 \\
\hline & \multirow[t]{3}{*}{ Teen } & NRC77 & 1.09 & C & C & C & 0.17 & 0.01 & 0.07 \\
\hline & & Pub30 & 0.22 & $<0.005$ & $<0.005$ & $<0.005$ & $<0.005$ & $<0.005$ & 0.02 \\
\hline & & Pub72 & 0.36 & $<0.005$ & $<0.005$ & $<0.005$ & $<0.005$ & $<0.005$ & 0.02 \\
\hline & \multirow[t]{3}{*}{ Child } & NRC77 & 1.02 & C & C & C & 0.15 & $<0.005$ & 0.06 \\
\hline & & Pub30 & 0.10 & $<0.005$ & $<0.005$ & $<0.005$ & $<0.005$ & $<0.005$ & 0.01 \\
\hline & & Pub72 & 0.06 & $<0.005$ & $<0.005$ & $<0.005$ & $<0.005$ & $<0.005$ & $<0.005$ \\
\hline & \multirow[t]{3}{*}{ Infant } & NRC77 & 0.41 & $\mathrm{C}$ & c & C & 0.11 & $<0.005$ & 0.03 \\
\hline & & Pub30 & 0.04 & $<0.005$ & $<0.005$ & $<0.005$ & $<0.005$ & $<0.005$ & $<0.005$ \\
\hline & & Pub72 & 0.07 & $<0.005$ & $<0.005$ & $<0.005$ & $<0.005$ & $<0.005$ & 0.01 \\
\hline \multirow[t]{12}{*}{ Y-90 } & \multirow[t]{3}{*}{ Adult } & NRC77 & $<0.005$ & C & C & C & 0.34 & 1.00 & $<0.005$ \\
\hline & & Pub30 & 0.02 & 0.02 & $<0.005$ & $<0.005$ & 0.52 & 0.64 & 0.12 \\
\hline & & Pub72 & 0.01 & 0.01 & $<0.005$ & $<0.005$ & 0.41 & 0.37 & 0.08 \\
\hline & \multirow[t]{3}{*}{ Teen } & NRC77 & 0.01 & $\mathrm{C}$ & c & $\mathrm{C}$ & 0.58 & 1.11 & $<0.005$ \\
\hline & & Pub30 & 0.02 & 0.02 & $<0.005$ & $<0.005$ & 0.52 & 0.64 & 0.12 \\
\hline & & Pub72 & 0.01 & 0.01 & $<0.005$ & $<0.005$ & 0.48 & 0.44 & 0.10 \\
\hline & \multirow[t]{3}{*}{ Child } & NRC77 & 0.01 & $\mathrm{C}$ & C & C & 0.52 & 0.53 & $<0.005$ \\
\hline & & Pub30 & 0.01 & 0.01 & $<0.005$ & $<0.005$ & 0.24 & 0.30 & 0.06 \\
\hline & & Pub72 & 0.01 & 0.01 & $<0.005$ & $<0.005$ & 0.37 & 0.72 & 0.11 \\
\hline & Infant & NRC77 & 0.01 & $\mathrm{C}$ & c & C & 0.53 & 0.21 & $<0.005$ \\
\hline & & Pub30 & $<0.005$ & $<0.005$ & $<0.005$ & $<0.005$ & 0.09 & 0.11 & 0.02 \\
\hline & & Pub72 & 0.01 & 0.01 & $<0.005$ & $<0.005$ & 0.30 & 1.02 & 0.13 \\
\hline Zr-95 & Adult & NRC77 & 0.06 & 0.02 & $\mathrm{C}$ & 0.03 & 1.00 & 0.09 & 0.01 \\
\hline & & Pub30 & 0.36 & 0.02 & 0.01 & 0.01 & 0.31 & 0.07 & 0.07 \\
\hline & & Pub72 & 0.21 & 0.02 & 0.01 & 0.01 & 0.51 & 0.04 & 0.08 \\
\hline & Teen & NRC77 & 0.08 & 0.03 & $\mathrm{C}$ & 0.04 & 1.52 & 0.08 & 0.02 \\
\hline & & Pub30 & 0.36 & 0.02 & 0.01 & 0.01 & 0.31 & 0.07 & 0.07 \\
\hline & & Pub72 & 0.20 & 0.02 & 0.01 & 0.01 & 0.65 & 0.05 & 0.10 \\
\hline & Child & NRC77 & 0.11 & 0.02 & C & 0.03 & 1.26 & 0.03 & 0.02 \\
\hline & & Pub30 & 0.17 & 0.01 & 0.01 & 0.01 & 0.14 & 0.03 & 0.03 \\
\hline & & Pub72 & 0.24 & 0.02 & 0.01 & 0.01 & 0.44 & 0.06 & 0.08 \\
\hline & Infant & NRC77 & 0.07 & 0.02 & C & 0.02 & 0.99 & 0.01 & 0.01 \\
\hline & & Pub30 & 0.06 & $<0.005$ & $<0.005$ & $<0.005$ & 0.05 & 0.01 & 0.01 \\
\hline & & Pub72 & 0.12 & 0.01 & 0.01 & 0.01 & 0.33 & 0.07 & 0.06 \\
\hline
\end{tabular}




\begin{tabular}{|c|c|c|c|c|c|c|c|c|c|}
\hline \multicolumn{10}{|c|}{ Table C.3 (continued) } \\
\hline \multirow[b]{2}{*}{ Nuclide } & \multirow{2}{*}{$\begin{array}{l}\text { Age } \\
\text { group }\end{array}$} & \multirow{2}{*}{$\begin{array}{l}\text { Dose } \\
\text { system }\end{array}$} & \multicolumn{7}{|c|}{ Normalized dose commitment } \\
\hline & & & Bone $^{a}$ & Liver & Thyroid & Kidney & Lung & LLI & Tbody or eff $^{D}$ \\
\hline \multirow[t]{12}{*}{$\mathrm{Nb}-95$} & Adult & NRC77 & 0.03 & 0.02 & $\mathrm{C}$ & 0.02 & 1.00 & 0.21 & 0.01 \\
\hline & & Pub30 & 0.14 & 0.03 & 0.02 & 0.03 & 0.32 & 0.11 & 0.08 \\
\hline & & Pub72 & 0.02 & 0.04 & 0.01 & 0.02 & 0.56 & 0.06 & 0.09 \\
\hline & Teen & NRC77 & 0.04 & 0.02 & $\mathrm{C}$ & 0.02 & 1.49 & 0.19 & 0.01 \\
\hline & & Pub30 & 0.14 & 0.03 & 0.02 & 0.03 & 0.32 & 0.11 & 0.08 \\
\hline & & Pub72 & 0.02 & 0.05 & 0.02 & 0.03 & 0.70 & 0.07 & 0.11 \\
\hline & Child & NRC77 & 0.05 & 0.02 & C & 0.02 & 1.22 & 0.07 & 0.01 \\
\hline & & Pub30 & 0.07 & 0.01 & 0.01 & 0.01 & 0.15 & 0.05 & 0.04 \\
\hline & & Pub72 & 0.02 & 0.04 & 0.02 & 0.02 & 0.49 & 0.09 & 0.08 \\
\hline & Infant & NRC77 & 0.03 & 0.01 & c & 0.01 & 0.95 & 0.03 & 0.01 \\
\hline & & Pub30 & 0.02 & 0.01 & $<0.005$ & 0.01 & 0.06 & 0.02 & 0.01 \\
\hline & & Pub72 & 0.02 & 0.03 & 0.01 & 0.02 & 0.37 & 0.11 & 0.07 \\
\hline \multirow[t]{12}{*}{ Mo-99 } & Adult & NRC77 & C & $<0.005$ & C & $<0.005$ & 0.37 & 1.00 & $<0.005$ \\
\hline & & Pub30 & $<0.005$ & 0.01 & $<0.005$ & 0.01 & 0.51 & 0.66 & 0.13 \\
\hline & & Pub72 & 0.01 & 0.02 & $<0.005$ & 0.02 & 0.64 & 0.31 & 0.11 \\
\hline & Teen & NRC77 & C & $<0.005$ & C & $<0.005$ & 0.62 & 1.08 & $<0.005$ \\
\hline & & Pub30 & $<0.005$ & 0.01 & $<0.005$ & 0.01 & 0.51 & 0.66 & 0.13 \\
\hline & & Pub72 & 0.01 & 0.02 & $<0.005$ & 0.02 & 0.79 & 0.37 & 0.13 \\
\hline & Child & NRC77 & $\mathrm{C}$ & $<0.005$ & C & $<0.005$ & 0.55 & 0.51 & $<0.005$ \\
\hline & & Pub30 & $<0.005$ & 0.01 & $<0.005$ & 0.01 & 0.24 & 0.30 & 0.06 \\
\hline & & Pub72 & 0.01 & 0.03 & $<0.005$ & 0.02 & 0.54 & 0.60 & 0.12 \\
\hline & Infant & NRC77 & C & $<0.005$ & C & $<0.005$ & 0.54 & 0.20 & $<0.005$ \\
\hline & & Pub30 & $<0.005$ & $<0.005$ & $<0.005$ & $<0.005$ & 0.09 & 0.12 & 0.02 \\
\hline & & Pub72 & 0.01 & 0.04 & 0.01 & 0.04 & 0.43 & 0.75 & 0.13 \\
\hline \multirow[t]{12}{*}{ Tc-99m } & Adult & NRC77 & $<0.005$ & $<0.005$ & $\mathrm{C}$ & $<0.005$ & 0.18 & 1.00 & $<0.005$ \\
\hline & & Pub30 & 0.01 & 0.02 & 0.15 & 0.01 & 0.22 & 0.03 & 0.05 \\
\hline & & Pub72 & 0.02 & 0.01 & 0.04 & 0.01 & 0.54 & 0.10 & 0.14 \\
\hline & Teen & NRC77 & $<0.005$ & $<0.005$ & $\mathrm{C}$ & $<0.005$ & 0.28 & 1.47 & $<0.005$ \\
\hline & & Pub30 & 0.01 & 0.02 & 0.15 & 0.01 & 0.22 & 0.03 & 0.05 \\
\hline & & Pub72 & 0.02 & 0.01 & 0.06 & 0.01 & 0.70 & 0.12 & 0.17 \\
\hline & Child & NRC77 & $<0.005$ & $<0.005$ & $\mathrm{C}$ & $<0.005$ & 0.23 & 1.16 & $<0.005$ \\
\hline & & Pub30 & 0.01 & 0.01 & 0.07 & 0.01 & 0.10 & 0.01 & 0.02 \\
\hline & & Pub72 & 0.02 & 0.02 & 0.09 & 0.01 & 0.43 & 0.19 & 0.17 \\
\hline & Infant & NRC77 & $<0.005$ & $<0.005$ & C & $<0.005$ & 0.19 & 0.49 & $<0.005$ \\
\hline & & Pub30 & $<0.005$ & $<0.005$ & 0.03 & $<0.005$ & 0.04 & $<0.005$ & 0.01 \\
\hline & & Pub72 & 0.02 & 0.02 & 0.11 & 0.01 & 0.33 & 0.22 & 0.17 \\
\hline \multirow[t]{12}{*}{ Ru-106 } & Adult & NRC77 & 0.01 & $\mathrm{C}$ & $\mathrm{C}$ & 0.01 & 1.00 & 0.10 & $<0.005$ \\
\hline & & Pub30 & 0.01 & 0.01 & 0.01 & 0.01 & 0.67 & 0.12 & 0.10 \\
\hline & & Pub72 & 0.01 & 0.01 & 0.01 & 0.01 & 0.63 & 0.06 & 0.09 \\
\hline & Teen & NRC77 & 0.01 & $c$ & c & 0.02 & 1.72 & 0.10 & $<0.005$ \\
\hline & & Pub30 & 0.01 & 0.01 & 0.01 & 0.01 & 0.67 & 0.12 & 0.10 \\
\hline & & Pub72 & 0.01 & 0.01 & 0.01 & 0.01 & 0.69 & 0.08 & 0.10 \\
\hline & Child & NRC77 & 0.01 & C & C & 0.02 & 1.53 & 0.05 & $<0.005$ \\
\hline & & Pub30 & 0.01 & 0.01 & 0.01 & 0.01 & 0.31 & 0.06 & 0.05 \\
\hline & & Pub72 & 0.01 & 0.01 & 0.01 & 0.01 & 0.62 & 0.12 & 0.09 \\
\hline & Infant & NRC77 & 0.01 & C & C & 0.01 & 1.24 & 0.02 & $<0.005$ \\
\hline & & Pub30 & $<0.005$ & $<0.005$ & $<0.005$ & $<0.005$ & 0.12 & 0.02 & 0.02 \\
\hline & & Pub72 & 0.01 & 0.01 & 0.01 & 0.01 & 0.46 & 0.15 & 0.08 \\
\hline
\end{tabular}




\begin{tabular}{|c|c|c|c|c|c|c|c|c|c|}
\hline \multicolumn{10}{|c|}{ Table C.3 (continued) } \\
\hline \multirow[b]{2}{*}{ Nuclide } & \multirow{2}{*}{$\begin{array}{l}\text { Age } \\
\text { group }\end{array}$} & \multirow{2}{*}{$\begin{array}{l}\text { Dose } \\
\text { system }\end{array}$} & \multicolumn{7}{|c|}{ Normalized dose commitment } \\
\hline & & & Bone $^{\mathrm{a}}$ & Liver & Thyroid & Kidney & Lung & LLI & Tbody or eff $^{D}$ \\
\hline \multirow[t]{12}{*}{$\mathrm{Ag}-110 \mathrm{~m}$} & Adult & NRC77 & $<0.005$ & $<0.005$ & $\mathrm{~b}$ & $<0.005$ & 1.00 & 0.07 & $<0.005$ \\
\hline & & Pub30 & 0.01 & 0.16 & 0.01 & 0.03 & 0.20 & 0.04 & 0.05 \\
\hline & & Pub72 & 0.02 & 0.10 & 0.02 & 0.02 & 0.23 & 0.03 & 0.05 \\
\hline & Teen & NRC77 & $<0.005$ & $<0.005$ & $\mathrm{~b}$ & 0.01 & 1.46 & 0.06 & $<0.005$ \\
\hline & & Pub30 & 0.01 & 0.16 & 0.01 & 0.03 & 0.20 & 0.04 & 0.05 \\
\hline & & Pub72 & 0.02 & 0.11 & 0.02 & 0.03 & 0.28 & 0.03 & 0.06 \\
\hline & Child & NRC77 & $<0.005$ & $<0.005$ & b & $<0.005$ & 1.18 & 0.02 & $<0.005$ \\
\hline & & Pub30 & 0.01 & 0.08 & 0.01 & 0.01 & 0.09 & 0.02 & 0.02 \\
\hline & & Pub72 & 0.02 & 0.10 & 0.02 & 0.03 & 0.22 & 0.04 & 0.05 \\
\hline & Infant & NRC77 & $<0.005$ & $<0.005$ & $\mathrm{~b}$ & $<0.005$ & 0.79 & 0.01 & $<0.005$ \\
\hline & & Pub30 & $<0.005$ & 0.03 & $<0.005$ & 0.01 & 0.04 & 0.01 & 0.01 \\
\hline & & Pub72 & 0.02 & 0.08 & 0.02 & 0.02 & 0.15 & 0.04 & 0.04 \\
\hline \multirow[t]{12}{*}{$\mathrm{I}-131$} & Adult & NRC77 & $<0.005$ & $<0.005$ & 1.00 & 0.01 & $\mathrm{C}$ & $<0.005$ & $<0.005$ \\
\hline & & Pub30 & $<0.005$ & $<0.005$ & 0.73 & $<0.005$ & $<0.005$ & $<0.005$ & 0.02 \\
\hline & & Pub72 & $<0.005$ & $<0.005$ & 0.37 & 0.00 & $<0.005$ & $<0.005$ & 0.02 \\
\hline & Teen & NRC77 & $<0.005$ & $<0.005$ & 1.23 & 0.01 & C & $<0.005$ & $<0.005$ \\
\hline & & Pub30 & $<0.005$ & $<0.005$ & 0.73 & $<0.005$ & $<0.005$ & $<0.005$ & 0.02 \\
\hline & & Pub72 & $<0.005$ & $<0.005$ & 0.55 & 0.00 & $<0.005$ & $<0.005$ & 0.03 \\
\hline & Child & NRC77 & $<0.005$ & $<0.005$ & 1.36 & 0.01 & C & $<0.005$ & $<0.005$ \\
\hline & & Pub30 & $<0.005$ & $<0.005$ & 0.34 & 0.00 & $<0.005$ & $<0.005$ & 0.01 \\
\hline & & Pub72 & $<0.005$ & $<0.005$ & 0.84 & $<0.005$ & $<0.005$ & $<0.005$ & 0.04 \\
\hline & Infant & NRC77 & $<0.005$ & $<0.005$ & 1.25 & $<0.005$ & C & $<0.005$ & $<0.005$ \\
\hline & & Pub30 & $<0.005$ & $<0.005$ & 0.13 & 0.00 & $<0.005$ & $<0.005$ & $<0.005$ \\
\hline & & Pub72 & $<0.005$ & $<0.005$ & 0.62 & $<0.005$ & $<0.005$ & $<0.005$ & 0.03 \\
\hline \multirow[t]{12}{*}{ I-133 } & Adult & NRC77 & $<0.005$ & 0.01 & 1.00 & 0.01 & C & $<0.005$ & $<0.005$ \\
\hline & & Pub30 & $<0.005$ & $<0.005$ & 0.67 & $<0.005$ & 0.01 & $<0.005$ & 0.02 \\
\hline & & Pub72 & $<0.005$ & $<0.005$ & 0.39 & $<0.005$ & $<0.005$ & $<0.005$ & 0.02 \\
\hline & Teen & NRC77 & 0.01 & 0.01 & 1.36 & 0.02 & C & $<0.005$ & $<0.005$ \\
\hline & & Pub30 & $<0.005$ & $<0.005$ & 0.67 & $<0.005$ & 0.01 & $<0.005$ & 0.02 \\
\hline & & Pub72 & $<0.005$ & $<0.005$ & 0.60 & $<0.005$ & $<0.005$ & $<0.005$ & 0.03 \\
\hline & Child & NRC77 & 0.01 & 0.01 & 1.79 & 0.02 & C & $<0.005$ & $<0.005$ \\
\hline & & Pub30 & $<0.005$ & $<0.005$ & 0.31 & $<0.005$ & 0.01 & $<0.005$ & 0.01 \\
\hline & & Pub72 & $<0.005$ & $<0.005$ & 1.04 & $<0.005$ & $<0.005$ & $<0.005$ & 0.05 \\
\hline & Infant & NRC77 & 0.01 & 0.01 & 1.65 & 0.01 & C & $<0.005$ & $<0.005$ \\
\hline & & Pub30 & $<0.005$ & $<0.005$ & 0.12 & $<0.005$ & $<0.005$ & $<0.005$ & $<0.005$ \\
\hline & & Pub72 & $<0.005$ & $<0.005$ & 0.92 & $<0.005$ & $<0.005$ & $<0.005$ & 0.05 \\
\hline \multirow[t]{12}{*}{ Cs-134 } & Adult & NRC77 & 0.44 & 1.00 & $\mathrm{C}$ & 0.34 & 0.12 & 0.01 & 0.86 \\
\hline & & Pub30 & 0.38 & 0.44 & 0.39 & 0.44 & 0.41 & 0.48 & 0.44 \\
\hline & & Pub72 & 0.24 & 0.23 & 0.22 & 0.23 & 0.21 & 0.27 & 0.23 \\
\hline & Teen & NRC77 & 0.59 & 1.33 & $\mathrm{C}$ & 0.44 & 0.17 & 0.01 & 0.65 \\
\hline & & Pub30 & 0.38 & 0.44 & 0.39 & 0.44 & 0.41 & 0.48 & 0.44 \\
\hline & & Pub72 & 0.22 & 0.22 & 0.21 & 0.22 & 0.21 & 0.23 & 0.22 \\
\hline & Child & NRC77 & 0.77 & 1.20 & C & 0.39 & 0.14 & $<0.005$ & 0.26 \\
\hline & & Pub30 & 0.18 & 0.21 & 0.18 & 0.21 & 0.19 & 0.22 & 0.20 \\
\hline & & Pub72 & 0.07 & 0.07 & 0.08 & 0.07 & 0.07 & 0.12 & 0.08 \\
\hline & Infant & NRC77 & 0.47 & 0.83 & $\mathrm{C}$ & 0.22 & 0.09 & $<0.005$ & 0.09 \\
\hline & & Pub30 & 0.07 & 0.08 & 0.07 & 0.08 & 0.07 & 0.08 & 0.08 \\
\hline & & Pub72 & 0.06 & 0.06 & 0.06 & 0.06 & 0.05 & 0.11 & 0.07 \\
\hline
\end{tabular}




\begin{tabular}{|c|c|c|c|c|c|c|c|c|c|}
\hline \multicolumn{10}{|c|}{ Table C.3 (continued) } \\
\hline \multirow[b]{2}{*}{ Nuclide } & \multirow{2}{*}{$\begin{array}{l}\text { Age } \\
\text { group }\end{array}$} & \multirow{2}{*}{$\begin{array}{l}\text { Dose } \\
\text { system }\end{array}$} & \multicolumn{7}{|c|}{ Normalized dose commitment } \\
\hline & & & Bone $^{a}$ & Liver & Thyroid & Kidney & Lung & LLI & Tbody or eff ${ }^{D}$ \\
\hline \multirow{12}{*}{ Cs-137 } & \multirow[t]{3}{*}{ Adult } & NRC77 & 0.77 & 1.00 & $\mathrm{c}$ & 0.36 & 0.12 & 0.01 & 0.69 \\
\hline & & Pub30 & 0.38 & 0.41 & 0.38 & 0.41 & 0.42 & 0.43 & 0.41 \\
\hline & & Pub72 & 0.22 & 0.22 & 0.21 & 0.22 & 0.21 & 0.27 & 0.22 \\
\hline & \multirow[t]{3}{*}{ Teen } & NRC77 & 1.08 & 1.37 & $\mathrm{C}$ & 0.49 & 0.19 & 0.01 & 0.50 \\
\hline & & Pub30 & 0.38 & 0.41 & 0.38 & 0.41 & 0.42 & 0.43 & 0.41 \\
\hline & & Pub72 & 0.21 & 0.21 & 0.20 & 0.21 & 0.20 & 0.25 & 0.21 \\
\hline & \multirow[t]{3}{*}{ Child } & NRC77 & 1.46 & 1.33 & C & 0.45 & 0.17 & 0.01 & 0.21 \\
\hline & & Pub30 & 0.18 & 0.19 & 0.18 & 0.19 & 0.19 & 0.20 & 0.19 \\
\hline & & Pub72 & 0.07 & 0.07 & 0.07 & 0.07 & 0.07 & 0.15 & 0.08 \\
\hline & \multirow[t]{3}{*}{ Infant } & NRC77 & 0.88 & 0.99 & C & 0.28 & 0.11 & $<0.005$ & 0.07 \\
\hline & & Pub30 & 0.07 & 0.07 & 0.07 & 0.07 & 0.07 & 0.08 & 0.07 \\
\hline & & Pub72 & 0.06 & 0.06 & 0.06 & 0.06 & 0.06 & 0.15 & 0.07 \\
\hline \multirow[t]{12}{*}{ Ba-140 } & \multirow[t]{3}{*}{ Adult } & NRC77 & 0.03 & $<0.005$ & C & $<0.005$ & 1.00 & 0.17 & $<0.005$ \\
\hline & & Pub30 & 0.06 & 0.01 & 0.01 & 0.01 & 0.04 & 0.10 & 0.02 \\
\hline & & Pub72 & 0.02 & 0.01 & 0.01 & 0.01 & 0.82 & 0.17 & 0.12 \\
\hline & \multirow[t]{3}{*}{ Teen } & NRC77 & 0.04 & $<0.005$ & $\mathrm{C}$ & $<0.005$ & 1.60 & 0.18 & $<0.005$ \\
\hline & & Pub30 & 0.06 & 0.01 & 0.01 & 0.01 & 0.04 & 0.10 & 0.02 \\
\hline & & Pub72 & 0.05 & 0.02 & 0.01 & 0.01 & 1.00 & 0.19 & 0.15 \\
\hline & \multirow[t]{3}{*}{ Child } & NRC77 & 0.06 & $<0.005$ & C & $<0.005$ & 1.37 & 0.08 & $<0.005$ \\
\hline & & Pub30 & 0.03 & $<0.005$ & $<0.005$ & $<0.005$ & 0.02 & 0.05 & 0.01 \\
\hline & & Pub72 & 0.03 & 0.01 & 0.01 & 0.01 & 0.72 & 0.30 & 0.12 \\
\hline & \multirow[t]{3}{*}{ Infant } & NRC77 & 0.04 & $<0.005$ & C & $<0.005$ & 1.25 & 0.03 & $<0.005$ \\
\hline & & Pub30 & 0.01 & $<0.005$ & $<0.005$ & $<0.005$ & 0.01 & 0.02 & $<0.005$ \\
\hline & & Pub72 & 0.07 & 0.01 & 0.01 & 0.01 & 0.57 & 0.36 & 0.11 \\
\hline \multirow[t]{12}{*}{ La-140 } & \multirow[t]{3}{*}{ Adult } & NRC77 & $<0.005$ & $<0.005$ & $\mathrm{C}$ & $\mathrm{C}$ & 0.30 & 1.00 & $<0.005$ \\
\hline & & Pub30 & 0.01 & 0.05 & $<0.005$ & 0.01 & 0.27 & 0.35 & 0.08 \\
\hline & & Pub72 & 0.01 & 0.02 & $<0.005$ & 0.01 & 0.26 & 0.22 & 0.07 \\
\hline & \multirow[t]{3}{*}{ Teen } & NRC77 & $<0.005$ & $<0.005$ & C & C & 0.47 & 1.06 & $<0.005$ \\
\hline & & Pub30 & 0.01 & 0.05 & $<0.005$ & 0.01 & 0.27 & 0.35 & 0.08 \\
\hline & & Pub72 & 0.01 & 0.03 & $<0.005$ & 0.01 & 0.31 & 0.26 & 0.09 \\
\hline & \multirow[t]{3}{*}{ Child } & NRC77 & $<0.005$ & $<0.005$ & c & C & 0.40 & 0.49 & $<0.005$ \\
\hline & & Pub30 & $<0.005$ & 0.02 & $<0.005$ & 0.01 & 0.13 & 0.16 & 0.04 \\
\hline & & Pub72 & 0.01 & 0.03 & 0.01 & 0.01 & 0.22 & 0.41 & 0.09 \\
\hline & Infant & NRC77 & $<0.005$ & $<0.005$ & C & C & 0.37 & 0.19 & $<0.005$ \\
\hline & & Pub30 & $<0.005$ & 0.01 & $<0.005$ & $<0.005$ & 0.05 & 0.06 & 0.01 \\
\hline & & Pub72 & 0.01 & 0.03 & $<0.005$ & 0.01 & 0.18 & 0.56 & 0.10 \\
\hline Np-239 & Adult & NRC77 & $<0.005$ & $<0.005$ & $\mathrm{C}$ & $<0.005$ & 0.32 & 1.00 & $<0.005$ \\
\hline & & Pub30 & 0.50 & 0.03 & $<0.005$ & $<0.005$ & 0.59 & 0.73 & 0.17 \\
\hline & & Pub72 & 0.13 & 0.01 & $<0.005$ & 0.01 & 1.57 & 0.43 & 0.23 \\
\hline & Teen & NRC77 & $<0.005$ & $<0.005$ & C & $<0.005$ & 0.54 & 1.11 & $<0.005$ \\
\hline & & Pub30 & 0.50 & 0.03 & $<0.005$ & $<0.005$ & 0.59 & 0.73 & 0.17 \\
\hline & & Pub72 & 0.13 & 0.01 & $<0.005$ & 0.01 & 2.00 & 0.51 & 0.29 \\
\hline & Child & NRC77 & $<0.005$ & $<0.005$ & C & $<0.005$ & 0.49 & 0.54 & $<0.005$ \\
\hline & & Pub30 & 0.23 & 0.01 & $<0.005$ & $<0.005$ & 0.27 & 0.34 & 0.08 \\
\hline & & Pub72 & 0.13 & 0.01 & $<0.005$ & 0.01 & 1.28 & 0.83 & 0.23 \\
\hline & Infant & NRC77 & $<0.005$ & $<0.005$ & C & $<0.005$ & 0.50 & 0.21 & $<0.005$ \\
\hline & & Pub30 & 0.09 & 0.01 & $<0.005$ & $<0.005$ & 0.10 & 0.13 & 0.03 \\
\hline & & Pub72 & 0.10 & 0.01 & $<0.005$ & 0.01 & 0.98 & 1.16 & 0.25 \\
\hline
\end{tabular}




\section{APPENDIX D: COMPARISON OF DOSE ESTIMATES FOR MIXTURES OF RADIONUCLIDES BASED ON DIFFERENT DOSIMETRY SYSTEMS}

\section{D.1. Comparison of dose estimates for ingestion of a mixture of radionuclides in drinking water}

This section compares maximum doses (across age groups) based on NRC77, Pub30, and Pub72 for mixtures of radionuclides in drinking water. The reference mixtures of radionuclides are based on data for the period 2002-2006 for liquid effluents from BWRs and PWRs in the U.S. (Table D.1; data provided by NRC Project Manager). The relative activities of radionuclides in drinking water are assumed to be proportional to the relative activities at the time of release.

\begin{tabular}{|c|c|c|}
\hline Radionuclide & BWR (Ci/y) & PWR (Ci/y) \\
\hline $\mathrm{H}-3$ & $7.16 \mathrm{E}+00$ & $1.03 \mathrm{E}+02$ \\
\hline C-14 & - & 3.66E-03 \\
\hline P-32 & 1.52E-05 & - \\
\hline Cr-51 & 4.40E-01 & 6.63E-03 \\
\hline Mn-54 & 1.51E-02 & - \\
\hline Fe-55 & $3.27 \mathrm{E}+01$ & 2.34E-02 \\
\hline Fe-59 & $2.29 \mathrm{E}-03$ & 2.53E-04 \\
\hline Co-58 & $2.75 E-04$ & 8.21E-03 \\
\hline Co-60 & 4.75E-03 & 8.88E-03 \\
\hline $\mathrm{Ni}-63$ & $1.24 \mathrm{E}-04$ & 8.32E-03 \\
\hline Cu-64 & $2.28 \mathrm{E}-04$ & - \\
\hline Zn-65 & 1.04E-03 & $3.75 E-04$ \\
\hline Sr-89 & 9.32E-05 & 3.18E-04 \\
\hline Sr-90 & 2.30E-02 & 6.06E-03 \\
\hline$Y-90$ & - & 5.74E-06 \\
\hline Zr-95 & 2.76E-02 & 5.43E-03 \\
\hline $\mathrm{Nb}-95$ & $1.78 \mathrm{E}-04$ & 2.36E-04 \\
\hline Mo-99 & 1.52E-04 & 3.47E-05 \\
\hline Tc-99m & 7.09E-05 & 9.71E-06 \\
\hline Ru-106 & 7.67E-05 & 1.63E-04 \\
\hline $\mathrm{Ag}-110 \mathrm{~m}$ & 2.81E-04 & 2.67E-02 \\
\hline I-131 & 4.77E-02 & 5.51E-04 \\
\hline $\mathrm{I}-133$ & 3.08E-05 & 1.37E-04 \\
\hline Cs-134 & 2.86E-03 & 7.45E-03 \\
\hline Cs-137 & $6.44 \mathrm{E}-03$ & 3.97E-04 \\
\hline Ba-140 & 2.52E-05 & - \\
\hline La-140 & 1.73E-04 & 5.23E-05 \\
\hline Np-239 & $3.75 E-05$ & 3.30E-06 \\
\hline
\end{tabular}

The comparison involves all three dosimetry systems and is restricted to two key dose quantities: (1) the maximum organ dose across age groups, and (2) the maximum whole body dose across age groups (total body dose in NRC77, $\mathrm{H}_{\mathrm{E}}$ in Pub30, and E in Pub72). Results are summarized in Table D.2 for BWRs and Table D.3 for PWRs. All entries in 
each table are normalized to the highest organ dose for the adult from the assumed mixture of radionuclides based on NRC77.

Table D.2. Comparison of maximum doses in specific age groups and across age groups from drinking water based on NRC77, Pub30, and Pub72 for a reference mixture of radionuclides in BWR effluents. Values normalized to highest organ dose for adults based on NRC77.

\begin{tabular}{ccccccc}
\hline \multirow{2}{*}{ Age group } & \multicolumn{3}{c}{ Highest organ dose $^{\mathrm{a}}$} & \multicolumn{3}{c}{ Highest "whole body dose" } \\
\cline { 2 - 7 } & & & & NRC77 & Pub30 & Pub72 \\
NRC77 & Pub30 & Pub72 & (Total body) & $\left(\mathrm{H}_{\mathrm{E}}\right)$ & $(\mathrm{E})$ \\
\hline Adult & 1.00 & 0.37 & 1.16 & 0.22 & 0.10 & 0.18 \\
Teen & 0.83 & 0.26 & 1.88 & 0.18 & 0.071 & 0.28 \\
Child & 2.03 & 0.26 & 3.76 & 0.43 & 0.071 & 0.62 \\
Infant & 1.51 & 0.17 & 10.2 & 0.32 & 0.046 & 1.64 \\
\hline All ages & $\mathbf{2 . 0 3}$ & $\mathbf{0 . 3 7}$ & $\mathbf{1 0 . 2}$ & $\mathbf{0 . 4 3}$ & $\mathbf{0 . 1 0}$ & $\mathbf{1 . 6 4}$ \\
\hline
\end{tabular}

${ }^{\mathrm{a}}$ For all age groups the organ receiving the highest dose is predicted by NRC77 to bone, by Pub30 to be thyroid, and by Pub72 to be spleen.

For BWR effluents the three dosimetry systems give substantially different conclusions regarding the maximum organ dose due to the high content of ${ }^{55} \mathrm{Fe}$ in the reference mixture of radionuclides and the fact the three systems yield much different dose per unit ingestion of ${ }^{55} \mathrm{Fe}$.

Table D.3. Comparison of maximum doses in specific age groups and across age groups from drinking water based on NRC77, Pub30, and Pub72 for a reference mixture of radionuclides in PWR effluents. Values normalized to highest organ dose for adults based on NRC77.

\begin{tabular}{ccccccc}
\hline \multirow{2}{*}{ Age group } & \multicolumn{3}{c}{ Highest organ dose } & \multicolumn{2}{c}{ Highest "whole body dose" } \\
\cline { 2 - 7 } & $\begin{array}{c}\text { NRC77 } \\
\text { (Thyroid) }\end{array}$ & $\begin{array}{c}\text { Pub30 } \\
\text { (Thyroid) }\end{array}$ & $\begin{array}{c}\text { Pub72 } \\
\text { (Thyroid) }\end{array}$ & $\begin{array}{c}\text { NRC77 } \\
\text { (Total body) }\end{array}$ & $\begin{array}{c}\text { Pub30 } \\
\left(\mathrm{H}_{\mathrm{E}}\right)\end{array}$ & $\begin{array}{c}\text { Pub72 } \\
(\mathrm{E})\end{array}$ \\
\hline Adult & 1.00 & 0.35 & 0.36 & 0.49 & 0.18 & 0.18 \\
Teen & 0.77 & 0.24 & 0.72 & 0.35 & 0.13 & 0.15 \\
Child & 1.61 & 0.24 & 0.40 & 0.70 & 0.13 & 0.22 \\
Infant & 1.16 & 0.16 & 0.76 & 0.58 & 0.081 & 0.34 \\
\hline All ages & $\mathbf{1 . 6 1}$ & $\mathbf{0 . 3 5}$ & $\mathbf{0 . 7 6}$ & $\mathbf{0 . 7 0}$ & $\mathbf{0 . 1 8}$ & $\mathbf{0 . 3 4}$ \\
\hline
\end{tabular}

For the reference mixture of radionuclides in PWR effluents, all three dosimetry systems predict that bone tissue (bone in NRC77 and bone surface in Pub30 and Pub72) receives the highest dose. The dose estimate for bone based on NRC77 arises almost entirely from ${ }^{90} \mathrm{Sr}$. The dose estimate for bone surface based on Pub30 or Pub72 arises mainly from ${ }^{90} \mathrm{Sr}$ and ${ }^{3} \mathrm{H}$. For all age groups the dose to bone based on NRC77 is higher than the dose to bone surface based on Pub30 or Pub72. The maximum "whole body dose" predicted by any of the systems is the total body dose to the child based on NRC77, which is about four times higher than the maximum effective dose equivalent $\mathrm{H}_{\mathrm{E}}$ based on Pub30 and about twice the maximum effective dose E based on Pub72. 


\section{D.2. Comparison of dose estimates for inhalation of a mixture of radionuclides}

This section compares maximum doses based on NRC77, Pub30, and Pub72 for inhalation of mixtures of the 28 radionuclides addressed earlier. The reference mixtures of radionuclides are based on data for the period 2002-2006 for airborne emissions from BWRs and PWRs in the U.S. (Table D.4; data provided by NRC Project Manager). The relative activities of radionuclides in air are assumed to be proportional to the relative activities at the time of release.

The comparison is restricted to two key dose quantities: (1) the maximum organ dose across age groups, and (2) the maximum whole body dose across age groups (total body dose in NRC77, $\mathrm{H}_{\mathrm{E}}$ in Pub30, and $\mathrm{E}$ in Pub72). Results are summarized in Table D.5 for BWRs and Table D.6 for PWRs. All entries in each table are normalized to the highest organ dose for the adult from the assumed mixture of radionuclides based on NRC77.

\begin{tabular}{|c|c|c|}
\hline Radionuclide & BWR (Ci/y) & PWR (Ci/y) \\
\hline $\mathrm{H}-3$ & 1.10E+01 & $1.00 \mathrm{E}+03$ \\
\hline C-14 & - & 2.16E-04 \\
\hline Cr-51 & 1.07E-04 & $2.23 \mathrm{E}-05$ \\
\hline Mn-54 & 4.34E-05 & - \\
\hline Fe-55 & 2.95E-04 & 5.55E-06 \\
\hline Fe-59 & 1.50E-05 & 5.11E-06 \\
\hline Co-58 & 2.03E-05 & 8.30E-05 \\
\hline Co-60 & 1.13E-04 & 7.90E-02 \\
\hline $\mathrm{Ni}-63$ & - & 6.10E-06 \\
\hline Cu-64 & - & 3.26E-02 \\
\hline Zn-65 & 4.52E-05 & 4.73E-05 \\
\hline Sr-89 & 2.00E-04 & 2.24E-06 \\
\hline Sr-90 & 3.10E-06 & 2.40E-07 \\
\hline Y-90 & - & 2.94E-07 \\
\hline Zr-95 & 1.81E-06 & 4.07E-06 \\
\hline $\mathrm{Nb}-95$ & 4.39E-07 & 4.53E-06 \\
\hline Mo-99 & $3.48 \mathrm{E}-04$ & 4.96E-06 \\
\hline Tc-99m & 3.32E-04 & 2.39E-04 \\
\hline Ru-106 & 3.39E-06 & 2.95E-05 \\
\hline $\mathrm{Ag}-110 \mathrm{~m}$ & 2.33E-05 & 7.00E-07 \\
\hline I-131 & $6.20 \mathrm{E}-03$ & 8.45E-03 \\
\hline |-133 & 9.99E-03 & 1.34E-04 \\
\hline Cs-134 & 8.16E-05 & 1.05E-05 \\
\hline Cs-137 & 3.38E-05 & 1.32E-03 \\
\hline Ba-140 & 2.45E-04 & 1.56E-07 \\
\hline La-140 & 2.89E-04 & $1.50 \mathrm{E}-11$ \\
\hline Np-239 & 4.75E-06 & - \\
\hline
\end{tabular}




\begin{tabular}{|c|c|c|c|c|c|c|}
\hline \multirow{2}{*}{\multicolumn{7}{|c|}{$\begin{array}{l}\text { Table D.5. Comparison of maximum inhalation doses based NRC77, Pub30, and } \\
\text { Pub72 for a reference mixture of radionuclides in BWR airborne emissions. Values } \\
\text { normalized to highest organ dose for adults based on NRC77. }\end{array}$}} \\
\hline \multirow[b]{2}{*}{ Age group } & \multicolumn{3}{|c|}{ Highest organ dose ${ }^{a}$} & \multicolumn{2}{|c|}{ Highest "whole body dose" } & \\
\hline & NRC77 & Pub30 & Pub72 & $\begin{array}{c}\text { NRC77 } \\
\text { (Total body) }\end{array}$ & $\begin{array}{c}\text { Pub30 } \\
\left(\mathrm{H}_{E}\right)\end{array}$ & $\begin{array}{l}\text { Pub72 } \\
\text { (E) }\end{array}$ \\
\hline Adult & 1.00 & 0.68 & 0.38 & 0.13 & 0.072 & 0.072 \\
\hline Teen & 1.23 & 0.68 & 0.55 & 0.13 & 0.072 & 0.080 \\
\hline Child & 1.39 & 0.31 & 0.82 & 0.12 & 0.033 & 0.083 \\
\hline Infant & 1.24 & 0.12 & 0.64 & 0.067 & 0.013 & 0.065 \\
\hline All ages & 1.39 & 0.68 & 0.82 & 0.13 & 0.072 & 0.083 \\
\hline
\end{tabular}

Table D.6. Comparison of maximum inhalation doses based NRC77, Pub30, and Pub72 for a reference mixture of radionuclides in PWR airborne emissions. Values are normalized to the highest organ dose for adults based on NRC77.

\begin{tabular}{|c|c|c|c|c|c|c|}
\hline \multirow[b]{2}{*}{ Age group } & \multicolumn{3}{|c|}{ Highest organ dose $^{a}$} & \multicolumn{3}{|c|}{ Highest "whole body dose" } \\
\hline & NRC77 & Pub30 & Pub72 & $\begin{array}{c}\text { NRC77 } \\
\text { (Total body) }\end{array}$ & $\begin{array}{c}\text { Pub30 } \\
\left(\mathrm{H}_{E}\right)\end{array}$ & $\begin{array}{l}\text { Pub72 } \\
\text { (E) }\end{array}$ \\
\hline Adult & 1.00 & 0.19 & 0.27 & 0.040 & 0.063 & 0.069 \\
\hline Teen & 1.45 & 0.19 & 0.33 & 0.041 & 0.063 & 0.079 \\
\hline Child & 1.17 & 0.087 & 0.24 & 0.036 & 0.029 & 0.068 \\
\hline Infant & 0.75 & 0.033 & 0.17 & 0.021 & 0.011 & 0.051 \\
\hline All ages & 1.45 & 0.19 & 0.33 & 0.041 & 0.063 & 0.079 \\
\hline
\end{tabular}

For the reference mixture of radionuclides from BWR effluents, all three dosimetry systems predict that the thyroid receives the highest tissue dose in all age groups, primarily from ${ }^{131} \mathrm{I}$ and ${ }^{133} \mathrm{I}$ and to a smaller extent from ${ }^{3} \mathrm{H}$. Thyroid doses based on NRC77 are higher than those based on Pub30 or Pub72 for all age groups. NRC77 and Pub72 predict that the highest thyroid dose is received by the child, while Pub30 predicts that the adult receives the highest thyroid dose. The highest "whole body dose" predicted by any of the systems is the total body dose to the adult or teen based on NRC77, which is $>50 \%$ higher than the highest effective dose equivalent $\mathrm{H}_{\mathrm{E}}$ or effective dose $\mathrm{E}$ predicted by Pub30 or Pub72, respectively.

For the reference mixture of radionuclides from PWR effluents, all three dosimetry systems predict that the lung receives the highest tissue dose in all age groups, primarily from ${ }^{60} \mathrm{Co}$ but with ${ }^{3} \mathrm{H}$ contributing a few percent of the total dose. Lung dose estimates based on NRC77 are higher than those based on Pub30 or Pub72 for all age groups. The age group receiving the highest lung dose is predicted by NRC77 and Pub72 to be the teen and by Pub30 to be the adult and teen. The highest "whole body dose" predicted by any of the systems is the effective dose E to the teen based on Pub72. 


\section{D.3. Comparison of external dose estimates for a mixture of radionuclides}

Reference airborne releases of BWRs and PWRs provided by the NRC Project Manager were used to compute annual doses according to the methods of RG 1.109 using dose coefficients listed in Section 5. For the calculations a $\chi / \mathrm{Q}$ of $1 \times 10^{-6} \mathrm{~s} \mathrm{~m}^{-3}$ and a $\mathrm{D} / \mathrm{Q}$ of 1 $\mathrm{x} 10^{-8} \mathrm{~m}^{-2}$ were assumed. The assumed annual release of the radionuclides is shown in each of the tables in which dose estimates are compared.

Tables D.7 and D.8 list estimated annual air dose estimates (beta and gamma) for noble gas releases from PWRs and BWRs, respectively. The air dose values based on RG 1.109 are in reasonable agreement with the values based on current nuclear decay data. This is consistent with the results listed in Table 5.2. Tables D.9 and D.10 contrast the annual skin and total body dose estimates for the PWR and BWR noble gas effluents. Despite significant differences in the contributions of the various radionuclides, the totals derived with the two sets of coefficients agree within a factor of two.

Tables D.11 and D.12 list estimates of annual skin and total body dose from particulate radionuclides deposited on the ground surface following their release to the atmosphere in the course of PWR and BWR operations, respectively. The dose coefficients of RG 1.109 yield lower estimates of both the skin and total body dose for the PWR emissions. The differences are substantial: skin dose, 5.8 vs. $11 \mathrm{mrem}$; and total body dose, 4.9 vs. $8.9 \mathrm{mrem}$. This discrepancy is largely associated with lower dose coefficients for Co-60 in RG 1.109 and the dominant role of this nuclide in the PWR effluent. For the BWR the value for the skin dose based on RG 1.109 is lower than the FGR-12 value; however, the totals for the total body are in reasonable agreement. 


\begin{tabular}{|c|c|c|c|c|c|}
\hline \multicolumn{6}{|c|}{$\begin{array}{c}\text { Table D.7. Annual beta and gamma air doses for noble gas } \\
\text { releases of a PWR. }\end{array}$} \\
\hline \multirow[b]{2}{*}{ Nuclide } & \multirow{2}{*}{$\begin{array}{c}\text { Release } \\
\text { (Ci/y) }\end{array}$} & \multicolumn{2}{|c|}{$\beta$-Air Dose (mrad) } & \multicolumn{2}{|c|}{ Y-Dose (mrad) } \\
\hline & & RG 1.109 & FGR-12 & RG 1.109 & FGR-12 \\
\hline Ar-41 & $1.02 E+00$ & $1.06 \mathrm{E}-04$ & 1.08E-04 & 3.01E-04 & $2.98 \mathrm{E}-04$ \\
\hline $\mathrm{Kr}-85$ & $3.49 E+00$ & $2.16 \mathrm{E}-04$ & 1.99E-04 & $1.91 \mathrm{E}-06$ & $1.76 \mathrm{E}-06$ \\
\hline $\mathrm{Kr}-85 \mathrm{~m}$ & $4.31 E+00$ & 2.70E-04 & & $8 \mathrm{E}-04$ & $1.55 E-04$ \\
\hline Kr-87 & 3.08E-02 & & & $3 \mathrm{E}-06$ & 5.57E-06 \\
\hline Kr-88 & & & & & \\
\hline Xe-131m & & 2.1 & & 06 & $E-06$ \\
\hline Xe-133 & $1.57 \mathrm{E}+01$ & & & & 4E-04 \\
\hline Xe-133m & 4.84E-01 & 2.27E-05 & 2.12E-05 & $5.02 E-06$ & 4.49E-06 \\
\hline Xe-135 & 4.19E-01 & 3.27E-05 & 3.03E-05 & 2.55E-05 & $2.38 \mathrm{E}-05$ \\
\hline Xe-135m & 4.13E-02 & 9.69E-07 & $9.18 \mathrm{E}-07$ & 4.41E-06 & 4.04E-06 \\
\hline Xe-137 & 1.42E-02 & 5.73E-06 & 5.45E-06 & 6.81E-07 & $6.18 \mathrm{E}-07$ \\
\hline \multirow[t]{2}{*}{ Xe-138 } & $6.16 \mathrm{E}-02$ & $9.29 \mathrm{E}-06$ & $9.45 \mathrm{E}-06$ & 1.80E-05 & 1.59E-05 \\
\hline & Total & 1.22E-03 & 1.14E-03 & 7.32E-04 & $6.96 \mathrm{E}-04$ \\
\hline
\end{tabular}

Table D.8. Annual beta and gamma air doses for noble gas releases of a BWR.

\begin{tabular}{|c|c|c|c|c|c|}
\hline \multirow[b]{2}{*}{ Nuclide } & \multirow{2}{*}{$\begin{array}{c}\text { Release } \\
(\mathrm{Ci} / \mathrm{y})\end{array}$} & \multicolumn{2}{|c|}{$\beta$-Air Dose (mrad) } & \multicolumn{2}{|c|}{$\gamma$-Dose (mrad) } \\
\hline & & RG 1.109 & FGR-12 & RG 1.109 & FGR-12 \\
\hline Ar-41 & $4.79 \mathrm{E}+00$ & 4.99E-04 & $5.06 \mathrm{E}-04$ & $1.41 \mathrm{E}-03$ & $1.40 \mathrm{E}-03$ \\
\hline $\mathrm{Kr}-83 \mathrm{~m}$ & 5.59E-01 & 5.11E-06 & 4.93E-06 & $3.42 E-07$ & $3.41 \mathrm{E}$ \\
\hline Kr-85 & $5.72 \mathrm{E}+00$ & 3.54E-04 & 3.27E-04 & $3.12 E-06$ & 2.89E-06 \\
\hline $\mathrm{Kr}-85 \mathrm{~m}$ & $4.11 \mathrm{E}+01$ & $2.57 \mathrm{E}-03$ & 2.40E-03 & $1.60 \mathrm{E}-03$ & 1.47E-03 \\
\hline $\mathrm{Kr}-87$ & $1.67 \mathrm{E}+01$ & $5.46 \mathrm{E}-03$ & 5.03E-03 & $3.27 \mathrm{E}-03$ & 3.02E-03 \\
\hline Kr-88 & $7.32 \mathrm{E}+01$ & $6.81 E-03$ & $6.07 \mathrm{E}-03$ & 3.53E-02 & $3.28 \mathrm{E}-02$ \\
\hline $\mathrm{Kr}-\mathrm{r}$ & $.78 \mathrm{E}+00$ & $2.95 \mathrm{E}-03$ & & 4.82E-03 & -03 \\
\hline & 01E-01 & 3.56E-06 & E-06 & $5.00 \mathrm{E}-07$ & $=-07$ \\
\hline & $52 \mathrm{E}+01$ & 2.17E-03 & 2.0 & 7.31E-04 & E-04 \\
\hline & $62 \mathrm{E}+00$ & 7.61E-05 & $7.10 \mathrm{E}-05$ & 1.68E-05 & 1.50E-05 \\
\hline Xe-1 & $1.83 \mathrm{E}+01$ & 1.43E-03 & $1.32 \mathrm{E}-03$ & 1.12E-03 & $1.04 \mathrm{E}-03$ \\
\hline Xe-135m & $1.51 \mathrm{E}+01$ & 3.54E-04 & 3.36E-04 & 1.61E-03 & 1.48E-03 \\
\hline Xe-137 & $2.17 E+01$ & 8.75E-03 & $8.34 \mathrm{E}-03$ & 1.04E-03 & $9.44 \mathrm{E}-04$ \\
\hline \multirow[t]{2}{*}{ Xe-138 } & $2.86 \mathrm{E}+01$ & 4.31E-03 & 4.39E-03 & 8.36E-03 & 7.36E-03 \\
\hline & Total & 3.58E-02 & 3.35E-02 & 5.93E-02 & 5.41E-02 \\
\hline
\end{tabular}




\begin{tabular}{|c|c|c|c|c|c|}
\hline \multicolumn{6}{|c|}{$\begin{array}{c}\text { Table D.9. Annual dose to skin and total body from noble gas } \\
\text { releases of a PWR. }\end{array}$} \\
\hline \multirow[b]{2}{*}{ Nuclide } & \multirow{2}{*}{$\begin{array}{c}\text { Release } \\
\text { (Ci/y) }\end{array}$} & \multicolumn{2}{|c|}{ Skin Dose (mrem) } & \multicolumn{2}{|c|}{ Total Body Dose (mrem) } \\
\hline & & RG 1.109 & FGR-12 & RG 1.109 & FGR-12 \\
\hline Ar-41 & $1.02 \mathrm{E}+00$ & 8.71E-05 & 1.07E-04 & 2.86E-04 & 2.32E-04 \\
\hline Kr-85 & $3.49 \mathrm{E}+00$ & 1.48E-04 & $1.70 \mathrm{E}-04$ & $1.78 \mathrm{E}-06$ & $3.10 \mathrm{E}-06$ \\
\hline $\mathrm{Kr}-85 \mathrm{~m}$ & $4.31 \mathrm{E}+00$ & 2.00E-04 & $2.20 \mathrm{E}-04$ & 1.60E-04 & 1.10E-04 \\
\hline Kr-87 & 3.08E-02 & 9.51E-06 & 1.04E-05 & 9E-06 & 4.55E-06 \\
\hline $\mathrm{Kr}-88$ & 4.53E-02 & 3.41E-06 & 3.54E-06 & 2.11E-05 & 1.63E-05 \\
\hline Xe-131m & 5.99E-01 & 9.05E-06 & 9.05E-06 & $1.74 \mathrm{E}-06$ & 7.78E-07 \\
\hline Xe-133 & $1.57 \mathrm{E}+01$ & 1.53E-04 & 1.65E-04 & $1.47 \mathrm{E}-04$ & 7.78E-05 \\
\hline Xe-133m & 4.84E-01 & 1.53E-05 & 1.52E-05 & 3.86E-06 & 2.32E-06 \\
\hline Xe-135 & 4.19E-01 & 2.47E-05 & 2.70E-05 & 2.41E-05 & 1.70E-05 \\
\hline Xe-135m & 4.13E-02 & 9.32E-07 & $9.10 \mathrm{E}-07$ & 4.09E-06 & 2.91E-06 \\
\hline Xe-137 & 1.42E-02 & 5.50E-06 & $6.22 \mathrm{E}-06$ & $6.40 \mathrm{E}-07$ & 5.45E-07 \\
\hline \multirow[t]{2}{*}{ Xe-138 } & 6.16E-02 & 8.08E-06 & 9.70E-06 & 1.73E-05 & $1.25 E-05$ \\
\hline & Total & 6.64E-04 & 7.44E-04 & 6.73E-04 & $4.80 \mathrm{E}-04$ \\
\hline
\end{tabular}

\begin{tabular}{|c|c|c|c|c|c|}
\hline \multicolumn{6}{|c|}{$\begin{array}{l}\text { Table D.10. Annual dose to skin and total body from noble gas } \\
\text { releases of a BWR. }\end{array}$} \\
\hline \multirow[b]{2}{*}{ Nuclide } & \multirow{2}{*}{$\begin{array}{c}\text { Release } \\
(\mathrm{Ci} / \mathrm{y})\end{array}$} & \multicolumn{2}{|c|}{ Skin Dose (mrem) } & \multicolumn{2}{|c|}{ Total Body Dose (mrem) } \\
\hline & & RG 1.109 & FGR-12 & RG 1.109 & FGR-12 \\
\hline Ar-41 & $4.79 \mathrm{E}+00$ & 4.99E-04 & 5.06E-04 & 1.41E-03 & 1.40E-03 \\
\hline $\mathrm{Kr}-83 \mathrm{~m}$ & 5.59E-01 & 5.11E-06 & 4.93E-06 & $3.42 \mathrm{E}-07$ & $3.41 \mathrm{E}-07$ \\
\hline $\mathrm{Kr}-85$ & $5.72 \mathrm{E}+00$ & 3.54E-04 & 3.27E-04 & 3.12E-06 & 2.89E-06 \\
\hline $\mathrm{Kr}-85 \mathrm{~m}$ & $4.11 \mathrm{E}+01$ & $2.57 \mathrm{E}-03$ & $2.40 \mathrm{E}-03$ & $1.60 \mathrm{E}-03$ & $1.47 \mathrm{E}-03$ \\
\hline Kr-87 & $1.67 \mathrm{E}+01$ & $5.46 \mathrm{E}-03$ & 5.03E-03 & $3.27 \mathrm{E}-03$ & 3.02E-03 \\
\hline Kr-88 & $7.32 \mathrm{E}+01$ & $6.81 \mathrm{E}-03$ & 6.07E-03 & 3.53E-02 & $3.28 \mathrm{E}-02$ \\
\hline $\mathrm{Kr}-89$ & $8.78 \mathrm{E}+00$ & $2.95 \mathrm{E}-03$ & $2.74 \mathrm{E}-03$ & 4.82E-03 & 3.87E-03 \\
\hline Xe-131m & 1.01E-01 & 3.56E-06 & 3.30E-06 & 5.0 & $4.62 \mathrm{E}-07$ \\
\hline Xe-133 & $6.52 \mathrm{E}+01$ & 2.17E-03 & 2.01E-03 & 7.31E-04 & 6.83E-04 \\
\hline Xe-133m & $1.62 \mathrm{E}+00$ & $7.61 \mathrm{E}-05$ & 7.10E-05 & 1.68E-05 & 1.50E-05 \\
\hline Xe-135 & $1.83 \mathrm{E}+01$ & 1.43E-03 & 1.32E-03 & 1.12E-03 & 1.04E-03 \\
\hline Xe-135m & $1.51 \mathrm{E}+01$ & 3.54E-04 & 3.36E-04 & $1.61 \mathrm{E}-03$ & $1.48 \mathrm{E}-03$ \\
\hline Xe-137 & $2.17 \mathrm{E}+01$ & 8.75E-03 & 8.34E-03 & $1.04 \mathrm{E}-03$ & $9.44 \mathrm{E}-04$ \\
\hline \multirow[t]{2}{*}{ Xe-138 } & $2.86 \mathrm{E}+01$ & 4.31E-03 & 4.39E-03 & 8.36E-03 & 7.36E-03 \\
\hline & Total & 3.58E-02 & 3.35E-02 & 5.93E-02 & 5.41E-02 \\
\hline
\end{tabular}




\begin{tabular}{|c|c|c|c|c|c|}
\hline \multirow[b]{3}{*}{ Nuclide } & \multirow{3}{*}{$\begin{array}{c}\text { Release } \\
(\mathrm{Ci} / \mathrm{y})\end{array}$} & \multirow{2}{*}{\multicolumn{2}{|c|}{ Skin Dose (mrem) }} & & \\
\hline & & & & \multicolumn{2}{|c|}{ Total Body Dose (mrem) } \\
\hline & & RG 1.109 & FGR-12 & RG 1.109 & FGR-12 \\
\hline $\mathrm{Ag}-110 \mathrm{~m}$ & $2.02 E-06$ & 1.59E-05 & 3.24E-05 & $1.36 \mathrm{E}-05$ & 2.60E-05 \\
\hline Ba-139 & 1.65E-05 & 3.83E-09 & 1.94E-07 & 3.40E-09 & 2.75E-09 \\
\hline Ba-140 & $1.64 \mathrm{E}-06$ & 7.50E-08 & 8.13E-07 & 6.56E-08 & 7.91E-08 \\
\hline $\mathrm{C}-14$ & $2.16 \mathrm{E}-04$ & $0.00 E+00$ & $1.22 \mathrm{E}-06$ & $0.00 \mathrm{E}+00$ & 2.08E-07 \\
\hline Ce-141 & 7.88E-07 & 2.38E-08 & $6.74 \mathrm{E}-08$ & 2.11E-08 & 3.54E-08 \\
\hline Ce-143 & $3.44 \mathrm{E}-07$ & 1.77E-09 & 3.76E-08 & $1.56 \mathrm{E}-09$ & 2.84E-09 \\
\hline Ce-144 & $2.28 \mathrm{E}-06$ & 3.59E-07 & 3.37E-07 & 3.10E-07 & 2.38E-07 \\
\hline Co-58 & 1.35E-04 & 1.17E-04 & $2.17 \mathrm{E}-04$ & 1.00E-04 & 1.76E-04 \\
\hline Co-60 & 1.16E-01 & $5.75 \mathrm{E}+00$ & $1.06 \mathrm{E}+01$ & $4.89 E+00$ & $8.79 \mathrm{E}+00$ \\
\hline Cr-51 & 5.12E-05 & 5.52E-07 & 1.04E-06 & 4.67E-07 & $8.40 \mathrm{E}-07$ \\
\hline Cs-134 & $2.58 \mathrm{E}-05$ & 4.04E-04 & 8.34E-04 & 3.47E-04 & 5.69E-04 \\
\hline Cs-136 & $1.20 E-06$ & 4.00E-07 & 7.95E-07 & 3.53E-07 & $6.35 \mathrm{E}-07$ \\
\hline Cs-137 & 2.00E-03 & 4.70E-02 & $2.35 \mathrm{E}-01$ & 4.03E-02 & 7.06E-02 \\
\hline Cs-138 & 3.32E-04 & 2.67E-07 & 2.24E-06 & 2.33E-07 & 3.34E-07 \\
\hline Cu-64 & $3.26 \mathrm{E}-02$ & 4.39E-05 & 1.35E-04 & 3.87E-05 & $6.30 \mathrm{E}-05$ \\
\hline Fe-55 & 2.33E-05 & $0.00 \mathrm{E}+00$ & $0.00 \mathrm{E}+00$ & $0.00 \mathrm{E}+00$ & $0.00 E+00$ \\
\hline Fe-59 & $1.90 E-05$ & 1.19E-05 & $2.25 \mathrm{E}-05$ & $1.01 \mathrm{E}-05$ & $1.86 \mathrm{E}-05$ \\
\hline $\mathrm{H}-3$ & $1.39 \mathrm{E}+01$ & $0.00 E+00$ & $0.00 E+00$ & $0.00 E+00$ & $0.00 \mathrm{E}+00$ \\
\hline I-130 & $4.50 \mathrm{E}-07$ & 5.89E-09 & 1.98E-08 & 4.85E-09 & 9.46E-09 \\
\hline |-131 & $1.20 \mathrm{E}-02$ & 4.91E-04 & $1.24 \mathrm{E}-03$ & 4.04E-04 & 7.00E-04 \\
\hline |-132 & 8.53E-04 & $2.45 E-06$ & $1.22 \mathrm{E}-05$ & 2.08E-06 & 3.58E-06 \\
\hline I-133 & $2.12 \mathrm{E}-04$ & $1.24 \mathrm{E}-06$ & 1.67E-05 & $1.02 \mathrm{E}-06$ & $2.26 \mathrm{E}-06$ \\
\hline I-134 & 5.95E-06 & 6.18E-09 & 4.26E-08 & $5.20 \mathrm{E}-09$ & 1.10E-08 \\
\hline I-135 & 2.85E-04 & 1.64E-06 & 7.55E-06 & 1.41E-06 & $2.30 \mathrm{E}-06$ \\
\hline La-140 & 5.09E-10 & 2.17E-11 & $1.41 \mathrm{E}-10$ & $1.92 \mathrm{E}-11$ & $3.68 \mathrm{E}-11$ \\
\hline Mn-54 & 3.17E-05 & 1.01E-04 & 1.91E-04 & 8.59E-05 & 1.56E-04 \\
\hline Mo-99 & 2.75E-05 & 2.49E-07 & 5.67E-06 & $2.15 \mathrm{E}-07$ & $2.68 \mathrm{E}-07$ \\
\hline $\mathrm{Na}-24$ & $5.12 \mathrm{E}-04$ & 1.39E-05 & $6.56 \mathrm{E}-05$ & $1.20 \mathrm{E}-05$ & 2.29E-05 \\
\hline $\mathrm{Nb}-95$ & 1.13E-05 & 3.56E-06 & 7.19E-06 & 3.03E-06 & 5.75E-06 \\
\hline $\mathrm{Nb}-95 \mathrm{~m}$ & $2.44 \mathrm{E}-06$ & $0.00 \mathrm{E}+00$ & 1.91E-08 & $0.00 E+00$ & 1.04E-08 \\
\hline $\mathrm{Nd}-147$ & 1.94E-06 & 3.82E-08 & 4.68E-07 & 3.19E-08 & 5.93E-08 \\
\hline $\mathrm{Ni}-63$ & $6.10 \mathrm{E}-06$ & $0.00 \mathrm{E}+00$ & $0.00 \mathrm{E}+00$ & $0.00 \mathrm{E}+00$ & $0.00 E+00$ \\
\hline Pr-144 & $5.86 \mathrm{E}-09$ & $2.42 \mathrm{E}-14$ & $1.78 \mathrm{E}-11$ & 2.10E-14 & $2.28 \mathrm{E}-13$ \\
\hline Rb-88 & $2.38 \mathrm{E}-05$ & 1.76E-09 & $9.77 \mathrm{E}-08$ & 1.54E-09 & 4.34E-09 \\
\hline Rb-89 & 2.32E-04 & 6.59E-08 & 5.90E-07 & 5.49E-08 & 9.60E-08 \\
\hline Ru-103 & 2.08E-06 & 5.13E-07 & 1.00E-06 & 4.40E-07 & 7.30E-07 \\
\hline Ru-105 & $1.26 \mathrm{E}-07$ & $1.78 \mathrm{E}-10$ & 2.08E-09 & $1.57 \mathrm{E}-10$ & 3.63E-10 \\
\hline Ru-106 & 2.95E-05 & 2.92E-05 & 3.07E-03 & 2.44E-05 & 7.47E-05 \\
\hline Sr-89 & 3.48E-06 & 1.71E-10 & 2.33E-05 & 1.47E-10 & $2.40 \mathrm{E}-07$ \\
\hline Sr-90 & 4.23E-07 & $0.00 \mathrm{E}+00$ & 3.75E-06 & $0.00 \mathrm{E}+00$ & 4.40E-08 \\
\hline Tc-101 & $6.28 \mathrm{E}-09$ & $2.78 \mathrm{E}-13$ & $6.49 \mathrm{E}-12$ & $2.50 \mathrm{E}-13$ & $4.50 \mathrm{E}-13$ \\
\hline Tc-99m & $9.00 \mathrm{E}-04$ & 3.71E-07 & 6.48E-07 & 3.24E-07 & $5.13 E-07$ \\
\hline Te-125m & 2.90E-05 & $1.21 \mathrm{E}-07$ & $0.00 E+00$ & 8.81E-08 & $0.00 E+00$ \\
\hline Te-132 & 1.06E-09 & $1.03 E-11$ & 2.06E-11 & 8.78E-12 & $1.47 \mathrm{E}-11$ \\
\hline W-187 & $9.79 \mathrm{E}-07$ & 5.25E-09 & 3.94E-08 & 4.52E-09 & 9.09E-09 \\
\hline Y-90 & $5.72 \mathrm{E}-07$ & 5.93E-12 & 3.19E-07 & $5.02 \mathrm{E}-12$ & 3.35E-09 \\
\hline Y-91m & 9.83E-08 & 2.23E-11 & $6.45 \mathrm{E}-11$ & 1.93E-11 & $3.44 \mathrm{E}-11$ \\
\hline Zn-65 & 1.08E-04 & 1.81E-04 & 3.42E-04 & 1.58E-04 & 2.83E-04 \\
\hline \multirow[t]{2}{*}{ Zr-95 } & $1.06 \mathrm{E}-05$ & 5.88E-06 & $1.21 \mathrm{E}-05$ & 5.07E-06 & 9.48E-06 \\
\hline & Total & $5.80 \mathrm{E}+00$ & $1.08 \mathrm{E}+01$ & $4.93 E+00$ & 8.87E+00 \\
\hline
\end{tabular}


Table D.12. Annual skin and total body dose from radionuclides released to atmosphere by a BWR and deposited on the ground surface.

\begin{tabular}{|c|c|c|c|c|c|}
\hline \multirow[b]{2}{*}{ Nuclide } & \multirow{2}{*}{$\begin{array}{c}\text { Release } \\
(\mathrm{Ci} / \mathrm{y})\end{array}$} & \multicolumn{2}{|c|}{ Skin Dose (mrem) } & \multicolumn{2}{|c|}{ Total Body Dose (mrem) } \\
\hline & & RG 1.109 & FGR-12 & RG 1.109 & FGR-12 \\
\hline $\mathrm{Ag}-110 \mathrm{~m}$ & 3.04E-05 & 2.39E-04 & 4.87E-04 & $2.05 E-04$ & 3.91E-04 \\
\hline Ba-140 & 2.23E-03 & 1.02E-04 & $1.10 \mathrm{E}-03$ & 8.92E-05 & 1.08E-04 \\
\hline Ва-139 & $6.05 E-02$ & 1.40E-05 & 7.12E-04 & $1.25 E-05$ & 1.01E-05 \\
\hline Ba-140 & 3.07E-04 & $1.40 \mathrm{E}-05$ & 1.52E-04 & $1.23 \mathrm{E}-05$ & 1.48E-05 \\
\hline Ce-141 & 3.35E-04 & 1.01E-05 & 2.87E-05 & 8.96E-06 & $1.50 \mathrm{E}-05$ \\
\hline Ce-143 & 8.22E-05 & 4.23E-07 & 8.98E-06 & 3.72E-07 & $6.78 \mathrm{E}-07$ \\
\hline Ce-144 & 7.77E-06 & 1.22E-06 & 1.15E-06 & 1.06E-06 & 8.10E-07 \\
\hline Co-58 & 3.05E-05 & 2.65E-05 & 4.91E-05 & 2.26E-05 & 3.97E-05 \\
\hline Co-60 & 1.38E-04 & $6.84 \mathrm{E}-03$ & 1.26E-02 & 5.81E-03 & 1.05E-02 \\
\hline Cr-51 & $1.75 E-04$ & $1.89 \mathrm{E}-06$ & $3.55 E-06$ & $1.60 \mathrm{E}-06$ & 2.87E-06 \\
\hline Cs-134 & 1.76E-04 & $2.76 \mathrm{E}-03$ & $5.69 \mathrm{E}-03$ & $2.36 \mathrm{E}-03$ & 3.88E-03 \\
\hline Cs-136 & 5.42E-05 & 1.81E-05 & 3.59E-05 & 1.59E-05 & 2.87E-05 \\
\hline Cs-137 & 5.19E-05 & 1.22E-03 & 6.09E-03 & 1.04E-03 & 1.83E-03 \\
\hline Cs-138 & $1.52 \mathrm{E}-01$ & $1.22 \mathrm{E}-04$ & 1.03E-03 & 1.07E-04 & 1.53E-04 \\
\hline Fe-55 & 2.95E-04 & $0.00 \mathrm{E}+00$ & $0.00 \mathrm{E}+00$ & $0.00 \mathrm{E}+00$ & $0.00 \mathrm{E}+00$ \\
\hline Fe-59 & 3.35E-05 & $2.10 \mathrm{E}-05$ & 3.97E-05 & $1.79 \mathrm{E}-05$ & 3.28E-05 \\
\hline $\mathrm{H}-3$ & $1.21 E+01$ & $0.00 E+00$ & $0.00 \mathrm{E}+00$ & $0.00 \mathrm{E}+00$ & $0.00 E+00$ \\
\hline |-130 & 1.21E-05 & $1.58 \mathrm{E}-07$ & 5.32E-07 & 1.30E-07 & 2.54E-07 \\
\hline I-131 & 7.01E-03 & 2.87E-04 & 7.22E-04 & 2.36E-04 & 4.09E-04 \\
\hline |-132 & 2.92E-02 & 8.37E-05 & 4.19E-04 & 7.12E-05 & 1.23E-04 \\
\hline $\mid-133$ & 1.16E-02 & $6.77 \mathrm{E}-05$ & $9.11 \mathrm{E}-04$ & 5.56E-05 & $1.23 \mathrm{E}-04$ \\
\hline |-134 & 5.69E-02 & 5.91E-05 & 4.07E-04 & 4.97E-05 & 1.05E-04 \\
\hline I-135 & 3.85E-02 & 2.22E-04 & $1.02 \mathrm{E}-03$ & $1.90 \mathrm{E}-04$ & 3.11E-04 \\
\hline La-140 & 3.20E-04 & 1.37E-05 & 8.83E-05 & 1.20E-05 & 2.31E-05 \\
\hline Mn-54 & 5.66E-05 & 1.80E-04 & $3.41 \mathrm{E}-04$ & $1.53 \mathrm{E}-04$ & $2.78 \mathrm{E}-04$ \\
\hline Mn-56 & 1.74E-03 & 3.64E-06 & 3.80E-05 & 3.08E-06 & 6.04E-06 \\
\hline Mo-99 & 3.70E-04 & 3.35E-06 & 7.63E-05 & 2.89E-06 & $3.61 E-06$ \\
\hline $\mathrm{Na}-24$ & 1.18E-03 & 3.20E-05 & 1.51E-04 & 2.76E-05 & 5.27E-05 \\
\hline Nb-95 & 2.59E-06 & 8.17E-07 & $1.65 \mathrm{E}-06$ & 6.94E-07 & $1.32 \mathrm{E}-06$ \\
\hline Nd-147 & 4.77E-06 & 9.40E-08 & 1.15E-06 & 7.83E-08 & 1.46E-07 \\
\hline $\mathrm{Ni}-63$ & 1.06E-04 & $0.00 \mathrm{E}+00$ & $0.00 \mathrm{E}+00$ & $0.00 \mathrm{E}+00$ & $0.00 \mathrm{E}+00$ \\
\hline Np-239 & 6.33E-06 & $2.45 \mathrm{E}-08$ & 7.80E-08 & 2.12E-08 & 4.57E-08 \\
\hline Pr-144 & 2.08E-06 & $8.59 \mathrm{E}-12$ & 6.31E-09 & 7.47E-12 & 8.10E-11 \\
\hline Rb-88 & 9.00E-02 & 6.66E-06 & 3.69E-04 & 5.82E-06 & 1.64E-05 \\
\hline $\mathrm{Rb}-89$ & 6.67E-02 & 1.90E-05 & 1.70E-04 & 1.58E-05 & 2.76E-05 \\
\hline Ru-103 & 4.97E-06 & $1.23 \mathrm{E}-06$ & $2.40 \mathrm{E}-06$ & 1.05E-06 & 1.74E-06 \\
\hline Ru-106 & 8.82E-06 & 8.74E-06 & $9.18 \mathrm{E}-04$ & 7.29E-06 & 2.23E-05 \\
\hline Sr-89 & 2.37E-04 & $1.16 \mathrm{E}-08$ & $1.59 \mathrm{E}-03$ & $1.00 \mathrm{E}-08$ & 1.64E-05 \\
\hline Sr-90 & 4.34E-06 & $0.00 \mathrm{E}+00$ & 3.85E-05 & $0.00 \mathrm{E}+00$ & 4.51E-07 \\
\hline Sr-91 & 7.31E-04 & 3.59E-06 & 4.33E-05 & 3.07E-06 & 4.18E-06 \\
\hline Sr-92 & $2.21 \mathrm{E}-03$ & $3.73 E-06$ & 9.26E-06 & 3.36E-06 & 6.08E-06 \\
\hline Tc-99m & 4.79E-04 & $1.98 \mathrm{E}-07$ & $3.45 \mathrm{E}-07$ & $1.73 \mathrm{E}-07$ & 2.73E-07 \\
\hline Te-129m & 5.78E-05 & 2.61E-06 & 8.77E-05 & 2.24E-06 & 2.20E-06 \\
\hline Te-132 & 2.07E-06 & 2.02E-08 & 4.02E-08 & $1.72 \mathrm{E}-08$ & 2.87E-08 \\
\hline Y-91m & 7.14E-03 & 1.62E-06 & 4.68E-06 & 1.40E-06 & $2.50 \mathrm{E}-06$ \\
\hline Zn-65 & 8.64E-05 & $1.45 \mathrm{E}-04$ & $2.74 \mathrm{E}-04$ & $1.26 \mathrm{E}-04$ & 2.26E-04 \\
\hline Zn-69 & 7.72E-06 & $0.00 \mathrm{E}+00$ & 1.23E-08 & $0.00 \mathrm{E}+00$ & 1.27E-10 \\
\hline Zr-95 & 1.81E-06 & 1.00E-06 & 2.06E-06 & 8.66E-07 & 1.62E-06 \\
\hline \multirow[t]{2}{*}{ Zr-97 } & $8.76 \mathrm{E}-08$ & 5.91E-10 & 1.01E-08 & 5.07E-10 & 3.07E-10 \\
\hline & Total & 1.25E-02 & 3.57E-02 & 1.07E-02 & 1.87E-02 \\
\hline
\end{tabular}




\section{REFERENCES}

Areva (2009). U.S. EPR Final Safety Analysis Report, Tier 2, Revision 1.

EPA (1993). Federal Guidance Report 12 (FGR-12). External exposure to radionuclides in air, water, and soil, Federal Guidance Report No. 12, EPA-402-R-93-081 (Oak Ridge National Laboratory, Oak Ridge, TN; U. S. Environmental Protection Agency, Washington, DC).

EPA (1999). FGR13. Cancer risk coefficients for environmental exposure to radionuclides. Federal Guidance Report No. 13, EPA 402-R-99-001 (Oak Ridge National Laboratory, Oak Ridge, TN; U. S. Environmental Protection Agency, Washington, DC).

GE-Hitachi (2009). ESBWR Design Control Document, Tier 2 Revision 6.

GE Nuclear Energy (1997). ABWR Standard Safety Analysis Report, Tier 2, Revision 4.

Hoenes, G. R.; Soldat, J. K. (1977). Age-specific radiation dose commitment factors for a one-year chronic intake. NUREG-0172. Richland, WA: Battelle Pacific Northwes Laboratories.

ICRP (1959). International Commission on Radiological Protection. Report of Committee 2 on Permissible Dose for Internal Radiation. ICRP Publication 2. Oxford: Pergamon Press

ICRP (1968). International Commission on Radiological Protection. Evaluation of radiation doses to body tissues from internal contamination due to occupational exposure. ICRP Publication 10. Oxford: Pergamon Press.

ICRP (1973). International Commission on Radiological Protection, Alkaline Earth Metabolism in Adult Man. ICRP Publication 20. Oxford: Pergamon Press.

ICRP (1975). International Commission on Radiological Protection, Report of the Task Group on Reference Man, ICRP Publication 23. Oxford: Pergamon Press.

ICRP (1977). International Commission on Radiological Protection, Annals of the ICRP. ICRP Publication 26. Oxford: Pergamon Press.

ICRP (1979) International Commission on Radiological Protection. Limits for intakes of radionuclides by workers. ICRP Publication 30, Part 1. Oxford: Pergamon Press.

ICRP (1980). International Commission on Radiological Protection. Limits for intakes by workers, ICRP Publication 30, Part 2. Oxford: Pergamon Press.

ICRP (1981). International Commission on Radiological Protection. Limits for intakes by workers, ICRP Publication 30, Part 3. Oxford: Pergamon Press. 
ICRP (1983). International Commission on Radiological Protection. Radionuclide transformations energy and intensity of emissions. ICRP Publication 38. Oxford: Pergamon Press.

ICRP (1988). International Commission on Radiological Protection. Limits for intakes by workers, ICRP Publication 30, Part 4. Oxford: Pergamon Press.

ICRP (1989). International Commission on Radiological Protection. Age-dependent doses to members of the public from intake of radionuclides, Part 1, ICRP Pub. 56. Oxford: Pergamon Press.

ICRP (1991). International Commission on Radiological Protection, “1990

Recommendations of the International Commission on Radiological Protection”, ICRP Publication 60. Oxford: Pergamon Press.

ICRP (1993). International Commission on Radiological Protection. Age-dependent doses to members of the public from intake of radionuclides: Part 2. ICRP Publication 67. Oxford: Pergamon Press.

ICRP (1994a). International Commission on Radiological Protection. Human respiratory tract model for radiological protection, ICRP Publication 66. Oxford: Pergamon Press.

ICRP (1994b). International Commission on Radiological Protection. Dose coefficients for intakes of radionuclides by workers, ICRP Publication 68. Oxford: Pergamon Press.

ICRP (1995a). International Commission on Radiological Protection. Age-dependent doses to members of the public from intake of radionuclides, Part 3, ICRP Pub. 69. Oxford: Pergamon Press.

ICRP (1995b). International Commission on Radiological Protection. Age-dependent doses to members of the public from intake of radionuclides, Part 4, ICRP Pub. 71. Oxford: Pergamon Press.

ICRP (1996). International Commission on Radiological Protection. Age-dependent doses to members of the public from intake of radionuclides, Part 5, Compilation of ingestion and inhalation dose coefficients. ICRP Pub. 72. Oxford: Pergamon Press.

ICRP (2008). International Commission on Radiological Protection. The 2007 Recommendations of the International Commission on Radiological Protection. ICRP Publication 103. Oxford: Pergamon Press.

Leggett, R. W.; Harrison, J. D.; Phipps, A. (2007). Reliability of the ICRP's dose coefficients for members of the public: IV. Basis of the human alimentary tract model and uncertainties in model predictions. Radiation Protection Dosimetry 123: 156-170. 
Martin, M. J. (1973). Radioactive Atoms, Suppl. 1, ORNL-4923, Oak Ridge National Laboratory, Oak Ridge, TN.

Mitsubishi (2009). US-APWR Design Control Document, Tier 2, Revision 2.

NRC (1977). U. S. Nuclear Regulatory Commission. Regulatory Guide 1.109. Calculation of annual doses to man from routine releases of reactor effluents for the purpose of evaluating compliance with 10 CFR Part 50, Appendix I.

Strenge, D. L.; Peloquin, R. A.; Whelan, G. (1986). LADTAP II - Technical Reference and User Guide. NUREG/CR-4013, Pacific Northwest Laboratory, Richland, Washington.

Strenge D. L.; Bander, T. J.; Soldat, J. K. (1987). GASPAR II - Technical Reference and User Guide. NUREG/CR-4653, Pacific Northwest Laboratory, Richland, Washington.

Westinghouse (2008). AP1000 Design Control Document, Tier 2, Revision 16. 